\title{
Revision der neotropischen Trauermücken - Teil I. Die Gattungen Cratyna Winnertz, Euricrium Enderlein, Metangela RübSAamen, Pseudosciara Schiner und Sciara Meigen (Diptera: Sciaridae)
}

Mit 33 Figuren und 2 Farbtafeln

Werner Mohrig ${ }^{1}$ und Frank Menzel ${ }^{2}$

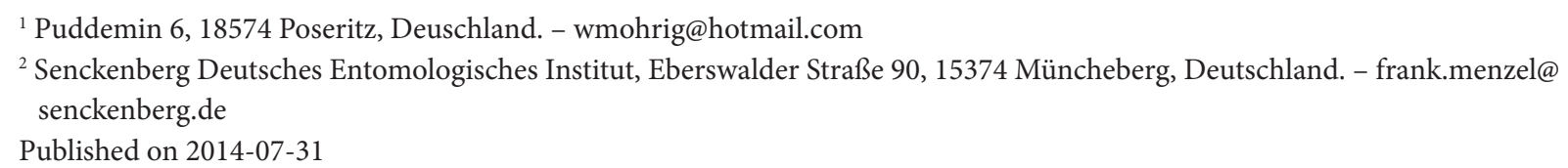

\section{Zusammenfassung}

Die vorliegende Revision umfasst 40 Arten aus den Gattungen Cratyna Winnertz, 1867 [4 Arten], Euricrium EndERLein, 1911 [8 Arten], Metangela Rübsaamen, 1894 [4 Arten], Pseudosciara Schiner, 1866 [21 Arten] und Sciara Meigen, 1803 [3 Arten]. Die Arten werden redeskribiert und abgebildet. 63 Spezies wurden neu kombiniert und 4 Namen als neue Synonyma auf dem Artniveau erkannt: Plastosciara barretoi LANE, 1960 als neues Synonym zu Cratyna boracensis (LANe, 1960); Plastosciara downsi LANe, 1960 als neues Synonym zu Cratyna cucarisi (LANe, 1960), Euricrium fulgescens Enderlein, 1911 als neues Synonym zu Euricrium ruebsaameni (Enderlein, 1911); Pseudosciara aitkeni Lane, 1959 als neues Synonym zu Pseudosciara forceps (Pettey, 1918). Zusätzlich werden 3 synonymisierte Namen restituiert [Metangela spinata Lane, 1955 restit., Pseudosciara ribeiroi (LAne, 1955) restit., Trichomegalosphys ENDERLEIN, 1911 restit.] und 2 präokkupierte Namen wurden ersetzt: Pseudos. willistoni MenZEL nom. nov. für Sciara concinna Williston, 1896 [praeocc.] und Pseudos. helleri Menzel nom. nov. für Sciara debilis Williston, 1896 [praeocc.]. Außerdem ergab sich die Notwendigkeit, für Pseudosciara willistoni Menzel nom. nov. einen Lectotypus zu designieren sowie für Pseudosciara muricata (Lengersdorf, 1926), Pseudosciara thoracica (Lengersdorf, 1930) und Metangela bicolorata (LeNGersdorf, 1930) Neotypen festzulegen. Für 2 Arten werden die bisher unbekannten Männchen ergänzend beschrieben [Euricrium varians (LANE), Pseudosciara humeropicta (Lengersdorf)]. Die Namen der Gattungsgruppe Zygomma Enderlein, 1911 [praeocc.], Mapiria Edwards, 1934 und Muhabbetiola KoçAK, 2009 sind jüngere Synonyme von Euricrium Enderlein, 1911. Die Gattung Pseudosciara Schiner wird in die beiden Subgenera Pseudosciara s. str. und Pseudosciarella subgen. nov. unterteilt. Die Genera Apelmocreagris EnderLeIn, 1911, Trichomegalosphys EnderLeIn, 1911 und Trichosia WinnerTz, 1867 sind nach dieser Revision in der neotropischen Region nicht vertreten. Diese 3 Namen müssen aus dem Katalog der neotropischen Sciaridae gestrichen werden. Die Gattung Pseudozygoneura Steffan, 1969 ist ebenfalls ein Synonym zu Cratyna Winnertz. Alle 41 von Hippa et al. (1998) beschriebenen Pseudozygoneura-Arten werden deshalb in das Subgenus Cratyna s. str. kombiniert.

\section{Stichwörter}

Diptera, Sciaridae, Apelmocreagris, Cratyna, Euricrium, Metangela, Pseudosciara, Sciara, Trichomegalosphys, neotropische Region, Systematik, neues Subgenus, neue Synonyma, Neukombinationen, Namensänderungen, Typendesignationen 


\section{Summary}

This revision covers 40 species of the genera Cratyna Winnertz, 1867 [4 species], Euricrium EnderLEIN, 1911 [8 species], Metangela RübsaAmen, 1894 [4 species], Pseudosciara Schiner, 1866 [21 species] and Sciara Meigen, 1803 [3 species]. The species are redescribed and illustrated. Sixty-three species are newly combined and four names identified as synonyms: Plastosciara barretoi LANe, 1960 is a new synonym of Cratyna boracensis (LANE, 1960); Plastosciara downsi LANE, 1960 is a new synonym of Cratyna cucarisi (LANE, 1960); Euricrium fulgescens ENDERLEIN is a new synonym of Euricrium ruebsaameni (Enderlein); Pseudosc. aitkeni LAne, 1959 is a new synonym of Pseudosc. forceps (Pettey, 1918). In addition, 3 names are raised from synonymy [Metangela spinata Lane, 1955 restit., Pseudosc. ribeiroi (LANe, 1955) restit., Trichomegalosphys Enderlein, 1911 restit.], and 2 preoccupied names were replaced: Pseudos. willistoni Menzel nom. nov. for Sciara concinna Williston, 1896 [preocc.] and Pseudos. helleri Menzel nom. nov. for Sciara debilis Williston, 1896 [preocc.]. It was further found necessary to designate a lectotype for Pseudosc. willistoni Menzel nom. nov. and neotypes for Pseudosc. muricata (Lengersdorf, 1926), Pseudosciara thoracica (Lengersdorf, 1930) and Metangela bicolorata (Lengersdorf, 1930). Unknown males of two species are described and illustrated [Euricrium varians (LANE), Pseudosc. humeropicta (LENGERSDORF)]. The genus group names Zygomma ENDERLEIN, 1911 [preocc], Mapiria EdwARds, 1934 and Muhabbetiola KoÇAK, 2009 are junior synonyms of Euricrium ENDERLEIN, 1911. The genus Pseudosciara Schiner was split into two subgenera Pseudosciara s. str. and Pseudosciarella subgen. nov. After this revision the genera Apelmocreagris ENDERLEIN, 1911, Trichomegalosphys EndERLEIN, 1911 and Trichosia Winnertz, 1867 are not represented within the Neotropical region and must be deleted from the catalog of Neotropical sciarids. The genus Pseudozygoneura Steffan, 1969 is also a synonym of Cratyna Winnertz. The 41 described species of Pseudozygoneura revised by Hippa et al. (1998) are therefore new combined in the subgenus Cratyna s. str.

\section{Key words}

Diptera, Sciaridae, Apelmocreagris, Cratyna, Euricrium, Metangela, Pseudosciara, Sciara, Trichomegalosphys, Neotropical Region, systematics, new subgenus, new synonyms, new combinations, name changes, designation of types

\section{Einleitung}

Die Untersuchungen an neuen Sciaridenmaterialien aus der Neotropis und vergleichende faunistische Studien mit anderen zoogeographischen Regionen werden gegenwärtig vor allem dadurch erschwert, weil die meisten Typen aus Süd- und Mittelamerika noch keiner modernen Revision unterzogen wurden. Eine wichtige Vorarbeit dazu hat Amorim (1992) mit seinem Katalog der neotropischen Sciaridae geleistet, der das Typenmaterial - soweit es ihm zugänglich war - gesichtet, Lectotypen designiert sowie viele Namen neu kombiniert oder synonymisiert hat. Darauf aufbauend fasst er jene Sciaridenarten übersichtlich zusammen, die bis dato vom Gebiet südlich der USA beschrieben waren. In dieser Publikation findet man erstmals auch detailliertere Informationen zum Verbleib des neotropischen Typenmaterials und zum Erhaltungszustand der vorgefundenen Exemplare. Erschwerend wirkt sich jedoch aus, dass der Katalog von keiner Revision der abgehandelten Arten begleitet wird. Figurierte Redeskriptionen und detaillierte Artvergleiche fehlen ebenso wie Bestimmungstabellen und Diskussionen zur Stellung der Spezies im System der Sciaridae. Zugleich gewinnt man den Eindruck, dass es dem Autor aufgrund des umfangreichen, weltweit verstreut aufbewahrten Materials oft nicht möglich war, die Typen direkt miteinander $\mathrm{zu}$ vergleichen. Aufgrund der vorstehend angesprochenen Probleme lassen sich viele neotropische Spezies bis zum heutigen Zeitpunkt nur schwer oder gar nicht identifizieren. Diese unbefriedigende Situation wird zudem von dem Umstand begleitet, dass viele Beschreibungen und Figuren (v. a. von BLANCHARD, EDWARDS, Enderlein, Lane, Lengersdorf, Philippi, RÜBSAAMEN, Schiner, Walker, Wiedemann und Williston) heute nicht mehr den gestiegenen deskriptiven Anforderungen genügen. Auf der hohen Sciaridendiversität in den süd- und mittelamerikanischen Regenwäldern basierend, wurden vor allem in den letzten 10 Jahren immer mehr Trauermückenarten neu entdeckt. Menzel \& MoHrig (2000: 13) listen für die Neotropis noch 186 valide Artnamen, 23 Synonyma und 10 species incertae sedis auf. Später wurden allein durch die Untersuchungen zur Fauna Costa Ricas (Mohrig 2003) und der Dominikanischen Republik (MoHrig et al. 2004) 87 neue Taxa hinzugefügt, was einem Wissenszuwachs von $44 \%$ entspricht. Dieses Beispiel zeigt, dass in der Neotropis das Aufdecken von bisher unerkannten Synonymen sowie das Redeskribieren und Figurieren von vermeintlich »älteren « Sciaridenarten für weiterführende Studien unerlässlich ist. Mit den folgenden Beiträgen wird der Versuch unternommen, einen Teil der bei AмоRim (1992) erfassten Artnamen aus der Neotropis zu revidieren. Im vorgelegten Teil I werden zunächst einige Typen von Apelmocreagris, Cratyna, Euricrium, Mapiria, Metangela, Pseudosciara, Sciara und Zygomma abgehandelt, die den Arbeiten von EDWARDS (1934), ENDERLEIN (1911), LANE (1946, 1947, 1955, 1959b, 1960), LENGERSDORF (1926, 1930b, 1931, 1944), RÜBSAAMEN (1894) und WiLLISTON (1896) zugrunde liegen. 


\section{Material und Methoden}

Für die Publikation wurden zahlreiche Sciaridentypen aus den Dipterensammlungen in Berlin, Bonn, Dresden, Halle an der Saale, Ithaca, Müncheberg, New York, São Paulo, Warschau und Wien ausgewertet. In den meisten Fällen werden die nomenklatorischen Schlussfolgerungen von neuen Materialien aus der Neotropis gestützt. Diese wurden in der Rubrik »weiteres Material « aufgelistet und befinden sich in den Dipterenkollektionen des Museu de Zoologia da Universidade de São Paulo (São Paulo), des Senckenberg Deutschen Entomologischen Instituts (Müncheberg), des Zoologischen Forschungsmuseums Alexander Koenig (Bonn) oder in der Privatsammlung Mohrig (Poseritz). Andernfalls gehen die getroffenen Aussagen auf die Originalbeschreibungen, spätere Revisionen (z. B. LANE 1959b) oder auf den Katalog der neotropischen Sciaridae (AMORIM 1992) zurück.

Die meisten Typexemplare fanden wir in genadeltem Zustand vor. Andere waren (partiell oder vollständig) in Glyzerin bzw. Kanadabalsam eingeschlossen. Nicht selten wurden die männlichen Genitalien, Flügel oder andere Körperteile abgetrennt, zwischen zwei Deckgläschen eingebettet und im Papprahmen oder auf einem Plättchen der Nadel beigefügt. Für mikroskopische Untersuchungen mussten die Körper von den Nadeln gelöst und zusammen mit den zuvor separierten Hypopygien eingebettet werden. Wenn nicht anders erwähnt, wurden alle Körperteile, die zu einem revidierten Exemplar gehören, wieder zusammengeführt und auf demselben Objektträger montiert. Die Präparation wurde nach den bei Menzel \& Mohrig (2000: 45) beschriebenen Arbeitsschritten vorgenommen. Als Einbettungsmedium wurde Kanadabalsam (präp. F. Menzel, W. Mohrig) oder Euparal (präp. P. VilkamaA) verwendet.

Die Bezeichnung der Körperteile richtet sich im Wesentlichen nach der in Menzel \& Mohrig (2000) verwendeten Nomenklatur. Die Begriffe »Valven« und »Stylus/ Styli« wurden durch die Bezeichnungen "Gonocoxite» und »Gonostylus/Gonostyli« ersetzt. Bei der Benennung der Flügeladern folgen wir MoHrig \& JASCHHOF (1999: 10, Fig. 3a) und Mohrig et al. (2004: 311, Fig. 1 D). Abweichend davon werden in der Literatur für die Aderabschnitte $\mathrm{x}, \mathrm{y}$ und $\mathrm{R}_{5}$ auch die Abkürzungen $\mathrm{bM}, \mathrm{r}-\mathrm{m}$ und $\mathrm{R}_{4+5}$ verwendet. In Anlehnung an einen überarbeiteten Weltkatalog der Sciaridae (Menzel in Vorbereitung) sind die Lokalitäten in der publizierten Form - ergänzt oder korrigiert durch Daten von den originalen Fundetiketten - wiedergegeben worden. Korrekturen, Präzisierungen und zusätzliche Informationen wurden vor allem für Bundesstaaten, Provinzen, Ortschaften und/oder geographische Einheiten in der jeweiligen Landessprache hinzugefügt [siehe eckige Klammern]. Die besprochenen Sciaridenkollektionen sind durch einen vierstelligen Buchstabencode abgekürzt, wie er bei Menzel (in Vorbereitung) zur Anwendung kommt. Für die einbezogenen Museen und Privatsammlungen, in denen die
Typen oder relevante Materialien deponiert sind, wurden folgende Abkürzungen benutzt:

AMNH American Museum of Natural History, Department of Entomology Collection, New York (USA)

BMNH The Natural History Museum, Department of Entomology, London (Großbritannien)

CUIC Cornell University Insect Collection, Department of Entomology, Ithaca (USA)

IMLA Facultad de Ciencias Naturales e Instituto Miguel Lillo, Universidad Nacional de Tucumán, Tucumán (Argentinien)

MLUH Zoologisches Institut der Martin-LutherUniversität Halle/Wittenberg, Halle an der Saale (Deutschland)

MZPW Muzeum i Instytut Zoologii, Polska Akademia Nauk, Warszawa [Warschau] (Polen)

MZSP Museu de Zoologia da Universidade de São Paulo, São Paulo (Brasilien)

NHMW Naturhistorisches Museum Wien, 2. Zoologische Abteilung - Entomologie, Wien (Österreich)

PWMP Privatsammlung Werner MoHRIG, Poseritz (Deutschland)

SDEI Senckenberg Deutsches Entomologisches Institut, Müncheberg (Deutschland)

SMTD Senckenberg Naturhistorische Sammlungen Dresden, Museum für Tierkunde, Dresden (Deutschland)

USNM U. S. National Museum of Natural History, Washington D. C. (USA)

UZMH Finnish Museum of Natural History, University of Helsinki, Helsinki (Finnland)

ZFMK Zoologisches Forschungsmuseum Alexander Koenig, Bonn (Deutschland)

ZMHB Leibniz-Institut für Evolutions- und Biodiversitätsforschung an der Humboldt-Universität zu Berlin, Museum für Naturkunde (Zoologie), Berlin (Deuschland)

ZMUC Zoologisk Museum, Københavns Universitet, København [Kopenhagen] (Dänemark)

ZMUH Universität Hamburg, Fachbereich Biologie, Zoologisches Institut und Zoologisches Museum (Deutschland)

\section{Revision des Typenmaterials}

\section{Ape/mocreagris ENDERLEIN, 1911}

Typusart: Lycoria bibionea SPEISER, 1909 - Wiss. Ergebn. schwed. zool. Exped. Kilimandjaro, Meru, DeutschOstafrikas (Dipt. Orthorh. Nemat.): 31-32; Fig. 1-2 (orig. des.) [= Apelmocreagris thoracica (MACQUART, 1838)]. 
Literatur: Sciara (Apelmocreagris) - ENDERLEIN (1911): 127 und 146; - Frey (1942): 29. Apelmocreagris EnderLEIN - EDWARDS (1914): 48; - LENGERSDORF (1941): 201 und 204 [als Synonym von Lycoria]; - LENGERSDORF (1942): 99; - STEFFAN (1980): 231; - AMORIM (1992): 57; - VilkamaA (2000): 51; - VilkamaA \& Hippa (2004): 4, 8 und 21; - AMORIM \& Rindal (2007): 8, 21, 27, 40, 65, 69, 70 und 75; - JAsChHof (2011): 459; - ShIN et al. (2013): 835.

Bemerkungen: Die Syntypen der Typusart Lycoria bibionea SPEISER stammen von 4 Lokalitäten aus dem Kilimandjaro-Gebiet in Tansania (SPEISER 1909, 1910): Obstgartensteppe am Kilimandjaro; am Fluß Ngare na nyuki in der Meru-Niederung; Kilimandjaro bei Kibonoto, 1000-1200 m ü. NN; Kulturzone des Kilimandjaro am Meru, 3000-3500 m ü. NN. ENDERLEIN (1911: 146) hat die Typenserie von Lycoria bibionea SPEISER offensichtlich nicht gesehen. Er beschreibt die Gattung Apelmocreagris auf der Basis eines ihm vorliegenden Materials aus Südafrika [4 웅, Transvaal, Zoutpansberg], das er als »bibionea SPEISER, 1909« identifiziert hat. $\mathrm{Zu}$ dieser Gattung stellt er auch noch Ap. bibionea var. miniaticeps ENDERLEIN, 1911 [2 9 ㅇ l locus typicus: »Westafrika, Fernando Po«; = Äquatorial-Guinea: Fernando Póo (Insel Bioko)] und Ap. leucacrocera ENDERLEIN, 1911 [1 1 o 3 ㅇ ㅇ ; locus typicus: »Südbrasilien, Santa Catarina«; = Brasilien: Estado de Santa Catarina, Nova Teutônia]. Uns lag 1 ㅇ von "Apelmocreagris bibionea (SPEISER)« [det. Enderlein; = Ap. thoracica (MACQUART, 1838)] aus dem Transvaal, ein Syntypus [?] von Ap. bibionea var. miniaticeps ENDERLEIN und der Lectotypus [ $\left.\sigma^{\star}\right]$ von Ap. leucacrocera ENDERLEIN vor (alle umpräpariert in Kanadabalsam und deponiert im MZPW).

Von Amorim (1992: 57) wurde Apelmocreagris auf der Basis von 3 neotropischen Arten wieder in den Gattungsrang erhoben. Neben leucacrocera ENDERLEIN aus Brasilien ordnete er diesem Genus noch die Arten blandula LENGERSDORF, 1944 und crinita LENGERSDORF, 1944 [= cingulata RüBSAAMEN, 1894] aus Mexiko zu [Revision der Typen siehe hier unter Sciara MEIgen bzw. unter Sciara cingulata RÜBSAAMEN in Mohrig et al. (2013): 247]. Bei den neotropischen "Apelmocreagris«-Arten sensu Amorim (1992) wurde jedoch festgestellt, dass diese zweifelsfrei zur Gattung Sciara MEIGEN gehören. Das bedeutet, dass Apelmocreagris ENDERLEIN in der Neotropis nicht vertreten ist und aus dem Verzeichnis der neotropischen Sciariden gestrichen werden muss. Auch für die aus der afrotropischen Region beschriebenen Namen bibionea (SPEISER, 1909), bibionea var. miniaticeps ENDERLEIN, 1911 und ruficollis (WALKER, 1848), die gegenwärtig jüngere Synonyme von Ap. thoracica (MACQUART, 1838) sind, besteht der Verdacht, dass sie zu Sciara MeIgen gehören. Sollte sich diese Vermutung bei einer in Vorbereitung befindlichen Revision der afrotropischen Sciariden bestätigen, dann wäre auch der Name Apelmocreagris Enderlein, 1911 ein Synonym zu Sciara MeIgen, 1803.

\section{Cratyna WinNeRTZ, 1867}

Typusart: Cratyna atra WinnerTz, 1867 - Monogr. Sciarinen: 167; Taf., Fig. 7 (mon.).

= Pseudosciara Kieffer, 1898 - Bull. Soc. Ent. France, 1898 (9): 194 [praeocc.; nec Pseudosciara SchIner, 1866]. Typusart: Pseudosciara pictiventris KIEFFER, 1898 - Bull. Soc. Ent. France, 1898 (9): 194-196 (orig. des; mon.) [= Cratyna atra WinNERTZ, 1867].

= Plastosciara Berg, 1899 - Comunic. Mus. Nac. Buen. Aires, 1(3): 78 [nom. nov. pro Pseudosciara Kieffer, 1898].

= Decembrina Frey, 1942 - Notul. Ent., 22: 21 und 34-35. Typusart: Decembrina prima FreY, 1942 - Notul. Ent., 22: 35 (orig. des.) [= Peyerimhoffia ambigua LeNGERsDORF, 1934].

= Dendrosciara Frey, 1942 - Notul. Ent., 22: 33 [als Subgenus von Neosciara Pettey, 1918].

Typusart: Lycoria (Neosciara) corticalis LENGERSDorf, 1930 - Flieg. Palaearkt. Reg., 2(1): 38-39; Taf. 3, Fig. 46 (orig. des.) [= Cratyna atra WinnerTz, 1867].

= Pseudozygoneura STEFFAN, 1969 - Insects of Micronesia, 12(7): 675 und 676-677.

Typusart: Pseudozygoneura musicola Steffan, 1969 Insects of Micronesia, 12(7): 677-679; Fig. 3 a-f (orig. des.; mon.).

Literatur: Plastosciara Berg [mitunter nur ex parte] ENDERLEIN (1911): 127 und 183; - Frey (1942): 24 und 34; - Shaw (1953): 29; - LANe (1960): 120; - StefFan (1966): 33 und 47; - StefFAn (1981): 254; - AMorim (1992): 63. Pseudozygoneura StefFAn - Hippa et al. (1998): 1; - Menzel \& Mohrig (2000): 13 und 266; VilkamaA (2000): 51, 54, 58 und 62; - VilkamaA \& Hippa (2004): 4, 7 und 21. Neosciara Pettey [ex parte] - LANe (1959a): 72. Cratyna Winnertz - Winnertz (1867): 167; - RÜBSAAMEN (1894): 19; - ENDERLEIN (1911): 124 und 186; - Menzel \& Mohrig (1998): 361; - Mohrig (1999): 167; - Menzel \& Mohrig (2000): 261, 608, 621 und 653; - Mohrig (2003): 22 und 65; Mohrig et al. (2004): 274; - VilkamaA \& Hippa (2004): 4, 7 und 21; - Mohrig \& Röschmann (2005): 325 und 348; - Mohrig \& Menzel (2009): 285, 291 und 292; Mohrig et al. (2013): 150 und 195; - SHIN et al. (2013): 834.

Bemerkungen: Pseudozygoneura Steffan, 1969 wird in Übereinstimmung mit Mohrig (1999: 182), Menzel \& Mohrig (2000: 266) und Mohrig et al. (2004: 275) als Synonym zu Cratyna WinnerTz, 1867 betrachtet. Die phylogenetischen Aspekte und die vorgeschlagene Synonymie von Pseudozygoneura Steffan zu Cratyna Winnertz s. str. haben bereits Menzel \& Mohrig (2000: 266-267) in der »Revision der paläarktischen Trauermücken« diskutiert. Sie kommen bei einer Gegenüberstellung von Cratyna WinnerTz mit Pseudozygoneura StefFAN zu dem Ergebnis, dass sich für Cratyna s. str. kein autapomorpher Merkmalszustand finden lässt, mit 
dem man ein Schwestergruppenverhältnis begründen könnte. Folglich schlagen sie vor, die außerpaläarktischen "Pseudozygoneura«-Arten [einschließlich der Typusart Pseudozygoneura musicola STEFfan] mit den Spezies von Cratyna s. str. [= Plastosciara s. str.] zu einem Monophylum zusammen zu fassen. Aus diesem Grund werden - in Übereinstimmung mit Mohrig $(1999,2003)$ und Mohrig et al. (2004) sowie im Sinne von LANE (1960) all jene Arten in das Subgenus Cratyna s. str. kombiniert, die in Hippa et al. (1998) beschrieben wurden. Daraus ergeben sich für das System der Sciaridae folgende Veränderungen:

AFROTROPIS: Cratyna ghanaensis (Hippa, VilkamaA \& Heinakroon, 1998) comb. nov.; Cr. indotata (Hippa, VilkamaA \& Heinakroon, 1998) comb. nov.; Cr. protrusa (HipPa, VilkamaA \& HeINAKRoON, 1998) comb. nov.; Cr. senticosa (HIPPA, VILKAMAA \& HEINAKROON, 1998) comb. nov.; Cr. torula (HIPPA, VIlKAMAA \& HEINAKROON, 1998) comb. nov. AUSTRALIS: Cratyna musicola (STEFFAN, 1969). NEOTROPIS: Cratyna brevispina (Hippa, VilkamaA \& Heinakroon, 1998) comb. nov.; Cr. clavula (HipPa, VilKamaA \& HeINAKROON, 1998) comb. nov.; Cr. crinita (HIPPA, VIlKAMAA \& Heinakroon, 1998) comb. nov.; Cr. excisa (HipPa, VilKamaA \& HeINAKRoON, 1998) comb. nov.; Cr. integra (Hippa, Vilkamaa \& Heinakroon, 1998) comb. nov. ORIENTALIS: Cratyna acuminata (HIPPA, VILKAMAA \& HEINAKROON, 1998) comb. nov.; Cr. aurora (HIPPA, VilkamaA \& Heinakroon, 1998) comb. nov.; Cr. brevimera (Hippa, VilkamaA \& Heinakroon, 1998) comb. nov.; Cr. clavigera (Hippa, VilkamaA \& HeINAKRoon, 1998) comb. nov.; Cr. clinostyla (HipPA, VIlKamaA \& HeINAKroon, 1998) comb. nov.; Cr. collina (HipPA, VilKamaA \& HeINAKRoON, 1998) comb. nov.; Cr. conica (Hippa, VilkamaA \& Heinakroon, 1998) comb. nov; Cr. coniciformis (Hippa, VilkamaA \& Heinakroon, 1998) comb. nov.; Cr. consilia (Hippa, VilkamaA \& HeINAKRoON, 1998) comb. nov.; Cr. constricta (HipPA, VilkamaA \& HeINAKRoon, 1998) comb. nov.; Cr. coronicornis (HipPa, VilkamaA \& HeINAKRoon, 1998) comb. nov.; Cr. crassichaeta (Hippa, VilkamaA \& Heinakroon, 1998) comb. nov.; Cr. dactylica (HipPa, VilkamaA \& Heinakroon, 1998) comb. nov.; Cr. delicia (Hippa, VilkamaA \& Heinakroon, 1998) comb. nov.; Cr. denticula (Hippa, VilkamaA \& Heinakroon, 1998) comb. nov.; Cr. epsilon (Hippa, VilkamaA \& Heinakroon, 1998) comb. nov.; Cr. expedita (Hippa, VilKamaA \& HEINAKRoon, 1998) comb. nov.; Cr. flagelloparva (Hippa, VilkamaA \& HeINAKroon, 1998) comb. nov.; Cr. foveola (HipPa, VilkamaA \& HeINAKROON, 1998) comb. nov.; Cr. gigas (HIPPA, VILKAMAA \& Heinakroon, 1998) comb. nov.; Cr. index (Hippa, VilkamaA \& Heinakroon, 1998) comb. nov.; Cr. intermedia (Hippa, VilkamaA \& Heinakroon, 1998) comb. nov.; Cr. kirkspriggsi (Hippa, VilkamaA \& HeinaKROON, 1998) comb. nov.; Cr. lagena (HIPPA, VILKAMAA \& Heinakroon, 1998) comb. nov.; Cr. latidactyla (Hippa, Vilkamaa \& Heinakroon, 1998) comb. nov.;
Cr.prominula (Hippa, VilkamaA \& Heinakroon, 1998) comb. nov.; Cr. quadrifalx (Hippa, VilkamaA \& Heinakroon, 1998) comb. nov.; Cr. redunca (Hippa, VILKAMAA \& HEINAKROON, 1998) comb. nov.; Cr. sagitta (Hippa, VilkamaA \& HeINAKROON, 1998) comb. nov.; Cr. spicicauda (Hippa, VilkamaA \& Heinakroon, 1998) comb. nov.; Cr. trichodactyla (Hippa, VilkamaA \& HeINAKRoON, 1998) comb. nov.

\section{Cratyna (Cratyna) aimoresi (LANE, 1960) comb. nov.} (Fig. 1)

Locus typicus: »Trinidad (B. W. I.)« [= British West Indies, Trinidad], Navy Base (Trinidad und Tobago). Holotypus: o , Reg.-Nr. 12.600, »X-1955« [= Oktober 1955; nec »VII-1955«], leg. AitKen (MZSP).

Erhaltungszustand: Der Holotypus ist in keinem guten Zustand. Ein Hinterbein und eine Fühlergeißel fehlen vollständig. Von den anderen 5 Beinen ist nur das zweite Hinterbein vollständig erhalten [den anderen Beinen fehlen jeweils die Fußglieder 2 bis 5]. Von einer Fühlergeißel existieren nur noch die Geißelglieder 1 bis 2 und die Kopfkapsel ist durch Trocknungsprozesse deformiert. Außerdem ist ein Flügel im Bereich des Analfeldes beschädigt und die verdickten Gonostyli sind durch Quetschung blasenförmig aufgetrieben. Thorax, Abdomen und andere Teile des Hypopygiums [Gonocoxite, Genitalplatte und Aedeagus] sind hingegen in einem sehr guten Zustand (umpräpariert in Kanadabalsam).

Literatur: Plastosciara aimoresi LANE - LANE (1960): 120-121; Fig. 1; - АMORIM (1992): 63.

Redeskription: $\sigma^{x}$. Kopf: rundlich und dunkel. Augenbrücke 2 bis 3-reihig. Fühlergrundglieder heller, Fühler-

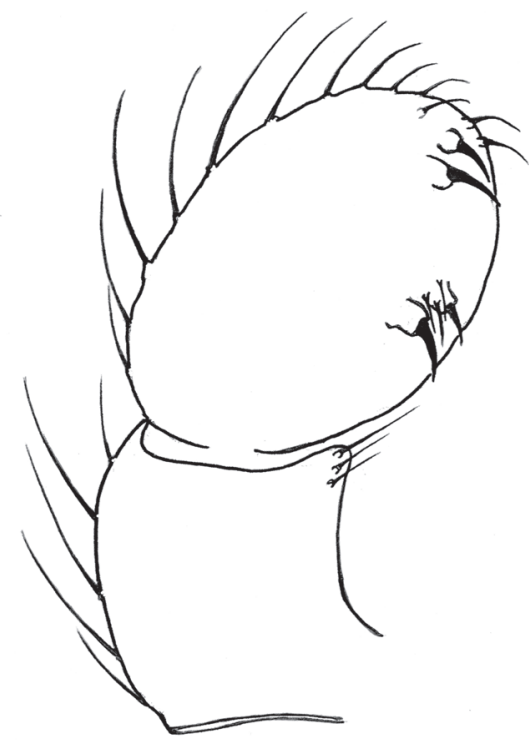

Fig. 1: Cratyna aimoresi (LANE), Holotypus ơ: Skizze von der deformierten linken Hälfte des Hypopygiums [Gonocoxit und Gonostylus], ventral. 
geißelglieder braun; 2. Fühlergeißelglied kurz, 2,2 mal so lang wie breit; Halsteil fast so lang wie das Basalteil; Halsteile bräunlich und leicht zweifarbig; Basalteil beim 2. Glied etwa 1,2 mal so lang wie breit, mit kurzen, feinen Sensillen und mit kräftig-langer, kranzartig angeordneter Behaarung [diese deutlich länger als die Gliedbreite]. Palpen kurz und 2-gliedrig; Grundglied schlank, mit mehreren Borsten und ohne vertiefte Sensillengrube; 2. Palpenglied kurz-oval, etwa $1 / 3 \mathrm{mal}$ so lang wie das Grundglied. Thorax: Mesonotum mit dunklerem Lateralfleck und Mittelstreif; Pleuralsklerite bräunlich, Coxen heller; Postpronotum beborstet. Flügel groß, gebräunt und mit breit ausgebildetem Analfeld; $\mathrm{R}_{1}=0,9 \mathrm{R} ; \mathrm{C}=2 / 3 \mathrm{w} ; \mathrm{y}=0,8 \mathrm{x}$; $\mathrm{x}$ distal mit 2 Makrotrichien und y vollständig mit Makrotrichien besetzt; hintere Flügeladern schwach ausgebildet und ohne Makrotrichien; M-Stiel länger als die $M_{1}$; CuA-Stiel kürzer als x. Halteren kurz gestielt und gebräunt. Coxen und Beine hellbraun, Tarsen angedunkelt; Vordertibienende ohne dichten Borstenfleck. Klauen ungezähnt. Abdomen: braun, Gonocoxite kurz und kräftig, ventrale Innenseiten spärlich und mäßig lang behaart; Gonostyli größer als die Gonocoxite, breit gerundet, mit 2 gleichartigen Dornen auf flachen Sockeln an der Spitze und 2 ungleichen Dornen in der Stylusmitte [um den kürzeren Dorn herum mit kurzen, feinen Borsten]. Genitalplatte breiter als hoch und membranös, mit halbkreisförmiger Querleiste und mit schmalem, fingerförmigem Fortsatz. Aedeagus sehr kurz. Größe: 1,8 mm. ․ Unbekannt.

Bemerkungen: Die Art ist durch die sehr kurzen Gonocoxite und die großen, runden Gonostyli mit 2 gleichartigen Dornen an der Stylusspitze und einem Paar verschieden starker Dorne in der Mitte der Stylusinnenseite gut charakterisiert. Neben der andersartigen Stylusbedornung ist Cr.aimoresi von Cr.boracensis (LANE) durch die vorhandene Querleiste auf der Genitalplatte, den sehr kurzen Aedeagus und die sehr kurzen Fühlergeißelglieder, bei denen das Halsteil fast so lang wie das Basalteil ist, unterscheidbar.

Cratyna (Cratyna) boracensis (LANE, 1960) comb. nov. (Fig. 2 a-c)

Locus typicus: »State of São Paulo, Mun. Salesópolis, Borácea « [= Estado de São Paulo, Município de Salesópolis, Boracéia] (Brasilien).

Holotypus: ${ }^{*}$, Reg.-Nr. 12.567, Juli 1949, leg. LANE \& Coher (MZSP).

Paratypen: $2 \sigma^{\star} \sigma^{\star}$, Reg.-Nr. 12.568 und 12.569, gleiche Funddaten (MZSP) [alle nicht untersucht!].

= Plastosciara barrettoi LANE, 1960 syn. nov. - Rev. Bras. Ent., 9: 120 und 122; 121, Fig. 2.

Locus typicus: »State of Rio de Janeiro, Itatiaia « [ = Estado de Rio de Janeiro, Itatiaia südwestlich von Resende] (Brasilien).

Holotypus: $0^{\star}$, August 1946, leg. BARretto (MZSP).

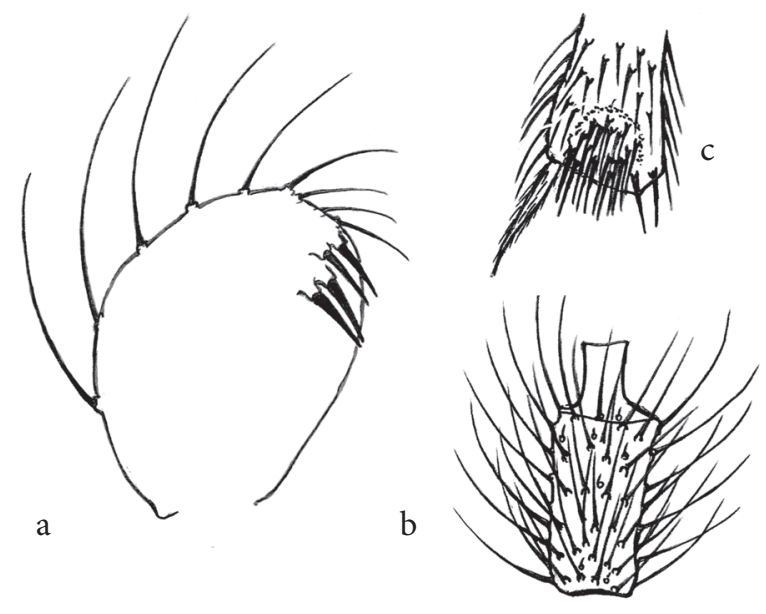

Fig. 2 a-c: Cratyna boracensis (LANE), Holotypus ơ: - a: Skizze vom deformierten Gonostylus ventral; - b: 2. Fühlergeißelglied; - c: Vordertibienende.

Paratypen: $1 \sigma^{\star}$, "State of S. Paulo, Embu « [= Estado de São Paulo, Embu südwestlich von São Paulo] (Brasilien), April 1954, leg. LANE (MZSP); 1 ○`, »Salesópolis, Borácea« [= Estado de São Paulo, Município de Salesópolis, Boracéia] (Brasilien), Juli 1949, leg. LAne \& CoHer (MZSP); $10^{\star}$, "Salesópolis, Borácea« [= Estado de São Paulo, Município de Salesópolis, Boracéia] (Brasilien), Juli 1947, leg. RABELLo (MZSP) [alle nicht untersucht!].

Erhaltungszustand: Der Holotypus von Plastosciara boracensis LANE ist fast vollständig erhalten [nur die Fühlergeißeln ab dem 8. Geißelglied fehlen]. Kopf, Thorax, Coxen, Flügel und Beine sind trotz einiger Deformationen in gutem Zustand. Das Hypopygium ist durch präparative Einflüsse deutlich aufgehellt, gequollen und gequetscht. Der Holotypus von Plastosciara barrettoi LANE ist partiell stark beschädigt. Einige Körperteile [ein Flügel, ein Bein, mehrere Fühlergeißelglieder und Teile des Abdomens] fehlen. Die Kopfkapsel ist an den Seiten deformiert und von den Fühlergeißeln existieren nur noch die Geißelglieder 1 bis 2 bzw. 1 bis 6 . Außerdem ist das männliche Genital etwas aufgehellt und die Gonostyli sind durch Quetschung fast rundlich (beide Holotypen umpräpariert in Kanadabalsam).

Literatur: Plastosciara barrettoi LANE - LANE (1960): 120 und 122-124; 121, Fig. 3; - AMorim (1992): 63. Plastosciara boracensis LANE - AMORIM (1992): 63.

Redeskription: $\sigma^{\star}$. Kopf: rundlich und dunkel. Augenbrücke 3-reihig. Fühlergeißelglieder braun und zur Fühlerspitze hin länger werdend; 3. Fühlergeißelglied 2,3 und 4. Geißelglied 2,5 bis 2,6 mal so lang wie breit; Halsteile hell- bis dunkelbraun, bei den Gliedern 1 bis 4 basal hell und an der Spitze braun beraucht [dadurch zweifarbig]; Halsteil beim 4. Geißelglied etwa $1 / 3 \mathrm{mal}$ so lang wie das Basalteil; Basalteil mit langen, feinen Sensillen und mit kräftig-langer Behaarung [diese deutlich länger als die Gliedbreite]. Palpen kurz, 2-gliedrig; 
Grundglied etwas hochrückig, mit 1 bis 2 langen Borsten; 2. Glied $1 / 2$ bis $2 / 3$ mal so lang wie das Grundglied. Thorax: Mesonotum weitgehend bräunlich; Pleuralsklerite bräunlich, Coxen heller; Postpronotum beborstet. Flügel groß, gebräunt und mit breit ausgebildetem Analfeld; $\mathrm{R}_{1}=1,0$ bis $1,1 \mathrm{R} ; \mathrm{C}=3 / 4 \mathrm{w} ; \mathrm{y}=\mathrm{x}$, beide nackt oder y distal mit bis zu 3 Makrotrichien; hintere Flügeladern schwach ausgebildet, ohne Makrotrichien; M-Stiel länger als die $\mathrm{M}_{1}$; CuA-Stiel kürzer als $\mathrm{x}$. Halteren kurz gestielt und gebräunt. Coxen und Beine hellbraun; Beine lang, Tarsen angedunkelt; Vordertibienende mit dichtem Borstenfleck. Klauen ungezähnt. Abdomen: braun; Gonocoxite kurz und kräftig, ventrale Innenseiten spärlich und mäßig lang behaart; Gonostyli etwas kürzer als Gonocoxite, breit gerundet und mit 4 gleichartigen, eng und paarig angeordneten Dornen an der Stylusspitze. Genitalplatte breiter als hoch und membranös, ohne halbkreisförmige Querleiste und mit schmalem Mittelfortsatz. Aedeagus mäßig lang, mit schwach ausgebildeter Basis. Größe: 1,9-2,1 mm.

․ Unbekannt.

Bemerkungen: Die Art ist durch die kurzen Gonocoxite, die runden Gonostyli mit je 2 gleichartigen und paarig eng beieinander stehenden Dornen an der Spitze, die 2-gliedrigen Palpen sowie die längeren 4. Fühlergeißelglieder mit kürzeren Halsteilen charakterisiert. Die Fehlinterpretation von LANE, dass es sich bei den untersuchten Holotypen um zwei verschiedene Arten handeln soll, ist auf Deformationen an den männlichen Genitalien zurückzuführen, die bei der Präparation von voluminösen Gonostyli oft eintreten. Die Identität von $P l$. barretoi LANE und $P l$. boracensis LANE ist zweifelsfrei gegeben aufgrund der 4 gleichartig langen und subapikal an der Stylusspitze inserierenden Dorne, die in zwei eng stehenden Paaren angeordnet sind. Für eine Identität spricht auch die Beschreibung der Stylusspitzenbedornung bei LANE, die er in beiden Originalbeschreibungen mit dem Wortlaut „dististyle with five or six spines on the upper internal angle" charakterisiert. Außerdem begründet LANE Pl. barretoi und $\mathrm{Pl}$. boracensis mit Farbunterschieden am Mesonotum, die in den beiden Präparaten jedoch nicht [mehr] zu erkennen sind.

\section{Cratyna (Cratyna) caraosi (LANE, 1960) comb. nov. (Fig. 3 a-c)}

Locus typicus: „State of São Paulo, Parque da Agua Funda, near the City of São Paulo« [= Estado de São Paulo, São Paulo, Parque da Agua Funda] (Brasilien).

Holotypus: đ`, Reg.-Nr. 12.598, März 1956, leg. LANE (MZSP).

Paratypus: $1 \sigma^{\star}$, Reg.-Nr. 12.599, gleiche Funddaten (MZSP) [nicht untersucht].

Erhaltungszustand: Der Holotypus ist unvollständig erhalten. Vorhanden sind nur noch je ein Vorder-, Mittel- und Hinterbein, beide Flügel, der Kopf mit beiden Fühlergeißeln [einige Geißelglieder deformiert oder fehlend], Thorax, Abdomen und Hypopygium. Das männliche Genital ist gequetscht, so dass beide Gonostyli beschädigt sind und die Genitalbasis schräg im Einbettungsmedium liegt (umpräpariert in Kanadabalsam).

Literatur: Plastosciara caraosi LANE - LANE (1960): 120 und 124; 123, Fig. 4; - AMORIM (1992): 63.

Redeskription: $\sigma^{\top}$. Kopf: rundlich und dunkel. Augenbrücke 3 bis 4 -reihig. Fühler einförmig braun, Halsteile heller; 4. Fühlergeißelglied 2,1 mal so lang wie breit; Halsteil 1/3 mal so lang wie das Basalteil, leicht zweifarbig; Behaarung grob, lang abstehend und länger als die Gliedbreite; Basalteile neben der groben Beborstung mit feinen, kurzen Haaren und sehr kurzen Sensillen. Palpen eingliedrig und groß; Grundglied ohne Sensillengrube und mit 6 Borsten. Thorax: bräunlich, mit Aufhellungen; Scutellum und Mediotergit zentral dunkel; Mesonotum recht kräftig behaart; Scutellum mit 4 starken Randborsten; Postpronotum beborstet. Flügel kurz, breit und gebräunt, mit gut entwickeltem Analfeld; $\mathrm{R}_{1}=1,4 \mathrm{R} ; \mathrm{C}=3 / 4 \mathrm{w} ; \mathrm{y}=1,4 \mathrm{x}$; $\mathrm{x}$ nackt und y distal mit 1 bis 2 Makrotrichien; hintere Flügeladern schwach, ohne Makrotrichien; M-Stiel länger als die kurze $\mathrm{M}_{1}$; M-Gabel kurz und breit geöffnet; $\mathrm{CuA}$-Stiel $=4 / 5 \mathrm{x}$. Coxen und Beine hellbraun, Tarsen angedunkelt; Vordertibienende mit großem, dichtem und dunklem Borstenfleck. Klauen ungezähnt. Abdomen: braun, Gonocoxite kurz und kräftig, ventrale Innenseiten sehr kurz behaart; Gonostyli fast so breit wie hoch und etwa 3/4 mal so lang wie die Gonocoxite; Gonostylus kugelig verdickt und breit gerundet; Innenseite der Gonostyli mit 4 kurzen, kräftigen und paarig angeordneten Dornen; beide Dornenpaare durch eine leicht bogenförmige und unbeborstete Ausran-

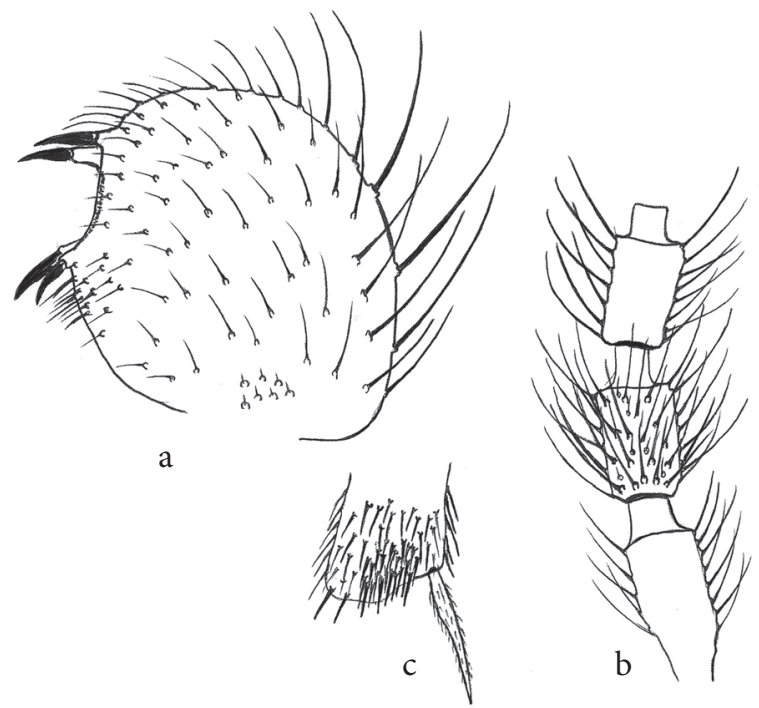

Fig. 3 a-c: Cratyna caraosi (LANE), Holotypus ơ : - a: Gonostylus ventral; - b: 1. bis 3. Fühlergeißelglied; - c: Vordertibienende. 
dung voneinander getrennt; Innenseite unter dem basalen Dornenpaar mit kurzen dörnchenartigen Borsten besetzt; Genitalplatte membranös und breit gerundet, mit halbkreisförmiger Querleiste und fingerförmigem Mittelfortsatz. Aedeagus kurz. Größe: 2,5 mm.

‥ Unbekannt.

Bemerkungen: In der Anordnung der Dorne am Gonostylus hat die Art Ähnlichkeit mit Cr. aimoresi (LANE). Beide haben 2 Dornpaare, von denen das erste Dornenpaar subapikal an der Spitze und das zweite Dornenpaar in der Mitte des Gonostylus steht. Von dieser unterscheidet sie sich jedoch durch die noch kürzeren und kompakteren Gonostyli, längere Fühlergeißelglieder mit kürzeren Halsteilen, die eingliedrig-verdickten Palpen sowie die auffällig kurzen und breiten Flügel. Außerdem zeichnet sich Cr. caraosi (LANE) durch eine größere Börstchengruppe unter dem basalen Dornenpaar aus, in der auch einige fein-hyaline Dörnchen stehen.

\section{Cratyna (Cratyna) cucarisi (LANE, 1960) comb. nov. (Fig. 4 a-d)}

Locus typicus: »State of Goiaz, Corumbá« [= Estado de Goiás, Corumbá de Goiás] (Brasilien).

Holotypus: ơ, Reg.-Nr. 12.574, November 1945, leg. BARRETTO (MZSP).

Paratypus: $10^{\star}$, Reg.-Nr. 12.575, gleiche Funddaten (MZSP) [nicht untersucht!].

= Plastosciara downsi LANE, 1960 syn. nov. - Rev. Bras. Ent., 9: 120 und 125-126; 123, Fig. 6.

Locus typicus: »Trinidad (B. W. I.)« [= British West Indies, Trinidad], Navy Base, Arena Forest (Trinidad und Tobago).

Holotypus: $\sigma^{\star}$, Reg.-Nr. 12.576, Lichtfallenfang in der Zeit von 17.45 Uhr bis 19.15 Uhr, »20/VI/1955« [=20. Juli 1955; nec »VIII-1955«], leg. Aitken (MZSP).

Paratypen: $31 \sigma^{\star} o^{\star}$, Reg.-Nr. 12.577-12.598, alle gleiche Funddaten [nicht untersucht!]. Die Paratypen wurden nach LANE (1960: 126) auf das BMNH, IMLA, MZSP, USNM und UZMH verteilt. Bekannt ist, dass sich am IMLA lediglich $2 o^{\star} o^{\star}$ aus der Typenserie befinden sollen und bei Revisionsarbeiten in der Sciaridenkollektion des UZMH keine Paratypen von $\mathrm{Pl}$. downsei LANE gefunden wurden [teste MENZEL in 2007].

Erhaltungszustand: Beide Holotypen wurden in Kanadabalsam eingebettet. Beim Holotypus von Pl. cucarisi LANE sind die Coxen und Beine nur noch partiell vorhanden [ein Vorderbein komplett erhalten; alle anderen Beine ohne Tibien und ohne Fußglieder]. Kopf und Fühlergeißelglieder sind vollständig, aber deformiert. Thorax, Abdomen und Flügel befinden sich in gutem Zustand. Am Hypopygium sind lediglich die Gonostyli durch Quetschung deformiert. Alle anderen Genitalstrukturen sind in sehr gut erhalten. Beim Holotypus von Pl. downsi LANE befinden sich Thorax, Abdomen, ein Flügel und beide Vorderbeine in sehr gutem Zustand. Beim zweiten Flügel ist die Flügelspitze zerstört. Die Kopfkapsel ist in frontaler Lage eingebettet und an einer Seite eingerissen. Beide Fühlergeißeln sowie einige Tibien und Fußglieder an den $\mathrm{p}_{2}$ und $\mathrm{p}_{3}$ fehlen. Das Hypopygium ist vollständig und etwas entfärbt. Hier sind lediglich die verdickten Gonostyli beschädigt.

Literatur: Plastosciara downsi LANE - AMORIM (1992): 63. Plastosciara cucarisi LANE - LANE (1960): 120 und 125; 123, Fig. 5; - AMORIM (1992): 63.

Redeskription: $\sigma^{*}$. Kopf: rundlich und dunkelbraun. Fühler einförmig braun; 4. Fühlergeißelglied lang, 3,3 mal so lang wie breit; Halsteil $1 / 5$ mal so lang wie das Basalteil, hell-bräunlich; Basalteil mit kurzen, feinen Sensillen; Behaarung grob, lang und dicht, gleich oder etwas länger als die Gliedbreite. Palpen klein und eingliedrig; Grundglied mit 2 stärkeren und 2 bis 3 kürzeren Borsten. Thorax: einheitlich braun; Mesonotum mit einigen stärkeren lateralen und präscutellaren Borsten; Scutellum mit 4 starken Randborsten; Postpronotum mit 1 bis 2 Borsten. Flügel leicht gebräunt; $R_{1}=1,2 \mathrm{R}$; $\mathrm{C}=4 / 5 \mathrm{w} ; \mathrm{y}=1,8 \mathrm{x}, \mathrm{x}$ nackt und y distal mit 5-6 Makrotrichien; hintere Flügeladern schwach ausgebildet und ohne Makrotrichien; M-Stiel länger als $\mathrm{M}_{1}$; M-Gabel kurz und weit geöffnet; CuA-Stiel kurz, $=1 / 2 \mathrm{x}$. Coxen und Beine hellbraun, Tarsen angedunkelt; Vordertibienende mit großem und dichtem Borstenfleck. Klauen ungezähnt. Abdomen: braun, Gonocoxite kurz und kräftig, ventrale Innenseiten dicht und kurz behaart; Gonostyli etwa so lang wie die Gonocoxite, breit gerundet und auf der Außenseite hoch gewölbt; am Innenwinkel des Gonostylus mit 3 eng stehenden, ungleichen Dornen [die beiden stärkeren Dorne auf höheren Sockeln stehend, der dritte Dorn basal etwas abgesetzt und mit unschein-

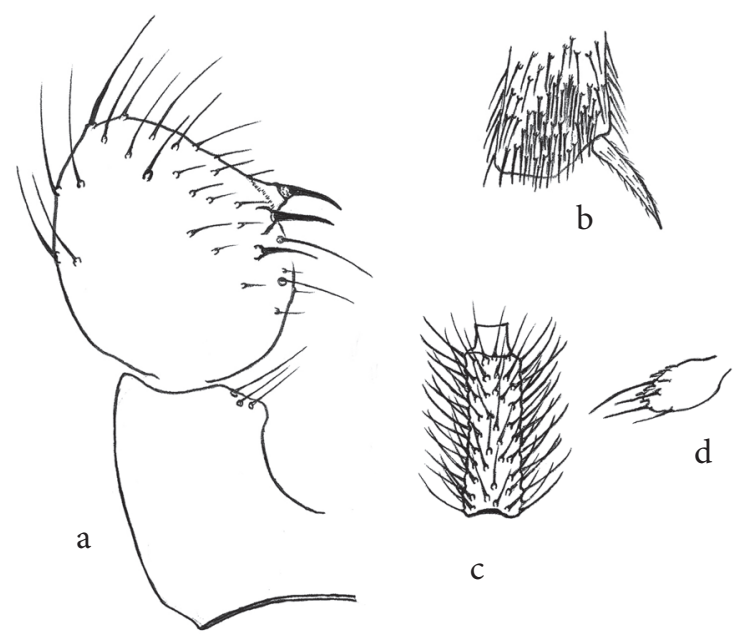

Fig. 4 a-d: Cratyna cucarisi (LANe), ơ: - a: Skizze von der deformierten linken Hälfte des Hypopygiums [Gonocoxit und Gonostylus] ventral, Holotypus von Plastosciara cucarisi Lane; b: Vordertibienende, Holotypus von Plastosciara cucarisi LANE; - c: 4. Fühlergeißelglied, Holotypus von Plastosciara downsi LANE; - d: Palpus, Holotypus von Plastosciara downsi Lane. 
bar flachem Sockel]; Innenseite unterhalb der Dorne mit zwei deutlich längeren Borsten; Dorne in der Mitte der Gonostyli fehlend. Genitalplatte membranös und flach gerundet, mit halbkreisförmiger Querleiste und fingerförmigem Mittelfortsatz. Aedeagus kurz und fein, mit trichterförmiger Basis. Größe: 2,5 mm.

․ Unbekannt.

Bemerkungen: Die Art ist durch die blasig aufgetriebenen und apikal hoch gewölbten Gonostyli mit nur drei Dornen an der Spitze gut charakterisiert, wodurch sie sich von den anderen Arten mit apikal gleichmäßig gerundeten Gonostyli und 4 paarig angeordneten, etwa gleichstarken Dornen unterscheidet. Bei Cr. cucarisi (LANE) fallen zudem die langen Fühlergeißelglieder mit dichterer Behaarung auf, deren Halsteile - im Gegensatz zu den vorstehend besprochenen Spezies - nicht verlängert sind. Die eingliedrigen Palpen und den hohen $\mathrm{C}-\mathrm{w}$-Index hat sie gemeinsam mit Cr. caraosi (LAne). Die Identität von Pl. downsi LAne mit Pl. cucarisi LANE konnte durch den Vergleich der Holotypen belegt werden. Von LANE (1960) wurden offensichtlich die bei der Präparation voluminöser Genitalien auftretende Deformation der Gonostyli überbewertet und der dritte, feinere Dorn übersehen.

\section{Euricrium ENDERLEIN, 1911}

Typusart: Euricrium ruebsaameni ENDERLEIN, 1911 [nec rübsaameni]: Arch. Naturgesch., 77(1) Suppl. 3: 142-143; Taf., Fig. 10 (mon.).

= Zygomma ENDERLEIN, 1911 syn. nov. - Arch. Naturgesch., 77(1) Suppl. 3: 126 und 143; Taf., Fig. 11 [praeocc.; nec Zygomma Bronn, 1859 - Coelenterata].

Typusart: Zygomma fasciatellum ENDERLEIN, 1911 Arch. Naturgesch., 77(1) Suppl. 3: 144-145; Taf., Fig. 11 (orig. des.; mon.).

= Mapiria EdWARDs 1934 syn. nov. - Revista Entomologia, 4(3): 368.

Typusart: Mapiria transversalis EDWARDS, 1934 - Revista Entomologia, 4(3): 369; 359, Fig. 2 (orig. des.; mon.).

= Muhabbetiola KoçAK, 2009 syn. nov. - in KoçAK \& Kemal (2009): Miscellaneous Papers 147-148: 7 [nom. nov. pro Zygomma ENDERLEIN, 1911].

Literatur: Zygoneura MEIGEN sensu Edwards [mitunter nur ex parte] - EDWARDS (1934): 369; - LENGERSDORF (1940): 245; - STEFFAN (1966): 39; - AMORIM (1992): 68; - AMORIM \& RindAL (2007): 52. Zygomma ENDERLEIN - EDWARDS (1914): 51; - SCHMITZ (1915): 157; - Lengersdorf (1940): 246; - MenZel \& Mohrig (2000): 721; - Mohrig (2003): 37 und 65; - JAschHoF \& Mohrig (2005): 308; - Mohrig \& Menzel (2009): 279, 285 und 292; - ShIn et al. (2013): 835. Mapiria EdwARds - Mohrig et al. (2013): 150 und 217. Euricrium ENDERLEIN - ENDERLEIN (1911): 126 und 142; - Shin et al. (2013): 835 .
Bemerkungen: Die Namen der Gattungsgruppe Zygoneura Meigen, Mapiria Edwards und Muhabbetiola KoçAK sind als feminin zu behandeln, weil die jeweiligen Autoren das so gehandhabt oder durch Indikation erkennbar gemacht haben. Im Gegensatz dazu sind Euricrium ENDERLEIN und Zygomma ENDERLEIN Neutrum, so dass die darin eingeschlossenen Namen der Artgruppe in der jeweils vom Autor vorgegebenen bzw. hier korrigierten Form gebraucht werden. Aus diesem Grund mussten in Übereinstimmung mit dem »International Code of Zoological Nomenclature« (ICZN 1999, IKZN 2000) mehrere Namen der Artgruppe dekliniert werden, bei denen eine Synonymie festgestellt und/oder eine Kombination zu Euricrium ENDERLEIN vorgenommen wurde. Davon betroffen sind auch inkorrekte (fehlerhafte) Namensbildungen, wie zum Beispiel bei Zygomma ENDERLEIN in MOHRIG (2003: 37-43).

SCHMitz (1915) und Lengersdorf (1940) analysieren vor allem die für Zygomma angeblich charakteristischen Flügelmerkmale, welche Enderlein (1911) dazu veranlassten, ein neues Genus Zygomma mit der Typusart Zygomma fasciatellum einzurichten. Beide Autoren kommen unabhängig voneinander zu dem Schluss, dass die bei ENDERLEIN beschriebenen Flügelader-Merkmale nicht ganz korrekt sind und diese weitestgehend auch für die Typusart von Zygoneura Meigen zutreffen. Auf dieser Grundlage stellen beide heraus, dass die Gattung Zygomma keinerlei Berechtigung habe und betrachten Zygomma ENDERLEIN als Synonym zu Zygoneura MEIGEN [siehe Schmitz (1915): 158; LENGERSDORF (1940): 246]. Folglich wurde von LENGERSDORF und späteren Autoren der Name Zygomma ENDERLEIN als Synonym zu Zygoneura MeIgEN betrachtet, wobei zur Begründung die breite $\mathrm{M}-\mathrm{Gabel}$, die vorgewölbte $\mathrm{M}_{1}$ und die relativ lange Behaarung der Fühlergeißelglieder als entscheidende Merkmale herangezogen wurden. Amorim (1992:68) schließt sich dieser Auffassung an und listet in seinem Katalog 10 »Zygoneura«-Arten mit neotropischer Verbreitung auf. Tatsächlich ist darunter nur die nordamerikanische flavicoxa JoHANNSEN eine echte Zygoneura. Alle anderen gehören zweifelsfrei zu Euricrium ENDERLEIN [=Zygomma ENDERLEIN] - mit Ausnahme der noch nicht revidierten Arten Zygoneura unimaculata LANE, 1955 [] und Sciara zygoneura Williston [0우. Die Ähnlichkeit im Flügelbau der beiden Gattungen beruht wahrscheinlich auf Konvergenz einer mehr oder weniger deutlich bauchig verbreiterten, vasenförmigen $\mathrm{M}-\mathrm{Gabel}$ [in Menzel \& Mohrig (2000) als "glockenförmigbauchige m-Gabel« bezeichnet]. Euricrium ENDERLEIN ist eine Gattung, die vermutlich der Ctenosciara-Gruppe nahe steht. Andererseits hat Zygoneura MeIGEN - unter Ausschluss von 3 species incertae sedis - nach gegenwärtigem Wissensstand nur eine holarktische Verbreitung und ist die Schwestergruppe von Xylosciara Tuомікоsкi [vergleiche hierzu mit Menzel \& Mohrig (2000): 565, 621].

Aufgrund der vorstehend genannten nomenklatorischen Neuerungen werden - in Ergänzung zu den 
hier abgehandelten Arten - auch die nachstehenden neotropischen Spezies in die Gattung Euricrium ENDERLEIN kombiniert: Euricrium acutum (MOHRIG, 2003) comb. nov. aus Costa Rica, Euricrium modicum (Mohrig, 2003) comb. nov. aus Costa Rica und Euricrium suspiciosum (MoHrig, 2003) comb. nov. aus Honduras. Außerdem gehören dieser Gattung zurzeit noch fünf unrevidierte Spezies an, deren korrekte Zugehörigkeit zum Genus Euricrium ENDERLEIN durch Sichtung der Typen noch bestätigt werden muss: Euricrium afrum LENGERSDORF, 1939 (Kongo; Zugehörigkeit fraglich!), Eur. antennarium LENGERSDORF, 1926 (Brasilien), Eur. borgmeieri LENGERSDORF, 1926 (Brasilien), Eur. myrmecophilum LENGERSDORF, 1925 (Brasilien) und Eur. pernitidum (EDWARDs, 1914) comb. nov. (Kenia; Zugehörigkeit fraglich!).

Bei näherer Betrachtung muss auch die monotypische Gattung Neozygoneura Lengersdorf, 1942 aus Südamerika [Beschreibung in Decheniana (Festschr.), 101 A-B: 99] mit der Typusart Neozygoneura fasciatellum Lengersdorf, 1942 einbezogen werden. Amorim (1992: 68) vermutet offensichtlich, dass die Namen Zygoneura fasciatella (ENDERLEIN, 1911) [original beschrieben als Zygomma fasciatellum] und Neozygoneura fasciatella LENGERSDORF, 1942 [nec fasciatellum] auf das gleiche Typenmaterial und die gleiche Typusart zurückgehen. Das ist falsch, weil LENGERSDORF (1942) eindeutig darauf hinweist, dass ihm aus dem Stettiner Museum andere, falsch determinierte Exemplar(e) von einer anderen Art vorgelegen haben. Dazu schreibt er, dass das/die von ihm untersuchte(n) Exemplar(e) »kaum mit dieser Art [gemeint ist Zygoneura fasciatella (ENDERLEIN)] zu einer Art vereinigt werden« kann, »da bei ihr die Hinteradern unbeborstet sind«. Daraufhin gibt er dieser abweichenden (neuen) Art - im Gegensatz zu Zygoneura fasciatellum (ENDERLEIN) [recte fasciatella] - den Namen Neozygoneura fasciatellum [recte fasciatella]. Daraus wird geschlussfolgert, dass LENGERSDORF (1942) nicht - wie von AMORIm (1992) postuliert - den Gattungsnamen Neozygoneura unberechtigt eingeführt hat. Vielmehr handelt es sich hier um zwei verschiedene Spezies in zwei verschiedenen Gattungen, die lediglich den gleichen Artnamen "fasciatellum « [recte fasciatella] tragen. Wir können hier den Gattungsnamen Neozygoneura LENGERSDORF, 1942 noch nicht aufklären, weil wir die Typusart Neozygoneura fasciatella LENGERSDORF bisher nicht revidieren konnten. Wir vermuten aber, dass Neozygoneura LENGERSDORF, 1942 ebenfalls zu Euricrium ENDERLEIN, 1911 gehören könnte.

\section{Euricrium alboantennatum (LANE, 1946) comb. nov. (Fig. 5 a-b)}

Locus typicus: "State of Rio de Janeiro" [= Estado de Rio de Janeiro], Itatiaia, Maromba (Brasilien).

Holotypus: ơ , Reg.-Nr. 6456, $1100 \mathrm{~m}$ ü. NN, August 1946, leg. Barretto (MZSP).
Paratypus: 1 ๆ , Reg.-Nr. 6457, „State of S. Paulo, Jaraguá« [= Estado de São Paulo, São Paulo, Jaraguá] (Brasilien), August 1945, leg. BARretto (MZSP) [nicht untersucht!].

Erhaltungszustand: Beim untersuchten Holotypus sind Kopf, Fühlergeißelglieder, Thorax, Coxen und Beine sowie die ersten beiden Abdominalsegmente gut erhalten. Von einer Fühlergeißel fehlen die beiden Spitzenglieder. Außerdem existiert nur noch ein Flügel, bei dem die Basis beschädigt ist. Das Hypopygium befindet sich in einem ausgezeichneten Zustand (umpräpariert in Kanadabalsam).

Literatur: Zygoneura alboantennata LANE - LANE (1946): 350-351; 349, Fig. 9; - LANe (1955): 255; - AMORIM (1992): 68. Zygomma alboantennata (LANE) - MoHrig (2003): 39. Muhabbetiola alboantennata (LANE) - KoçAK \& Kemal (2009): 7.

Redeskription: $\sigma^{*}$. Kopf: rundlich. Augenbrücke 3 bis 4-reihig. Fühler braun und an der Spitze depigmentiert, dadurch die beiden letzten Geißelglieder weißlich-gelb; 4. Fühlergeißelglied 2,8 mal so lang wie breit; Halsteil braun, scharf abgesetzt und deutlich verlängert, etwas länger als 1/4 des Basalteils; Fühlergeißelglieder sehr dicht und so lang wie die Gliedbreite behaart. Palpen lang und 3-gliedrig; Grundglied mit mehreren Borsten und deutlich begrenztem Sensillenfeld; alle Palpenglieder schlank, 2. und 3. Palpenglied stabförmig lang. Thorax: dunkelbraun; Mesonotum flach, ohne grobe Borsten und nahezu unbehaart; seitlich bis in Höhe des Flügelansatzes mit mehrreihig angeordneten, sehr kurzen und feinen, sensorienartig vertieften Härchen, die von runden, hell abgesetzten Insertionsstellen umgrenzt sind [ähnliche Behaarung auch am Hinterkopf vorhanden]; Katepisternit keilförmig verlängert; Scutellum spärlich behaart, mit 2 etwas längeren und stärkeren Randborsten. Flügel ungetrübt und einfarbig hellbraun; Flügel relativ kurz und breit, ohne Farbbinden; Flügelmembran leicht gebräunt, mit breitem Analfeld; $\mathrm{R}_{5}$ mit einseitig dorsalem Makrotrichienbesatz, ventral nur mit 4 Makrotrichien [davon eine in der Mitte und

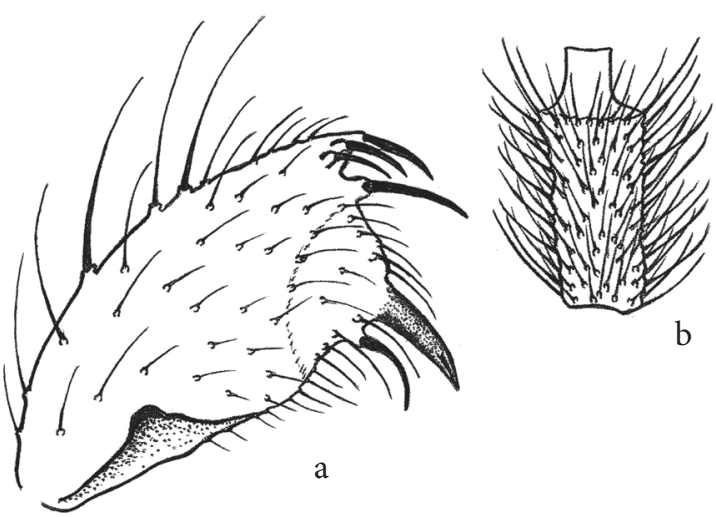

Fig. 5 a-b: Euricrium alboantennatum (LANE), Holotypus $\sigma^{*}$ : - a: Gonostylus ventral; - b: 4. Fühlergeißelglied. 

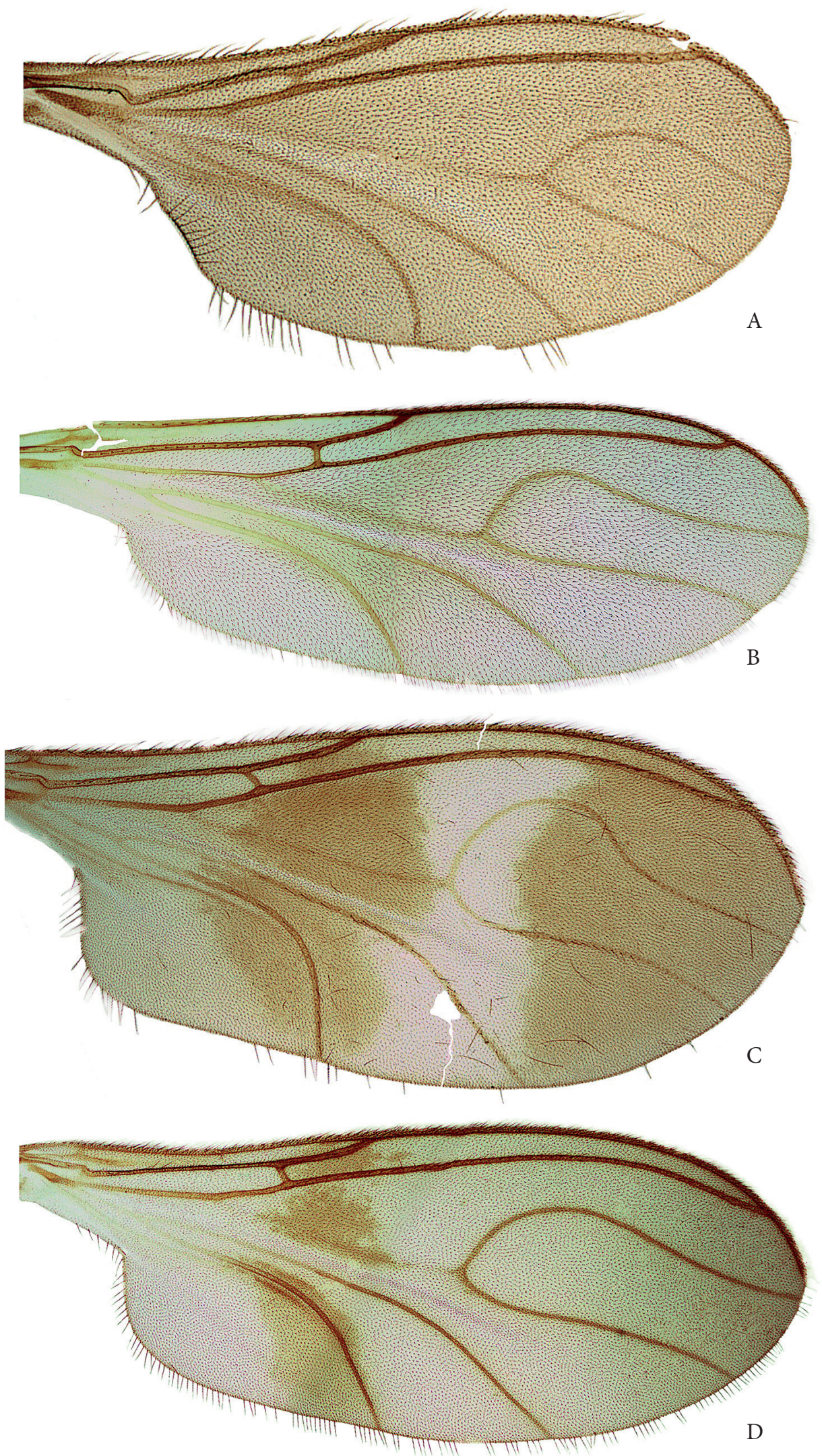

Tafel 1, Fig. A-D: Flügel von neotropischen Sciaridenarten aus der Gattung Euricrium: - A: Euricrium ruebsaameni ENDERLEIN ơ, Holotypus von Euricrium fulgescens ENdERLEIN; - B: Euricrium glaberrimum (Edwards) o`, Holotypus; - C: Euricrium fasciatellum (ENDERlein) + , Holotypus von Zygoneura maculipennis LANE; - D: Euricrium varians (LANE) + , Holotypus. 
3 an der Spitze von $\mathrm{R}_{5}$ ]; $\mathrm{R}_{1}=1 / 2 \mathrm{R} ; \mathrm{C}=3 / 4 \mathrm{w} ; \mathrm{y}=0,8 \mathrm{x}$, beide ohne Makrotrichien; M-Stiel deutlich länger als $\mathrm{M}_{2} ; \mathrm{M}_{1}$ basal stark vorgewölbt; $\mathrm{M}$-Gabel in der Mitte nur wenig verengt, dadurch parallelseitig breit und nur leicht vasenförmig; $\mathrm{CuA}-\mathrm{Stiel}=2 / 3 \mathrm{x} ; \mathrm{CuA}_{1}$ leicht, $\mathrm{CuA}_{2}$ stärker zum Flügelhinterrand gebogen; hintere Flügeladern ohne Makrotrichien. Halteren kurz gestielt und dunkel. Coxen und Beine hell-bräunlich, Tarsen angedunkelt; Vordertibien ohne Dörnchen in der Grundbeborstung und mit einem breiten, einreihigen Borstenkamm; alle Borsten des Vordertibienfleckes fein, hell und auf einer Leiste stehend [ohne bogenförmige Berandung]; Tibiensporn ca. 1/3 mal länger als die Tibienspitze breit; je ein Sporn an den Mittel- und Hinterbeinen etwas verkürzt. Klauen fein gezähnt. Abdomen: bräunlich, relativ lang und spärlich behaart. Hypopygium braun; ventrale Genitalbasis ohne interkoxale Differenzierung; Gonocoxite etwa 1,5 mal länger als die Gonostyli, an der ventralen Innenseite mäßig lang und fein behaart; Gonostyli kompakt, zur Spitze hin keulenförmig verbreitert und apikal breit abgestutzt; ventrales Spitzendrittel des Gonostylus leicht abgeflacht und ausgerandet [diese Ausrandung bis $\mathrm{zu}$ der zurückgesetzten Dornengruppe nahe der Außenseite reichend]; Gonostylus am Innenwinkel mit kräftigem Spitzenzahn; über dem Zahn mit 3 (4) etwas isoliert in Reihe stehenden Dornen und darunter mit 1 (2) nach innen-unten gebogenen Dornen. Genitalplatte kurz, membranös und breit gerundet; Zähnchenfeld schmal, mit feinen Zähnchen. Aedeagus mäßig lang, mit breithalbkreisförmiger Basis. Größe: 2,3 mm.

‥ Siehe LANE (1946): 350.

Bemerkungen: Die Art ist im Stylusbau Eur. acutum (Mohrig, 2003) aus Costa Rica und Eur. suspiciosum (Mohrig, 2003) aus Honduras sehr ähnlich. Sie unterscheidet sich von Eur. acutum durch breitere Gonostyli, anders angeordnete Dorne, einen kürzeren Aedeagus, die längere Behaarung der Fühlergeißelglieder, die zwei depigmentierten Endglieder der Fühlergeißel und das fast nackte Mesonotum. Von Eur. suspiciosum unterscheidet sie sich durch das etwas verlängerte Gesicht, den Besitz von höchstens 4 Dornen über dem Spitzenzahn und die länger behaarten Fühlergeißelglieder. MoHrig (2003: 39) meldet Eur. alboantennatum (LANE) auch aus Costa Rica.

\section{Euricrium bolivianum (EDWARDS, 1934) comb. nov. (Fig. 6 a-c)}

Locus typicus: "Yungasweg« [= Departamento La Paz, Los Yungas, Weg in die Yungas zwischen La Paz und Coroico] (Bolivien).

Holotypus: ơ, 2500-4000 m ü. NN., 11.10.1906, leg. GARLEPP (SMTD).

Erhaltungszustand: Am Holotypus sind der Kopf mit den Palpen und dem ersten Fühlergeißelglied, die Flügel, der Thorax mit den Coxen und 4 Beine vorhanden. Die Segmente 3 und 4 des Abdomens sowie die anderen
Fühlergeißelglieder fehlen. Das Hypopygium ist stark deformiert [nur Genitalplatte mit Aedeagus und Spitze von einem Gonostylus in gutem Zustand] (umpräpariert in Kanadabalsam).

Literatur: Zygoneura boliviana EDWARDS - EDWARDS (1934): 369-370; 359, Fig. 3; - LENGERSDORF (1940): 247; - LANE (1946): 351; - AMORIM (1992): 68.

Redeskription: ${ }^{\star}$. Kopf: dunkel; Augenbrücke 2-reihig, an den Rändern deutlich verschmälert und nur 1-reihig. Fühlerbehaarung lang und abstehend, deutlich länger als die Gliedbreite; 1. Fühlergeißelglied 2,7 mal so lang wie breit, dicht und länger als die Gliedbreite beborstet; Basalteil zwischen der grob-langen Beborstung mit feinen, deutlich kürzeren Haaren und mit hellen Sensillen; Halsteil einfarbig dunkelbraun und verlängert, etwa $1 / 3$ mal so lang wie das Basalteil. Palpen lang und 3-gliedrig; Grundglied mit mehreren langen Borsten und mit schwach berandetem Sensillenfeld; alle Palpenglieder schlank, 2. und 3. Palpenglied stabförmig lang. Thorax: Mesonotum dunkelbraun, nahezu unbehaart und nur lateral mit kurzen, feinen Härchen; Katepisternit keilförmig verlängert; Scutellum und Thorakalsklerite dunkel, membranöse Teile der Thoraxseiten grobkörnig strukturiert. Scutellum spärlich behaart, mit 2 längeren und stärkeren Randborsten. Flügel groß und lang, ohne Farbbinden; Flügelmembran leicht gebräunt und mit gut entwickeltem, aber schmalem Analfeld; $\mathrm{R}_{5}$ mit einseitig dorsalem Makrotrichienbesatz; $\mathrm{R}_{1}=2 / 3 \mathrm{R}$; $\mathrm{x}$ sehr lang; y kürzer als $1 / 2 \mathrm{x}$, beide nackt; $M$-Stiel deutlich kürzer als $M_{2} ; M_{1}$ basal stark vorgewölbt; $M-$ Gabel in der Mitte stark verengt, dadurch relativ schmal und stark vasenförmig; hintere Flügeladern ohne Makrotrichien;

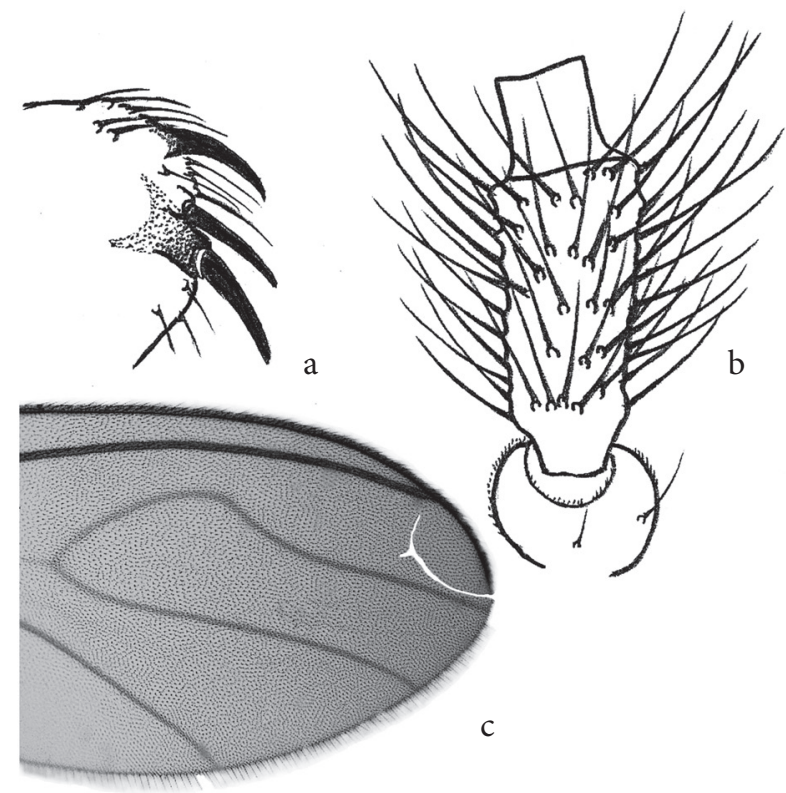

Fig. 6 a-c: Euricrium bolivianum (Edwards), Holotypus o': - a: Zahn und Dorne an der Spitze des rechten Gonostylus, ventral; - b: Pedicellus und 1. Fühlergeißelglied; - c: Flügelspitze mit M-Gabel. 
$\mathrm{C}=4 / 5$ w. Halteren kurz gestielt und gebräunt. Coxen und Beine dünn, einfarbig dunkelbraun; Vordertibien ohne Dörnchen in der Grundbeborstung; Vordertibia an der Spitze mit einem einreihigen, leicht gebogenen Borstenkamm [bestehend aus 6 bis 7 dunklen, grobhyalinen Dornborsten]. Klauen fein gezähnt. Abdomen: dunkelbaun; Beborstung spärlich, lang und dunkel. Hypopygium einfarbig braun, ventrale Genitalbasis ohne Basallobus; Innenseiten kurz und relativ dicht behaart; Gonostylus länglich-oval, etwa 2,3 mal so lang wie breit, mit gerader Innenseite und an der Spitze etwas abgeflacht; Spitze des Gonostylus dorsal mit einem kräftigen, der Außenseite genäherten Zahn; ventral lediglich dicht beborstet und dorsal darunter mit mit 2 kräftigen Dornen [der untere Dorn stärker und auf einem hohen Sockel lobusartig abgesetzt, unmittelbar darüber mit einem deutlich schlankeren Dorn auf kurzem Sockel]. Genitalplatte breiter als hoch, membranös und flach gerundet, in der Mitte etwas ausgerandet; Zähnchenfeld breiter als hoch, mit sehr feinen, einspitzigen Zähnchen. Aedeagus mäßig lang und schlank. Größe: 2,4 mm. ㅇ. Unbekannt.

Bemerkungen: Die Art ist von allen anderen EuricriumArten durch den dorsal inserierenden Zahn an der Spitze des Gonostylus mit den beiden darunter stehenden Dornen, von denen einer lobig abgesetzt iseriert, unterscheidbar. Die Flügel haben eine relativ helle Flügelmembran, Farbbinden fehlen, $\mathrm{x}$ ist sehr lang und der $\mathrm{C}$-w-Index ist durch die lange $\mathrm{C}$ ausgesprochen hoch. Mit der Zahnstruktur am Gonostylus, dem einreihigen Borstenkamm an der Vordertibia, den deutlich gezähnten Klauen und der basal vasenförmig verbreiterten M-Gabel, die im weiteren Verlauf stark verengt ist, gehört diese Art zweifelsfrei zu Euricrium Enderlein. Nach LENGERSDORF (1940) soll Eur. bolivianum (EDWARDS) auch aus Mexiko bekannt sein.

\section{Euricrium fasciatellum (ENDERLEIN, 1911) comb. nov. (Tafel 1, Fig. C)}

Locus typicus: "Santa Catharina" [= Estado de Santa Catarina] (Brasilien).

Lectotypus: $0^{\star}$, leg. LÜDERWALdT (MZPW) [des. AMORIM (1992): 68].

Paralectotypen: $20^{\top} o^{\star}$ und 3 우, gleiche Funddaten (MZPW) [davon nur 1 ㅇ untersucht! (Menzel \& Mohrig 2000: 722)].

= Zygoneura maculipennis LANE, 1946 - Revista Entomologia, 17(3): 348-350 und 351 [praeocc.; nec Zygoneura maculipennis SkUSE, 1891].

Locus typicus: »State of S. Paulo, Jaraguá« [= Estado de São Paulo, São Paulo, Jaraguá] (Brasilien).

Holotypus: + , Reg.-Nr. 6452, August 1945, leg. LANE (MZSP).

Paratypen: 1 ㅇ, Reg.-Nr. 6453, „S. Paulo, Ferraz de Vasconcelos « [= Estado de São Paulo, Ferraz de Vasconcelos östlich von São Paulo] (Brasilien), August 1946, leg. LANE (MZSP); 1 \%, Reg.-Nr. 6454, »State of Rio de Janeiro « [= Estado de Rio de Janeiro], Itatiaia, Maromba (Brasilien), 1100 m ü. NN, August 1946, leg. BARretto (MZSP) [beide nicht untersucht!].

= Zygoneura stonei LANE, 1947 - Revista Entomologia, 18(1-2): 214 [nom. nov. pro Zygoneura maculipennis LANE, 1946].

Erhaltungszustand: Der Lectotypus [ $\left.\sigma^{\star}\right]$ und 2 Paralectotypen [우] von Zygomma fasciatellum ENDERLEIN wurden in Kanadabalsam umpräpariert. Davon wurden das $\sigma^{*}$ und 1 o bereits in Menzel \& Mohrig (2000) revidiert. Beim Holotypus von Z. maculipennis LANE [=Z. stonei LANE] sind Thorax, Flügel, alle Coxen und Beine sowie das Abdomen gut erhalten. Der Kopf liegt in zwei Teilen vor. Außerdem existieren nur noch von einer Fühlergeißel die ersten beiden Geißelglieder (umpräpariert in Kanadabalsam).

Literatur: Zygoneura stonei LANE - LANE (1955): 255 und 258. Zygoneura fasciatellum (ENDERLEIN) [recte fasciatella] - LENGERSDORF (1940): 246; - LENGERSDORF (1942): 99. Zygoneura (Zygomma) fasciatella (ENDERLEIN) - Frey (1942): 35-36. Zygoneura fasciatella (ENDERLEIN) - Amorim (1992): 68. Zygomma fasciatellum ENDERLEIN - Enderlein (1911): 144-145; Taf., Fig. 11; - Schmitz (1915): 157; - Menzel \& Mohrig (2000): 722-723; Abb. 605-607; - Mohrig (2003): 37-38 und 39; Fig. 27; Mohrig \& Menzel (2009): 284, Fig. 16.31. Muhabbetiola fasciatella (ENDERLEIN) - KoçAK \& Kemal (2009): 7.

Redeskription: $\sigma^{x}$. Kopf: rundlich und dunkelbraun. Augenbrücke 3 bis 4 -reihig. Fühler lang und dunkelbraun; Fühlergrundglieder dunkel; 4. Fühlergeißelglied 2,2 mal so lang wie breit; Geißelglieder sehr dicht, grob, abstehend und dunkel behaart; Haare länger als die Gliedbreite; Halsteil schmal und scharf abgesetzt; Basalteil 2,6 mal so lang wie das Halsteil; die letzten beiden Fühlergeißelglieder auffällig gelb-weiß gefärbt. Palpen dunkel und 3-gliedrig [im Präparat schlecht sichtbar]. Thorax: dunkelbraun; Coxen und Beine hellgelb. Postpronotum nackt. Mesonotum dunkelbraun bis schwarz und mit längeren lateralen, zentralen und skutellaren Borsten; feinere Behaarung des Thorax dunkelbraun bis hell. Vordertibien ohne Dörnchen in der Grundbeborstung, Tibienende der $p_{1}$ mit breitem, einreihigem Borstenkamm [dieser etwa 3/4 mal so breit wie das Vordertibienende und aus hellen Borsten bestehend]; Tibienenden der $p_{2}$ und $p_{3}$ mit je einem verkürzten Sporn; Tibien der $\mathrm{p}_{3}$ mit einer einreihigen Dörnchenreihe. Klauen deutlich gezähnt, mit 4 eng anliegenden, gröberen Nebenzähnchen. Flügel relativ kurz und breit, mit gut ausgebildetem Analfeld; Flügelmembran hell, mit 2 stark gebräunten Querbinden an der Flügelspitze [bis zur Einmündung von $\mathrm{M}_{1}$ ] und über den Bereich von $\mathrm{R}_{1}$ bis zur Einmündung von $M_{2}$ [bei Menzel \& Mohrig (2000): Flügelmembran rauchbraun und über die gesamte Flügelmembran in Nähe der M-Gabelbasis und der Flügelbasis mit 2 hellen 
Querbinden]; hintere Adern deutlich und bis auf den M-Stiel mit Makrotrichien; $M_{1}$ und $M_{2}$ divergierend in den Flügelrand mündend; $\mathrm{M}$-Stiel deutlich kürzer als $\mathrm{M}_{2}$; $\mathrm{M}_{2}$ gleichmäßig s-förmig geschwungen; $M_{1}$ basal stark vorgewölbt; M-Gabel in der Mitte stark verengt, dadurch relativ schmal und stark vasenförmig; $\mathrm{CuA}_{1}$ und $\mathrm{CuA}_{2}$ zunächst fast parallel verlaufend; $\mathrm{CuA}_{2}$ in der hinteren Hälfte gleichmäßig gebogen und fast senkrecht in den Flügelrand mündend; $\mathrm{x}=1,5 \mathrm{y}$, beide nackt; CuA-Stiel lang, = $3 / 4 \mathrm{x} ; \mathrm{R}_{5}$ mit einseitig dorsalem Makrotrichienbesatz; $\mathrm{R}_{1}$ sehr kurz, = 1/2 $\mathrm{R}$ und weit vor der M-Gabelbasis in $c$ mündend; $C=4 / 5 \mathrm{w}$. Halteren kurz gestielt und dunkel. Abdomen: dunkelbraun, die ersten beiden Abdominalsegmente gelblich; Körperbehaarung grob, lang und dunkel. Hypopygium breiter als hoch, einfarbig dunkelbraun und ohne ventralen Basallobus; Basis des Ventralausschnittes tief ausgerandet; Innenseite der Gonocoxite lang behaart; Gonostyli auffällig dicht mit Mikrotrichien besetzt und apikal deutlich verschmälert; Spitze des Gonostylus lobusartig ausgezogen, mit einem schmalen Endzahn und 3 hyalinen Dornen in der lichten Spitzenbehaarung. Genitalplatte breiter als hoch, apikal gerundet [im Präparat deformiert]. Aedeagus kurz und schlank. Größe: 1,5 mm.

․ Palpengrundglied schlank, mit 3 Borsten besetzt und mit großem, unberandetem Sensillenfeld [2. und 3. Glied in den Präparaten schlecht sichtbar oder fehlend]; 2. Fühlergeißelglied 2,7 mal so lang wie breit. Basalteil etwa 3,5 mal so lang wie das Halsteil; CuAStiel $=1 / 2 \mathrm{x}$; alle anderen Merkmale wie beim $\sigma^{*}$. Größe: 2,0-2,2 mm.

Bemerkungen: Der Name Zygoneura maculipennis LANE ist präokkupiert [nec Zygoneura maculipennis SKUSE, 1891], was LANE (1947) selbst erkannt hat. Folgerichtig setzte er für die besprochene Art mit Zygoneura stonei einen neuen Namen ein. Amorim (1992) hat die artliche Identität von Zygoneura stonei LANE mit Eur. fasciatellum (ENDERLEIN) richtig erkannt, ordnete die Art jedoch fälschlich in das Genus Zygoneura Meigen ein. Die Synonymisierung von AMORIM (1992) wird hier durch Typenvergleich bestätigt. Die Typusart von Zygomma ENDERLEIN wurde bereits in Menzel \& MoHrig (2000: 722) redeskribiert und abgebildet. Die systematische Stellung von Euricrium ENDERLEIN [= Zygomma ENDERLEIN] und einige phylogenetische Aspekte werden in Menzel \& Mohrig (2000: 577, 723) diskutiert. Mohrig (2003) meldet Eur. fasciatellum (ENDERLEIN) auch aus Costa Rica.

\section{Euricrium freemani (LANE, 1955) comb. nov.} (Fig. 7 a-d)

Locus typicus: Estado de Santa Catarina, Nova Teutônia, » $27^{\circ} 11^{\prime}$ B. $52^{\circ} 23^{\prime} \mathrm{L}$. « [= 27 $7^{\circ} 11^{\prime} \mathrm{S} 52^{\circ} 23^{\prime} \mathrm{W}$ ] (Brasilien).

Holotypus: ${ }^{\star}$, Reg.-Nr. 7732, Juli 1948, leg. PlaumanN (MZSP).
Paratypen: $7 o^{\star} o^{\star}$ und 4 ㅇ 우, Reg.-Nr. 7733-7740, gleiche Funddaten wie der Holotypus und/oder Estado de São Paulo, São Paulo, Jaraguá (Brasilien), August 1945, leg. LANE (MZSP) [alle nicht untersucht!].

Erhaltungszustand: Beim Holotypus sind Kopf, Fühlergeißelglieder, Thorax, Coxen, Beine, Abdomen und ein Flügel vollständig erhalten. Bei dem zweiten Flügel fehlt die vordere Hälfte. Das Hypopygium befindet sich in einem sehr guten Zustand. Es ist aber an einigen Stellen rotbraun aufgehellt (umpräpariert in Kanadabalsam).

Literatur: Zygoneura freemani LANE - LANE (1955): 255 und 258-259; Fig. 2 a-b; - AMORIm (1992): 68.

Redeskription: $\sigma^{\star}$. Kopf: rundlich. Augenbrücke 3-reihig. Fühler einfarbig braun, mit sehr langen Halsteilen; Basalteile mit kurzer und feiner Grundbehaarung und 2 wirtelig angeordneten Borstenkränzen am apikalen und basalen Ende [hier mit sehr langen Borsten]; zwischen den beiden Borstenkränzen mit einigen kürzeren, feineren Haaren sowie mit sehr kurzen und lang-gebogenen Sensillen; 4. Fühlergeißelglied 3,2 mal so lang wie breit; Halsteil einfarbig dunkelbraun, scharf abgesetzt und sehr lang [=4/5 mal so lang wie das Basalteil]. Palpen lang und 3-gliedrig; Grundglied mit 7 bis 9 Borsten [davon eine kräftige Außenborste deutlich länger] und mit großem, leicht vertieftem Sensillenfeld; alle Palpenglieder schlank und hellbraun; Endglied etwa so lang wie das Grundglied, 2. Glied 3/4 mal so lang wie das Endglied.

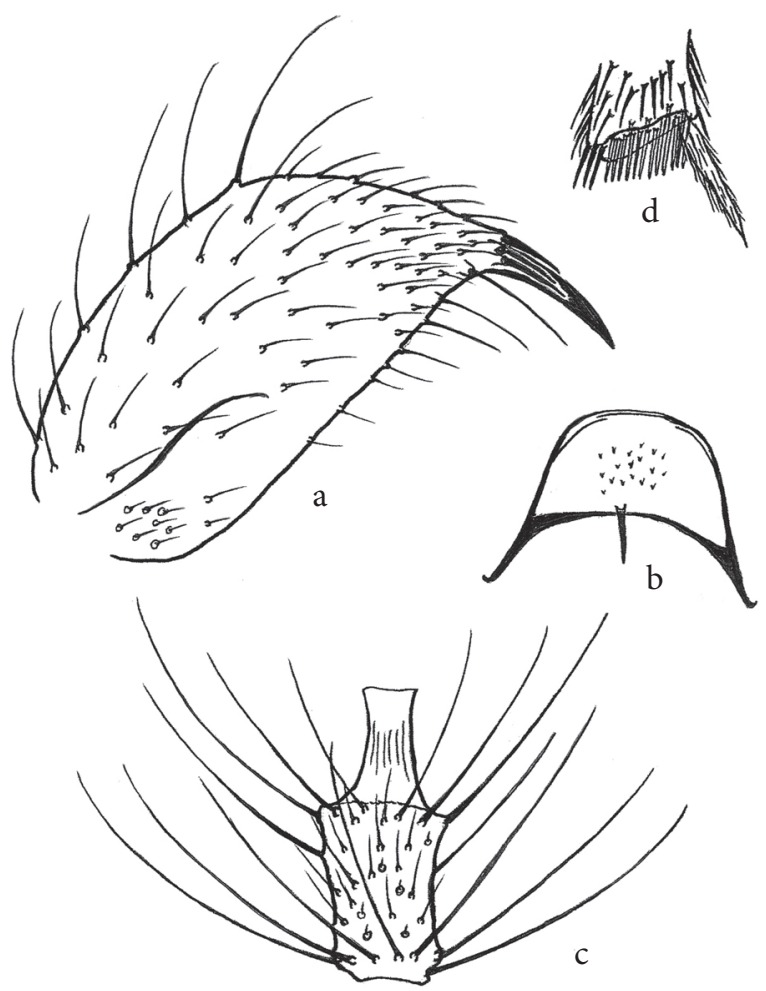

Fig. 7 a-d: Euricrium freemani (LANE), Holotypus ơ : - a: Gonostylus ventral; - b: Genitalplatte mit Aedeagus ventral; - c: 4 . Fühlergeißelglied; - d: Vordertibienende. 
Thorax: dunkelbraun; Mesonotum flach, nahezu unbehaart; Seiten des Mesonotums mit wenigen, feinen, sensorienartigen Härchen auf kleinen, hellen Insertionsstellen; Katepisternit keilförmig verlängert; Scutellum sehr kurz und spärlich behaart. Flügel breit und sehr hell, mit kaum sichtbaren hinteren Flügeladern; Flügelmembran durchsichtig klar, mit breitem Analfeld; $\mathrm{R}_{5}$ mit einseitig dorsalem Makrotrichienbesatz; $\mathrm{R}_{1}$ etwas kürzer als $=1 / 2 \mathrm{R} ; \mathrm{C}=4 / 5 \mathrm{w}$; $\mathrm{y}$ kurz und $\mathrm{x}$ sehr lang; $\mathrm{y}=2 / 5 \mathrm{x}$, beide ohne Makrotrichien; $M-S t i e l$ etwa so lang wie $M_{2}$; $M_{1}$ basal stark vorgewölbt; M-Gabel in der Mitte nur wenig verengt, dadurch breit und nur leicht vasenförmig; $\mathrm{CuA}-$ Stiel $=1 / 2 \mathrm{x} ; \mathrm{CuA}_{1}$ leicht und $\mathrm{CuA}_{2}$ stärker zum Flügelhinterrand gebogen; hintere Flügeladern ohne Makrotrichien. Halteren kurz gestielt und dunkelbraun. Coxen braun, Femora und Tibien heller, Tarsen angedunkelt; Vordertibien ohne Dörnchen in der Grundbeborstung und mit sehr breitem, einreihigem Borstenkamm [aus hellen, hyalinen Borsten bestehend und fast die gesamte Tibienbreite einnehmend]; Tibiensporne der Mittel- und Hinterbeine mit je einem reduzierten Tibiensporn [dieser etwa 1/4 kürzer als der andere]. Klauen fein gezähnt. Abdomen: dunkel, relativ kurz und spärlich behaart. Hypopygium bräunlich; ventrale Basis ohne interkoxale Differenzierung; Gonocoxite wenig länger als die Gonostyli, an der ventralen Innenseite kurz und spärlich behaart; Gonostyli verschmälert und zugespitzt, 2,2 mal so lang wie breit; Spitze mit langem und kräftigem Zahn und mit 2 [seltener 3] etwa halb so langen, dünnen Dornen unmittelbar an der Zahnbasis; Innenseite der Gonostyli geschlossen, unter dem Zahn mit 2 bis 3 längeren Borsten. Genitalplatte breiter als hoch, apikal breit gerundet; Zähnchenfeld kreisförmig, mit feinen und einspitzigen Zähnchen. Aedeagus kurz. Größe: 2,3 mm. ㅇ. Siehe LANE (1955): 259.

Bemerkungen: Die Art ist durch den langen Zahn an der Spitze des Gonostylus sowie durch die eng an seiner Basis stehenden Dörnchen Eur. glaberrimum (EDwARDs) sehr ähnlich. Von dieser unterscheidet sich Eur. freemani (LANE) vor allem im Bau der Flügel [andersartige M-Gabel, andere Flügelader-Indizes] und in den Fühlergeißelgliedern mit deutlich längeren Halsteilen und den beiden wirteligen Borstenreihen auf den Basalteilen. Die Art wurde nach der Beschreibung von LANE noch nicht wieder gefunden.

Euricrium glaberrimum (EDWARDS, 1934) comb. nov. (Fig. 8 a-c; Tafel 1, Fig. B)

Locus typicus: »Cordillere, Mapiri« [= Departamento La Paz, Cordillera Real, bei Mapiri] (Bolivien).

Holotypus: ơ , 4000-5000 m ü. NN, 14.5.1903, leg. GARLEPP (SMTD).

Erhaltungszustand: Dem Holotypus fehlen ein Mittelund ein Hinterbein sowie einige Geißelglieder an der Fühlerspitze [Geißelglieder 11 bis 14 bzw. das 14. Glied].
Einen guten Erhaltungszustand weisen der Thorax, die Flügel, Coxen, 4 Beine, das 1. bis 4 . Abdominalsegment sowie der Kopf mit den verbleibenden Fühlergeißelgliedern auf. Im Gegensatz dazu ist das Hypopygium stark gequetscht und nur an den Spitzen der Gonostyli gut erhalten (umpräpariert in Kanadabalsam).

Literatur: Zygoneura glaberrima EDWARDS - EDWARDS (1934): 370-371; 359, Fig. 4 [in part als glaberima]; LANE (1946): 351; - AMORIM (1992): 68.

Redeskription: ${ }^{\star}$. Kopf: rundlich und dunkel; Augenbrücke 3-reihig. Fühler lang und einfarbig dunkelbraun; Fühlergrundglieder dunkel; 4. Fühlergeißelglied 2,9 mal so lang wie breit, dicht und länger als die Gliedbreite behaart; Halsteil einfarbig dunkelbraun, scharf abgesetzt und deutlich verlängert, 2/5 mal so lang wie das Basalteil; Basalteil neben den grob-langen Borstenhaaren mit feinen, langen Sensillen [diese mit auffällig hellen Insertionshöfen]. Palpen lang und 3-gliedrig; Grundglied mit 7 Borsten [davon eine kräftige Außenborste deutlich länger] und mit großem, leicht vertieftem Sensillenfeld; alle Palpenglieder dunkelbraun, lang und schlank [ähnlich wie bei Eur. freemani (LANE); LängenBreiten-Verhältnisse wegen vorhandener Deformationen nicht messbar]. Thorax: Mesonotum schwarz und nahezu unbehaart, nur lateral mit sehr kurzen und feinen Härchen auf kleinen, hellen Insertionsstellen; Katepisternit keilförmig verlängert; Scutellum und Thoraxsklerite dunkel; Scutellum sehr kurz und spärlich behaart; membranöse Teile der Thoraxseiten auf orange-rotbraunem Grund dicht und grobkörnig dunkel strukturiert. Flügel hell, lang und basal verschmälert; Flügelmembran ohne Farbbinden und mit schmalem Analfeld; hintere Flügeladern hellbraun ausgefärbt und gut sichtbar; $\mathrm{R}_{5}$ mit einseitig dorsalem Makrotrichienbesatz; $\mathrm{R}_{1}$ sehr kurz, nur wenig länger als $1 / 3 \mathrm{R}$; $\mathrm{C}=3 / 4 \mathrm{w}$; y kurz und $\mathrm{x}$ sehr lang; $\mathrm{y}=1 / 3 \mathrm{x}$, $\mathrm{x}$ nackt und $\mathrm{y}$ distal mit 2 bis 3 Makrotrichien; M-Stiel deutlich kürzer als $M_{2} ; M_{1}$ basal stark vorgewölbt; M-Gabel in der Mitte stark verengt, relativ schmal und dadurch lang vasenförmig; $\mathrm{CuA}-S t i e l=2 / 5 \mathrm{x} ; \mathrm{CuA}_{1}$ leicht und $\mathrm{CuA}_{2}$ stärker zum Flügelhinterrand gebogen; hintere Flügeladern ohne Makrotrichien. Halteren kurz gestielt und gebräunt. Coxen und Beine lang und schlank;
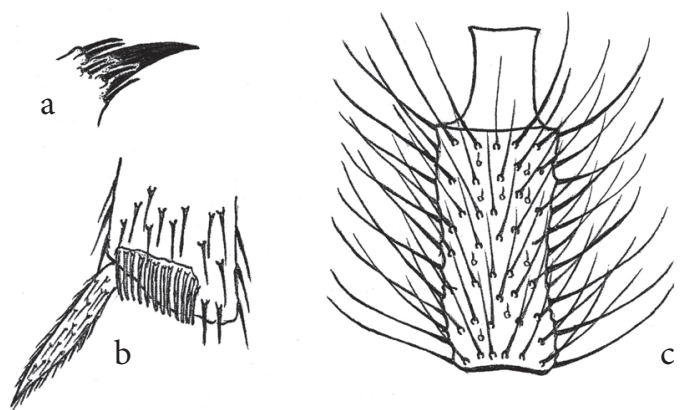

Fig. 8 a-c: Euricrium glaberrimum (EDwARDs), Holotypus $\sigma^{*}$ : - a: Zahn und Dorne an der Spitze des Gonostylus, ventral; b: Vordertibienende; - c: 4. Fühlergeißelglied. 
Vorderbeine mit gelblichen Coxen und dunkelbraunen Femora; Coxen und Femora der $\mathrm{p}_{2}$ und $\mathrm{p}_{3}$ dunkelbraun; Tibien und Fußglieder der $\mathrm{p}_{1}$ bis $\mathrm{p}_{3}$ hellbraun; Vordertibien ohne Dörnchen in der Grundbeborstung und mit einreihigem, leicht gebogenem Borstenkamm [dieser etwa 1/2 mal so breit wie das Vordertibienende und aus hellen Borsten bestehend]. Klauen fein gezähnt. Abdomen: dunkelbraun, spärlich, fein und dunkel beborstet. Hypopygium braun, ventrale Basis ohne Basallobus; Innenseite der Gonocoxite kurz und fein behaart; Gonostyli [im Präparat stark deformiert] nach der Originalbeschreibung voluminös und außen stark gerundet; Spitze des Gonostylus mit kräftig-kurzem, wenig gebogenem Zahn; an der Basis des Spitzenzahns mit 5 bis 6 kurzen, eng anliegenden und fein-hyalinen Dornen. Genitalplatte breiter als hoch, apikal breit gerundet; Aedeagus kurz und dünn; Zähnchenfeld mit feinen, einspitzigen Zähnchen. Größe: $2,5 \mathrm{~mm}$.

․ Unbekannt.

Bemerkungen: Die Art ist durch die blasig erweiterten Gonostyli, den kurzen Spitzenzahn und die 5 bis 6 Dörnchen an der Zahnbasis gut charakterisiert. Sie ist Eur. freemani (LANE) sehr ähnlich, unterscheidet sich von dieser aber vor allem durch den deutlich kürzeren Spitzenzahn am Gonostylus, die höhere Anzahl von kürzeren und feineren Dornen an der Zahnbasis, die kürzeren Fühlerhalsteile sowie die kürzere und viel dichtere Behaarung der Fühlergeißelglieder. Von Eur. glaberrimum (EDWARDs) existiert zurzeit nur der Holotypus.

\section{Euricrium ruebsaameni ENDERLEIN, 1911}

(Fig. 9 a-c; Tafel 1, Fig. A)

Locus typicus: „Süd-Brasilien, Santa Catharina» [= Estado de Santa Catarina] (Brasilien).

Holotypus: + , ohne Funddatum, leg. LüDERWALdT (MZPW).

= Lycoria fulgescens ENDERLEIN, 1911 syn. nov. - Arch. Naturgesch., 77 (1) Suppl. 3: 170-171.

Locus typicus: »Santa Catharina« [= Estado de Santa Catarina] (Brasilien).

Holotypus: $\sigma^{*}$, ohne weitere Funddaten, leg. LÜDERWALDT (MZPW).

Erhaltungszustand: Der Holotypus von Eur. ruebsaameni ENDERLEIN liegt in 3 Präparaten vor (umpräpariert in Kanadabalsam). Bei dem + fehlen ein Vorderbein, beide Fühlergeißeln sowie die Palpenglieder 2 und 3 . Der Thorax ist stark deformiert. Abdomen, beide Halteren und ein Flügel sind gut erhalten. Der zweite Flügel ist in der Mitte getrennt und liegt in zwei Teilen vor. Auch der Holotypus von Lycoria fulgescens ENDERLEIN wurde in Kanadabalsam umpräpariert (1 Dauerpräparat). Beide Flügel und das männliche Genital sind in perfektem Zustand. Der Thorax und die Kopfkapsel sind etwas deformiert. Das Abdomen, ein Vorderbein und die Mittel- und Hinterbeine sind gut er halten. Es fehlen lediglich ein Vorderbein, einige Tarsenglieder und einige Geißelglieder von den Fühlerspitzen.

Literatur: Neosciara fulgescens (ENDERLEIN) - LENGERSDORF (1941): 202; - LENGERSDORF (1942): 99. Euricrium fulgescens (ENDERLEIN) - AMORIM (1992): 61. Euricrium rübsaameni ENDERLEIN [recte ruebsaameni] - Enderlein (1911): 142-143; Taf., Fig. 10; - LengersDORF (1925): 92. Euricrium ruebsaameni (ENDERLEIN) AMORIM (1992): 61.

Redeskription: $\sigma^{\star}$. Kopf: braun, Palpen und Mundteile heller. Augenbrücke in der Mitte 3-reihig und an den Seiten 2-reihig. Fühler einfarbig dunkelbraun; Grundglieder dunkelbraun; 4. Fühlergeißelglied 2,7 mal so lang wie breit, borstig abstehend und etwas länger als die Gliedbreite behaart; Halsteil scharf abgesetzt und verlängert, etwa $1 / 4$ mal so lang wie das Basalteil. Palpen 3-gliedrig und hellbraun; Grundglied schlank, mit 2 bis 3 Borsten [davon 1 lange Außenborste] und mit großem, berandetem Sensillenfeld; Sensillen lang und gebogen; 2. Glied lang-eiförmig, etwa $1 / 2 \mathrm{mal}$ so lang wie das schlanke Endglied. Thorax: Mesonotum braun, kurz und spärlich behaart; Katepisternit keilförmig verlängert; Scutellum und Metanotum braun; Scutellum mit kurzen, feinen und dunklen Borsten, Randborsten kaum länger; Pleuralsklerite einheitlich braun. Flügel relativ kurz und gebräunt, mit gut entwickeltem Analfeld; Flügelmembran mit dichtem Mikrotrichienbesatz, entlang der $\mathrm{CuA}_{1}$ mit
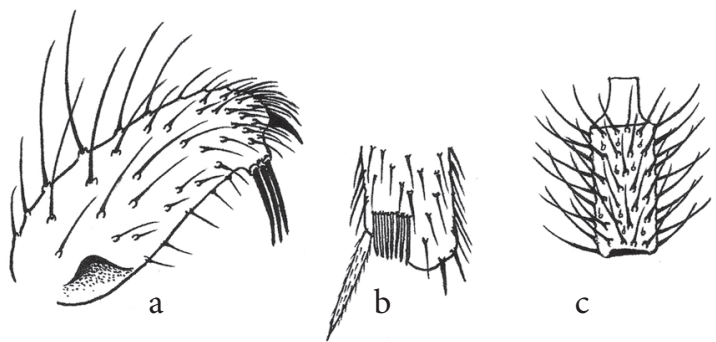

C

Fig. 9 a-c: Euricrium ruebsaameni Enderlein, Holotypus $\mathrm{o}^{*}$ : - a: Gonostylus ventral; - b: Vordertibienende; - c: 4. Fühlergeißelglied.

hellem Längsstreif; $\mathrm{R}_{5}$ mit einseitig dorsalem Makrotrichienbesatz; $\mathrm{R}_{1}=2 / 3 \mathrm{R}$ und weit vor der M-Gabelbasis in c mündend, $\mathrm{C}=2 / 3 \mathrm{w} ; \mathrm{y}=\mathrm{x}$, beide ohne Makrotrichien; M-Gabel sehr kurz und breit; M-Stiel = 1,6 mal so lang wie $M_{2} ; M_{2}$ nur schwach s-förmig geschwungen; $M_{1}$ an der Basis hoch gewölbt und in der hinteren Hälfte fast parallel mit $M_{1}$ zum Flügelrand verlaufend, dadurch M-Gabel kurz und breit, in der Mitte nicht verengt und nur schwach vasenförmig; CuA-Stiel = 3/5 x; CuA wenig und $\mathrm{CuA}_{2}$ stark zum Flügelhinterrand gebogen; hintere Flügeladern ohne Makrotrichien. Halteren kurz gestielt und hellbraun [Halterenkopf im Präparat fehlend]. Coxen und Beine hellbraun bis gelblich; Beine lang und schlank; Vordertibien ohne Dörnchen in der Grundbehaarung; Spitze der Vordertibia mit einreihigem Borstenkamm [dieser $1 / 2 \mathrm{mal}$ so breit wie die Tibienspitze und aus 8 
hellen Borsten bestehend]; Tibienenden der $\mathrm{p}_{2}$ und $\mathrm{p}_{3}$ mit je einem etwas verkürzten Sporn. Klauen fein gezähnt. Abdomen: heller als der Thorax, aber deutlich gebräunt; Tergite und Sternite schwach sklerotisiert und spärlich dunkel behaart. Hypopygium braun; ventrale Genitalbasis v-förmig, ohne Basallobus oder basale Borstengruppe; Gonocoxite grob und lang beborstet, ventrale Innenseiten kurz und spärlich behaart; Gonostyli lang und schmal, 3,1 mal so lang wie breit und deutlich kürzer als die Gonocoxite; Spitze des Gonostylus gerundet, grob beborstet und mit kurzem, kräftigem Zahn; subapikal auf der Innenseite des Gonostylus mit 3 langen, schlanken Dornen auf deutlichem Lobus; alle Dorne etwa gleichlang. Genitalplatte breiter als hoch und ? konisch verschmälert [Genitalplattenseiten möglicherweise umgeschlagen]; Zähnchenfeld kreisförmig, mit feinen und einspitzigen Zähnchen. Aedeagus kurz, mit breit-halbkreisförmiger Basis. Größe: 2,2 mm.

ㅇ. Kopf: dunkelbraun; Augenbrücke 2 bis 3-reihig. Palpen 3-gliedrig; Grundglied schlank, mit 7 bis 10 Borsten [davon 1 lange Außenborste] und mit großem, schwach berandetem Sensillenfeld. Mesonotum dunkel, mit leichten Aufhellungen an den Schulterecken und den Seitenrändern; Behaarung auf dem Mesonotum kurz und spärlich; Scutellum und Metanotum dunkel. Vordertibia mit 2 feinen Dornborsten in der Grundbehaarung; Tibienende der $\mathrm{p}_{1}$ mit einem einreihigem Borstenkamm [dieser etwa $1 / 2 \mathrm{mal}$ so breit wie die Tibienspitze und aus 7 hellbraunen Borsten bestehend]. Flügel leicht gebräunt, mit aufgehelltem Streif entlang der $\mathrm{CuA}_{1} ; \mathrm{R}_{1}=3 / 4 \mathrm{R}$, deutlich vor der M-Gabelbasis in c mündend; $\mathrm{y}=0,9 \mathrm{x}$, beide ohne Makrotrichien; $\mathrm{C}=3 / 4 \mathrm{w}$; CuA-Stiel = 2/3 x; CuA wenig und $\mathrm{CuA}_{2}$ auffallend stark zum Flügelhinterrand gebogen. Halteren kurz gestielt und dunkelbraun; Abdomen: schwach sklerotisiert, mit deutlicher Pubeszenz und spärlich behaart; Coxen braun, Beine [soweit vorhanden] heller; Vordertibien mit einreihigem Borstenkamm aus 6 Borsten. Klauen fein gezähnt; alle anderen Merkmale wie beim ${ }^{\star}$. Größe: $2,8 \mathrm{~mm}$.

Bemerkungen: Die Gattung Euricrium wurde von ENDERLEIN (1911) nach einem weiblichen Exemplar aus Brasilien aufgestellt. Er nennt die Art Euricrium ruebsaameni und begründet sie mit einer breiten M-Gabel, mit der stark nach vorn gebogenen $M_{1}$, den angeblich ungezähnten Klauen [im Gegensatz zu Metangela RüBSAAMEN mit vergleichbarer Flügeladerung] sowie einer mit Trichosia Winnertz vergleichbar starken Pubeszenz der Flügelmembran. Das letztgenannte Merkmal stimmt nicht, da es sich bei Eur. ruebsaameni um eine Pubeszenz handelt, die durch einen dichten Besatz etwas längerer Mikrotrichien entsteht, nicht aber durch Makrotrichien, wie sie bei einigen Arten von Trichosia [insbesondere auf der Membran zwischen den Ästen der M-Gabel] auftreten kann. Die Mikrotrichien auf der Flügelmembran sind bei Eur. ruebsaameni von den Makrotrichien auf den Ästen von $\mathrm{R}_{1}$ und $\mathrm{R}_{5}$ deutlich verschieden. Von ENDERLEIN nicht erwähnt wird die stark zum Flügelhinterrand gebogene $\mathrm{CuA}_{2}$, obwohl er sie in Fig. 10 gut abgebildet hat.

Amorim (1992: 61) stellt zu Euricrium noch die neotropischen Arten antennarium LENGERSDORF, 1926; borgmeieri LENGERSDORF, 1926 und myrmecophilum LENGERSDORF, 1925. Die vierte Art, die von AMOrim zu Euricrium gezählt wird, ist fulgescens (ENDERLEIN). Da uns der Holotypus von Lycoria fulgescens ENDERLEIN vorliegt [ebenfalls von LüDERwALDT in Santa Catharina gesammelt], besteht wegen des typisch einreihigen Tibienkammes, der fein gezähnten Klauen, der schwach sklerotisierten Abdominalsklerite mit starker Pubeszenz und der völlig identischen Flügeladerung kein Zweifel daran, dass es sich bei Eur. fulgescens ENDERLEIN um das $\sigma^{\top}$ von Eur. ruebsaameni Enderlein handelt. Das $\sigma^{\star}$ wurde von ENDERLEIN trotz der auffälligen Flügeladerung unter dem Namen Lycoria fulgescens [= Sciara Meigen] beschrieben. Amorim hat den Holotypus im Jahre 1984 untersucht und das Typexemplar mit "Zygoneura fulgescens" beschriftet. In seinem Kata$\log$ (AMORIM 1992: 61) führt er die Art jedoch richtig unter Euricrium ENDERLEIN auf. Aufgrund der Merkmalskombination "Vordertibienende mit einreihigem Borstenkamm, vorgewölbte $M_{1}$, Fühlergeißelglieder mit verlängerten Halsteilen und mit langer Behaarung, spärlich-kurz behaartes Mesonotum, keilförmig verlängertes Katepisternit, $\mathrm{R}_{5}$ mit einseitig dorsalem Makrotrichienbesatz, Gonostylus mit kräftigem Spitzenzahn« gehört das $0^{\star}$ zweifelsfrei zur Gattung Euricrium ENDERLEIN.

\section{Euricrium transversale (EDWARDS, 1934) comb. nov.}

Locus typicus: »Bolivia-Mapiri, Lorenzopata « [= Departamento La Paz, Cordillera Real, Mapiri, Lorenzopata] (Bolivien).

Holotypus: ㅇ, 9.5.1903, leg. GARLEPP (SMTD).

Erhaltungszustand: Vom Holotypus sind der Kopf mit beiden Fühlergeißeln, der Thorax, das Abdomen und 4 Beine gut erhalten [ein Vorder- und ein Hinterbein fehlend]. Die meisten Fühlergeißelglieder sind durch Schrumpfung deformiert. Ein Flügel fehlt und vom zweiten Flügel ist nur noch die basale Hälfte vorhanden (umpräpariert in Kanadabalsam).

Literatur: Mapiria transversalis EDWARDs - EDWARDS (1934): 369; 359, Fig. 2. Zygoneura transversalis (EDWARDs) - AMORIM (1992): 68. Zygomma transversalis (EDWARDS) [recte transversale] - MoHRIG (2003): 38.

Redeskription: + . Kopf: dunkel und rundlich; Mundwerkzeuge etwas verlängert. Augenbrücke geschlossen, 4-reihig. Fühler dunkelbraun und an der Spitze depigmentiert, dadurch die letzten beiden Geißelglieder weißlich-hell; 4. Fühlergeißelglied 2,0 mal so lang wie breit, Halsteil kurz und dunkel; Fühlerbehaarung dicht, etwa $1 / 2$ mal so lang wie die Gliedbreite. Palpen schlank, 3-gliedrig; Grundglied mit berandetem Sensillenfeld und 
mit 6 bis 7 Borsten. Thorax: dunkelbraun; Mesonotum flach, fein und spärlich behaart; Scutellum kurz behaart, Randborsten reduziert [diese in Länge und Stärke nicht mehr von den begleitenden Borsten unterscheidbar]; Postpronotum nackt; Pleuralsklerite ohne Borsten und ohne auffallenden Mikrotrichienbesatz. Flügel dunkel gebändert, mit Aufhellungen in der Basalzelle, im Analfeld, in der Flügelmitte sowie zwischen M-Stiel und $\mathrm{CuA}_{1} ; \mathrm{R}_{5}$ mit einseitig dorsalem Makrotrichienbesatz; $\mathrm{R}_{1}=2 / 3 \mathrm{R}$; y sehr kurz, etwa $1 / 4 \mathrm{x}$; y mit 2 bis 3 Makrotrichien, $\mathrm{x}$ nackt; $\mathrm{M}-$ Gabel durch die hoch gewölbte $\mathrm{M}_{1}$ vasenförmig gewölbt, mit einer zusätzlichen Querader zwischen $M_{1}$ und $R_{5}$ [siehe Edwards (1934): 359, Fig. 2]; hintere Flügeladern ohne Makrotrichien. Halteren kurz gestielt und hell. Vorderbeine einschließlich Coxen hell; Mittelbeine einheitlich braun, Hinterbeine auffallend dunkel; Vordertibia mit breitem Kamm aus hyalinen Borsten; Klauen fein gezähnt. Abdomen: bräunlich, nur 2. Abdominalsegment hell; letztes Abdominalsegment auffallend lang und schmal; Cerci kurz. Größe: 3,5 mm. $\sigma^{*}$. Unbekannt.

Bemerkungen: Map. transversalis EDWARDs ist die Typusart von Mapiria EDwards, 1934. Sie ist durch die dunkel gebänderten Flügel und die stark vasenförmig gebogene M-Gabel Eur. fasciatellum (ENDERLEIN) sehr ähnlich, unterscheidet sich von dieser aber durch die fehlenden Makrotrichien auf den hinteren Flügeladern. Euricrium transversale (EDWARDS) ist außerdem gekennzeichnet durch eine ungewöhnliche Querader zwischen $M_{1}$ und $\mathrm{R}_{5}$, was bei den Sciariden nur selten auftritt. Außerdem besitzt sie ein Ovipositor-ähnlich verlängertes letztes Abdominalsegment.

\section{Euricrium varians (LANE, 1955) comb. nov.}

(Fig. 10 a-b; Tafel 1, Fig. D)

Locus typicus: Estado de São Paulo, Município de Salesópolis, »Boracéa « [= Boracéia] (Brasilien).

Holotypus: ㅇ, Reg.-Nr. 7728, 14.8.1947, leg. LANE [etikettiert mit »E. RABELLO \& Trav. F. \& J. LANE«] (MZSP).

Paratypen: 4 ㅇ 우, Reg.-Nr. 7729-7731, gleiche Funddaten wie der Holotypus und/oder Estado de Santa Catarina, Nova Teutônia, " $27^{\circ} 11^{\prime}$ B. $52^{\circ} 23^{\prime} \mathrm{L}$. " [= 27 $11^{\circ}$ 'S $\left.52^{\circ} 23^{\prime} \mathrm{W}\right]$ (Brasilien), Juli 1948, leg. Plaumann (MZSP) [alle nicht untersucht!].

Weiteres Material: $19 \sigma^{\top} o^{-1}$ und 4 9 , Sam.-Nr. 70842, Prov. Puntarenas, Parque National Corcovado, $600 \mathrm{~m}$ südlich vom Cerro Rincón (Costa Rica), $745 \mathrm{~m}$ ü. NN, 23.4.-24.6.2002, Malaisefallenfang, leg. Azofeifa (18 $\sigma^{\star} \sigma^{\star}$ 3 우 우 PWMP; 1 저 1 아 SDEI).

Erhaltungszustand: Beim Holotypus sind die Abdominalsegmente ineinander geschoben, wodurch das Abdomen sehr kurz wirkt. Die Kopfkapsel ist frontal eingedrückt und abgeplattet. Außerdem fehlen ein
Mittel- und ein Hinterbein. Alle anderen Körperteile sind gut erhalten (umpräpariert in Kanadabalsam).

Literatur: Zygoneura varians LANE - LANE (1955): 255 und 257-258; - AMORIM (1992): 68.

Redeskription: + . Kopf: dunkelbraun, Gesicht und Mundwerkzeuge etwas verlängert. Fühler einförmig braun; 4. Fühlergeißelglied 1,8 bis 2,1 mal so lang wie breit, bräunlich; Behaarung der Basalteile etwa so lang wie die Gliedbreite; Halsteil 1/4 mal so lang wie das Basalteil. Palpen schlank und 3-gliedrig; Grundglied mit 7 bis 8 Borsten. Thorax: kontrastreich gelb und braun gefärbt; Mesonotum gelb und mit 3 dunklen Streifen, kurz und fein behaart; Scutellum und Pleuralsklerite leuchtend gelb, Katepisternit und Pleurotergit an der Spitze dunkel; Mediotergit mit dunklem Basalstreif; Metanotum gelb; membranöser Bereich hinter dem mesothorakalen Spiraculum auffallend geschwärzt. Flügel leicht gebändert, mit dunkler Flügelspitze und einem bis zum Hinterrand reichenden Fleck im Bereich der $\mathrm{R}_{1} ; \mathrm{R}_{1}$ kurz, etwas kürzer als $1 / 2 \mathrm{R} ; \mathrm{y}=1 / 2 \mathrm{x}$, beide nackt; $\mathrm{C}=3 / 4 \mathrm{w}$; M-Stiel etwas kürzer als die $M_{2} ; M_{1}$ basal stark vorgewölbt; M-Gabel in der hinteren Hälfte deutlich verengt, dadurch vasenförmig; CuA-Stiel = 2/3 x; $\mathrm{CuA}_{2}$ deutlich zum Flügelhinterrand gebogen; hintere Flügeladern ohne Makrotrichien. Halteren kurz gestielt, mit gelbem Stiel und dunkelbraunem Halterenkopf. Beine der $\mathrm{p}_{1}$ bis $\mathrm{p}_{3}$ lang und schmal; Coxen und Femora der Vorderbeine gelb; Coxen und Femora der Mittel- und Hinterbeine deutlich dunkler, gebräunt; Vordertibienende mit breitem, einreihigem

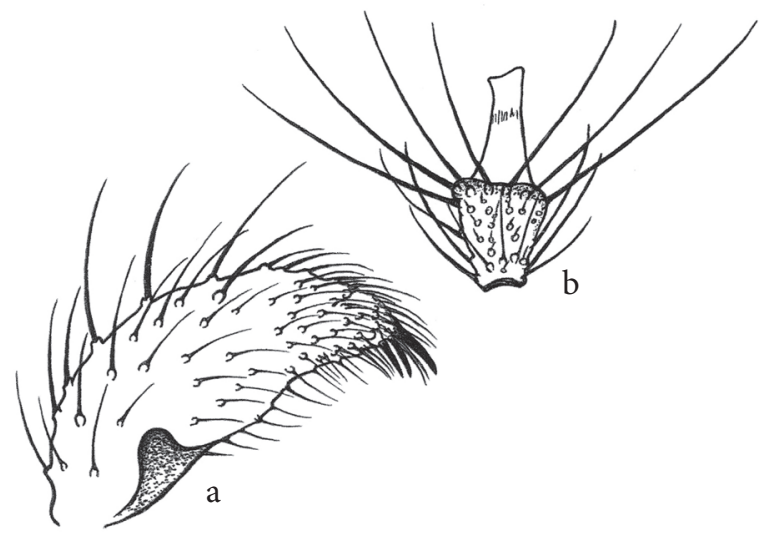

Fig. 10 a-b: Euricrium varians (LANE), $0^{\star}$ aus Costa Rica (PWMP): - a: Gonostylus ventral; - b: 4. Fühlergeißelglied.

Borstenkamm [dieser fast die gesamte Breite der Tibienspitze einnehmend]. Klauen fein gezähnt. Abdomen: spärlich, lang und dunkel behaart; 1. und 2. Abdominalsegment vollständig gelb; bei den anderen Abdominalsegmenten Sternite gelblich und Tergite dunkelbraun. Größe: 1,9-2,2 mm.

${ }^{\star}$. Kopf: dunkelbraun; Gesicht und Mundwerkzeuge leicht verlängert. Augenbrücke 3-reihig. Fühlergeißeln lang und mit wirtelig-abstehender Behaarung; alle 
Geißelglieder mit dunkelbraunen Basalteilen und deutlich helleren Halsteilen; Grundglieder einfarbig dunkelbraun; 4. Fühlergeißelglieder 2,6 mal so lang wie breit; Basalteil kurz, an der Basis und in Heilsteilnähe mit sehr langen, kranzartig angeordneten Borsten [der apikale Kranz mit lang abstehenden Borsten, der basale Kranz mit deutlich kürzeren und enger anliegenden Borsten; dazwischen mit einigen vereinzelt stehenden, langen Borsten]; zwischen den beiden Borstenkränzen mit kurzen, feinen Börstchen und langen Sensillen; Halsteil 1,1 mal so lang wie das Basalteil und deutlich aufgehellt, apikal nicht auffallend zweifarbig. Palpen 3-gliedrig, lang und schlank; Grundglied schmal, ohne vertieftes Sensillenfeld und mit 6 bis 7 Borsten; 2. Glied 3/4 mal so lang wie das Endglied; Endglied 4/5 mal so lang wie das Grundglied. Thorax: Mesonotum braun, mit 2 dunkleren Seitenstreifen und sehr schwach behaart [nur mit wenigen braunen, sehr kurzen Börstchen]; Postpronotum nackt; Scutellum bräunlich, spärlich und kurz behaart [2 Randborsten nur wenig stärker und kaum länger]; Mediotergit bräunlich, zentral etwas dunkler; Pleuralsklerite bräunlich; Katepisternit keilförmig verlängert und basal gelb; Pleurotergit gelb; membranöser Bereich hinter dem mesothorakalen Spiraculum grob strukturiert und schwärzlich. Flügel hell, nicht dunkel gebändert und mit gut entwickeltem Analfeld; $\mathrm{R}_{1}$ sehr kurz, etwa 1/3 R; y = 1/2 x, beide nackt; $\mathrm{M}$-Gabel leicht vasenförmig; hintere Flügeladern ohne Makrotrichien; $\mathrm{C}=3 / 4 \mathrm{w}$. Halteren kurz gestielt, mit basal aufgehelltem Stiel und dunkelbraunem Halterenkopf. Coxen und Beine bräunlich; Vordertibien ohne Dörnchen in der Grundbehaarung und mit breitem, einreihigem Borstenkamm [dieser fast so breit wie die Tibienspitze]. Klauen fein gezähnt. Abdomen: sehr spärlich, lang und dunkel beborstet; Tergite schwach sklerotisiert, bräunlich; Sternite etwas heller, aber deutlich gebräunt. Hypopygium braun, ohne interkoxale Differenzierung an der ventralen Basis; ventrale Innenseiten der Gonocoxite spärlich und mäßig lang behaart; Gonostyli zugespitzt und außen gleichmäßig gerundet, mit langem Spitzenzahn und 3 bis 4 kürzeren Subapikaldornen; Innenseite der Gonostyli geschlossen, in der Mitte etwas bauchig. Genitalplatte breiter als hoch und sklerotisiert, apikal breit gerundet; Zähnchenfeld kreisförmig, mit recht groben und einspitzigen Zähnchen. Aedeagus mäßig lang; alle anderen Merkmale wie beim ‥ Größe: 1,6-1,8 mm.

Bemerkungen: Die Art unterscheidet sich im weiblichen Geschlecht von allen anderen Euricrium-Arten durch die auffallend gelbe Thoraxfärbung, die im starken Kontrast zu den 3 dunklen Streifen des Mesonotums, der Spitze des Katepisternits und insbesondere zur nahezu schwarzen Färbung des membranösen Bereiches hinter dem mesothorakalen Spiraculum steht. Auffallend sind auch die leicht gebänderten Flügel, die an Eur. fasciatellum (ENDERLEIN) erinnern. Die $\sigma^{\top} \sigma^{\top}$ sind etwas weniger kontrastreich gefärbt und haben einheitlich helle Flügel ohne dunkle Bänderung. Auffallend ist aber auch bei ihnen die schwarze Färbung des membranösen Berei- ches hinter dem mesothorakalen Spiraculum. Außerdem zeichnet sich das Männchen im Fühlerbau durch die sehr kurzen Basalteile und die sehr langen Halsteile aus.

\section{Metangela RüBSAAMEN, 1894}

Typusart: Metangela calliptera RüBSAAMEN, 1894 - Berl. Ent. Z., 39(1): 24-25; Fig. 2; Taf. 2, Fig. 3; Taf. 3, Fig. 17 [des. ENDERLEIN (1911): 140].

Literatur: Metangela RÜBSAAMEN - RÜBSAAMEN (1894): 19 und 24; - LENGERSDORF (1926): 166; - SHAW (1953): 28 [ex parte]; - LANE (1946): 351; - LANE (1955): 256 und 259; - Amorim (1992): 62; - Schulz \& Menzel (2000): 200; - Schulz (2002): 19; - VilkamaA \& HipPa (2004): 4, 8, 9 und 21; - Mohrig \& Menzel (2009): 283 und 292; - SHIN et al. (2013): 835 [nec Metangela RüBSAAMEN sensu JOHANNSEN - JOHANNSEN (1912): 113 und 116; - CuRran (1930): 35; - RAPP (1946): 125; - CURRAN (1965): 119; - STEFFAN (1966): 32 und 38; - StefFan (1981): 250; - Poole (1996): 239; - Arnett (2000): 856 (alle Fehlbestimmung; = Acuatella MoHrig, 2003)].

Bemerkungen: Das Genus wurde von RüBSAAMEN für 2 Weibchen aus Brasilien aufgestellt, die sich durch Makrotrichien auf der Flügelmembran, eine schmale Flügelbasis, eine wie bei Zygoneura vorgewölbte $M_{1}$ und gezähnte Klauen auszeichnen. Das Typenmaterial von Met. calliptera (우 우) befindet sich im ZMHB und wurde untersucht. Ein Exemplar aus der Kollektion LeNGERSDORF aus São Paulo hat LANE (1946) korrekt als Männchen dieser Art identifiziert [kein Typexemplar!]. LANE (1946, 1955) beschreibt mit Met. ruebsaameni und Met. spinata zwei weitere Arten, von denen Met. spinata LANE später von AмоRiм (1992) fälschlich mit Met. calliptera synonymisiert wurde. Die Typen von Trichosia bicolorata Lengersdorf, 1930 [ $\sigma^{*}$ aus Costa Rica] und Metangela fasciata LENGERSDORF, 1926 [ 9 aus Brasilien] waren im ZMUH und ZFMK nicht auffindbar und konnten von uns nicht untersucht werden [beide im Hamburger Museum im 2. Weltkrieg zerstört]. Für Met. fasciata LENGERSDORF ist die Zugehörigkeit zu Metangela im Sinne von AMORIM (1992) wegen des Fehlens authentischen Materials noch nicht sicher belegbar. Im Gegensatz dazu wurde Trichosia bicolorata LENGERSDORF [= Met. bicolorata (LENGERSDORF, 1930)] in Costa Rica (2002) und Ecuador (1996) wieder gefunden. Auf der Basis des neuen Materials wurde die Art nachbeschrieben und figuriert sowie ein Neotypus für das Taxon designiert [Begründung siehe dort].

Wegen mehrerer Merkmale [lange Palpen mit mehreren Borsten und fehlender Sensillengrube, Gonostylus ohne Spitzenzahn und mit langen Geißelhaaren, pelzartig dichte Spitzenbeborstung am Gonostylus, hoch-dreieckiges Katepisternit, Scutellum mit 4 stärkeren Randborsten, Vordertibia mit unregelmäßig bogenförmigem Borstenfleck, Klauen gezähnt] gehört die Gattung Metangela RÜBSAAMEN wahrscheinlich zur Pseudolycoriella-Gruppe und steht der Gattung Pseudolycoriella Menzel \& 
Mohrig, 1998 nahe. Phylogenetisch interessant ist, dass bei allen revidierten Metangela-Arten die Flügelmembran, der M-Stiel sowie die $\mathrm{M}_{1}$ und $\mathrm{M}_{2}$ beidseitig [ventral und dorsal!] mit langen Makrotrichien besetzt sind. Zum Grundmuster der Gattung gehören offensichtlich auch das stark reduzierte Analfeld an der Flügelbasis, die beidseitig mit Makrotrichien besetzte $\mathrm{R}_{5}$ und der verlängerte CuA-Stiel [dieser länger als $\mathrm{x}$ ]. Durch die äußerst langen Makrotrichien auf der Costa $\mathrm{c}$ und dem hinteren Rand der Flügelmembran entsteht der Eindruck, dass die Metangela-Spezies gegenüber den Arten aus anderen Gattungen besonders reich und dicht beborstet sind, was aber nicht stimmt. An diesen Randbereichen kommt es lediglich zur Überlagerung von ventral und dorsal inserierenden Makrotrichien, die deutlich über den Flügelrand hinaus reichen (siehe Tafel 2, Fig. E).

\section{Metangela bicolorata (LENGERSDORF, 1930) comb. nov. (Fig. 11 a-d)}

Locus typicus: Prov. Limón, Pococi, P. N. Braulio Carrillo, Estación Quebrada Gonzáles (Costa Rica).

Neotypus: ${ }^{\star}$, Sam.-Nr. 67599, 400-500 m ü. NN, Malaisefallenfang, 23.4.2002, leg. Hanson \& Godoy (ZFMK) [hier designiert].

Begründung: Der Holotypus [ $\left.0^{*}\right]$ mit den Funddaten „September 1925, Farm La Caja, $8 \mathrm{~km}$ westlich von S. José« [= Prov. Heredia, La Caja nordwestlich von San José (Costa Rica)] wurde mit anderen Sammlungsteilen des ZMUH im 2. Weltkrieg in Hamburg zerstört [persönliche Mitteilung durch K. Schütte, ZMUH]. Auch in der Kollektion von Franz LENGERSDORF (ZFMK) konnte nach intensiver Suche kein Exemplar mit diesem Namen und von dieser Art aufgefunden werden. Wegen der Ähnlichkeit von Met. bicolorata (LENGERsDorf) mit der Typusart Met. calliptera RüBSAAMEN wird zur Stabilisierung des Namens für das nominelle Taxon der Artgruppe »bicolorata LENGERSDORF« ein Neotypus festgelegt, denn die von LENGERSDORF (1930b: 127) gegebene Beschreibung [v. a. zur Abdomenfärbung und zum männlichen Genital] und der schlecht figurierte Gonostylus (Fig. 2) lassen sich keiner der beiden Arten eindeutig zuordnen. Als Neotypus wurde ein Exemplar mit dem gleichen Geschlecht und aus dem gleichen Land (Costa Rica) ausgewählt, das der Beschreibung von Lengersdorf (1930b) am ehesten gerecht wird. Der Neotypus wurde in der Kollektion von Franz LengersDORF am Forschungsmuseum Alexander Koenig in Bonn (ZFMK) deponiert.

Weiteres Material: $1 \delta^{\star}$, Manabi, Cerro Pata de Pajaro (Ecuador), $00,01^{\circ} \mathrm{N} 79,57^{\circ} \mathrm{W}, 19.6 .-21.6 .1996$, leg. HibBs (PWMP).

Erhaltungszustand: Der Neotypus befindet sich in einem sehr guten Zustand. Alle Körperteile sind vorhanden und das Genital wurde separat in Ventralansicht eingebettet (präpariert in Kanadabalsam).
Literatur: Trichosia bicolorata LENGERSDORF - LENGERSDORF (1930b): 127, Abb. 2; - LANE (1955): 255.

Redeskription: ${ }^{\star}$. Kopf: rundlich, Mundteile kurz. Augenbrücke 3 bis 4-reihig. Fühlergrundglieder dunkel; 1. Fühlergeißelglied in der Basalhälfte gelblich hell; obere Hälfte des 1. Gliedes und alle anderen Geißelglieder braun; Basalteile der Geißelglieder kurz und dicht behaart [Behaarung höchstens $1 / 2$ mal so lang wie die Gliedbreite] und mit sehr kurzen, feinen Sensillen auf hellen Insertionshöfen; 4. Fühlergeißelglied 2,1 bis 2,3 mal so lang wie breit; Insertionshöfe der Borsten auf dem Basalteil partiell zu einer feinen Oberflächenstruktur verbunden; Halsteil einfarbig hellbraun und kurz, etwa 1/5 mal so lang wie das Basalteil. Palpen lang, 3-gliedrig und braun; Grundglied schlank, mit 5-6 langen Borsten und mit unberandetem Sensillenfeld; Sensillen kurz und fein; 2. Palpenglied länglich, 2/3 mal so lang wie das schlanke Endglied. Thorax: dunkelbraun, lediglich einige membranöse Bereiche und unterhalb des Scutellums gelblich aufgehellt; Postpronotum unbeborstet; Mesonotum glatt, lateral fein und dunkel behaart, mit 3 dunkleren Streifen; Scutellum mit kurzen und feinen Borsten, 4 Randborsten etwas kräftiger und länger; Pleuralsklerite, Scutellum und Metanotum dicht-pelzig mit Mikrotrichien besetzt; Katepisternit hoch-dreieckig und einfarbig dunkelbraun. Flügel hell, ohne dunkle Farbbänder; Flügelbasis [einschließlich basale Bereiche der Flügeladern] deutlich aufgehellt; Analfeld reduziert; Flügelmembran beidseitig mit langem Makrotrichienbesatz; hintere Flügeladern bis zur Basis dicht mit Makrotrichien; M-Stiel sowie die basale Hälfte von $M_{1}$ und $M_{2}$ beidseitig beborstet; $\mathrm{CuA}_{1}$ und $\mathrm{CuA}_{2}$ einseitig dorsal beborstet [nur $\mathrm{CuA}_{1}$ in Nähe des Flügelrandes mit 2 bis 3 ventralen Makrotrichien], $R_{5}$ fast bis zur Mitte mit beidseitigem Makrotrichienbesatz; $\mathrm{R}_{1}=0,9 \mathrm{R} ; \mathrm{y}=1,1 \mathrm{x}$; $\mathrm{x}$ nackt und y distal mit 1-3 Makrotrichien; $\mathrm{C}=1 / 2 \mathrm{w}$;

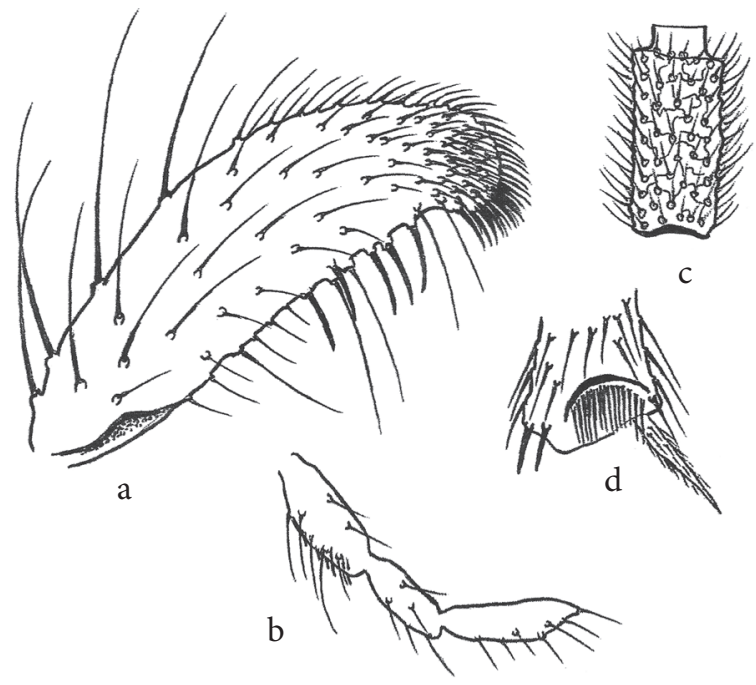

Fig. 11 a-d: Metangela bicolorata (LENGERSDORF), Neotypus $\sigma^{\top}$ aus Costa Rica: - a: Gonostylus ventral; - b: Palpus lateral; - c: 4. Fühlergeißelglied; - d: Vordertibienende. 
M-Stiel länger als die $\mathrm{M}_{2}$; M-Gabel lang und gleichmäßig zum Hinterrand der Flügelspitze gebogen; CuAStiel lang, =1,2 $\mathrm{x} ; \mathrm{CuA}_{2}$ stark zum Flügelhinterrand gebogen; CuP lang und deutlich sklerotisiert. Halteren kurz gestielt, mit hellbraunem Stiel und dunkelbraunem Halterenkopf. Beine lang und schlank, Femora und Tibien auffallend lang, dunkel behaart; Coxen und Femora gelb, Tibien und Tarsen angedunkelt; Vordertibien mit einem Sporn; $\mathrm{p}_{2}$ und $\mathrm{p}_{3}$ mit zwei gleichlangen Spornen, diese etwas länger als die Tibienenden breit; Vordertibienende mit flach und scharf bogenförmig berandetem, eingesenktem Borstenfleck; Borstenfleck unregelmäßig, fast einreihig und etwas gebogen [etwa 2/3 mal so breit wie die Tibienspitze]. Klauen deutlich gezähnt, mit 4 bis 5 groben Nebenzähnchen. Abdomen: dunkel, spärlich, fein und relativ lang behaart; Tergite und Sternite hellgelb, die letzten 2 Abdominalsegmente und das Hypopygium dunkelbraun; Gonocoxite und Gonostyli mit langen Mikrotrichien; ventrale Genitalbasis ohne interkoxale Differenzierung; Gonocoxite kräftig; ventrale Innenseiten spärlich, aber recht lang behaart; Gonostyli lang und schmal [3,2 mal so lang wie breit], wenig kürzer als die Gonocoxite, an der Spitze gerundet und gestirnt; Spitze des Gonostylus ohne Zahn, nur dicht und dunkel behaart; Innenseite bis zur Mitte mit 5 bis 7 dunklen, hyalinen Dornen und mit 3 bis 4 geißelhaarähnlichen Borsten [davon wenigstens ein Geißelhaar auffällig lang]; Genitalplatte etwas breiter als hoch, sklerotisiert und ohne Mittelstrukturen; Genitalplattenspitze breit gerundet und membranös, dadurch deutlich heller. Aedeagus sehr lang, mit kurzer Basis; Zähnchenfeld nur mit wenigen, einspitzigen Zähnchen. Größe: 3,2 mm.

․ Unbekannt.

Bemerkungen: Trichosia bicolorata LENGERSDORF wird in der Originalbeschreibung charakterisiert durch einen dichten Makrotrichienbesatz auf der Flügelmembran [einschließlich der hinteren Flügeladern], ein »helles" [gelbliches] 1. Fühlergeißelglied sowie »helle« [gelbliche] Abdominalsegmente mit Ausnahme der letzten beiden Abdominalsegmente und des Hypopygiums. Diese Merkmalskombination ist im Kontext mit der von LENGERSDORF gegebenen Stylusabbildung so originell, dass die richtige Identifikation der beiden untersuchten Exemplare aus Costa Rica und Ecuador zweifelsfrei belegt ist. Die Art gehört nicht [wie von LENGERSDorf aufgrund der Membranmakrotrichien postuliert und von AMORIM (1992) übernommen] zur Gattung Trichosia Winnertz, sondern zu Metangela RüBSAAMEN. Sie zeigt deutliche Beziehungen zu Met. calliptera RüBsAAMEN, von der sie sich durch das längere 4. Geißelglied, längere und apikal deutlich gestirnte Gonostyli mit einer größeren Anzahl von hyalinen Dornen auf der Innenseite sowie die fehlenden Farbbänder auf der Flügelmembran unterscheidet. Die Gattung Trichosia Winnertz ist in der Neotropis gegenwärtig nicht präsent und ist aus dem Verzeichnis der neotropischen Sciaridae zu streichen.

\section{Metangela calliptera RüBSAAMEN, 1894}

(Fig. $12 \mathrm{a}-\mathrm{c}$ )

Locus typicus: »Brasil« [nach AмоRim (1992) wahrscheinlich zwischen Rio de Janeiro und Bahia] (Brasilien).

Lectotypus: + , Mus.-Nr. 6206, ohne Funddatum, leg. Sello (ZMHB) [des. Amorim (1992): 62].

Paralectotypus: 1 , gleiche Funddaten (ZMHB).

Weiteres Material: 1 ơ $^{\star}$, Reg.-Nr. 6458 [in LANE (1946) fälschlich als "Allotype" ausgewiesen; etikettiert als "Alotipo«], »State of S. Paulo, Cantareira « [= Estado de São Paulo, São Paulo, Cantareira] (Brasilien), 3.10.1945, leg. Barretto (MZSP); 1 o $^{\star}$ ex Coll. Lengersdorf, Estado de São Paulo, Juquiá (Brasilien), Juli 1947, leg. LANE (ZFMK); 1 오, Prov. Sucumbios, Sacha Lodge (Ecuador), $00,50^{\circ} \mathrm{S} 76,50^{\circ} \mathrm{W}, 270 \mathrm{~m}$ ü. NN, Malaisefallenfang, 4.5.-14.5.1994, leg. НiвBs (PWMP).

Erhaltungszustand: Der Lectotypus ( + ) ist fast vollständig erhalten. Nur ein Vorderbein und eine Fühlergeißel fehlen. Ein Flügel war abpräpariert und befindet sich in sehr gutem Zustand. Die meisten Körpermerkmale sind aber sehr schlecht zu erkennen, weil sich das Exemplar in einer Luftblase mit eingetrockneten Glyzerin-Resten befindet. Außerdem ist das o durch das ursprünglich verwendete Einbettungsmittel gequollen und aufgehellt. Vom Paralectotypus (ㅇ) existieren noch der Thorax, beide Flügel, alle Beine und das Abdomen. Der Kopf und die Fühlergeißeln fehlen, die Flügelspitzen sind beschädigt und das Abdomen ist partiell verschmutzt. Die Hypopygien der beiden $\sigma^{\star} o^{\star}$ aus dem MZSP und ZFMK sind leicht deformiert, deren Stylusform aber gut zu erkennen (alle 4 Exemplare umpräpariert in Kanadabalsam).

Literatur: Metangela calliptera RÜBSAAMEN - RÜBSAAMEN (1894): 24-25; Fig. 2; Taf. 2, Fig. 3; Taf. 3, Fig. 17; LANE (1946): 351-352; 349, Fig. 6 [kein Typenmaterial!]; - LANe (1955): 256 und 260; - AMORIM (1992): 62.

Redeskription: + . Kopf: rundlich und dunkelbraun. Augenbrücke 3-reihig. Fühlergeißelglieder einfarbig dunkel und mit kurzen, breiten Halsteilen; 4. Geißelglied 1,8 mal so lang wie breit; Behaarung etwa $1 / 2 \mathrm{mal}$ so lang wie die Gliedbreite; Palpen 3-gliedrig, Grundglied mit mehreren längeren Borsten [Sensillenfeld beim Lectotypus nicht sichtbar und Längen-BreitenVerhältnisse nicht mehr ermittelbar]. Thorax: dunkelbraun; Postpronotum unbeborstet; Mesonotum glatt, lateral kurz und fein behaart; Katepisternit hoch-dreieckig, nicht verlängert; Scutellum gut abgesetzt, mit kurzen Borsten [Anzahl der längeren Randborsten an beiden Typexemplaren nicht mehr erkennbar]; Pleuralsklerite, Scutellum und Metanotum dicht-pelzig mit langen Mikrotrichien besetzt. Flügel breiter und Analfeld nicht ganz so stark reduziert wie beim $0^{*}$; alle Flügeladern und die gesamte Flügelmembran bis 


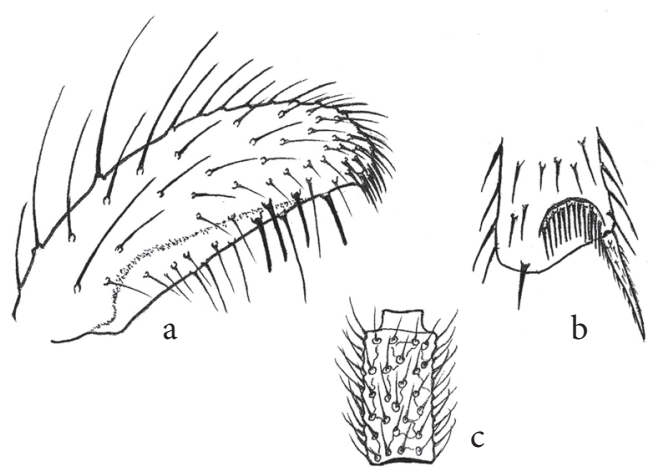

Fig. 12 a-c: Metangela calliptera RüBSAAMEN, $0^{\boldsymbol{t}}$ aus Brasilien (MZSP): - a: Gonostylus ventral; - b: Vordertibienende; - c: 4. Fühlergeißelglied.

zur Basis dicht mit Makrotrichien; Flügelbasis braun, nicht gelblich aufgehellt; $\mathrm{R}_{5}$ mit beidseitigem Makrotrichienbesatz [mindestens in der vorderen Hälfte von $\mathrm{R}_{5}$, manchmal auch fast bis zur Höhe der $\mathrm{R}_{1}$-Einmündung reichend]; Flügelmembran beidseitig mit langen Makrotrichien besetzt; hintere Flügeladern mit dichtem Makrotrichienbesatz $\left[M_{1}\right.$ und $M_{2}$ mindestens in der Spitzenhälfte beidseitig beborstet; $\mathrm{M}$-Stiel, $\mathrm{CuA}$ und $\mathrm{CuA}_{2}$ einseitig dorsal beborstet und nur distal mit einigen ventralen Makrotrichien]; CuP deutlich ausgefärbt, basal unbeborstet und in der Spitzenhälfte mit einer einseitig dorsalen Makrotrichienreihe; M-Stiel mäßig lang und deutlich gebogen, fast 1,4 mal so lang wie die s-förmig geschwungene $\mathrm{M}_{2}$; M-Gabel recht lang, breit und stark gekrümmt; Flügelmembran zwischen Costa $c$ und $\mathrm{R}_{5}$ angedunkelt und mit zwei auffälligen, dunklen Bändern [ein Farbband an der Flügelspitze fast bis zur Basis der M-Gabel, das zweite von der Einmündung von $\mathrm{R}_{1}$ in die Costa bis zur Einmündung von $\mathrm{CuA}_{2}$ in den Flügelhinterrand reichend; mit Aufhellungen lediglich zwischen $\mathrm{M}$-Stiel und dem Verlauf der $\mathrm{CuA}_{1}$ ]; $\mathrm{R}_{1}=1 / 2$ bis $2 / 3 \mathrm{R} ; \mathrm{y}=3 / 5$ bis $3 / 4 \mathrm{x}$, beide ohne Makrotrichien; $\mathrm{C}=3 / 5$ bis $2 / 3 \mathrm{w}$; M-Stiel lang, = 1,3 bis 1,4 mal so lang wie $M_{2}$; M-Gabel recht lang, deutlich zum Hinterrand der Flügelspitze gebogen; CuA-Stiel lang, $=0,9$ bis $1,1 \mathrm{x}$; $\mathrm{CuA}_{1}$ im Spitzendrittel deutlich, $\mathrm{CuA}_{2}$ sehr stark zum Flügelhinterrand gebogen. Halteren kurz gestielt und gebräunt. Beine sehr lang und schlank, auffallend lang und dunkel behaart; Coxen und Beine gelb, lediglich Femora der $\mathrm{p}_{3}$ in der Spitzenhälfte deutlich gebräunt; Vordertibien ohne Dörnchen in der Grundbeborstung [hier nur mit sehr langen, grannenartig langen und groben Borsten]; Tibiensporne an den $\mathrm{p}_{2}$ und $\mathrm{p}_{3}$ gleichlang [diese etwa so lang wie die Tibienspitzen breit]; Tibienende der $\mathrm{p}_{1}$ mit einem scharf und flach bogig berandetem Borstenfleck; Tibienfleck mit unregelmäßig einreihigem Borstenkamm [dieser etwa 1/2 mal so breit wie die Tibienspitze]; Klauen deutlich gezähnt. Abdomen: spärlich, fein und relativ lang behaart; Tergite und Sternite gelblich, die letzten 2 Abdominalsegmente und Cerci dunkel; Cerci kurz und breit. Größe: 3,0-3,9 mm. $\overbrace{}^{\star}$. Kopf: Augenbrücke 3-reihig; Fühlergrundglieder und Fühlergeißelglieder braun, nur 1. und 2. Geißelglied ein wenig aufgehellt; 4 . Fühlergeißelglied 2,1 bis 2,3 mal so lang wie breit; Halsteil einfarbig braun, scharf abgesetzt und kurz, etwa 1/2 mal so lang wie breit und etwas kürzer als 0,2 mal so lang wie das Basalteil; Basalteil mit sehr kurzen und feinen Sensillen in weißlich aufgehellten Insertionshöfen; Behaarung etwa 1/2 mal so lang wie die Gliedbreite; Haare auf runden Insertionsstellen inserierend, dazwischen mit feiner Gitterlinienstruktur. Palpen 3-gliedrig, mit 8 langen Borsten und mit unberandetem Sensillenfeld. Thorax: braun; Mesonotum einfarbig dunkel und glatt, nur am Vorderrand mit Mikrotrichien, laterale Behaarung fein und kurz; Scutellum mit wenigen Borsten, aber mit dichtem Mikrotrichienbesatz [längere Randborsten in beiden Präparaten fehlend und dadurch nicht sichtbar]; Postpronotum unbeborstet; Antepronotum, prothorakales Episternit, Pleuren und Mediotergit dicht-pelzig mit Mikrotrichien besetzt. Flügel schmaler als beim $\circ$, mit stärker reduziertem Analfeld; $R_{1}=2 / 3 \mathrm{R}$; $\mathrm{y}=3 / 5 \mathrm{x}$, beide nackt; CuA-Stiel lang, $=0,9$ mal so lang wie die lange $\mathrm{x}$; M-Stiel mäßig lang und deutlich gebogen, fast 1,4 mal so lang wie die s-förmig geschwungene $M_{2}$; $\mathrm{C}=2 / 3$ w. Coxen und Beine gelblich, nur Spitzenviertel der Femora und die Fußglieder angedunkelt; Behaarung der Beine lang und dunkel; Vordertibia ohne Dörnchen in der Grundbeborstung; Tibienende der $\mathrm{p}_{1}$ mit kleinerem, flach bogenförmig berandetem Borstenfleck [dieser aus dunklen, dicht angeordneten Borsten bestehend und etwa 3/5 mal so breit wie die Tibienspitze]. Klauen deutlich gezähnt. Abdomen: heller als der Thorax, aber nicht eindeutig gelblich wie beim + [nicht alle Segmente durchgängig erhalten]; Beborstung des Abdomens spärlich, lang und dunkel; alle anderen Körpermerkmale wie beim + . Hypopygium breiter als hoch und bräunlich; ventrale Genitalbasis ohne interkoxale Differenzierung; Gonocoxite kräftig, ventrale Innenseiten spärlich und kurz behaart; Gonostyli kürzer als die Gonocoxite; Gonostylus länglich und schmal, 2,8 mal so lang wie breit; Spitze des Gonostylus gerundet, pelzig-dicht behaart und ohne Zahn; Innenseite bis zur Mitte mit 4 hyalinen Dornen und mit 2 bis 3 langen Borsten [davon 2 Geißelhaare in der oberen Hälfte des Gonostylus inserierend]; Genitalplatte schmal, dadurch nur wenig breiter als hoch; Spitze der Genitalplatte konisch verjüngt. Aedeagus sehr lang, mit sehr kurzer Basis; Zähnchenfeld nicht sichtbar. Größe: 2,4-2,6 mm.

Bemerkungen: Die Zugehörigkeit der $\sigma^{\star} \sigma^{\star}$ aus dem MZSP und ZFMK zu den beiden 우 ㅇa aus der Typenserie von Met. calliptera RüBSAAMEN wurde von LANE richtig erkannt. Diese wird auf der Basis der gut zueinander passenden Flügeläderung und wegen der beiden dunklen Farbbinden auf der Flügelmembran bestätigt. Im Genitalbau [Form und Bedornung der Gonostyli] hat sie große Ähnlichkeit mit Met. bicolorata (LENGERSDORF) [Unterschiede zu dieser Art siehe dort]. 
Metangela ruebsaameni LANE, 1946

(Fig. 13 a-c; Tafel 2, Fig. E)

Locus typicus: "State of S. Paulo« [= Estado de São Paulo], Batêa (Brasilien).

Holotypus: $\sigma^{\top}$, Reg.-Nr. 6462, November 1940; leg. LANE (MZSP).

Erhaltungszustand: Am Holotypus sind der Thorax, das Abdomen, beide Flügel, die Coxen und 5 Beine gut erhalten. Beide Fühlergeißeln und ein Vorderbein fehlen und die Kopfkapsel ist frontal im Bereich der Augenbrücke deformiert. Das Hypopygium befindet sich in einem sehr guten Zustand, ist aber rotbraun aufgehellt (umpräpariert in Kanadabalsam; 2 Präparate).

Weiteres Material: 1 ơ $^{\Uparrow}$ aus Coll. LANE, São Paulo, Jaraguá (Brasilien), November 1951, leg. LANE (MZSP).

Literatur: Metangela rübsaameni LANe [recte ruebsaameni] - LANE (1946): 352; 349, Fig. 7. Metangela rubsämeni LANE [recte ruebsaameni] - LANE (1955): 256. Metangela ruebsaameni LANE - AMORIM (1992): 62.

Redeskription: ${ }^{7}$. Kopf: rundlich. Augenbrücke wahrscheinlich 2-reihig [im Präparat deformiert]. FühlergeiBeln kurz; Scapus, Pedicellus und Fühlergeißelglieder einfarbig dunkelbraun; 2. Fühlergeißelglied 2,0 mal so lang wie breit [3. und 4. Glied deformiert]; Halsteil kurz und scharf abgesetzt, $=0,2 \mathrm{mal}$ so lang wie das Basalteil; Basalteil mit lang-anliegenden Sensillen und ohne auffällige Gitterlinienstruktur; Fühlerbehaarung grob und abstehend, $=4 / 5 \mathrm{mal}$ so lang wie die Gliedbreite. Palpen 3-gliedrig, schlank und gebräunt; Grundglied mit 9 Borsten und großem, unberandetem Sensillenfeld; 2. Palpenglied etwa $1 / 2$ mal so lang wie das schlanke Endglied. Thorax: dunkelbraun; Mesonotum mit kurzen lateralen und längeren präscutellaren Haaren, vorn und seitlich mit feinen Mikrotrichien, zentral glatt [ohne Mikrotrichienbesatz]; Katepisternit hoch-dreieckig; Scutellum spärlich behaart, mit 4 etwas längeren Randborsten; alle Pleuralsklerite einschließlich Scutellum und Mediotergit kurz und fein mit Mikrotrichien besetzt. Flügel ungetrübt und gleichmäßig gebräunt, nicht gebändert; Flügelmembran und hintere Flügeladern fast vollständig mit Makrotrichien besetzt, nur an der Flügelbasis spärlicher und partiell unbeborstet; alle Flügeladern dicht und beidseitig mit Makrotrichien $\left[R_{1}, R_{5}, M\right.$-Stiel, $M_{1}$ und $M_{2}$ über die ganze Länge beidseitig beborstet, hier auch etwas aufgelockert auf der $\mathrm{CuA}_{1}$ und $\mathrm{CuA}_{2}$ vorhanden]; $\mathrm{CuP}$ schwach sklerotisiert und fast vollständig unbeborstet [nur mit 3 Makrotrichien]; M-Stiel = 1,4 mal so lang wie die schwach gekrümmte $\mathrm{M}_{2} ; \mathrm{M}$-Gabel relativ lang und schmal, beide Äste schwach zum Flügelhinterrand gebogen; $\mathrm{R}_{1}=0,7 \mathrm{R} ; \mathrm{C}=3 / 5 \mathrm{w} ; \mathrm{y}=1,5 \mathrm{x} ; \mathrm{y}$ auf ganzer Länge und $\mathrm{x}$ distal bis zur Hälfte mit beidseitigem [ventralem und dorsalem!] Makrotrichienbesatz; CuA-Stiel

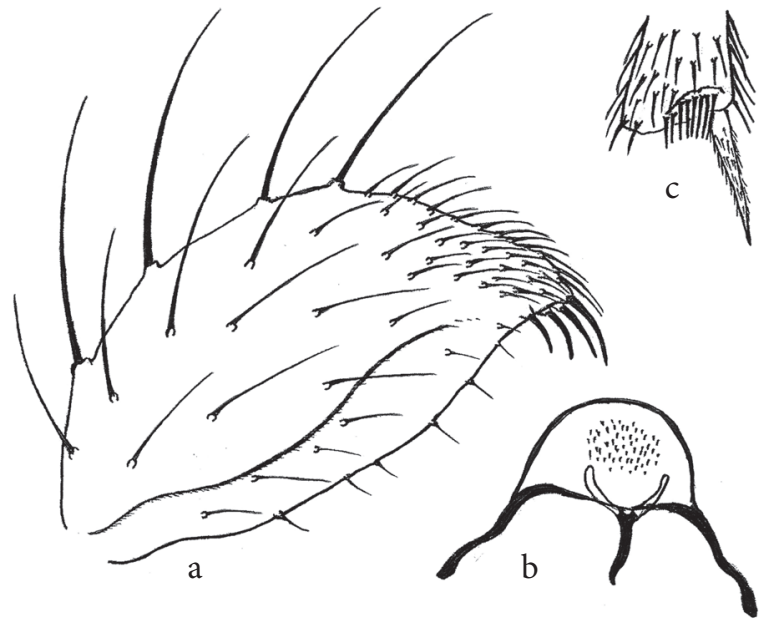

Fig. 13 a-c: Metangela ruebsaameni LANE, Holotypus $\sigma^{*}$ : - a: Gonostylus ventral; - b: Genitalplatte mit Aedeagus ventral; - c: Vordertibienende.

unbeborstet und lang, $=\mathrm{x} ; \mathrm{CuA}_{1}$ leicht und $\mathrm{CuA}_{2}$ stark zum Flügelhinterrand gebogen. Halteren kurz gestielt, mit hellem Stiel und gebräuntem Halterenkopf. Beine lang und schlank; alle Coxen sowie Femora der $p_{1}$ und $\mathrm{p}_{2}$ gelblich; Femora der $\mathrm{p}_{3}$, alle Tibien und Tarsenglieder bräunlich; Vordertibien ohne Dörnchen in der Grundbehaarung und mit einreihigem, undeutlich berandetem Borstenkamm; Borstenkamm breit [fast 3/4 mal so breit wie die Tibienspitze] und aus dunklen Borsten bestehend; Tibiensporne der $\mathrm{p}_{2}$ und $\mathrm{p}_{3}$ gleichlang, etwa so lang wie die Tibienspitze breit. Klauen gezähnt. Abdomen: einfarbig braun, mit langer, dichter und dunkler Behaarung. Hypopygium braun, etwa so hoch wie breit; ventrale Genitalbasis ohne interkoxale Differenzierung; Gonocoxite etwa 1,5 mal so lang wie die Gonostyli, an der ventralen Innenseite recht lang und dicht behaart; Gonostyli verdickt und apikal zugespitzt, etwa 1,8 mal so lang wie breit; Innenseite ventral etwas ausgehöhlt und dorsal deutlich geflügelt; gesamte Innenseite lediglich mit kurzen, feinen Borsten [lange Borsten und Geißelhaare fehlend]; Spitze des Gonostylus kurz und recht spärlich behaart, am Innenwinkel mit 4 kurzen, Dornen. Genitalplatte kurz, sklerotisiert und breit gerundet; Zähnchenfeld groß, mit grob-einspitzigen Zähnchen. Aedeagus ziemlich kurz und mit breiter Basis. Größe: 2,7 mm.

\section{․ Unbekannt.}

Bemerkungen: AMORIM (1992) gibt fälschlich 1947 als Publikationsjahr an. In Wirklichkeit ist die LANEsche Originalbeschreibung auf den Dezember 1946 datiert. Die Zuordnung von ruebsaameni LANE zur Gattung Metangela ist nicht so eindeutig wie bei den anderen Arten der Gattung, weil die scharfe Berandung des Vordertibienfleckes sehr schwach ausgeprägt ist, die Tibien deutlich kürzer behaart sind und bei den Gonostyli die 4 hyalinen Dorne nicht auf der Innenseite, sondern an der Stylusspitze stehen. Die langen, geißelhaarähnlichen Borsten auf den Innenseiten der 
Gonostyli sind offensichtlich vollständig reduziert und der Mikrotrichienbesatz an den Thoraxseiten ist zwar vorhanden, aber nicht so auffallend lang und pelzartig dicht ausgeprägt wie bei den anderen Metangela-Arten. Für die Zuordnung sprechen aber die gezähnten Klauen, der beidseitig dichte Makrotrichienbesatz auf den hinteren Flügeladern und der Flügelmembran sowie eine stark zum Flügelrand gebogene $\mathrm{CuA}_{2}$.

\section{Metangela spinata LANE, 1955 restit.}

(Fig. 14 a-c)

Locus typicus: Estado de São Paulo, Município de Salesópolis, »Boracéa« [= Boracéia] (Brasilien).

Holotypus: $0^{7}$, Reg.-Nr. 7720, November 1947, leg. LANE (MZSP) [nicht untersucht!].

Paratypen: $10^{\star}$, vom locus typicus, November 1947, leg. Rabela-Travass (MZSP); $10^{\star}$, Reg.-Nr. 7721, Estado de São Paulo, Juquiá (Brasilien), Juli 1947, leg. LANE (MZSP).

Weiteres Material: $10^{7}$, Brit. Mus. 1938-40, "Nova Teutonia, $27^{\circ} 11^{\prime}$ B. $52^{\circ} 23^{\prime} \mathrm{L}$. " [= Estado de Santa Catarina, Nova Teutônia, $27^{\circ} 11^{\prime} \mathrm{S} 52^{\circ} 23^{\prime} \mathrm{W}$ ] (Brasilien), 16.12.1937, leg. Plaumann (MZSP); 1 , Estado de São Paulo, São Paulo, Jaraguá (Brasilien), November 1951, leg. LANE (MZSP).

Erhaltungszustand: Einer der beiden Paratypen war fälschlich als "Holotipo" etikettiert. Von den beiden untersuchten Paratypen sind Kopf, Fühlergeißelglieder, Thorax, Beine und einige Abdominalsegmente mit Hypopygium erhalten. Die Flügel sind in gutem Zustand (umpräpariert in Kanadabalsam; 3 Präparate). Außerdem lagen noch $10^{\star}$ und 1 \% aus dem MZSP vor (siehe weiteres Material; umpräpariert in Euparal). Beim ơ fehlen beide Flügel und zwei Beine. Auch das ? ist nur noch unvollständig erhalten [ein Flügel und zwei Beine fehlend].

Literatur: Metangela spinata LANE - LANE (1955): 256 und 259-260; Fig. 3; - Aмоrim (1992): 62 [als Synonym zu Met. calliptera RübsaAmen]; - VilkamaA \& Hippa 2004: 4, 8, 21 und 23-24.

Redeskription: $0^{\top}$. Kopf: rundlich und dunkelbraun. Augenbrücke 3 bis 4-reihig. Fühlergeißelglieder lang und schlank, mit kurzen Halsteilen; Scapus und Pedicellus deutlich gebräunt; 1. und 2. Geißelglied gelblich aufgehellt; 4. Fühlergeißelglied 3,0 bis 3,2 mal so lang wie breit; Halsteil scharf abgesetzt und einfarbig dunkel, etwas kürzer als 0,2 mal so lang wie das Basalteil; Basalteil hellbraun behaart und mit sehr kurzen, feinen Sensillen; Behaarung so lang wie die Gliedbreite, etwas anliegend; Haare auf kreisrunden Insertionsstellen sitzend, die durch feine Gitterlinien verbunden sind. Palpen 3-gliedrig und schlank; Grundglied mit 3 bis 4 kräftigen Borsten und mit unberandetem Sensillenfeld. Thorax: dunkelbraun; Mesonotum ohne dichten Mikrotrichienbesatz, lediglich kurz und fein behaart; Katepisternit hoch-dreieckig;
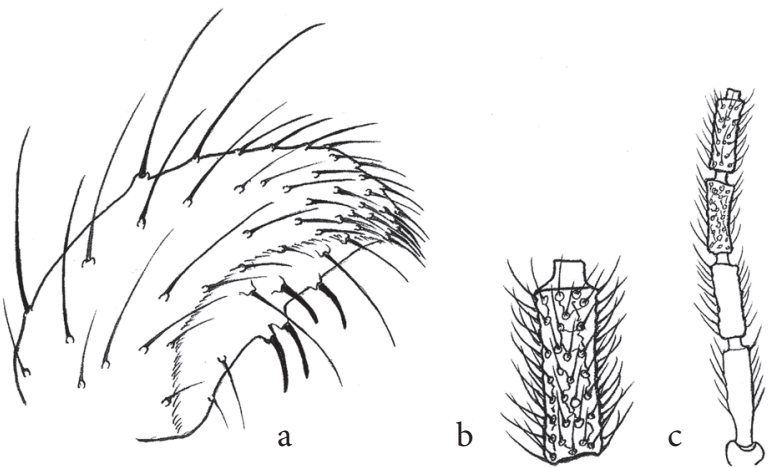

Fig. 14 a-c: Metangela spinata LANE, Paratypus $\sigma^{*}$ : - a: Gonostylus ventral; - b: 4. Fühlergeißelglied; - c: Pedicellus und 1. bis 4. Fühlergeißelglied.

Scutellum mit mehreren längeren Randborsten; alle Pleuralsklerite einschließlich Scutellum und Mediotergit pelzartig-dicht mit langen Mikrotrichien besetzt [nur Spitze des Katepisternits fast nackt]. Flügel an der Spitze und unterhalb der $\mathrm{CuA}_{2}$ leicht angedunkelt, aber nicht deutlich dunkel gebändert; Flügelmembran und hintere Flügeladern vollständig mit Makrotrichien besetzt [nähere Beschreibung siehe beim 9 ]; $\mathrm{R}_{1}$ lang, $=0,8$ bis $1,0 \mathrm{R} ; \mathrm{C}=3 / 5 \mathrm{w} ; \mathrm{y}=1,4 \mathrm{x}$, y vollständig und $\mathrm{x}$ distal mit 2 Makrotrichien; M-Stiel sehr lang, = 1,8 mal so lang wie die s-förmig geschwungene $\mathrm{M}_{2} ; \mathrm{M}$-Gabel sehr kurz und breit, deutlich zum Flügelhinterrand gebogen; CuA-Stiel lang, =1,3 $\mathrm{x}$ und ohne Makrotrichien; $\mathrm{CuA}_{1}$ leicht und $\mathrm{CuA}_{2}$ stark zum Flügelhinterrand gebogen; CuP lang und deutlich sklerotisiert. Halteren kurz gestielt und gebräunt. Coxen und Beine lang und schlank; Coxen und obere 2/3 der Femora gelblich, unteres Drittel der Femora und Fußglieder gebräunt; Tibienfleck der $\mathrm{p}_{1}$ bogenförmig berandet, mit unregelmäßig einreihigem Borstenkamm; Tibiensporne der Mittelbeine gleichlang, etwa so lang wie die Tibienspitze breit. Klauen deutlich gezähnt, mit schlanken Nebenzähnchen. Abdomen: deutlich heller als der Thorax, hell-bräunlich; die letzten 2 Abdominalsegmente und das Hypopygium dunkler; ventrale Genitalbasis ohne interkoxale Differenzierung; Gonocoxite deutlich länger als die Gonostyli, basale Hälfte der ventralen Innenseiten länger und dichter behaart als in der Spitzenhälfte; Gonostyli kurz und kompakt, etwa 2,0 mal so lang wie breit; Gonostylus basal breit und apikal stark verschmälert, mit schmal gerundeter Spitze und dichter Beborstung; ventrale Innenseite etwas ausgehöhlt, mit 4 hyalinen Dornen und 2 bis 3 längeren Geißelhaaren [1 oder 2 davon in der oberen Hälfte sehr lang]; Genitalplatte breiter als hoch und deutlich sklerotisiert, apikal breit gerundet. Aedeagus kräftig und lang, mit kurztrichterförmiger Basis; Zähnchenfeld klein, kaum sichtbar. Größe: 2,7-3,0 mm.

․ Augenbrücke 3 bis 4-reihig; Geißelglieder deutlich kürzer als beim o ${ }^{*}$; 4 . Fühlergeißelglied 2,6 mal so lang wie breit; längere Behaarung auf dem Basalteil 3/4 mal so lang wie die Gliedbreite; kürzere Behaarung und feine Sensillen mit deutlichen Insertionshöfen; Halsteil sehr kurz, nur 0,1 mal so lang wie das Basalteil. Beine länger, 
mit grob gezähnten Klauen; Coxen und obere Hälfte der Femora gelblich, untere Hälfte der Femora und Fußglieder gebräunt. Flügel größer; $\mathrm{R}_{1}$ lang, $=0,9 \mathrm{R} ; \mathrm{R}_{5}$ im Spitzendrittel mit beidseitigem Makrotrichienbesatz, im weiteren Verlauf bis zur Mitte vereinzelt mit ventralen Makrotrichien und ab der Mitte nur noch mit einseitig dorsalem Makrotrichienbesatz; Flügelmembran beidseitig mit langen Makrotrichien besetzt; hintere Flügeladern mit dichtem Makrotrichienbesatz [M-Stiel, $\mathrm{M}_{1}$ und $\mathrm{M}_{2}$ über die ganze Länge beidseitig beborstet; $\mathrm{CuA}_{1}$ und $\mathrm{CuA}_{2}$ einseitig dorsal beborstet und nur noch in Nähe des Flügelrandes mit 3 bis 4 ventralen Makrotrichien]; CuP deutlich ausgefärbt, nur einseitig dorsal mit einer Makrotrichienreihe; M-Stiel sehr lang, fast 2,0 mal so lang wie die s-förmig geschwungene $\mathrm{M}_{2}$; M-Gabel sehr kurz, breit und stark gekrümmt; $\mathrm{y}=1,5 \mathrm{x} ; \mathrm{x}$ nackt und y vollständig beborstet; CuA-Stiel lang, $=1,3 \mathrm{x} ; \mathrm{C}=3 / 5 \mathrm{w}$. Abdomen länger und kräftiger dunkel beborstet; alle anderen Merkmale wie beim ${ }^{\star}$. Größe: 3,8 $\mathrm{mm}$.

Bemerkungen: Met. spinata LANE ist von AMORIM (1992) fälschlich als Synonym von Met. calliptera RÜBSAAMEN betrachtet worden. VilkamaA \& Hippa (2004) verwenden den ursprünglichen Namen wie in der Originalbeschreibung [unter Nichtbeachtung der vorgeschlagenen Synonymie bei AMORIM (1992) und in Unkenntnis über die artliche Verschiedenheit zu Met. calliptera RüBSAAMEN]. Tatsächlich handelt es sich jedoch um eine andere Art, so dass der Name »spinata LANE« hier wieder eingesetzt wird. Met.spinata LANE unterscheidet sich von Met. calliptera RÜBSAAMEN durch die kurzen und basal breiten Gonostyli mit andersartiger Bedornung, die langen Fühlergeißelglieder, die ungebänderte Flügelmembran und durch den vollständig mit Makrotrichien besetzten $y$-Abschnitt.

\section{Pseudosciara SCHINER, 1866}

Typusart: Pseudosciara hirtella Schiner, 1866 - Verh. zool.-bot. Ges. Wien, 16: 930-931 (orig. des.; mon.).

= Megalosphys ENDERLEIN, 1911 - Arch. Naturgesch., 77(1) Suppl. 3: 126 und 129-130.

Typusart: Megalosphys luteicoxa Enderlein, 1911 Arch. Naturgesch., 77(1) Suppl. 3: 130-131; Taf., Fig. 4-5 (orig. des.).

= Chaetomegalosphys LENGERSDORF, 1930 - Zool. Anz., 92(5-6): 123.

Typusart: Chaetomegalosphys thoracica LENGERSDORF, 1930 - Zool. Anz., 92(5-6): 123-124 (mon.).

Literatur: Trichosia WINNERTZ sensu LANE - LANE (1955): 255 und 256; - Malavasi et al. (1976): 363; AMABIs et al. (1979): 200; - BüsEN et al. (1982): 247; AmABis (1983): 416; - LAICINE et al. (1984): 282; - LARA (1987): 125; - ? FUGE (1994): 299; - EsteBAN et al. (1997): 721 und 727; - ? FUGE (1997): 85; - PENALVA et al. (1997): 169; - ? Fuge (1999): 191; - GodAy \& Esteban (2001): 242; - SERnA et al. (2004): 907; - Siviero et al. (2006): 115;
- Stocker et al. (2006): 286; - MAdAlena et al. (2007): 410 [alle Fehlbestimmung]. Megalosphys EnderLeIN LENGERSDORF (1926): 167; - LENGERSDORF (1930a): 55; - LENGERSDORF (1930b): 123 und 129; - EDWARDS (1931): 78; - EDWARDS (1934): 367; - LENGERSDORF (1940): 247; - SHIN et al. (2013): 835. Megalosphys (Chaetomegalosphys) - LENGERSDORF (1931): 253. Chaetomegalosphys LENGERSDORF - EDWARDS (1934): 367 und 368. Pseudosciara SCHINER - SCHINER (1866): 928 und 930; - Edwards (1934): 366; - LENGERSDORF (1940): 247; LENGERSDORF (1941): 205; - FREEMAN (1951): 4 und 26; - ShaW \& SHAW (1951): 20; - SHAW (1953): 29; - LANE (1959b): 287; - STEFFAN (1981): 252; 251, Fig. 17; 253, Fig. 26; - Amorim (1992): 63; - Evenhuis (1994): 177; - Hippa et al. (1997): 155; - VilkamaA (2000): 55 und 63; - Mohrig (2003): 31 und 65; - Mohrig et al. (2004): 271 und 307; - VilKamAa \& HipPA (2004): 4, 8, 21, 23 und 24; - AMORIM \& Rindal (2007): 52; - GonÇALVES (2006): 174; - Mohrig \& Menzel (2009): 279, 283 und 292; - JAsChHof (2011): 459; - Mohrig et al. (2013): 150 und 231; - SHIN et al. (2013): 835.

Bemerkungen: Schon EdwARDs (1934: 367) hat Megalosphys ENDERLEIN und Chaetomegalosphys LENGERSDORF mit Pseudosciara Schiner synonymisiert. Zum gleichen Ergebnis kommt auch AmORIM (1992), der Pseudos. hirtella SCHINER jedoch nicht revidiert hat und in seinem Katalog fälschlich notiert, dass der Holotypus von hirtella SCHINER verschollen ist [vergleiche hierzu auch mit der Diskussion bei Pseudosciara hirtella]. Im Gegensatz zu EDWARDs (1928) gehört Trichomegalosphys ENDERLEIN, 1911 restit. mit der orientalisch verbreiteten Typusart Trichom. funesta ENDERLEIN [= Trichom. laticornis (WALKER, 1857) comb. nov.; = sulcata (VAN DER WULP, 1887)] nicht zu Pseudosciara Schiner [weitere Informationen dazu bei Pseudos. pubescens (Morgante)].

Die Gattung Pseudosciara ScHINer ist unverkennbar charakterisiert durch den sehr langen CuA-Stiel in Verbindung mit einem ausgedehnt beidseitigen Makrotrichienbesatz auf den vorderen und hinteren Flügeladern. Ein weiteres gutes Merkmal ist der Borstenfleck am Vordertibienende (Tibialorgan), der typischerweise eine palisadenförmige, hyaline Borstenreihe aufweist, die durch isoliertere Borsten im bogenförmig begrenztem Areal ergänzt wird. Selten ist der gesamte bogenförmig begrenzte Bereich an der Tibienspitze noch dicht mit Borsten besetzt. Die Klauen sind ungezähnt, das Postpronotum ist nackt. Die Fühlergeißelglieder sind schlank und haben gut abgesetzte, zweifarbige Halsteile [mit mehr oder weniger deutlichem, dunklem Ring am Halsteilende]. Die Körperfärbung ist bei den meisten Arten sehr kontrastreich [durch gelbe Fühlergrundglieder und basale Geißelglieder, gelbe Bereiche auf dem Mesonotum und den Thoraxskleriten, hellgelb bzw. dunkelbraun gefärbte Abdominalsegmente und Hypopygien. Häufiger als in anderen Gattungen treten außerdem dunkle Flecken oder Bänder auf der Flügelmembran und Makrotrichien auf der Flügelmembran auf. Typisch 

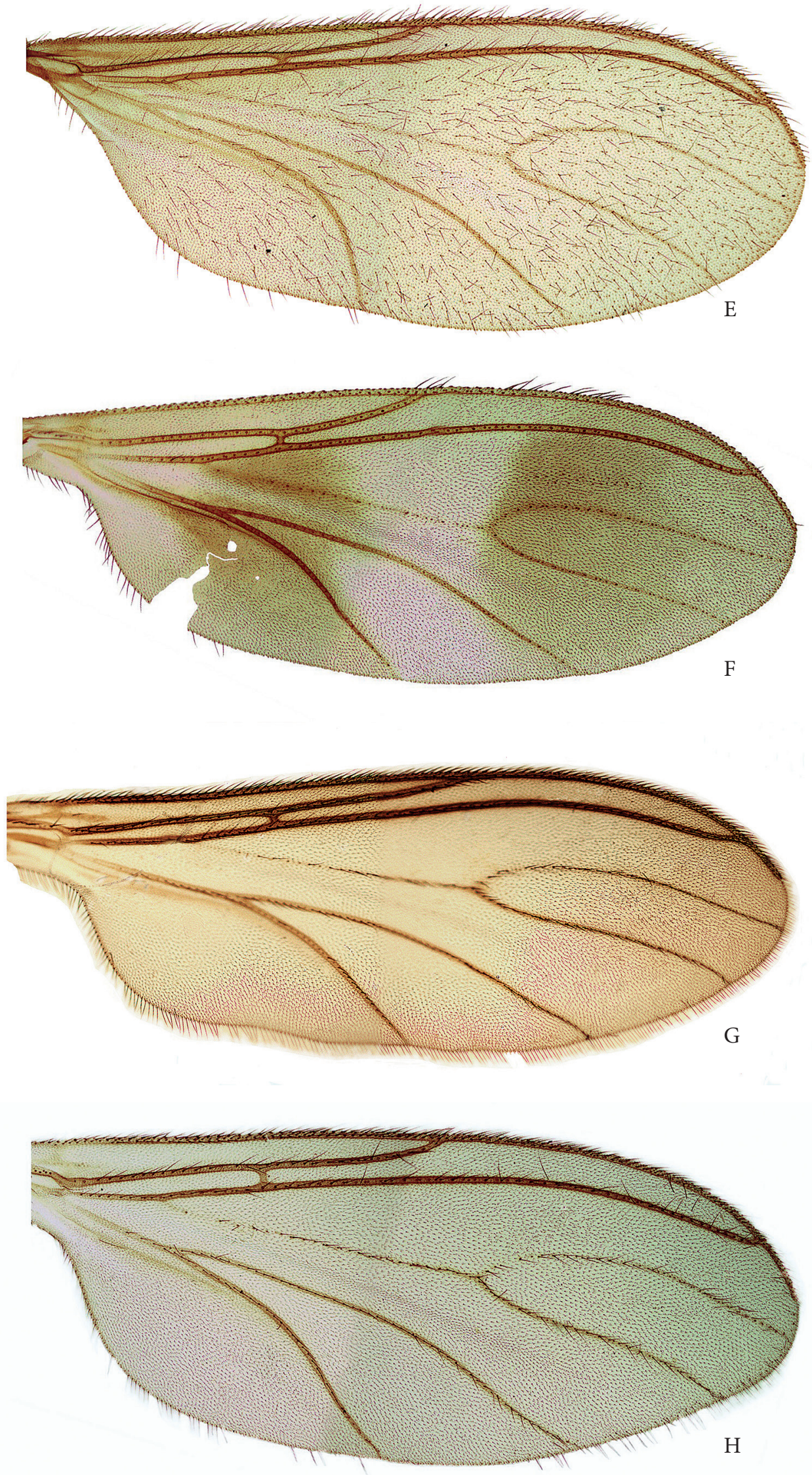

Tafel 2, Fig. E-H: Flügel von neotropischen Sciaridenarten aus den Gattungen Metangela und Pseudosciara: - E: Metangela

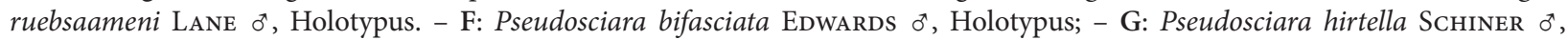
Holotypus; - H: Pseudosciara thoracica (Lengersdorf) ơ, Neotypus. 
und äußerst konstant bei Pseudosciara s. str. ist außerdem die Bedornung der Gonostylusspitze, die fast immer einen kräftigen Spitzenzahn aufweist, der von mindestens 4 kräftigen, seltener von bis zu 14 kürzeren Dornen umgeben ist. Charakteristisch für die Mehrzahl der Arten ist außerdem ein Mitteldorn auf der ventralen Innenseite der Gonostyli, der nur bei wenigen Arten fehlt. Die Untergattung Pseudosciarella subgen. nov. - dem gegenwärtig nur eine Art zugeordnet werden kann - ist bei sonst ähnlicher Merkmalskombination vor allem dadurch gekennzeichnet, dass der Spitzenzahn am Gonostylus fehlt und die Spitze des Gonostylus dicht mit mehr als 20 schlanken Dörnchen besetzt ist. Außerdem besitzt die Typusart von Pseudosciarella nur ein schwach berandetes Sensillenfeld auf dem Palpengrundglied und ungewöhnlich lange Außenborsten auf dem 1. und 2. Palpenglied. Die lange Borste auf dem 2. Palpengied gehört auch zum Grundmuster von Pseudosciara s. str., ist dort jedoch noch wesentlich kürzer ausgeprägt.

\section{Subgenus Pseudosciara SCHINER, 1866 s. str.}

Typusart: Pseudosciara hirtella SchINer, 1866 - Verh. zool.-bot. Ges. Wien, 16: 930-931 (orig. des.; mon.).

\section{Pseudosciara (Pseudosciara) antunesi (LANE, 1946) comb. nov.}

Locus typicus: "State of S. Paulo, Cantareira« [= Estado de São Paulo, São Paulo, Cantareira] (Brasilien).

Holotypus: q, Reg.-Nr. 6467, November 1946, leg. BARRETTO (MZSP).

Paratypus: 1 \% , Reg.-Nr. 6468, "State of Rio de Janeiro« [= Estado de Rio de Janeiro], Distrito Federal (Brasilien), April 1938, leg. SHAnNon (MZSP).

Erhaltungszustand: Vom Holotypus sind beide Flügel und beide Fühlergeißeln nicht mehr vorhanden. Alle anderen Körperteile [Kopf mit Scapus und Pedicellus, Thorax, Coxen, Beine und Abdomen] befinden sich in einem ausgezeichneten Zustand (umpräpariert in Kanadabalsam; 2 Präparate). Der Paratypus ist gut erhalten (umpräpariert in Kanadabalsam).

Literatur: Trichosia antunesi LANE - LANE (1946): 353-354. Trichomegalosphys antunesi (LANE) - AMORIM (1992): 67.

Redeskription: ㅇ. Kopf: gelb, nur Ocellenregion dunkel. Augenbrücke 5-reihig. Fühlergrundglieder gelblich-braun; Fühlergeißelglieder dunkel; 4. Fühlergeißelglied 4,0 mal so lang wie breit, dicht und so lang wie die Gliedbreite behaart. Palpen 3-gliedrig und gelb. Thorax: Mesonotum im vorderen Drittel gelb, dahinter dunkel, einschließlich Scutellum und zentraler Bereich des Mediotergits; Pleuralsklerite und Metanotum einheitlich gelb; Scutellum mit 4 starken Randborsten; Postpronotum nackt. Flügel im Spitzendrittel mit dunklem Band; Flügelmembran und hintere Flügeladern mit Makrotrichien; Flügeladern kräftig [mit Ausnahme des M-Stiels und der $\mathrm{M}_{2}$ ]; $\mathrm{R}_{1}$ lang, gegenüber der $\mathrm{M}$-Gabelbasis in $\mathrm{c}$ mündend; $\mathrm{y}=\mathrm{x}$, beide mit Makrotrichien; $\mathrm{C}=1 / 2 \mathrm{w}$ oder etwas kürzer; $\mathrm{CuA}$ Stiel lang. Halteren mit gelbem Halterenstiel und dunklem Halterenkopf. Coxen und Femora gelbbräunlich, Tarsen angedunkelt; Vordertibienende mit großem Fleck aus palisadenartig angeordneten, hellen Borsten und mit bogenförmiger Berandung. Klauen ungezähnt. Abdomen: 1. Tergit gelb, 2. bis 5. Tergit dunkelbraun, basal mit gelben Bändern; Sternite und Cerci gelblich. Größe: 4,0-5,8 mm. ơ. Unbekannt.

Bemerkungen: Amorim (1992: 67) gibt fälschlich 1947 als Publikationsjahr an. In Wirklichkeit ist die LANEsche Originalbeschreibung auf den Dezember 1946 datiert. Die Art wurde wegen der Makrotrichien auf der Flügelmembran im Genus Trichosia beschrieben und später von Amorim (1992) in die Gattung Trichomegalosphys ENDERLEIN gestellt. Trichomegalosphys ENDERLEIN ist aber ein orientalisches Faunenelement, das in der neotropischen Region nicht vorkommt. Aufgrund der typischen Körperfärbung, der Palpen-Merkmale sowie dem charakteristischen Borstenfleck an den Vordertibien mit palisadenartig angeordneten, hyalinen Borsten und bogiger Berandung gehört Trichosia antunesi LANE zweifellos zur Gattung Pseudosciara Schiner. Den Makrotrichienbesatz auf der Flügelmembran hat sie gemeinsam mit Pseudos. ribeiroi (LANe), Pseudosc. melanocephala (Fabricius), Pseudosc. pubescens (Morgante) und einigen anderen, noch unbeschriebenen Arten aus dem SDEI und PWMP. Eine Zuordnung der noch unbekannten $0^{\star} \sigma^{\star}$ erscheint zu einem späteren Zeitpunkt auf der Basis der dunklen Flügelspitzen, der charakteristischen Körperfärbung und der erheblichen Körpergröße möglich. Zur Diskussion des Gattungsnamens Trichomegalosphys vergleiche unter Pseudosciara pubescens (MORGAnTE).

\section{Pseudosciara (Pseudosciara) boracensis LANE, 1959} (Fig. 15)

Locus typicus: »State of S. Paulo, Boracéa« [= Estado de São Paulo, Município de Salesópolis, Boracéia] (Brasilien).

Holotypus: ơ , Reg.-Nr. 13.694, Juni 1948, leg. LANE (MZSP).

Paratypen: 2 o $^{\star}$, Reg.-Nr. 13.695 und 13.696, „Campos de Jordão« [Estado de São Paulo, Campos de Jordão] (Brasilien), Januar 1954 und Dezember 1955, alle leg. LANE (MZSP) [nicht untersucht!].

Erhaltungszustand: Dem Holotypus fehlen beide Flügel und von beiden Fühlergeißeln sind nur noch die Geißelglieder 1 bis 5 vorhanden. Die Kopfkapsel ist leicht deformiert. Thorax, Coxen, Beine und Hypopygium sind in einem sehr guten Zustand [nur 2 Dorne am linken Gonostylus abgebrochen] (umpräpariert in Kanadabalsam). 


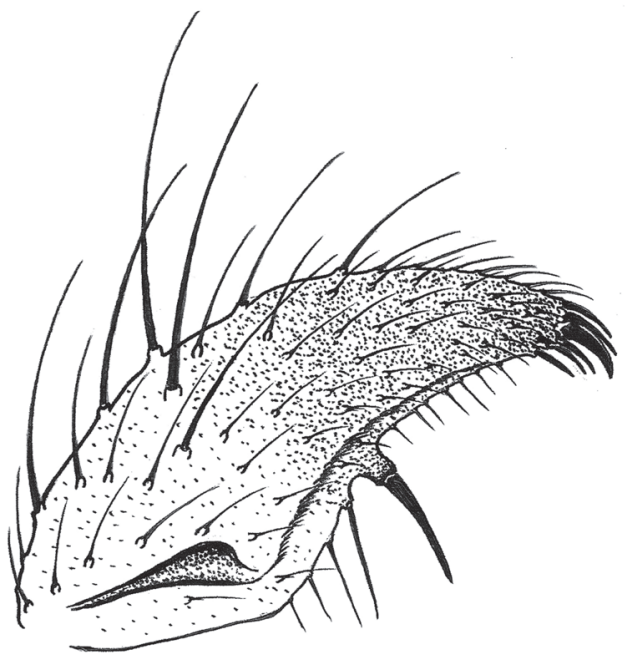

Fig. 15: Pseudosciara boracensis LANE, Holotypus $0^{\star}$ : Gonostylus ventral.

Literatur: Pseudosciara boracensis LANE - LANE (1959b): 289 und 290-291; 293, Fig. 3-4; - AMORIM (1992): 64.

Redeskription: $\sigma^{\star}$. Kopf: Prefrons und Augenhinterrand gelblich, Ocellenregion dunkel. Augenbrücke 3-reihig. Fühler braun; Grundglieder und erstes Fühlergeißelglied etwas gelblich aufgehellt; 4. Fühlergeißelglied 2,3 mal so lang wie breit; Behaarung des Basalteils dicht, grob und abstehend, etwa 3/5 mal so lang wie die Gliedbreite; Halsteil kurz und einfarbig braun. Palpen 3-gliedrig und etwas gebräunt. Thorax: Mesonotum [mit Ausnahme des Präscutums], antethorakales Anepisternit, antemesothorakales Epimeron, Pleurotergit, Scutellum und Mediotergit braun; postthorakales Episternit mit einem auffallenden, braunen Fleck; Präscutum, Antepronotum, präthorakales Episternit, Katepisternit und postthorakales Episternit gelb; Scutellum mit 4 starken Randborsten; Postpronotum nackt. Coxen und Femora gelb, deutlich kontrastiert zu den dunkleren Tibien und Tarsen; Vordertibienende mit großem Fleck aus palisadenartig angeordneten, hellen Borsten und mit bogenförmiger Berandung. Klauen ungezähnt. Abdomen: braun, mit gelblichen Aufhellungen am 1., 4. und 5. Tergit; Sternite gelblich-braun. Flügel beim Holotypus fehlend. Gonocoxite gelb, ventrale Innenseiten in der Spitzenhälfte deutlich länger behaart; Gonostyli zur Spitze dunkler gefärbt, zugespitzt und in der Mitte der Innenseite mit einem langen Dorn auf hohem Sockel; Stylusspitze mit kräftigem Zahn und 5 etwas kürzeren Dornen [2 Dorne über und 3 Dorne unter dem Zahn]; Genitalplatte membranös, apikal gerundet und fast so hoch wie breit; Zähnchenfeld rundlich, mit sehr kurzen und feinen Zähnchen. Aedeagus lang und dünn, mit einer breiten, halbkreisförmigen Basis. Größe: 3,3 mm.

․ Unbekannt.

Bemerkungen: Die Art ist durch die Thoraxfärbung, den Farbkontrast zwischen Coxen und Femora zu den Tibien und Tarsen sowie durch die längere Behaarung in der
Spitzenhälfte der ventralen Innenseiten der Gonocoxite gut charakterisiert.

\section{Pseudosciara (Pseudosciara) cariba LANE, 1959 \\ (Fig. 16 a-b)}

Locus typicus: »Trinidad (B. W. I.)« [= British West Indies, Trinidad], Arena Forest (Trinidad und Tobago). Holotypus: $\sigma^{*}$, Reg.-Nr. 13.697, Lichtfallenfang mit weißem Licht, 25.7.1955, leg. Aitken (MZSP).

Weiteres Material: $1 \sigma^{\star}$, Prov. Heredia, La Selva (Costa

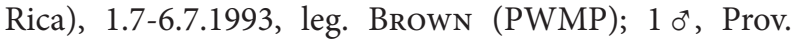
Guanacaste, Santa Rosa National Park (Costa Rica), $10,95^{\circ} \mathrm{N} 85,62^{\circ} \mathrm{W}, 27.9 .-18 \cdot 10.1986$, leg. Gould \& JANZEN (PWMP); $10^{\star}$, Prov. Puntarenas, Corcovado National Park, Cerro Rincon (Costa Rica), $04,12^{\circ} \mathrm{S} 78,98^{\circ} \mathrm{W}$, $745 \mathrm{~m}$ ü. NN, Malaisefallenfang, 1.8.-25.9.2002, leg. Azofeifa (PWMP); $10^{*}$, Prov. Zamora-Chinchijpe, Rio Bombuscaro (Ecuador), 04,12 ${ }^{\circ} \mathrm{S} 78,98^{\circ} \mathrm{W}, 1100 \mathrm{~m}$ ü. NN, Malaisefallenfang, 22.6.-4.7.1996, leg. HibBs (PWMP). $4 \sigma^{\star} \sigma^{\star}$, Prov. Sucumbios, Sacha Lodge (Ecuador), 00,50 ${ }^{\circ} \mathrm{S}$ $76,50^{\circ} \mathrm{W}, 270 \mathrm{~m}$ ü. NN, Malaise-Falle, 3.7.-13.7.1994, leg. Hiввs (PWMP).

Erhaltungszustand: Beim Holotypus sind die Kopfkapsel und die noch vorhandenen Fühlergeißelglieder 1 bis 4 bzw. 1 bis 8 leicht deformiert. Alle anderen Körperteile [Thorax, Flügel, Coxen, Beine, Abdomen und Hypopygium] sind gut erhalten (umpräpariert in Kanadabalsam).

Literatur: Pseudosciara cariba LANE - LANe (1959b): 289 und 291-292; 293, Fig. 5-6; - AMORIM (1992): 64; MoHrig et al. (2004): 271.

Redeskription: $\sigma^{\star}$. Kopf: Prefrons, Mundpartie und Palpen sowie Augenhinterrand gelblich; Ocellenregion dunkel. Augenbrücke 3 bis 4-reihig. Fühlergrundglieder gelb, erstes Fühlergeißelglied etwas heller als die folgenden Glieder; Fühlergeißelglieder lang und dünn, Halsteile gut abgesetzt und zweifarbig; 4. Fühlergeißelglied 3,5-4,0 mal so lang wie breit, Behaarung borstig abstehend und so lang oder etwas länger als die Glied-
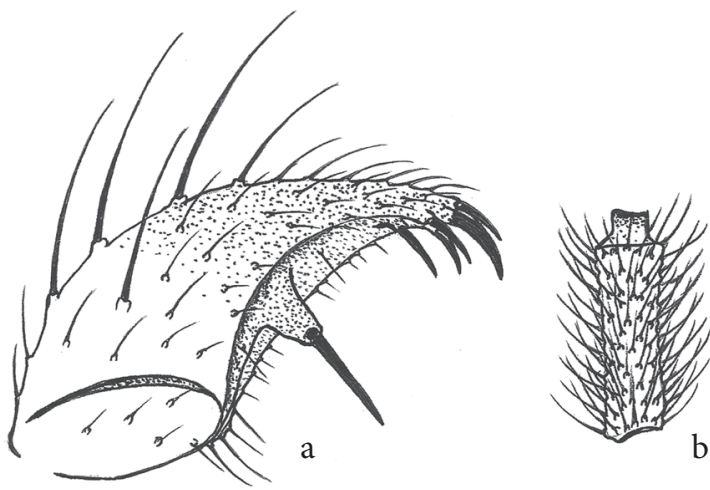

Fig. 16 a-b: Pseudosciara cariba Lane, Holotypus $\sigma^{*}$ : - a: Gonostylus ventral; - b: 4 . Fühlergeißelglied. 
breite. Palpen 3-gliedrig. Thorax: Mesonotum im vorderen Drittel und lateral gelb, im mittlerem und hinteren Bereich diffus dunkler, je einen Lateralfleck mit Mittelstreif andeutend; Scutellum und Mediotergit zentral dunkel; Pleuralsklerite gelb bis bräunlich; Katepisternit gelb; Scutellum mit 4 starken Randborsten; Postpronotum nackt. Flügel hell; hintere Flügeladern mit Makrotrichien; $\mathrm{R}_{1}$ kurz, weit vor der M-Gabelbasis in $\mathrm{c}$ mündend, $\mathrm{R}_{1}=3 / 4 \mathrm{R} ; \mathrm{C}=2 / 3 \mathrm{w}$; $\mathrm{y}$ etwa $=\mathrm{x}$, beide mit Makrotrichien. Halteren mit hellem Halterenstiel und dunklem Halterenkopf. Coxen und Beine gelb, Tarsen leicht angedunkelt; Vordertibienende mit großem Fleck aus palisadenartig angeordneten, hellen Borsten und mit bogenförmiger Berandung. Klauen ungezähnt. Abdomen: braun, mit gelblichen Aufhellungen am 1 . und 4. Tergit; Intersegmentalmembranen gelblich; Sternite gelblich-braun. Gonocoxite gelb, Gonostyli zur Spitze hin dunkelbraun gefärbt; ventrale Innenseiten der Gonocoxite relativ kurz behaart; Gonostyli basal eckig verbreitert, apikal zugespitzt und in der Mitte der Innenseite mit einem kräftigen Dorn auf hohem und breitem Sockel; Stylusspitze mit relativ langem Zahn und 4 etwas kürzeren Dornen [2(1) Dorne über und 2(3) Dorne unter dem Zahn]; Genitalplatte membranös und hoch gerundet; Aedeagus dünn. Größe: 1,9-2,2 mm. ㅇ. Unbekannt.

Bemerkungen: Diese kleine Art ist durch das bräunliche Mesonotum ohne deutliche Flecken oder Bänder, die hellen Gonocoxite, die dunkleren und basal breit-eckigen Gonostyli sowie die langen Fühlergeißelglieder mit langer Behaarung charakterisiert.

\section{Pseudosciara (Pseudosciara) willistoni Menzel nom. nov. \\ (Fig. 17 a-b)}

Derivatio nominis: Die Art wurde nach ihrem Entdecker Prof. Samuel Wendell Williston (1852-1918) umbenannt [nom. nov. pro Sciara concinna Williston, 1896; primäres Homonym].

= Sciara concinna Williston, 1896 - Trans. Ent. Soc. Lond., 1896 (3): 265 und 266 [praeocc.; nec Sciara concinna WinnerTz, 1867 - Monogr. Sciarinen: 150-151 (Corynoptera)]; primäres Homonym.

Locus typicus: »West Indies«, St. Vincent [Insel der Kleinen Antillen] (St. Vincent).

Lectotypus: đ`, Reg.-Nr. 20387, 1000 ft. ü. NN, leg. SмIтH (AMNH) [hier designiert].

Paralectotypen: 3 o o $^{\top}$ vom locus typicus, Reg.-Nr. 20387, 500, 1000 und $1500 \mathrm{ft}$. ü. NN, alle leg. SMITH (AMNH); $1 \sigma^{*}$ vom locus typicus, Typ.-Nr. 2709.4, $1500 \mathrm{ft}$. ü. NN, leg. Sмith (CUIC). Ein weiteres Exemplar, von dem nach AMORIM (1992) nur noch die Beine erhalten sind, soll sich im BMNH befinden [nicht untersucht!]. Nach Williston (1896: 266) besteht die Typenserie aus mehreren $0^{\top} \sigma^{\top}$ und +9 o .
Weiteres Material: $2 \sigma^{\star} o^{\star}$, Prov. Guanacaste, Santa Rosa National Park (Costa Rica), $10,95^{\circ} \mathrm{N} 85,62^{\circ} \mathrm{W}$, 6.9.27.9.1986 und 27.9.-18.10.1986, leg. Gould \& JANZEN (PWMP); $40^{\star} \sigma^{\star}$, Prov. Sucumbios, Sacha Lodge (Ecuador), 00,50 $76,50^{\circ} \mathrm{W}, 270 \mathrm{~m}$ ü. NN, 4.5.-14.5.1994, leg. Hibвs; $10^{\star}$, Manabi, Cerro Pata de Pajaro (Ecuador), $00,01^{\circ} \mathrm{N} 79,57^{\circ} \mathrm{W}$, Malaisefallenfang, 19.6.-21.6.1996, leg. Hiввs (PWMP).

Erhaltungszustand: Beim Lectotypus sind Kopf, Thorax, Coxen, Beine, Abdomen und das Hypopygium gut erhalten. Die beiden Fühlergeißeln, ein Flügel und ein Bein fehlen. Die Fühlergeißeln sind aber bei 2 Paralectotypen aus dem AMNH und dem CUIC vorhanden (alle 5 Exemplare umpräpariert in Kanadabalsam).

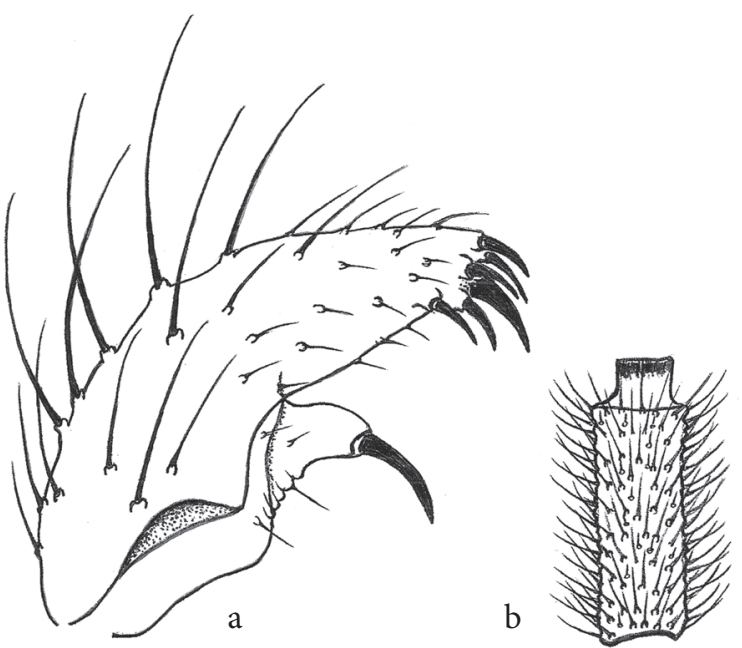

Fig. 17 a-b: Pseudosciara willistoni Menzel, o : - a: Gonostylus vom Lectotypus ventral; - b: 4. Fühlergeißelglied von einem $\sigma^{\star}$ aus Costa Rica (PWMP).

Literatur: Sciara concinna WILLISTON - AMORIM (1992): 69.

Redeskription: ${ }^{\star}$. Kopf: dunkel, nur Mundpartie und Palpen gelblich. Augenbrücke 3-reihig. Fühler einheitlich dunkel, Halsteile heller, leicht zweifarbig; 4. FühlergeiBelglied 2,9-3,2 mal so lang wie breit, Behaarung etwas kürzer als die Gliedbreite. Palpen 3-gliedrig. Thorax: dunkelbraun; Präscutum, Postpronotum und Flügelbasis etwas heller; Scutellum mit 4 starken Randborsten; Postpronotum nackt. Flügel hell; $\mathrm{R}_{1}$ lang, = 4/5 R; $\mathrm{C}$ wenig länger $1 / 2 \mathrm{w}$; y etwa $=\mathrm{x}$, beide mit Makrotrichien; Analader $\mathrm{A}_{1}$ schwach ausgebildet und meist mit wenigen Makrotrichien [häufiger mit 1 bis 4 Makrotrichen, seltener ohne Makrotrichienbesatz oder mit einer deutlichen Reihe bestehend aus 6 bis 9 Makrotrichien]; hintere Flügeladern mit Makrotrichien. Halteren kurz gestielt und dunkel. Coxen und Femora gelb, Tibien und Tarsen angedunkelt; Vordertibienende mit großem Fleck aus palisadenartig angeordneten, hellen Borsten und mit bogenförmiger Berandung. Klauen ungezähnt. Abdomen: Tergite dunkelbraun, ohne helle Ränder; Sternite 
gelblich. Gonocoxite und Gonostyli einheitlich braun; ventrale Innenseiten der Gonocoxite kurz und spärlich behaart; Basalhälfte des Gonostylus daumenförmig verbreitert und mit kräftigem Dorn auf lobusförmigem Sockel; Stylusspitze mit kräftigem Zahn und 5 kürzeren Dornen [3 Dorne über und 2 Dorne unter dem Zahn]; Genitalplatte schwach sklerotisiert und hoch gerundet. Aedeagus mäßig lang und dünn. Größe: 2,0-2,6 mm.

우. Siehe WiLliston (1896): 266.

Bemerkungen: Williston (1896) erwähnt eine nicht näher definierte Anzahl von Exemplaren, die ihm bei der Artbeschreibung vorlag. Ausführlich wird das $\circ$ charakterisiert. Für das $\sigma^{*}$ gibt er nur an, dass die Fühlergeißeln - im Gegensatz zum + - länger als der Körper sind. AMORIM (1992) stellt heraus, dass er im BMNH lediglich ein Typexemplar von Sciara concinna Williston gefunden hat. $\mathrm{Zu}$ diesem Tier schreibt Amorim, dass nur noch die Beine vorhanden sind, so dass sich das Geschlecht nicht mehr feststellen lässt. Im Gegensatz dazu haben uns $5 \sigma^{\top} \sigma^{\star}$ aus der Typenserie von Pseudos. willistoni [= concinna (WILlisTON, 1896), praeocc.] vorgelegen [4 $\sigma^{\top} \sigma^{\top}$ aus dem AMNH und $1 \sigma^{-1}$ aus dem CUIC]. Zur Erhöhung der Namensstabilität designieren wir an dieser Stelle einen Lectotypus. Die Art ist durch das dunkle Mesonotum, das dunkle Hypopygium und den daumenförmigen Fortsatz in der basalen Hälfte des Gonostylus gekennzeichnet. Sie ist durch den lobusartigen Sockel des Mitteldorns Pseudos. nigricolor (ENDERLEIN) ähnlich, unterscheidet sich von dieser aber durch die viel geringere Größe und die hellen Coxen an den $p_{1}$ bis $p_{3}$.

\section{Pseudosciara (Pseudosciara) coroicoensis EDWARDS, 1934 \\ (Fig. 18 a-e)}

Locus typicus: »Yungas von Coroico« [= Departamento La Paz, Prov. Nor Yungas, Los Yungas, bei Coroico] (Bolivien).

Holotypus: 우, $1800 \mathrm{~m}$ ü. NN, 30.11.1906, leg. GARLEPP (SMTD).

Weiteres Material: $1 \sigma^{\top}$ [ohne Fühlergeißeln; in LANE (1959b) fälschlich als »Allotype« ausgewiesen; etikettiert als »Alotipo«], Prov. Tucumán, Tafi del Valle, Quebrada de la Angustura (Argentinien), 1800 m ü. NN, 26.2.1953, leg. Golbach (MZSP); $15 \sigma^{\top} \sigma^{*}$, Arizona, Cochise County, Huachuca Mts., Ash Cyn Road (USA), $11 \sigma^{\star} \sigma^{\star}, 13.9 .-$ 22.9.1993; $2 o^{\star} o^{\star}, 24.9 .-5.10 .1993 ; 2 o^{\top} o^{*}, 22.10 .-31.10$. 1993, alle leg. McFARLAND (PWMP).

Erhaltungszustand: Der Holotypus ( 9 ) ist sehr gut und fast vollständig erhalten. Nur ein Flügel fehlt. Von dem Exemplar aus dem MZSP ( $\left.\sigma^{\star}\right)$ sind noch der Kopf, Thorax, Abdomen, beide Flügel, alle Coxen, 4 Beine und 3 einzelne Fühlergeißelglieder vorhanden. Das Hypopygium befindet sich in einem guten Zustand. Nur der lange Dorn in der

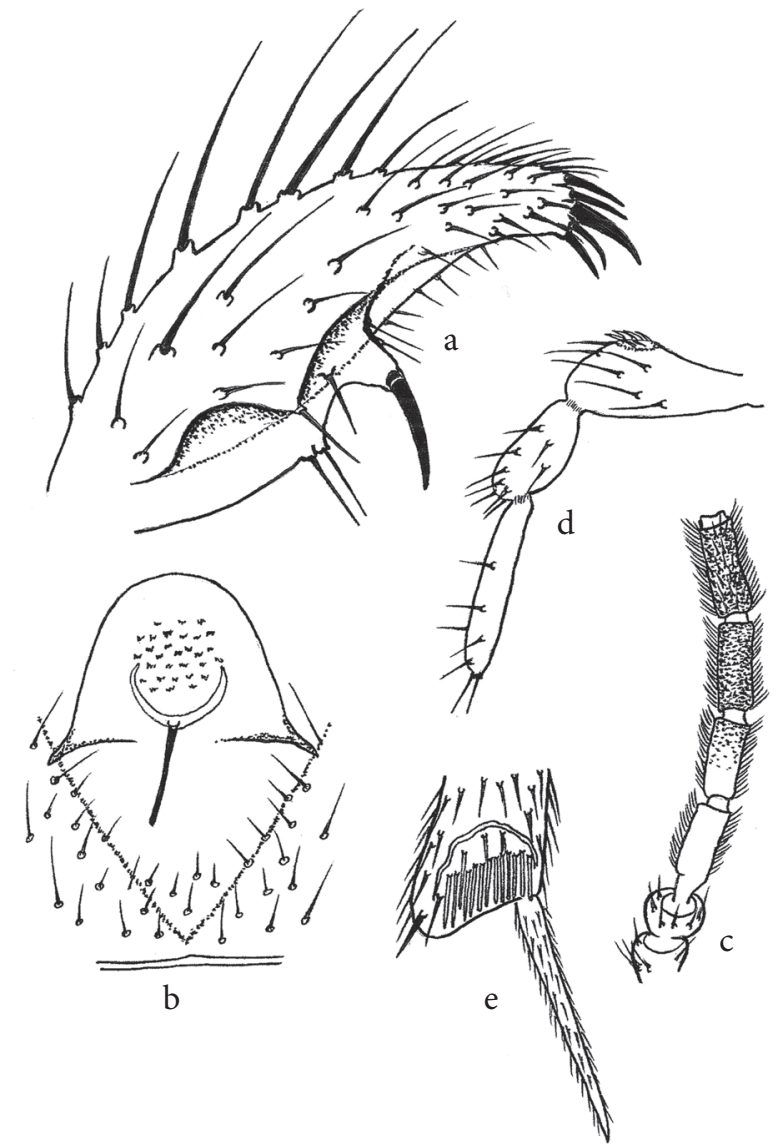

Fig. 18 a-e: Pseudosciara coroicoensis EDWARds, $0^{*}$ aus Arizona, USA (PWMP): - a: Gonostylus ventral; - b: Basis des Hypopygiums mit Genitalplatte und Aedeagus ventral; c: Scapus, Pedicellus und 1. bis 4. Fühlergeißelglied; - d: Palpus lateral; - e: Vordertibienende.

Mitte des linken Gonostylus ist abgebrochen (beide Exemplare umpräpariert in Kanadabalsam).

Literatur: Pseudosciara coroicoensis EDWARDS - EDWARDS (1934): 368; - LANE (1959b): 288 und 292; - AMORIM (1992): 64 .

Redeskription: + . Kopf: Gesicht und Palpen gelblich, Ocellenregion dunkel. Augenbrücke 3-reihig. Fühler braun; Fühlergrundglieder und erstes Fühlergeißelglied gelblich; 4. Fühlergeißelglied etwa 3,5 mal so lang wie breit, Behaarung etwa so lang wie die Gliedbreite. Palpen 3-gliedrig. Thorax: Mesonotum gelb, ohne dunkle Flecken oder Streifen; Scutellum und alle anderen Thoraxsklerite gelb; Scutellum mit 4 starken Randborsten; Postpronotum nackt. Flügel hell; $\mathrm{R}_{1}=3 / 4 \mathrm{R} ; \mathrm{C}$ etwas länger als $1 / 2 \mathrm{w}$; $\mathrm{y}=\mathrm{x}$, beide mit Makrotrichien; CuA-Stiel länger als $\mathrm{x}$; Analader $A_{1}$ nicht sichtbar und ohne Makrotrichien. Halteren einheitlich gelb. Coxen und Femora gelb, Tibien und Tarsen dunkler; Vordertibienende mit großem Fleck aus palisadenartig angeordneten, hellen Borsten und mit bogenförmiger Berandung. Klauen ungezähnt. Abdomen: braun, mit gelblichen Aufhellungen am 3. bis 6. Tergit. Größe: 2,4 mm. 
$\sigma^{\star}$ [nach Exemplaren aus den USA]. 4. Fühlergeißelglied 3,0 bis 3,5 mal so lang wie breit; Abdominaltergite mit basalen und schmalen apikalen Aufhellungen; Gonocoxite gelb, ventrale Innenseiten kurz und spärlich behaart; Gonostyli zur Spitze dunkler gefärbt, basal verbreitert und eckig; in der Mitte der Innenseite mit einem leicht gebogenen Dorn auf hohem Sockel; Stylusspitze mit kräftigem Zahn und 4 etwas kürzeren Dornen [2 Dorne über und 2 Dorne unter dem Zahn]; Genitalplatte membranös und hoch gerundet; Aedeagus mäßig lang und dünn; alle anderen Merkmale wie beim + . Größe: $2,2 \mathrm{~mm}$.

Bemerkungen: Die Art ist durch die einheitlich gelbe Thoraxfärbung ohne dunkle Flecken oder Streifen auf dem Mesonotum sowie die einfarbig gelben Halteren gut gekennzeichnet [alle anderen vergleichbaren Pseudosciara-Arten haben einen dunklen Halterenkopf]. Die Abbildungen wurden von einem männlichen Exemplar aus Arizona angefertigt. Sie sind mit dem untersuchten o aus dem MZSP [Fundort: Prov. Tucumán, Tafi del Valle, Quebrada de la Angustura (Argentinien)] identisch.

\section{Pseudosciara (Pseudosciara) helleri Menzel nom. nov. (Fig. 19 a-b)}

Derivatio nominis: Die Art wurde nach unserem Freund und Kollegen Dipl.-Biol. Kai Heller (Quickborn, Deutschland) umbenannt [nom. nov. pro Sciara debilis Williston, 1896; primäres Homonym].

= Sciara debilis Williston, 1896 - Trans. Ent. Soc. Lond., 1896 (3): 265 und 266-267; Taf. 8, Fig. 22 [praeocc., nec Sciara debilis WinNerTZ, 1867 - Monogr. Sciarinen: 116; = Lycoriella (Lycoriella) ingenua (Dufour, 1839)].

Locus typicus: »West Indies«, St. Vincent [Insel der Kleinen Antillen] (St. Vincent).

Lectotypus: ${ }^{\top}$, leg. SMith (BMNH) [des. AMORIm (1992): 64] [nicht untersucht!].

Paralectotypen: $1 \sigma^{7}$, gleicher Fundort, Reg.-Nr. 20385, $1000 \mathrm{ft}$. ü. NN, leg. Sмiтн (AMNH). Williston (1896) erwähnt 6 weitere $\sigma^{\top} \sigma^{\top}$, von denen AMORIM (1992) nur

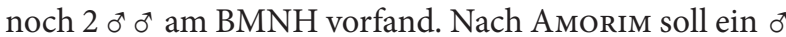
aus der Typenserie artverschieden vom Lectotypus sein.

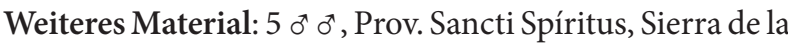
Escambray, bei Topes de Collantes, Rio Caburni (Kuba), 25.9.1992, leg. Stark (3 o $^{\top} \sigma^{\top}$ SDEI; $2 \sigma^{\top} \sigma^{\top}$ PWMP); $1 \sigma^{\star}$, Prov. Sancti Spíritus, Sierra de la Escambray, bei Topes de Collantes (Kuba), 27.4.1992, leg. STARK (SDEI); $1 \sigma^{\text {t }} 1$ 우, Prov. Sancti Spíritus, Sierra de la Escambray, Cudina bei Topes de Collantes (Kuba), 25.4.1992, leg. STARK (SDEI); $10^{\star}$, Prov. Villa Clara, Santa Clara, Universidad Central "Marta Abreu" de Las Villas (Kuba), Botanischer Garten am Rio Ochoa, 24.4.1992, leg. Stark (SDEI); $10^{\text {* }}$, Prov. Cienfuegos, Sierra de la Escambray, an der Straße zum Pico San Juan, ca. $10 \mathrm{~km}$ vor dem Gipfel, $950 \mathrm{~m}$ ü. NN, 28.4.1992, leg. Stark (SDEI); $1 \sigma^{\star}$, Große Antillen, Puerto Rico (USA), $17,97^{\circ} \mathrm{N} 66,86^{\circ} \mathrm{W}$, Guanica State Forest,

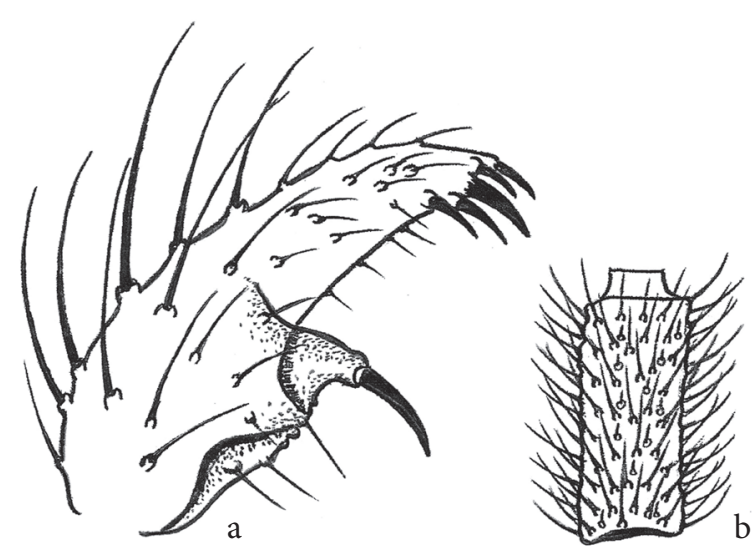

Fig. 19 a-b: Pseudosciara helleri Menzel, ơ: - a: Gonostylus vom Paralectotypus ventral; - $\mathbf{b}$ : 4. Fühlergeißelglied von einem ${ }^{\text {t }}$ aus der Dominikanischen Republik (PWMP).

15.7.-21.7.1996, leg. Canals (PWMP); $170^{\top} 0^{\top}$, Prov. Pedernales, Las Abejas, $20 \mathrm{~km}$ nordöstlich von Pedernales (Dominikanische Republik), $1500 \mathrm{~m}$ ü. NN, 26.11.27.11.1992, leg. GRIMALDi \& STARK $\left(15 o^{*} o^{*}\right.$ AMNH;

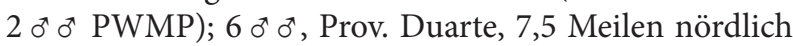
von San Francisco de Macoris (Dominikanische Republik), $800 \mathrm{ft}$. ü. NN, Mai-Juni 1991, leg. Almanzar (5 o $^{\top}{ }^{\top}$ AMNH; $1 \sigma^{7}$ PWMP) [in Mohrig et al. (2004: 271) fälschlich als Pseudosciara aitkeni LANE ausgewiesen].

Erhaltungszustand: Vom untersuchten Paralectotypus aus dem AMNH sind Kopf, Thorax, Abdomen, die Coxen, 4 Beine und die Fühlergeißelglieder 1 bis 4 gut erhalten. Das Hypopygium befindet sich in einem ausgezeichneten Zustand [nur Aedeagus deformiert]. Dem Exemplar fehlen jedoch beide Flügel (umpräpariert in Kanadabalsam).

Literatur: Pseudosciara aitkeni LANe sensu Mohrig - Mohrig et al. (2004): 271; 313, Fig. 4 a und c [Fehlbestimmung]. Megalosphys debilis WILLISTON - ENDERLeIN (1911): 135. Pseudosciara debilis (Williston) - ? LENGERSDORF (1940): 248; Fig. 1; - LANE (1959b): 289 und 292; - AMORIM (1992): 64.

Redeskription: ${ }^{\star}$. Kopf: Prefrons und Palpen gelblich, Ocellenregion und Augenhinterrand dunkel. Augenbrücke 3-reihig. Fühlergrundglieder und 1. Fühlergeißelglied gelbbraun, alle anderen Geißelglieder dunkel; 4. Fühlergeißelglied etwa 2,5 mal so lang wie breit, Halsteil gut abgesetzt, einfarbig braun; Behaarung etwas kürzer als die Gliedbreite. Palpen 3-gliedrig. Thorax: Mesonotum dunkel; Postpronotum nackt; Präscutum und ein Seitenstreifen gelb; Scutellum und zentrales Mediotergit dunkel; Thoraxseiten mit Ausnahme des antethorakalen Anepisternits und des Katepisternits weitgehend gelb; Scutellum mit 4 starken Randborsten. Flügel hell; $R_{1}=2 / 3 R$; C wenig länger als $1 / 2 \mathrm{w}$; $y$ deutlich kürzer als $\mathrm{x}$, beide mit Makrotrichien; Analader $\mathrm{A}_{1}$ mit einer Makrotrichienreihe; hintere Flügeladern mit Makrotrichien. Halteren dunkel. Coxen und Femora gelb, Tibien 
und Tarsen angedunkelt; Vordertibienende mit großem Fleck aus palisadenartig angeordneten, hellen Borsten und mit bogenförmiger Berandung. Klauen ungezähnt. Abdomen: Tergite dunkelbraun, mit gelben Intersegmentalmembranen; 1 . Tergit und alle Sternite gelblich. Gonocoxite gelb, ventrale Innenseiten kurz und spärlich behaart; Gonostyli dunkel; Basalhälfte des Gonostylus daumenförmig verbreitert und mit kräftigem Dorn; Stylusspitze mit kräftigem Zahn und 4 kürzeren Dornen [2 Dorne über und 2 Dorne unter dem Zahn]; Genitalplatte schwach sklerotisiert und hoch gerundet; Aedeagus mäßig lang und dünn. Größe: 1,8-2,4 mm.

ㅇ. . Bekannt [1 ㅇ im SDEI]. Größe: 2,7 mm.

Bemerkungen: Williston beschreibt die Art unter dem päokkupierten Namen Sciara debilis auf der Basis von $8 o^{\star} o^{\star}$. Pseudos. helleri [= debilis (Williston, 1896); praeocc.] ist durch das dunkle Mesonotum, die gelben Gonocoxite und die dunklen Gonostyli mit je einem daumenförmigen Fortsatz in der basalen Hälfte gekennzeichnet. Von ähnlichen Arten wie Pseudos. delectata (Williston) unterscheidet sie sich vor allem durch die Makrotrichienreihe auf der Analader $\mathrm{A}_{1}$.

\section{Pseudosciara (Pseudosciara) delectata (WILLISTON, 1896) \\ (Fig. 20 a-b)}

Locus typicus: »West Indies«, St. Vincent [Insel der Kleinen Antillen] (St. Vincent).

Lectotypus: ơ leg. Smith (BMNH) [des. Amorim (1992): 64] [nicht untersucht!].

Paralectotypen: $1 \sigma^{*}$, gleicher Fundort, Typ.-Nr. 2710, $1000 \mathrm{ft}$. ü. NN, leg. Smith (CUIC). Nach Williston (1896) besteht die Typenserie aus 6 Exemplaren [alles $o^{t} o^{\top}$ und alle vom locus typicus]. Amorim (1992) fand am BMNH $2 \sigma^{\top}$ und 1 or. Das $q$ wird in der Originalbeschreibung nicht erwähnt, gehört folglich nicht zur Typenserie und ist nach AMORIM (1992) artverschieden vom Lectotypus. Die beiden fehlenden ơ $\sigma^{\top}$ könnten sich noch in der Sammlung des AMNH befinden.

Weiteres Material: $1 \sigma^{\star}$, Prov. Puntarenas, Jaco (Costa Rica), Gartenanlage in Küstennähe, Gelbschalenfang, 24.8.-30.8.1996, leg. Mohrig (PWMP); $2 \sigma^{\star} \sigma^{*}$, Texas, Innenstadt von Housten (USA), 3.11.-6.11.1996, leg. Mohrig und 15.2.1996, leg. Eue (PWMP); $10^{\text {* }} 1$ 운, Texas, Sam Housten National Forest bei Willis, ca. 60 Meilen nördlich von Housten (USA), 3.11.-6.11.1996, leg. Mohrig (PWMP); $20^{\star} o^{\star}$, Texas, Tiki Island, La Marque, ca. 25 Meilen südlich von Housten (USA), 3.11.-6.11.1996, leg. Mohrig (PWMP); 20 o $^{\star}$ o $^{*}$ 우 운, Alabama, Baldwin Co., Raft River (USA), $30,77^{\circ} \mathrm{N}$

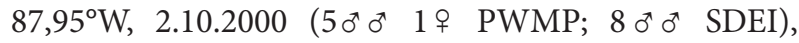
28.6.2002 (2 $\sigma^{\star} \sigma^{\star} 1$ क PWMP; $2 \sigma^{\star} \sigma^{\star}$ SDEI) und 7.9.2002 (1 $\sigma^{\star}$ SDEI), alle leg. Mohrig; $2 o^{\star} o^{\star}$, Baldwin Co., Byrnes Lake (USA), $30,79^{\circ} \mathrm{N} 87,91^{\circ} \mathrm{W}$, Barberfallenfang, leg. McCREAdie (PWMP, SDEI).

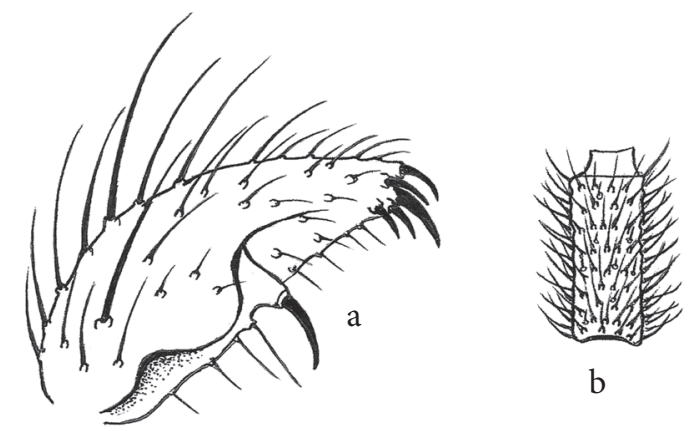

Fig. 20 a-b: Pseudosciara delectata (Williston), o aus Texas, USA (PWMP): - a: Gonostylus ventral; - b: 4. Fühlergeißelglied.

Erhaltungszustand: Beim untersuchten Paralectotypus aus dem CUIC fehlen ein Bein und eine Fühlergeißel. Die Glieder 2 bis 8 der anderen Fühlergeißel, der dorsale Bereich der Kopfkapsel und die Außenseiten der Gonostyli sind deformiert. Alle anderen Körperteile befinden sich in einem sehr guten Zustand (umpräpariert in Kanadabalsam).

Literatur: Sciara delectata Williston - WillistoN (1896): 265 und 267. Pseudosciara delectata (Williston) - LANE (1959b): 289; - Amorim (1992): 64.

Redeskription: ${ }^{\star}$. Kopf: Gesicht, Mundpartie und Palpen gelb; Ocellenregion dunkel. Augenbrücke 3-reihig. Fühler mit gelben Grundgliedern und dunkler Fühlergeißel; Halsteile kurz und leicht zweifarbig; 4. Fühlergeißelglied 2,7 bis 3,0 mal so lang wie breit; Behaarung der Geißelglieder etwas länger als die halbe Gliedbreite. Palpen 3-gliedrig. Thorax: überwiegend gelb; Mesonotum mit dunklen Lateralflecken und mit Mittelstreif, auch Scutellum und Mediotergit zentral dunkel; Pleuralsklerite überwiegend gelb, mit dunkleren Partien am Katepisternit, Episternit und an der Grenze von Mediotergit und Metanotum; Mesonotum mit starken dunklen Borsten, lateral und auch zentral kräftig behaart; Postpronotum nackt; Scutellum mit 4 starken Randborsten. Flügel leicht rauchig; $\mathrm{R}_{1}$ relativ kurz, $=2 / 3 \mathrm{R}$; $\mathrm{C}$ wenig länger als $1 / 2 \mathrm{w}$; $\mathrm{y}$ etwa $=\mathrm{x}$, beide mit Makrotrichien; Analader $\mathrm{A}_{1}$ nicht sichtbar und häufig ohne Makrotrichienbesatz [seltener mit 1 bis 2 Matrotrichien]; hintere Flügeladern mit Makrotrichien. Halteren mit gelbem Halterenstiel und dunklem Halterenkopf. Coxen und Beine gelb, Tarsen angedunkelt; Vordertibienende mit großem Fleck aus palisadenartig angeordneten, hellen Borsten und mit bogenförmiger Berandung. Klauen ungezähnt. Abdomen: hell und dunkel gebändert, dunkle Tergite mit gelben basalen und apikalen Rändern und gleichfarbigen Intersegmentalmembranen; Sternite gelblich. Gonocoxite gelb, Gonostyli einheitlich braun; ventrale Innenseiten der Gonocoxite kurz und spärlich behaart; Basalhälfte des Gonostylus daumenförmig verbreitert und mit einem kräftigen Dorn auf lobusförmigem Sockel; Stylusspitze mit kräftigem Zahn und 4 kürzeren Dornen [2 Dorne 
über und 2 Dorne unter dem Zahn]; Genitalplatte membranös und hoch gerundet; Aedeagus mäßig lang und dünn. Größe: 1,8-2,1 mm.

오. Bekannt [3 우 ㅇi im PWMP]. Größe: 2,4 mm.

Bemerkungen: Diese kleine Art ist durch die leuchtend gelben Bänder am Abdomen und die gelben Bereiche des Thorax auffallend kontrastreich. In Verbindung mit der starken Behaarung des Mesonotums ist sie durch das zweifarbige Hypopygium und den daumenförmigen Fortsatz in der basalen Hälfte des Gonostylus gekennzeichnet. Die Exemplare aus Texas (USA) haben dunklere Fühlergrundglieder und ein etwas dunkleres Mesonotum durch die Verschmelzung der Lateralflecken mit dem Mittelstreif. Sie stimmen aber in allen anderen Merkmalen mit den untersuchten Exemplaren aus Mittelamerika überein. Pseudos. delectata (WILlisTON) ist in der Körperfärbung und im Bau der Gonostyli Pseudos. helleri [= debilis (Williston, 1896); praeocc.] sehr ähnlich und unterscheidet sich von dieser vor allem durch die fehlende Makrotrichienreihe auf der Analader $A_{1}$, gedrungenere Gonostyli und schlankere Fühlergeißelglieder.

\section{Pseudosciara (Pseudosciara) forceps (PETTEY, 1918)}

(Fig. 21 a-f)

Locus typicus: »Florida, at Palatka« [= Florida, Putnam Co., bei Palatka] (USA).

Holotypus: ${ }^{\star}$, Typ.-Nr. 207, 3.5.-4.5.1916, leg. BrAdLEY (CUIC).

= Pseudosciara aitkeni LANE 1959 syn. nov. - Rev. Bras. Biol., 19(3): 289 und 290; 293, Fig. 1-2.

Locus typicus: »Trinidad (B. W. I.)« [= British West Indies, Trinidad], Navy Base (Trinidad und Tobago).

Holotypus: ơ, Reg.-Nr. 13.691, Dezember 1955, leg. Aitken (MZSP).

Paratypen: $6 \sigma^{\top} \sigma^{-}$, Reg-Nr. 13.692-13.693 und 13.78313.784, gleiche Funddaten (BMNH, MZSP) [nicht untersucht!].

Weiteres Material: $1 \sigma^{\star}$, Expl.-Nr. 2598, New York, Ithaca (USA), 1.9.1940, leg. Johannsen (CUIC); 5 ๙ $^{\star}$, Prov. Guanacaste, Santa Rosa National Park (Costa Rica), $10,95^{\circ} \mathrm{N} 85,62^{\circ} \mathrm{W}, 27.9 .-18 \cdot 10.1986\left[3 o^{*} o^{*}\right]$ und 18.10. 8.11.1986 [2 $\left.\sigma^{\star} \sigma^{\star}\right]$, alle leg. Gould \& JANZEN (PWMP).

Erhaltungszustand: Beim Holotypus von Pseudos. aitkeni LANE fehlen nur die Fühlergeißelglieder 9 bis 14 bzw. 13 bis 14. Einige Dorne an den Gonostyli sind abgebrochen. Alle anderen Körperteile sind in gutem Zustand (umpräpariert in Kanadabalsam). Der Holotypus von Sciara forceps Pettey lag als Dauerpräparat vor. Das Genital ist gut erhalten.

Literatur: Pseudosciara aitkeni LANE - AMORIM (1992): 64 [nec sensu Mohrig in Mohrig et al. (2004): 271; 313, Fig. 4 a und c; Fehlbestimmung, = Pseudosciara

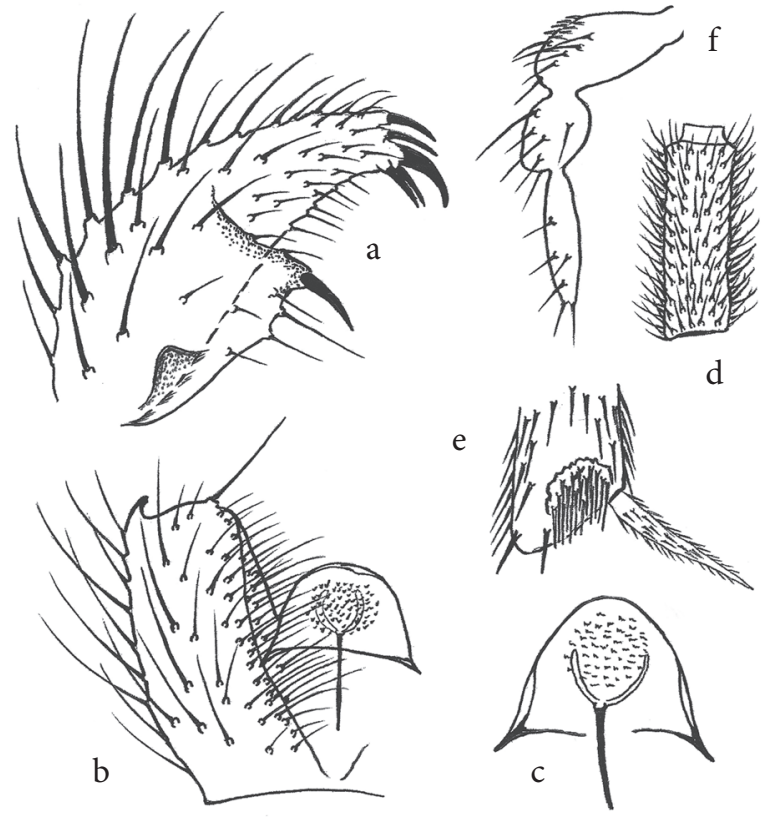

Fig. 21 a-f: Pseudosciara forceps (Pettey), o : - a: Gonostylus ventral, Holotypus von Pseudosciara aitkeni LANE; - b: Genitalplatte, Aedeagus und ventralseitige Beborstung der linken Gonocoxite von einem ơ aus Costa Rica (PWMP); - c: Genitalplatte und Aedeagus ventral von einem ot aus Costa Rica (PWMP); - d: 4. Fühlergeißelglied von einem $\sigma^{\top}$ aus Costa Rica (PWMP); - e: Vordertibienende von einem $\sigma^{t}$ aus Costa Rica (PWMP); - f: Palpus lateral von einem ơ aus Costa Rica (PWMP).

helleri Menzel]. Sciara forceps Pettey - Pettey (1918): 320 und 328; Taf. 30, Fig. 1; Taf. 31, Fig. 32; - Stone \& LAFFoON (1965): 230; - STEFFAN (1966): 44 und 52. Pseudosciara forceps (Pettey) - Mohrig et al. (2013): 231-233; Fig. 50 a-f.

Redeskription: $\sigma^{\top}$. Kopf: Prefrons und Augenhinterrand gelblich, Ocellenregion dunkel. Augenbrücke 3-reihig. Fühlergrundglieder und 1. Fühlergeißelglied gelbbraun, alle anderen Geißelglieder dunkler; 4. Fühlergeißelglied 2,9-3,4 mal so lang wie breit; Halsteile gut abgesetzt, leicht zweifarbig; Behaarung etwas länger als die halbe Geißelgliedbreite. Palpen 3-gliedrig. Thorax: Mesonotum im vorderen Drittel gelb, mittlerer und hinterer Teil sowie Scutellum dunkel [bei den Exemplaren aus Costa Rica gesamtes Mesonotum gelblich-braun gefärbt], alle übrigen Sklerite der Thoraxseiten gelb. Flügel hell; $\mathrm{R}_{1}$ relativ kurz, = 3/4 R; C länger als $1 / 2 \mathrm{w}$; $\mathrm{y}=\mathrm{x}$, beide mit Makrotrichien; hintere Flügeladern mit Makrotrichien; Analader $A_{1}$ nicht sichtbar und ohne Makrotrichien. Halteren mit hellem Halterenstiel und dunklem Halterenkopf. Coxen und Beine hell, Tarsen leicht angedunkelt; Vordertibienende mit großem Fleck aus palisadenartig angeordneten, hellen Borsten und mit bogenförmiger Berandung. Klauen ungezähnt. Abdomen: dunkelbraun; 1. Tergit gelb, 4. und 5. Tergit mit gelblichen Aufhellungen; Sternite gelblich. Gonocoxite gelb, ventrale Innenseiten lang und dicht behaart; Gonostyli zur Spitze dunkler, die Basalhälfte des Gonostylus daumenförmig verbreitert 
und mit kräftigem Mitteldorn; Stylusspitze mit kräftigem Zahn und 4 etwas kürzeren Dornen [2 Dorne über und 2 Dorne unter dem Zahn]; Genitalplatte membranös und hoch gerundet; Aedeagus relativ lang. Größe: 2,2-2,5 mm. ․ Unbekannt.

Bemerkungen: Die Art ist durch das im hinteren Teil dunkle Mesonotum [ohne Streifen] bei sonst einheitlich gelbem Thorax, die gelben Coxen und Beine, das gelbe 1 . Abdominaltergit sowie die gelbfleckigen 4 . und 5. Tergite gut charakterisiert. Ein wichtiges Bestimmungsmerkmal ist die lange und dichte Behaarung an den ventralen Innenseiten der Gonocoxite, die innerhalb der Gattung nur sehr selten auftritt. Der Holotypus von Pseudos. aitkeni LANE stimmt mit dem Holotypus von Pseudos. forceps (Pеттеу) und den anderen Exemplaren aus Costa Rica vollständig überein.

\section{Pseudosciara (Pseudosciara) hirtella SCHINER, 1866} (Fig. 22 a-c; Tafel 2, Fig. G)

Locus typicus: Venezuela [nec »Columbien«; Diskussion siehe unter Bemerkungen].

Holotypus: $0^{\star}, 1864$, leg. LINDIG (NHMW).

Weiteres Material: $10^{\star}$, Prov. Sucumbios, Sacha Lodge (Ecuador), $00,50^{\circ} \mathrm{S} 76,50^{\circ} \mathrm{W}, 270 \mathrm{~m}$ ü. NN, Malaisefallenfang, 4.5.-14.5.1994, leg. Нiввs (SDEI).

Erhaltungszustand: Bei dem untersuchten Exemplar fehlen die Fühlergeißelglieder und der Thorax ist deformiert. Die Coxen, beide Flügel, das Abdomen und das Hypopygium sind gut erhalten. Außerdem existiert nur noch ein Vorderbein ohne Klauen (in Kanadabalsam umpräpariert, 2 Präparate). Aus diesem Grund wurde die Redeskription auf der Basis eines zweiten ơ aus Ecuador ergänzt [siehe weiteres Material].

Literatur: Pseudosciara hirtella SCHINER - SCHINER (1866): 930-931; - EDWARDS (1934): 367; - LENGERSDORF (1940): 247-248; - LENGERSDORF (1942): 98-99; - LANE (1959b): 289 und 294-295; - AMORIM (1992): 64.

Redeskription: $0^{t}$. Kopf: dunkelbraun, Palpen und Mundteile heller, aber deutlich gebräunt; Prefrons grob und dunkelbraun beborstet. Augenbrücke 3-reihig, in der Mitte 2-reihig. Fühlergrundglieder dunkelbraun; Fühlergeißel dunkelbraun, auch die letzten Geißelglieder; 4. Fühlergeißelglied 3,0 mal so lang wie breit; Basalteil dicht, grob, abstehend und dunkel behaart, mit sehr kurzen und feinen Sensillen; Behaarung etwa 3/4 mal so lang wie die Gliedbreite; Halsteil kurz, breiter als hoch, scharf abgesetzt und apikal etwas stärker gebräunt. Palpen lang und 3-gliedrig; Grundglied hochrückig verdickt, mit 8 bis 11 Borsten und mit dunkler, scharf berandeter Sensillengrube; 2. und 3. Glied schlank, beide so lang wie das Grundglied oder 2. Glied nur 2/3 mal so lang wie das Grundglied. Thorax: Meso-

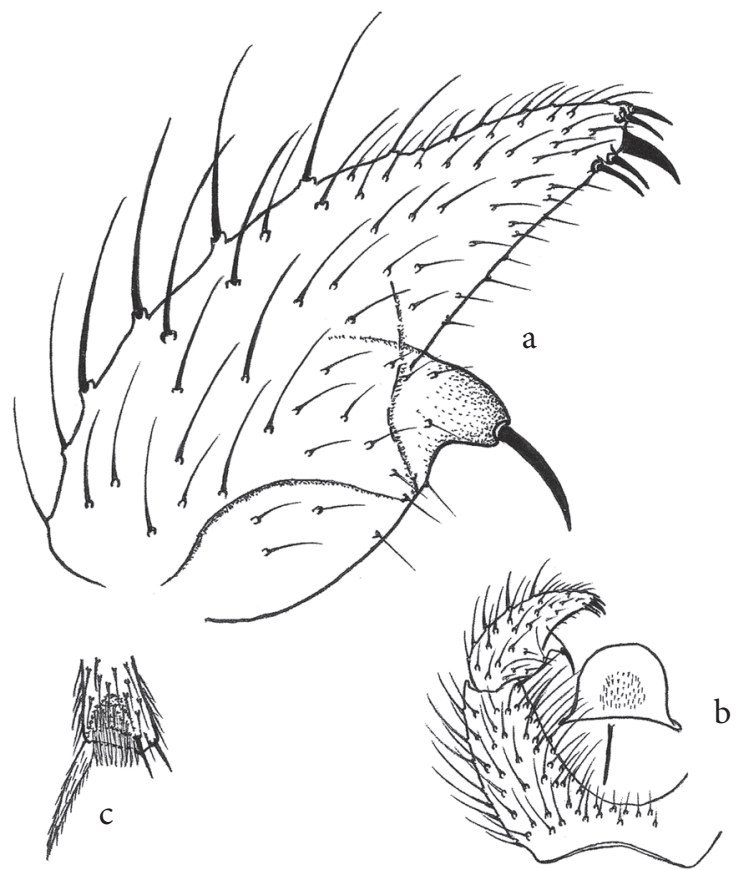

Fig. 22 a-c: Pseudosciara hirtella Schiner, Holotypus $0^{*}$. - a: Gonostylus ventral; - b: Linke Seite des Hypopygiums mit Genitalplatte und Aedeagus; - c: Vordertibienende.

notum braun, Schulterecken und zwei schmale Seitenstreifen heller gelbbraun; Mesonotum mit kräftig-langen zentralen und lateralen Borsten [lateral mit 8 bis 9 dunklen, in einer Reihe angeordneten Borsten vor der Flügelbasis]; kürzere Behaarung des Mesonotums spärlich, kurz und dunkel. Scutellum, Mediotergit und Metanotum dunkel; Pleuralsklerite einfarbig dunkel. Katepisternit hoch-dreieckig und dunkelbraun, nur an der Spitze etwas gelblich aufgehellt. Scutellum gut abgesetzt, mit 4 kräftig-langen Randborsten. Flügel groß und recht hell, aber deutlich gebräunt; Analfeld groß und gut ausgebildet; Flügelmembran ohne Makrotrichien; hintere Flügeladern vollständig mit Makrotrichien besetzt [CuA-Stiel nur an der Basis zu 2/5 unbeborstet]; M-Gabel sehr lang und schmal, etwa so lang wie der M-Stiel; M-Gabel vollständig sowie die Hälfte von $\mathrm{CuA}_{1}$ und $\mathrm{CuA}_{2}$ mit beidseitigem Makrotrichienbesatz [alle anderen Bereiche mit einseitig dorsaler Makrotrichienreihe]; Analader $\mathrm{A}_{1}$ nicht sichtbar, ohne Makrotrichienbesatz oder nur angedeutet mit 1 bis 2 Makrotrichien; R-R1-Aderkomplex sehr lang, nur wenig vor der M-Gabelbasis in c mündend; $R_{1}$ und $\mathrm{R}_{5}$ vollständig mit beidseitigem Makrotrichienbesatz; $\mathrm{R}_{1}=0,9 \mathrm{R} ; \mathrm{y}=1,5 \mathrm{x}$, beide vollständig mit Makrotrichien [x einseitig dorsal und y beidseitig]; CuA-Stiel lang, $=1,5 \mathrm{y} ; \mathrm{C}=1 / 2 \mathrm{w}$. Halteren kurz gestielt, mit weißlichgelbem Halterenstiel und dunkelbraunem Halterenkopf. Beine kräftig und sehr lang; Coxen und Femora gelb, in starkem Kontrast zum dunkelbraunen Thorax und Abdomen; Tarsen der $p_{1}$ bis $p_{3}$ vollständig bzw. spätestens ab der Mitte des 1. Gliedes gebräunt; alle Tibien mit langen und dunklen Spornen; Sporne an den $\mathrm{p}_{2}$ und $\mathrm{p}_{3}$ etwa gleichlang; Tibien der Vorderbeine mit groben, dunklen Dörnchen in der Grundbehaarung; Spitze der Vordertibia 
mit großem, scharf berandeten Borstenfleck [dieser fast so breit wie die Tibienspitze], alle Borsten hell und fast in einer Reihe stehend [darüber nur mit wenigen Borsten unterhalb der Berandung]. Klauen ungezähnt. Abdomen: Tergite und Sternite einheitlich dunkelbraun, Abdominalsegmente lang, kräftig und dunkel behaart. Hypopygium dunkelbraun, nur die innere Membran und die Genitalbasis gelbbraun aufgehellt; ventrale Genitalbasis ohne Basallobus oder basale Borstengruppen; Gonostyli nicht dunkler als die Gonocoxite; ventraler Innenrand der Gonocoxite von der Basis bis zur Spitze hin länger werdend behaart; ventrale Basis des Hypopygiums breit und geschlossen; Gonostyli zur Spitze stark verschmälert, in der unteren Hälfte mit daumenförmig breiter Basis und mit gleichmäßig nach innen-unten gebogenem Mitteldorn [dieser auf einer lobusförmig hohen Basis stehend]; Stylusspitze zugespitzt und spärlichlicht beborstet; an der Spitze mit kräftigem, gebogenem Zahn und mit 4 groben Dornen auf kurzen Sockeln [alle Dorne kürzer als der Zahn; 2 Dorne über und 2 Dorne unter dem Zahn stehend]; Innenseite der Gonostyli dorsal flach ausgerandet, ventral in der basalen Hälfte lobusartig verdickt; Gonostylus auf der lobigen Basis des Innendorns mit einer längeren Borste, die über dem Dorn inseriert; am ventralen Innenwinkel unterhalb des Dornlobus mit 3 bis 4 längeren, geraden Borsten. Genitalplatte sklerotisiert, hoch gerundet und fast so hoch wie breit; Zähnchenfeld sehr groß und rundlich; Zähnchen einspitzig, basal sehr grob und apikal sehr fein. Aedeagus relativ lang und dünn, mit breit-halbkreisförmiger Basis. Größe: 2,9-3,5 mm.

․ Unbekannt.

Bemerkungen: Pseudosciara hirtella Schiner ist die Typusart der Gattung Pseudosciara Schiner. In der Originalbeschreibung gibt SchINeR (1866: 931) den Fundort mit "Columbien" an, was nicht korrekt ist. Denn auf den Etiketten des einzigen, in der Sammlung SCHINER (NHMW) befindlichen Exemplars findet man die Aufschrift »hirtella, Alte Sammlung / Lindig, 1864, Venezuela / Type«. Es wird vermutet, dass SCHINER den Fundort bei seiner Niederschrift noch dem bis 1830 existierenden, historischen Staatsgebilde »República de la Gran Colombia« [= Großkolumbien] zugeschrieben hat, zu dem neben dem heutigen Kolumbien und Venezuela auch noch die Staaten Ecuador und Panama sowie Teile von Peru und Guyana gehörten.

Pseudos. hirtella Schiner zählt zu den Pseudosciara-Arten mit einem auffallend großen, daumenförmig abgesetzten Fortsatz in der Stylusmitte, der in einen Mitteldorn endet. Charakteristisch sind auch der dunkle Thorax, das ebenfalls einheitlich dunkle Abdomen mit kaum hellerem Hypopygium und die kurze C. Edwards (1934: 367) hat die Art offensichtlich als letzter mit anderen Pseudosciara-Arten verglichen. Dahingegen kannte LANE (1959b) den Holotypus offensichtlich nicht, hat aber 58 Exemplare als Pseudos. hirtella identifiziert. AмоRIM (1992) gibt den Typus als verschollen an, da er ihn im
NHMW nicht gefunden hat. Wenn die Determination von LANE korrekt ist, wofür seine Redeskription und der Gonostylus-Vergleich mit Pseudos. nigricolor (ENDERLEIN) sprechen, dann ist Pseudos. hirtella SCHINER von Argentinien über Brasilien und Venezuela bis nach Trinidad und Tobago verbreitet.

\section{Pseudosciara (Pseudosciara) humeropicta (LENGERS-} DORF, 1931)

(Fig. 23 a-b)

Locus typicus: Rio de Janeiro (Brasilien).

Holotypus: 우 12.10.1893, ohne Angabe des Sammlers (MLUH).

Weiteres Material: $1 \sigma^{\star}$, Prov. Sucumbios, Sacha Lodge (Ecuador), 00,50 ${ }^{\circ} \mathrm{S} 76,50^{\circ} \mathrm{W}, 270 \mathrm{~m}$ ü. NN, Malaisefallenfang, 4.5.-14.5.1994, leg. НiвBs (PWMP); $10^{\star}, 7.7 .1996$, Prov. Esmaraldas, Bilsa, Biologische Station, $00,34^{\circ} \mathrm{N}$ 79,71 ${ }^{\circ} \mathrm{W}$, leg. Hibis (PWMP).

Erhaltungszustand: Vom Holotypus sind Kopf, Thorax, Flügel, Coxen, Beine und Abdomen gut erhalten. Die Fühlergeißeln fehlen (umpräpariert in Kanadabalsam).

Literatur: Megalosphys (Chaetomegalosphys) humeropicta LENGERSDORF - LENGERSDORF (1931): 253-254; Abb. 2. Pseudosciara humeropicta (Lengersdorf) - LANE (1959b): 288; - AMORIM (1992): 64.

Redeskription: + . Kopf: dunkel, einschließlich Mundpartie und Palpen. Augenbrücke 3 bis 4-reihig. Fühlergrundglieder bräunlich; Fühlergeißelglieder im Präparat fehlend [nach LENGERSDORF (1931: 253) 1. Geißelglied = 2,0 mal so lang wie breit]. Palpen 3-gliedrig und braun; Grundglied hochrückig verdickt, mit 5 bis 6 Borsten [davon eine längere Außenborste] und mit großer, vertiefter Sensillengrube; 2. Palpenglied länglich-oval und 3. Glied stabförmig schlank. Thorax: Mesonotum dunkel, mit 3 angedeuteten dunkleren Streifen; Präscutum etwas

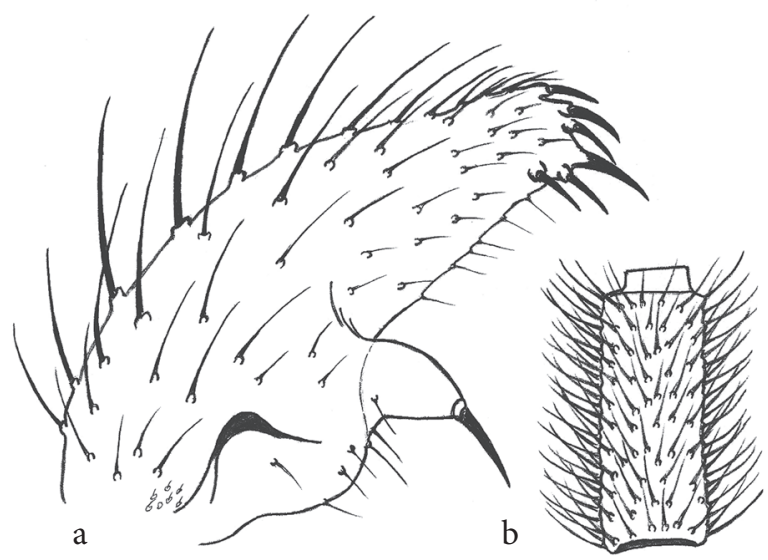

Fig. 23 a-b: Pseudosciara humeropicta (LENGERSDORF), $\sigma^{*}$ aus Costa Rica (PWMP):-a: Gonostylus ventral; - b: 4. Fühlergeißelglied. 
heller; Scutellum, Mediotergit und Metanotum einheitlich dunkel; Pleuralsklerite einschließlich Katepisternit einheitlich dunkelbraun; nur Postpronotum, präthorakales Episternit und Flügelbasis heller; Mesonotum mit starken, dunklen lateralen Borsten und auch zentral kräftig behaart; Scutellum mit 4 starken Randborsten; Postpronotum nackt. Flügel leicht rauchig; $\mathrm{R}_{1}$ lang, $=4 / 5 \mathrm{R}$ und kurz vor der M-Gabelbasis in c mündend; $C=3 / 5 \mathrm{w}$; y kurz, = $1 / 2 \mathrm{x}$, beide mit Makrotrichien; M-Gabel lang und schmal; $M_{1}$ und Spitzenhälfte der $M_{2}$ schwach sklerotisiert; CuA-Stiel lang und in der distalen Häfte beborstet, = 1,2 x; Analader $\mathrm{A}_{1}$ nicht sichtbar und ohne Makrotrichien; hintere Flügeladern mit Makrotrichien. Halteren mit gelbem Halterenstiel und dunklem Halterenkopf. Coxen gelb; Vorder- und Mittelbeine gelbbräunlich, Femora der Hinterbeine dunkler, Tarsen angedunkelt; Vordertibienende mit großem Fleck aus nahezu palisadenartig angeordneten, hellen Borsten und mit bogenförmiger Berandung. Klauen ungezähnt. Abdomen: Tergite einheitlich dunkel, Sternite nur unwesentlich heller. Größe: 3,2 mm.

${ }^{\star}$. Kopf: Ocellenregion und Hinterhaupt schwärzlichdunkelbraun; Gesicht, Palpen und Mundteile etwas heller. Augenbrücke 4-reihig. Fühler einheitlich braun; 4. Fühlergeißelglied 2,6-2,8 mal so lang wie breit, kürzer als breit und abstehend behaart; Halsteil sehr kurz und einfarbig braun; Palpen 3-gliedrig, 3. Glied kürzer als 1. und 2. Glied zusammen. Thorax: Mesonotum schwarzbraun, angedeutet 3-streifig; Präscutum etwas heller; Scutellum, Mediotergit und Metanotum sowie alle Pleuralsklerite dunkelbraun [nur Feld am mesothorakalen Spiraculum und Flügelansatz hell]. Flügel leicht gebräunt; $\mathrm{R}_{1}=\mathrm{R}$ und in Höhe der M-Gabelbasis in $\mathrm{c}$ mündend, $\mathrm{C}=1 / 2 \mathrm{w} ; \mathrm{y}=\mathrm{x}$, beide mit Makrotrichien; M-Gabel lang und schmal, $M_{1}$ und Spitzenhälfte der $\mathrm{M}_{2}$ schwach sklerotisiert; CuA-Stiel lang; alle hinteren Flügeladern mit Makrotrichien. Halterenkopf dunkel. Coxen gelb, Femora bräunlich [der Femur der $\mathrm{p}_{3}$ etwas dunkler]; Tibien und Tarsen angedunkelt; Vordertibienende mit palisadenartig-hellem und bogig berandetem Borstenfleck. Klauen ungezähnt. Abdomen: alle Tergite und Sternite sowie Hypopygium braun; ventrale Innenseiten der Gonocoxite lang, aber nicht dicht behaart; Gonostyli basal mit daumenförmigem Fortsatz, der in einen lobusförmigen Sockel mit Mitteldorn mündet; Stylusspitze verschmälert, mit Spitzenzahn und 5 kürzeren Dornen [davon 3 Dorne oberhalb und 2 Dorne unterhalb des Spitzenzahns]. Genitalplatte gerundet. Aedeagus relativ lang und sklerotisiert. Größe: 3,0 mm.

Bemerkungen: Die beiden $\sigma^{\star} \sigma^{\star}$ aus Ecuador stimmen in der Körperfärbung, der langen $R_{1}$, der kurzen $C$ sowie in der schmalen und schwach sklerotisierten M-Gabel mit dem Holotypus gut überein. Diese dunkle Art ist gewissermaßen eine kleinere Ausgabe von Pseudos. nigricolor (ENDERLEIN) sensu LANE. Nach den vorliegenden Beschreibungen wird explizit auf den „blackish“ Femur der $\mathrm{p}_{3}$ hingewiesen, so dass die Zuordnung der Männ- chen gesichert erscheint. Die in der Gonostylusbedornung ebenfalls ähnliche Pseudos. willistoni [= concinna (Williston, 1896); praeocc.] unterscheidet sich von Pseudos. humeropicta durch ein schlankeres 4. Fühlergeißelglied mit längerem und deutlich zweifarbigem Halsteil sowie einen basal schlankeren Gonostylus mit kräftigerem Spitzenzahn und schmalerem Sockel des Mitteldorns.

\section{Pseudosciara (Pseudosciara) /uteicoxa (ENDERLEIN, 1911) \\ (Fig. 24 a-c)}

Locus typicus: »Santa Catharina« [= Estado de Santa Catarina] (Brasilien).

Lectotypus: $0^{\star}$, leg. LÜDERWALdT (MZPW) [des. AMORIM (1992): 64].

Paralectotypen: $2 o^{\star} o^{\star} 5$ 우 + , gleiche Funddaten (MZPW) [nicht untersucht!].

Weiteres Material: $2 \sigma^{\star} o^{\star}$, Prov. Limon, Pococi, Braulio Carrillo National Park, Estancion Quebrada Gonzales (Costa Rica), 400-500 m ü. NN, Malaisefallenfang, 21.8.2002, leg. Hansson \& Godoy (PWMP); 1 주 2 우 우, Prov. Sucumbios, Sacha Lodge (Ecuador), 00,50 $\mathrm{S}$ $76,50^{\circ} \mathrm{W}, 270 \mathrm{~m}$ ü. NN, Malaisefallenfänge, 4.5.-14.5.1994 [1 o ]; 3.7.-13.7.1994 [1 o ] und 21.11.-1.12.1996 [1 ㅇ], alle leg. Нiввs (PWMP).

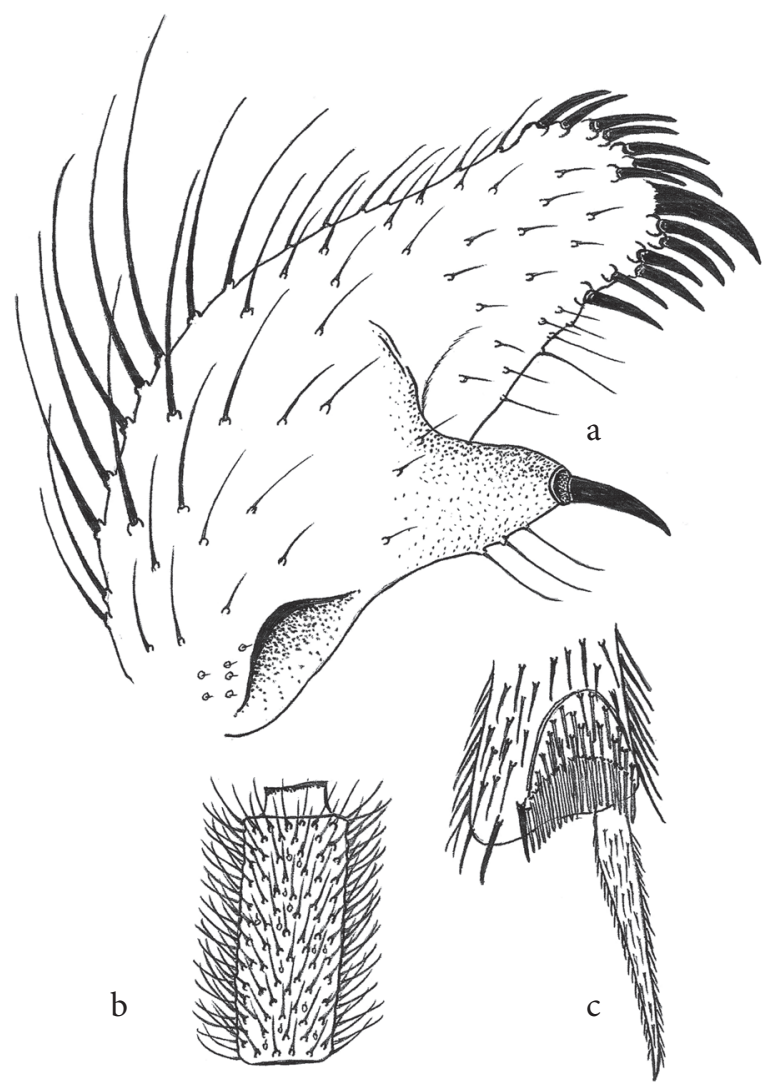

Fig. 24 a-c: Pseudosciara luteicoxa (Enderlein), o $0^{*}$ aus Ecuador (PWMP): - a: Gonostylus ventral; - b: 4. Fühlergeißelglied; - c: Vordertibienende. 
Erhaltungszustand: Bei dem untersuchten Lectotypus ist der Kopf mit den Palpen, den Fühlergrundgliedern und den Fühlergeißelgliedern 1 bis 3 vorhanden. Der Thorax ist etwas deformiert. Die Coxen und Femora der $\mathrm{p}_{1}$ bis $\mathrm{p}_{3}$, eine Hintertibia und ein Vorderbein mit Tarsen und Klauen sind erhalten. Der hintere Flügelrand incl. Analfeld ist ab der $\mathrm{CuA}_{1}$ zerstört. Das Genital ist hingegen vollständig erhalten und befindet sich in einem sehr guten Zustand (umpräpariert in Kanadabalsam).

Literatur: Megalosphys luteicoxa ENDERLEIN - ENDERLEIN (1911): 130-131; Taf., Fig. 4-5; - EDWARDs (1931): 78; - EdWARDS (1934): 367; - LENGERSDORF (1930a): 55; - Lengersdorf (1940): 247; - LENGERSDORF (1942): 98. Pseudosciara luteicoxa (ENDERLEIN) - LANE (1959b): 289 und 295; - AMORIM (1992): 64.

Redeskription: ${ }^{\star}$. Kopf: dunkelbraun und partiell geschwärzt, Ocellenregion und Hinterhaupt schwarzbraun; Gesicht, Palpen und Mundteile wenig heller. Augenbrücke 4 bis 5-reihig. Fühler dunkelbraun, Grundglieder etwas heller; 4. Fühlergeißelglied 2,5-2,7 mal so lang wie breit, dicht und kurz behaart [etwa so lang wie die Hälfte der Gliedbreite]; Halsteil kurz und dunkelbraun, am Ende stärker gebräunt; Palpen 3-gliedrig und braun; Grundglied mit mehreren Borsten und mit großem, scharf berandetem und leicht vertieftem Sensillenfeld; 3. Palpenglied dünn, etwa so lang wie das Grundglied. Thorax: Mesonotum dunkelbraun, mit lateralen Aufhellungen; Präscutum und Seiten des Scutellums etwas heller; Mediotergit, Metanotum und Pleuralsklerite dunkelbraun [nur postthorakales Episternit etwas heller]. Flügel leicht gebräunt; $\mathrm{R}_{1}=1,4 \mathrm{R}$ und etwas vor der M-Gabelbasis in $\mathrm{C}$ mündend; $\mathrm{M}$-Stiel etwas länger als die schlanke M-Gabel; $\mathrm{C}=1 / 2 \mathrm{w} ; \mathrm{y}=0,8-1,0 \mathrm{x}$, beide mit Makrotrichien; CuA-Stiel lang, =1,4-1,5 x; alle hinteren Flügeladern mit Makrotrichien; Analader $A_{1}$ mit einer Makrotrichienreihe. Halteren dunkel. Coxen gelb, Femora dunkelbraun; Spitze der Vordertibia mit dichtem und bogenförmig berandetem Borstenfleck; Borsten bräunlich und in der unteren Hälfte des Tibienfleckes breit-bogenförmig, palisadenartig angeordnet. Klauen ungezähnt. Abdomen: Tergite, Sternite und Hypopygium einheitlich dunkelbraun; ventrale Innenseiten der Gonocoxite lang und nicht auffällig dicht behaart; Gonostylus in der ventralen Basishälfte mit breitem, daumenförmigem Fortsatz, der in einen kurzen Mitteldorn endet; Spitze des Gonostylus mit kräftigem Spitzenzahn und mit 12 bis 13 kürzeren Dornen [6 (seltener 7) Dorne über und 6 Dorne unter dem Zahn]; Genitalplatte klein, deutlich breiter als hoch, braun sklerotisiert und gerundet. Zähnchenfeld groß und rundlich, mit groben und einspitzigen Zähnchen. Aedeagus lang, mit breiter und halbkreisförmiger Basis. Größe: 3,7 mm.

․ Die 4 Weibchen aus Ecuador (PWMP) stimmen in der Körperfärbung und den Flügelmerkmalen mit den beiden $\sigma^{x} o^{x}$ vom gleichen Fundort und dem Lectotypus aus Brasilien überein. Größe: 4,2 mm.
Bemerkungen: Pseudosciara luteicoxa (ENDERLEIN) ist die Typusart von Megalosphys. Edwards (1934: 367) hat die Typen untersucht und auf dessen Basis Megalosphys Enderlein, 1911 richtigerweise mit Pseudosciara SCHiner, 1866 synonymisiert. Die Art ist durch ihre Größe, die dunkle Körperfärbung, die kurzen Fühlergeißelglieder mit kurzer Behaarung, die kurze C, die Makrotrichienreihe auf der Analader $\mathrm{A}_{1}$, den daumenförmigen Fortsatz an den Gonostyli und vor allem durch die vielen Dorne neben dem Spitzenzahn charakterisiert. Sie gehört damit in die Nähe von Pseudos. pedunculata (ENDERLEIN), wenn man LANE (1959b: 297) in der Zuordnung des $\sigma^{*}$ folgt.

\section{Pseudosciara (Pseudosciara) melanocephala}

(FABRICIUS, 1805)

(Fig. $25 a-b)$

Locus typicus: »America meridionali« [= Südamerika]. Syntypen: $1 \sigma^{\star}$, ohne weitere Daten, leg. SMIDT (? ZMUC); $1 \mathrm{o}^{*}$, ohne weitere Daten, leg. DE Sehestedt (? ZMUC) [beide nicht untersucht!].

Weiteres Material: $10^{\star}$ ex Coll. LoEw, Reg.-Nr. 10902, "Surinam« (Suriname), ohne weitere Funddaten (ZMHB); 2 우 을 Fonteboa, Rio Negro (Brasilien), ohne Funddatum, leg. von RöDER, det. LENGERSDORF (MLUH, SDEI).

Erhaltungszustand: Das $\sigma^{*}$ aus Suriname (ZMHB), welches RüBSAAMEN (1894) zur Redeskription vorlag, ist in einem guten Zustand. Der Kopf mit Fühlergeißeln und Palpen, der Thorax mit allen Beinen und beiden Flügeln sowie das Abdomen mit dem Hypopygium sind vollständig erhalten. Durch die alte Präparationsweise [in Glycerin und unter Glas] ist das ganze Tier stark abgeplattet und die Körperfärbung etwas verblasst. Präparativ bedingt, gibt es am Hypopygium [besonders an den Gonostyli] Deformationen. Ein Flügel ist separat eingebettet. Die beiden $q$ $q$ aus Brasilien sind ebenfalls recht gut erhalten. Bei einem + (SDEI) fehlen die Fühlergei-

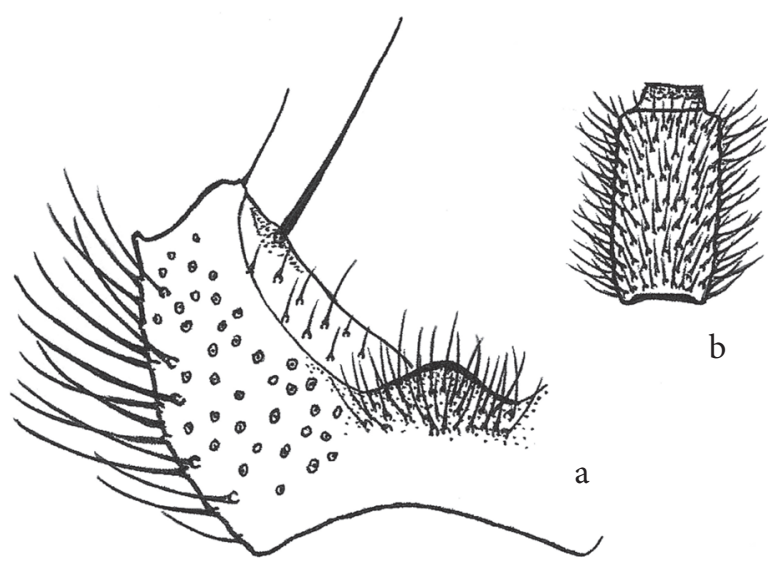

Fig. 25 a-b: Pseudosciara melanocephala (FABricius), o aus Suriname (ZMHB). - a: Basis des Hypopygiums und linke Gonocoxite ventral; - b: 4. Fühlergeißelglied. 
ßeln. An beiden Exemplaren fehlen zudem je 2 Beine. Zwei bzw. drei Beine und jeweils ein Flügel wurden separat eingebettet (alle umpräpariert in Kanadabalsam).

Literatur: Sciara melanocephala FABRICIUS - FABRICIUS (1805): 60; - WiedemANN (1821): 33-34; - WiedeMANN (1828): 69. Trichosia melanocephala (FABRICIUS) - RüBsaAmen (1894): 23-24, Fig. 1; Taf. 3, Fig. 21; - LANE (1946):353; - LANE (1955): 255 und 257. Megalosphys melanocephala (FABRICIUS) - ENDERLEIN (1911): 135. Trichomegalosphys melanocephala (FABRICIUs) - LANE (1953): 256-257; Fig. 1; - AMORIM (1992): 67-68; - VILKAMAA \& Hippa (2004): 4, 8, 21 und 23-24 [nec Pseudos. melanocephala (RÜBSAAMEN) [recte (FABRICIUs)] sensu MoHrig Mohrig (2003): 31-32; Fig. 22 a-c; - Mohrig \& Menzel (2009): 282, Fig. 16.18; alle Fehlbestimmung, = bisher unbeschriebene Pseudosciara-Spezies].

Redeskription: $\sigma^{\star}$. Kopf: dunkelbraun, Palpen und Mundteile gelblich. Augenbrücke 4-reihig. Fühler basal dunkelbraun, zur Spitze hin heller werdend; die letzten 3 Geißelglieder depigmentiert und dadurch weißlichgelb aufgehellt; Grundglieder dunkelbraun; 4. Fühlergeißelglied 2,3 mal so lang wie breit, dicht, fein und kurz behaart; Behaarung etwa 1/2 mal so lang wie die Gliedbreite; Halsteil kurz und breit, leicht zweifarbig; Palpen 3-gliedrig; Grundglied und 2. Glied hochrückig; Grundglied mit mehreren langen Borsten und mit großem, vertieftem Sensillenfeld; Endglied schlank, etwa 1,5 mal so lang wie das verdickte 2 . Glied. Thorax: Mesonotum gelbbraun, gelb und relativ lang [aber fein] behaart; Scutellum und Mediotergit gelblich; Pleuralsklerite einfarbig gelblich; Scutellum mit 4 kräftiglangen Randborsten; Flügel bräunlich, am Vorderrand zwischen der Costa und $\mathrm{R}_{5}$ stärker gebräunt; Flügelbasis mit großem, gut ausgebildetem Analfeld; gesamte Flügelmembran mit Ausnahme der vorderen Flügelbasis mit Makrotrichien [nur von der CuA-Gabelbasis über die rs-Querader bis zur Costa unbeborstet]; alle Vorder- und Hinteradern dicht mit Makrotrichien besetzt [nur R, die distale Hälfte des CuA-Stiels und 1/3 von x mit einseitig dorsalem Makrotrichienbesatz; alle anderen Flügeladern beidseitig beborstet]; Analader $\mathrm{A}_{1}$ braun ausgefärbt und mit sehr dichtem Makrotrichienbesatz [ventral mehrreihig beborstet, dorsal mit einer Makrotrichienreihe]; $\mathrm{R}_{1}=1,1 \mathrm{R}$ und deutlich hinter der M-Gabelbasis in $\mathrm{c}$ mündend; M-Stiel etwas länger als die schlanke M-Gabel; $\mathrm{y}=0,6$ bis 1,0 x, beide dicht mit Makrotrichien; CuAStiel lang, = 1,3-1,4 x, nur die basale Hälfte unbeborstet; C sehr kurz, $=2 / 5 \mathrm{w}$. Halteren kurz gestielt und gelblich. Beine lang und kräftig; Coxen und Femora gelbbraun, Tibien und Tarsen dunkler [mit deutlichem Kontrast zu den hellen Coxen und Femora]; Spitze der Vordertibien mit großem, berandetem Borstenfleck, Borsten hell und in der unteren Hälfte palisadenartig dicht angeordnet. Klauen ungezähnt. Abdomen: Tergite und Sternite gelb, diese sehr lang und gelb behaart; Hypopygium und die letzten beiden Abdominalsegmente dunkelbraun, die
Tergite dunkel und am Hinterrand dicht behaart; Gonocoxite basal gelblich, Ventralseite ungewöhnlich lang und dicht behaart; ventrale Genitalbasis durch eine lobusartig breite, dicht und lang behaarte Brücke geschlossen; Gonostyli länglich-rund, über dem Mitteldorn zur Spitze nicht deutlich verschmälert; Stylusspitze mit kräftigem Spitzenzahn und 4 bis 5 Dornen [2 Dorne über und 2 bis 3 kürzere Dorne unter dem Zahn]; Genitalplatte klein, nur wenig kürzer als breit und an der Spitze etwas ausgerandet [dadurch fast viereckig]; Genitalplattenränder wulstartig mit einer ventralen Membran versteift, die die gesamte Genitalplattenspitze umschließt und über einen senkrechten Mittelsteg mit der Genitalplattenbasis verbunden ist; Zähnchenfeld klein und rundlich, mit grob-einspitzen Zähnchen Aedeagus relativ lang und kräftig, mit kurzhalbkreisförmiger Basis. Größe: 4,5 mm.

ㅇ. Kopf rundlich und braun, mit gelblichem Gesicht; Thorax und Abdomen rötlich-gelb; vorletztes Abdominalsegment zur Hälfte oder ganz gebräunt, letztes Abdominalsegment und Cerci braun; Scapus und Pedicellus dunkelbraun; Fühlergeißeln basal dunkelbraun, ab dem 5. oder 6. Geißelglied depigmentiert und dadurch weißlich-gelb gefärbt; 4. Fühlergeißelglied 3,2 mal so lang wie breit, mit sehr kurzem Halsteil [dieses etwa $1 / 2$ mal so hoch wie breit]. Flügel breiter und stärker gebräunt; CuA-Stiel etwas länger, $=1,4$ bis 1,7 mal so lang wie $\mathrm{x} ; \mathrm{C}=1 / 2 \mathrm{w}$; alle anderen Merkmale wie beim ๑. Größe: 4,0-4,6 mm.

Bemerkungen: Die beiden untersuchten $\circ$ ㅇ aus Brasilien stimmen in der Körperfärbung und Flügeladerung [einschließlich Makrotrichienbesatz auf den Flügeladern] mit dem ơ überein. Pseudos. melanocephala (FABRICIUs) ist aufgrund ihrer Größe, der gelben bis rötlich-gelben Färbung von Thorax und Abdomen, der hellen Körperbehaarung, des dunklen Kopfes und der dunklen Abdomenspitze eine sehr auffällige Pseudosciara-Art. Charakteristisch für das ơ sind die fast viereckige Genitalplatte mit ventraler Mittelmembran sowie die breite, dicht behaarte und lobusartig vorgewölbte Brücke zwischen den ventralen Innenseiten der Gonocoxite [= flach-konisch zugespitzer Basallobus mit dichtem und recht langem Borstenbesatz]. Beide Merkmale sind recht ungewöhnlich, weil diese Strukturen bei keiner anderen Pseudosciara-Art zu finden sind. Auch die Gonostyli weichen von der typischen Stylusform dadurch ab, dass sie auf der Innenseite vom Mitteldorn bis zur Stylusspitze nicht deutlich verschmälert sind. Die Art wurde von Mohrig (2003: 31) nicht richtig interpretiert, so dass Trichosia ribeiroi LANE fälschlich zum Synonym zu Pseudos. melanocephala (FABRICIUs) erklärt wurde [vergleiche hierzu auch mit der Diskussion bei Pseudos. ribeiroi]. Von Amorim (1992: 68) wird mit bicolorata LENGERSDORF, 1930 nur noch eine andere »Trichosia«-Art mit angeblich neotropischer Verbreitung aufgelistet, die jedoch zur Gattung Metangela RüBSAAMEN gehört [weitere Anmerkungen siehe dort]. 
Pseudosciara (Pseudosciara) muricata (LENGERSDORF, 1926)

(Fig. 26 a-b)

Locus typicus: "Süd-Peru, Sivia« [= Prov. Ayacucho, Sivia; kleiner Ort linksseits des Amazonas östlich von Pichari] (Peru).

Neotypus: $0^{\top}$ [2 Präparate] ex Coll. Lengersdorf, Sam.Nr. 710, Eingangs-Nr. 1-1937, Hamburger Süd-PeruSammelreise 1936, $520 \mathrm{~m}$ ü. NN, gestreift beim Hause, an niederem Gestrüpp und über der Erde, Kescherfang, 26.5.1936, ohne Angabe des Sammlers (ZFMK) [hier designiert].

Begründung: Der Originalbeschreibung von LENGERsDORF (1926: 167) lagen mindestens $10^{\star}$ und 1 ㅇ zugrunde. Der Autor beschreibt in derselben Arbeit 4 südamerikanische Arten. Nur bei Megalosphys muricata LENGERSDORF gibt er keine Daten zur Typenserie bekannt [genauere Angaben über Umfang des Materials, zum locus typicus, zu den Sammelumständen, zum Funddatum und zum Kollektor fehlen in der Beschreibung von Meg. muricata LENGERSDORF vollständig]. Lediglich aus der sehr kurzen Einleitung geht hervor, dass das Material - möglicherweise auch das von Meg. muricata LENGERSDORF - von P. BORGMEIER in Brasilien gesammelt worden ist. Die unfigurierte und recht oberflächlich abgefasste Originalbeschreibung reicht heute in der artenreichen Gattung nicht mehr aus, um Meg. muricata LENGERSDORF zweifelsfrei von anderen Pseudosciara-Arten mit sehr ähnlichen Genitalstrukturen abzutrennen. Das Typenmaterial konnte jedoch in keinem der aufgelisteten Museen aufgefunden werden und fehlt auch in der Sammlung des Autors (ZFMK). AMORIM (1992: 64) konnte die Syntypen auf seiner Europa-Reise ebenfalls nicht finden und vermerkt diesen Sachverhalt im Katalog der neotropischen Sciariden mit "not located". Aus den vorstehend genannten Gründen gehen wir davon aus, dass das Typenmaterial von Meg. muricata LENGERSDORF in Zukunft nicht mehr beigebracht werden kann und führen hier zur Stabilisierung des Namens einen Neotypus ein. Zu diesem Zweck wurde von uns das einzig verfügbare $0^{*}$ aus der Sammlung des Autors (ZFMK) ausgewählt, welches vom südamerikanischen Festland stammt, dessen Fundort dem ursprünglichen locus typicus (? Brasilien) am Nahesten kommt und auf das die LENGERSDORFsche Beschreibung passt. Der Neotypus wurde in der Kollektion von Franz Lengersdorf am Forschungsmuseum Alexander Koenig in Bonn (ZFMK) deponiert.

Weiteres Material: 1 i ex Coll. Lengersdorf, Sam.Nr. 725, gleiche Funddaten wie der Neotypus (ZFMK); $67 \sigma^{\star} \sigma^{\top}$ und 13 ㅇ ㅇ , Prov. Puntarenas, Jaco (Costa Rica), Gartenanlage mit Palmen in Küstennähe, Gelbschalenfang, 24.8.-30.8.1996, leg. Mohrig (64 o o $o^{\star} 11$ 우 우 PWMP; $3 o^{\star} o^{\star} 2$ 우 ㅇ SDEI); $1 \sigma^{\star}$, Prov. Sancti Spíritus, Sierra de la Escambray, bei Topes de Collantes (Kuba), 25.4.1992, leg. StARK (SDEI).

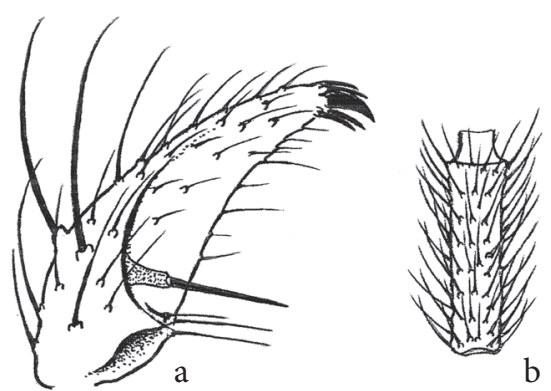

Fig. 26 a-b: Pseudosciara muricata (Lengersdorf), $0^{\top}$ aus Costa Rica (PWMP): - a: Gonostylus ventral; - b: 4. Fühlergeißelglied.

Erhaltungszustand: Beim Neotypus sind Kopf, Fühlergrundglieder und Fühlergeißelglieder 1 bis 4, Thorax, Flügel, Coxen, Beine, Teile des Abdomens und das Hypopygium gut erhalten (umpräpariert in Kanadabalsam).

Literatur: Megalosphys muricata LENGERSDORF Lengerdorf (1926): 167-168. Pseudosciara (Megalosphys) muricata (LeNGersdorf) - LENGERdorf (1941): 205. Pseudosciara muricata (LENGERSDORF) - AMORIM (1992): 64 .

Redeskription: ${ }^{\star}$. Kopf: sehr dunkel, nur Mundpartie und Palpen gelb. Augenbrücke 2 bis 3-reihig. Fühler mit sehr dunklen Grundgliedern und braunen Fühlergeißeln; Fühlergeißelglieder lang und schlank; 4. Fühlergeißelglied 4,0 bis 4,4 mal so lang wie breit; grobe Behaarung auf dem Basalteil länger als die Gliedbreite; Halsteil kurz, scharf abgesetzt und dunkelbraun, durch den apikal stärker gebräunten Ring etwas zweifarbig; Palpen 3-gliedrig, gelblich bis deutlich gebräunt; Grundglied hochrückig, mit 3 bis 6 Borsten und mit kleinem, vertieftem Sensillenfeld. Thorax: Mesonotum, Scutellum und Mediotergit einheitlich dunkel; Pleuralsklerite überwiegend dunkel [nur Postpronotum, präthorakales Episternit und Flügelbasis gelblich]; Mesonotum mit starken dunklen Borsten, lateral und auch zentral kräftig behaart; Scutellum mit 4 starken Randborsten; Postpronotum nackt. Flügel leicht rauchig; $\mathrm{M}$-Stiel deutlich länger als die schlanke M-Gabel; $\mathrm{R}_{1}$ kurz, $=2 / 5$ bis $1 / 2 \mathrm{R} ; \mathrm{C}=2 / 3 \mathrm{w} ; \mathrm{y}=0,7 \mathrm{x}$; $\mathrm{y}$ vollständig und $\mathrm{x}$ distal bis zur Hälfte mit Makrotrichien; CuA-Stiel lang, = 1,4 bis 1,5 x; Analader A nicht sichtbar und ohne Makrotrichien; hintere Flügeladern mit Makrotrichien. Halteren mit gelbem Halterenstiel und dunklem Halterenkopf. Coxen und Beine gelb, Tarsen angedunkelt; Vordertibienende mit großem Fleck aus palisadenartig angeordneten, hellen Borsten und mit bogenförmiger Berandung. Klauen ungezähnt. Abdomen: mit dunklen Tergiten und nur wenig helleren Sterniten, nur Intersegmentalmembran gelblich. Gonocoxite überwiegend gelb, Gonostyli einheitlich braun; ventrale Innenseiten der Gonocoxite kurz und spärlich behaart; Gonostyli lang, schmal und unmittelbar an der Basis eckig verbreitert; ventrale Seite des Gonostylus weiträumig mit einem bogenförmigen Ausschnitt, in dem nahe der Basis ein stilettartig langer Mitteldorn steht; Stylus- 
spitze mit einem kurzen, breiten Zahn und mit 4 kürzeren, dünneren Dornen [2 Dorne über und 2 Dorne unter dem Zahn]; Genitalplatte membranös und breit gerundet. Aedeagus mäßig lang und dünn. Größe: 1,8-2,3 mm. ․ . Siehe LENGERSDORF (1926): 167. Größe: 2,0-2,7 mm.

Bemerkungen: Diese kleine Art ist durch die dunkle Körperfärbung mit dunklen Fühlern, sehr langen Fühlergeißelgliedern und dem auffallend langen, nahe der Stylusbasis inserierenden Mitteldorn sehr gut gekennzeichnet. Die Syntypen von Meg. muricata LENGERSDORF konnten weder von LANE noch von AMORIM aufgefunden werden. Auch in der Sammlung Lengersdorf (ZFMK) gibt es keinen Hinweis auf deren Verbleib [teste Menzel in 1993, 1997, 2007]. Das einzige, in der Sammlung LENGERSDORF vorhandene Männchen wurde 1936 in Peru gesammelt und von LENGERSDORF handschriftlich als Pseudosciara muricata etikettiert. Dieses Exemplar stimmt in allen Merkmalen mit den Männchen aus Costa Rica und Kuba überein [siehe weiteres Material].

\section{Pseudosciara (Pseudosciara) neotropica LANE, 1959} (Fig. 27 a-b)

Locus typicus: "State of S. Paulo« [= Estado de São Paulo], Campos do Jordão (Brasilien).

Holotypus: ${ }^{\star}$, Reg.-Nr. 13.738, Dezember 1955, leg. LANE (MZSP).

Paratypen: $2 \sigma^{\star} o^{\star}$, gleiche Fundort wie der Holotypus, Dezember 1945 und Januar 1954, leg. LANE; 3 o $^{\star}$, " Boracéa " [= Estado de São Paulo, Município de Salesópolis, Boracéia] (Brasilien), November 1947, leg. RabELlo; $2 o^{\star} o^{\star}$, »Cantareira « [= Estado de São Paulo, São Paulo, Cantareira] (Brasilien), August 1945, leg. LANE; $10^{\text {T, }}$ "State of Rio de Janeiro, Itatiaia" [= Estado de Rio de Janeiro, Itatiaia südwestlich von Resende] (Brasilien), August 1945, leg. Barretto (Reg.-Nr. 13.739-13.743; BMNH, MZSP) [alle nicht untersucht!].

Weiteres Material: $3 \sigma^{\star} \sigma^{\star}$, Prov. Olancho, Parque National La Muralla [15 km nordwestlich von La Unión]

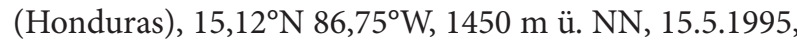
leg. Cordero (PWMP); 4 đ o ๙ $^{\star}$ Prov. Cortés, 5 km nördlich von Buenos Aires, »Parque National Cusunco« [= Parque National Montaña de Cusuco, nordöstlich von

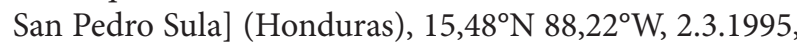
leg. Cordero (PWMP); $40^{\star} 0^{\star}$, Prov. Francisco Morazán, Cerro Uyuca [= Berg ca. $15 \mathrm{~km}$ südöstlich von Tegucipalpa], San Antonio de Oriente (Honduras), $14,03^{\circ} \mathrm{N}$ 87,07º W, 6.2.1995, leg. CORDERo (PWMP).

Erhaltungszustand: Am Holotypus fehlen nur eine Fühlergeißel und einige Fußglieder an den $\mathrm{p}_{2}$ und $\mathrm{p}_{3}$. Außerdem ist die Kopfkapsel frontal eingedrückt und ein Flügel in Höhe der $\mathrm{R}_{1}$-Einmündung beschädigt. Alle anderen Körperteile [Thorax, der zweite Flügel, alle Coxen, Femora und Tibien, Abdomen und Hypopygium] sind sehr gut erhalten (umpräpariert in Kanadabalsam).
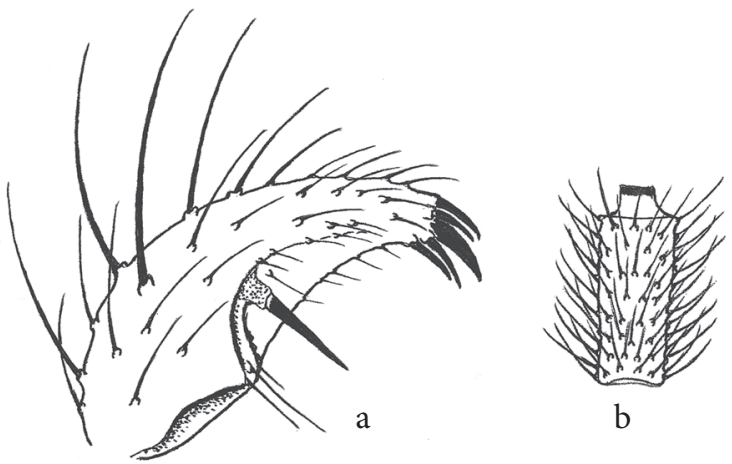

Fig. 27 a-b: Pseudosciara neotropica LANe, Holotypus $0^{\star}$ : a: Gonostylus ventral; - b: 4 . Fühlergeißelglied.

Literatur: Pseudosciara neotropica LANE - LANE (1959b): 289 und 295-296; 293, Fig. 8-9; - AMORIM (1992): 64.

Redeskription: $\sigma^{\top}$. Kopf: Prefrons, Mundpartie und Palpen sowie unterer Augenhinterrand gelblich-braun; Ocellenregion und Hinterkopf dunkel. Augenbrücke 3-reihig. Fühlergrundglieder und erstes Fühlergeißelglied heller als die folgenden Glieder, aber deutlich gebräunt; Fühlergeißelglieder lang; Halsteile kurz, gut abgesetzt und zweifarbig; 4. Fühlergeißelglied 2,7 mal so lang wie breit; Behaarung borstig abstehend und etwa so lang wie die Gliedbreite. Palpen 3-gliedrig; Grundglied etwas hochrückig, mit 5 Borsten und mit kleinem, grubig vertiefem Sensillenfeld; 2. Glied 3/5 mal so lang wie das längliche Grundglied; Endglied schlank und doppelt so lang wie das 2. Glied. Thorax: Mesonotum im vorderen Drittel und lateral gelb, im mittleren Bereich mit je einem scharf begrenzten, dunklen Lateralfleck und mit dunklem Mittelstreif; Scutellum und Mediotergit zentral dunkel; Pleuralsklerite gelb-bräunlich, mit einem diffusen, dunkleren Band oberhalb des Katepisternits; Scutellum mit 4 starken Randborsten; Postpronotum nackt. Flügel hell; $\mathrm{R}_{1}$ lang, $=0,9 \mathrm{R}$ und deutlich vor der M-Gabelbasis in c mündend; $C=3 / 5 \mathrm{w}$; $\mathrm{y}=1,1 \mathrm{x}$, beide vollständig mit Makrotrichien; hintere Flügeladern mit Makrotrichien [nur basale Hälfte des CuA-Stiels unbeborstet]; CuA-Stiel lang, = 1,4 x; Analader $A_{1}$ nicht sichtbar und ohne Makrotrichien. Halteren mit hellem Halterenstiel und dunklem Halterenkopf. Coxen und Beine gelb, Tarsen leicht angedunkelt; Vordertibienende mit großem Fleck aus palisadenartig angeordneten, hellen Borsten und mit bogenförmiger Berandung. Klauen ungezähnt. Abdomen: braun, mit gelblichen Aufhellungen am 1. und an der Basis des 4. und 5. Tergits; Intersegmentalmembranen gelblich; Sternite gelblich-braun. Gonocoxite gelb, Gonostyli dunkel; ventrale Innenseiten der Gonocoxite kurz behaart; ventrale Basis des Gonostylus breit eckig abgesetzt, apikal zugespitzt und in der Mitte der Innenseite mit einem kräftigen Dorn auf schlankem Sockel; Stylusspitze mit relativ langem Zahn und 4 etwas kürzeren Dornen 2 Dorne über und 2 Dorne unter dem Zahn]; Genitalplatte membranös und hoch gerundet, 
nur an der Genitalplattenspitze etwas abgeflacht. Aedeagus dünn. Größe: 2,3 mm.

‥ Unbekannt.

Bemerkungen: Die Art ist von Pseudos. cariba LANE nur ganz schwer zu unterscheiden, weil zwischen beiden nur wenige morphologische Unterschiede bestehen. Pseudos. neotropica LANE ist etwas größer und die zwei dunklen Lateralflecken sowie der Mittelstreif auf dem gelben Mesonotum sind schärfer konturiert. Außerdem sind im Gegensatz zu Pseudos. cariba die Fühlergeißelglieder kürzer, die $\mathrm{R}_{1}$ im Verhältnis zur M-Gabel länger, die Gonostyli insgesamt dunkler und die Basis des Mitteldorns ist etwas schmaler und kürzer.

Pseudosciara (Pseudosciara) pubescens (MoRgante, 1969) comb. nov.

(Fig. 28 a-c)

Locus typicus: State of São Paulo [= Estado de São Paulo], Estrada da Capela km 18, Taiaçupeba, Mogi das Cruzes (Brasilien).

Holotypus: ${ }^{\star}$, Februar 1968, leg. SCHNEIDER (MZSP) [nicht untersucht!].

Paratypen: $100^{*} \sigma^{*} 10$ 우, gleiche Funddaten (MZSP) [davon $20^{\top} o^{\star}$ untersucht].

Erhaltungszustand: Uns lagen 2 Paratypen aus dem MZSP vor. Bei einem $\sigma^{*}$ befinden sich am Kopf nur noch die ersten 3 bzw. 4 Geißelglieder. Die anderen Geißelglieder sind abgebrochen und wurden - soweit noch vorhanden - separat eingebettet. Ein Flügel ist unterhalb der M-Gabel stark beschädigt. Das zweite $o^{\top}$ ist besser erhalten, hat aber nur noch 4 Beine. Von beiden Exemplaren wurden Flügel und Genitalien separat eingebettet (umpräpariert in Kanadabalsam).

Literatur: Trichosia pubescens Morgante - Morgante (1969): 572; 573, Fig. 1; 575, Fig. 5-7; - Malavasi et al. (1976): 363-370; Fig. 1-4; - AMABIS et al. (1979): 200-212; Fig. 1-13; - BüSEN et al. (1982): 247-260; Fig. 1-8; Amabis (1983): 416-422: Fig. 1-4; - Laicine et al. (1984): 282; - LARA (1987): 125-126; - ? FUGE (1994): 299-311; Fig. 1-8; - EsteBAn et al. (1997): 721-723, 727 und 729; - ? Fuge (1997): 85-93; Fig. 1-5; - Penalva et al. (1997): 169-171; Fig. 7; - ? FUGE (1999): 191-200; Fig. 1-7; - Goday \& Esteban (2001): 242-245; - Serna et al. (2004): 907-918; Fig. 1-7 und 9-10; - Siviero et al. (2006): 115, Fig. 5; - STOCKER et al. (2006): 286; - MADALENA et al. (2007): 410-412 und 414; Fig. 1 a-c. Trichomegalosphys pubescens (Morgante) - AMORIM (1992): 68; - AMORIM \& Rindal (2007): 76, Fig. 104; - ANDRIOLI et al. (2008): 76-83; Fig. 1-5; - MAdalena et al. (2008): 1233-1239; Fig. $1 \mathrm{~d}$ und $2 \mathrm{~b}$.

Redeskription: $0^{\star}$. Kopf: dunkelbraun, einschließlich Palpen und Mundteile. Augenbrücke 4 bis 5-reihig. Fühler einheitlich braun; 4 . Fühlergeißelglied 2,8 mal so

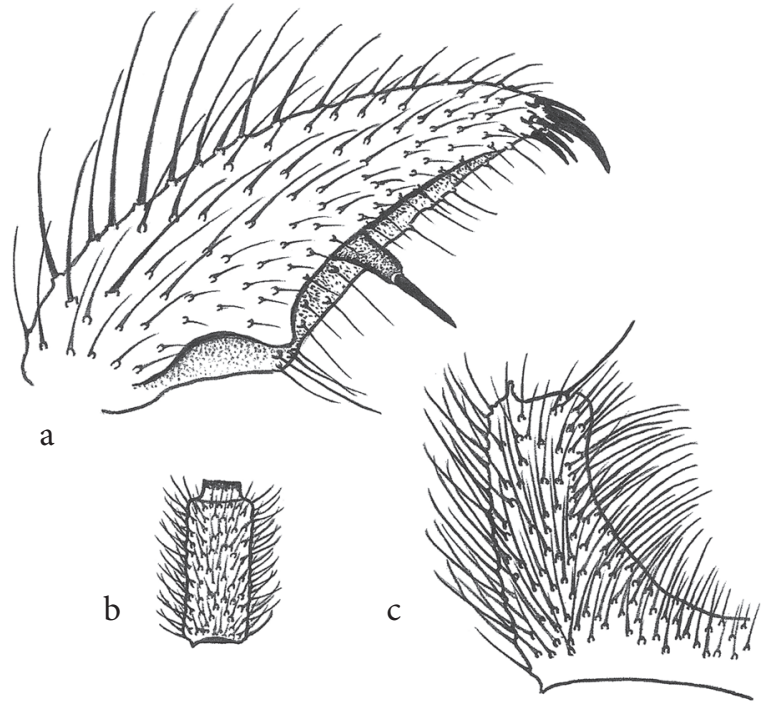

Fig. 28 a-c: Pseudosciara pubescens (Morgante), Paratypus $o^{\top}:-$ a: Gonostylus ventral, - b: 4. Fühlergeißelglied; - c: Linke Gonocoxite ventral.

lang wie breit, dicht und fein behaart; Fühlerbehaarung abstehend und etwa halb so lang wie die Gliedbreite; Halsteil kurz, leicht zweifarbig; Palpen 3-gliedrig und dunkelbraun, Grundglied verdickt, mit zahlreichen groben Borsten und mit großem, leicht vertieftem Sensillenfeld; 2. Glied lang-stabförmig, etwa so lang wie das Grundglied; Endglied schlank, = 1,5 mal so lang wie das 2. Glied. Thorax: Mesonotum schwärzlich, nur ein schmaler Seitenstreif etwas heller; Scutellum und Mediotergit zentral dunkler, Pleuralsklerite dunkelbraun, fast schwärzlich. Flügel am Vorderrand zwischen Costa und $\mathrm{R}_{5}$ stark gebräunt; $\mathrm{R}_{1}=0,8-0,9 \mathrm{R}$, deutlich vor der M-Gabelbasis in $\mathrm{c}$ mündend, $\mathrm{M}$-Stiel deutlich kürzer als die sehr lange M-Gabel; $C=2 / 5$ bis $1 / 2 \mathrm{w} ; \mathrm{y}=1,0-1,2 \mathrm{x}$, beide vollständig mit Makrotrichien; CuA-Stiel lang, =1,5 x; hinteren Flügeladern mit Makrotrichien [nur basale Hälfte von CuA-Stiel und M-Stiel unbeborstet]; etwa die vordere Hälfte der Flügelmembran und einige basale Bereiche des Membranrandes mit Makrotrichien [Costalzelle und basale Flügelhälfte etwa von der Querader r-s bis zur Einmündung von $\mathrm{CuA}_{2}$ in den Flügelrand ohne Makrotrichienbesatz]; Analader $\mathrm{A}_{1}$ bräunlich ausgefärbt und mit einer Makrotrichienreihe [ausgedehnt mit 10 bis 18 Makrotrichien]. Halteren kurz gestielt und dunkel. Coxen und Beine dunkelbraun, nicht heller als die Pleuralsklerite; Femora dicht und lang behaart; Spitze der Vordertibien mit bogig berandetem Borstenfleck, Borsten hell und in der unteren Hälfte palisadenartig dicht angeordnet. Klauen ungezähnt. Abdomen: Tergite, Sternite und Hypopygium einheitlich dunkelbraun; ventrale Basis des Hypopygiums breit geschlossen; ventrale Innenseiten der Gonocoxite dicht und lang behaart; Gonostyli basal verbreitert, unterhalb der Mitte etwas eckig abgesetzt und apikal zugespitzt; ventrale Innenseite in der Mitte mit einem geraden Dorn auf schmalem, dunklem Sockel; Stylusspitze mit Spitzenzahn und 4 kürzeren Dornen [2 Dorne unter und 2 Dorne über bzw. neben dem Zahn]; 
Genitalplatte sklerotisiert und hoch gerundet; Zähnchenfeld sehr groß und breit, mit groben und einspitzigen Zähnchen. Aedeagus lang und dünn, mit einer flachen und breiten Basis. Größe: 4,8-5,4 mm.

ㅇ. Siehe Morgante (1969): 572.

Bemerkungen: Die Redeskription wurde anhand der untersuchten Paratypen $\left[2 o^{\star} o^{\star}\right]$ angefertigt. Beide Präparate tragen keine Fundortetiketten, sind als "Bradysia pubescens sp. n. / J. S. Morgante det.« etikettiert und besitzen Paratypen-Zettel. Von Амоrim (1992) wurde die Art zusammen mit antunesi (LANE), melanocephala (FABRICIUS) und ribeiroi (LANE) zur Gattung Trichomegalosphys ENDERLEIN gestellt. Als Begründung galt wahrscheinlich der dichte Makrotrichienbesatz auf der Flügelmembran, was für Trichomegalosphys aber kein unikales Merkmal ist. Alle 4 Arten gehören zweifelsfrei zum Genus Pseudosciara Schiner. Von der Typusart des Genus Trichomegalosphys ENDERLEIN, 1911 restit. lag uns ein Typexemplar zum Vergleich vor [Trichom. funesta ENDERLEIN, 1911; Syntypen: 2 ㅇ $q$ von der Insel Sumatra (Indonesien) / = Trichom. laticornis (WALKER, 1857) comb. nov.; Synonymie in EDWARDs (1928)]. Diese Typusart ähnelt Pseudosciara ScHINER durch den langen $\mathrm{CuA}$-Stiel und den Makrotrichienbesatz auf den hinteren Flügeladern, unterscheidet sich aber durch ein beborstetes Postpronotum, einen großen und völlig unberandeten Borstenfleck an den Vordertibien sowie kurze Palpen mit nur einer starken Außenborste auf dem Grundglied. Die Gattung Trichomegalosphys ENDERLEIN gehört dem entsprechend nicht zur neotropischen Fauna und ist zurzeit nur aus der orientalischen Region bekannt. In der Gattung Pseudosciara zeichnet sich Pseudos. pubescens (Morgante) durch den dichten Makrotrichienbesatz in der vorderen Hälfte der Flügelmembran aus. Von anderen Arten mit Makrotrichien auf der Flügelmembran und vergleichbarem Stylusbau unterscheidet sie sich durch die einheitlich dunkle, fast schwärzliche Körperfärbung.

\section{Pseudosciara (Pseudosciara) pygmaea (ENDERLEIN, 1911) \\ (Fig. 29 a-b)}

Locus typicus: "Santa Catharina« [= Estado de Santa Catarina] (Brasilien).

Lectotypus: $\sigma^{*}$, leg. LÜDERWALdT (MZPW) [des. Amorim (1992): 65] [nicht untersucht!].

Paralectotypen: $190^{\top} o^{\star}$ und 1 우, gleiche Funddaten wie der Lectotypus (MZPW) [nicht untersucht!]; $10^{\star}$, Mus.-Nr. G 1376, gleiche Funddaten (ZMHB); $10^{*}$, ohne Mus.-Nr., gleiche Funddaten (ZMHB).

Weiteres Material: $4 \sigma^{\star} \sigma^{\star}$, Prov. Sucumbíos, Sacha Lodge (Ecuador), 0,50 ${ }^{\circ} \mathrm{S} 76,50^{\circ} \mathrm{W}, 270 \mathrm{~m}$ ü. NN, Malaisefallenfang, 4.5.-14.5.1994, leg. HiвBs; $14 \sigma^{\top} o^{\star}$, gleiche Funddaten, Malaisefallenfang, 3.7.-13.7.1994, leg. Нiввs (17 o o $^{*}$ PWMP; 1 o SDEI).

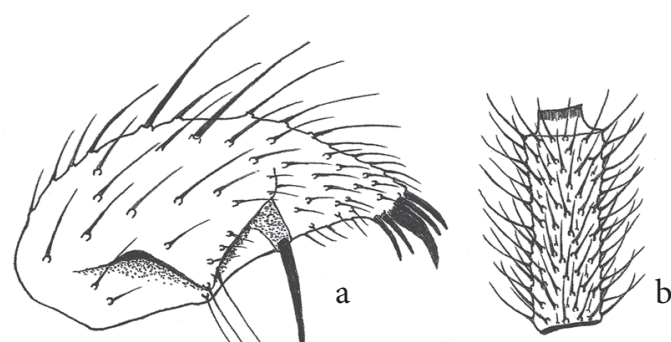

Fig. 29 a-b: Pseudosciara pygmaea (ENDERLEIN), Paralectotypus $\mathrm{o}^{\mathbf{t}}$ : - a: Gonostylus ventral; - b: 4 . Fühlergeißelglied.

Erhaltungszustand: Bei einem der untersuchten Paralectotypen mit der Mus.-Nr. G 1376 (ZMHB) sind Kopfkapsel, Thorax, Coxen, Beine und Abdomen in gutem Zustand. Das Hypopygium ist leicht deformiert [mit übereinander liegenden Gonostylusspitzen und abgebrochenem Basaldorn am linken Gonostylus]. Die beiden Flügel sind am basalen Analfeld, an der Flügelspitze oder an der Costa beschädigt. Von den beiden Fühlern sind nur noch Scapus, Pedicellus sowie das 1. und 2. Fühlergeißelglied erhalten. Außerdem fehlen von einem Vorderbein die Tibia und die Fußglieder. Das andere $\sigma^{\star}$ aus dem ZMHB [Paralectotypus ohne Mus.-Nr.] ist ähnlich erhalten. Hier sind die Flügelspitzen beschädigt und bei 3 Beinen der $\mathrm{p}_{1}$ bis $\mathrm{p}_{3}$ fehlen die Fußglieder. Außerdem sind die Palpen und die Fühlergeißelglieder 3-14 bzw. 7-14 nicht mehr vorhanden. Im Gegensatz dazu befindet sich das Genital in einem ausgezeichneten Zustand (beide $o^{\star} o^{\star}$ umpräpariert in Kanadabalsam).

Literatur: Megalosphys pygmaea ENDERLEIN - ENDERLEIN (1911): 134-135; - LENGERSDORF (1930a): 55. Megalosphys (Pseudosciara) pygmaea ENdERLEIN - LENGERSDORF (1942): 99. Pseudosciara pygmaea (ENDERlein) LENGERSDORF (1940): 249; - LENGERSDORF (1941): 205; - LANE (1959b): 288 und 297; - AMORIM (1992): 65.

Redeskription: $\sigma^{\star}$. Kopf: Prefrons und Mundpartie gelblich, Augenhinterrand bräunlich, Ocellenregion dunkel. Augenbrücke 3-reihig, in der Mitte 2-reihig. Fühlergeißeln braun, Grundglieder und erstes Fühlergeißelglied etwas heller; 4. Fühlergeißelglied 3,0 mal so lang wie breit, grob und abstehend behaart; Basalteile rauh und mit langen, gebogenen Sensillen; Halsteile kurz und zweifarbig [apikal dunkelbraun beraucht]; Behaarung dicht und etwas länger als die Gliedbreite. Palpen lang und 3-gliedrig; Grundglied mit mehrern Borsten und mit kleinem, vertieftem Sensillenfeld; 2. Glied länglichoval, etwa 4/5 mal so lang wie das schlanke Endglied. Thorax: Mesonotum braun, zentral etwas dunkler; Präscutum heller; Frontpartie des Scutellums, Mediotergit und Pleuralsklerite bräunlich; Katepisternit und postthorakales Episternit gelb; Postpronotum nackt. Flügel hell; $\mathrm{R}_{1}=4 / 5 \mathrm{R}$; R- $\mathrm{R}_{1}$-Aderkomplex relativ kurz, dadurch $\mathrm{R}_{1}$ deutlich vor der $\mathrm{M}$-Gabelbasis in $\mathrm{c}$ mündend; $\mathrm{C}=2 / 3 \mathrm{w} ; \mathrm{y}=0,7$ bis $0,9 \mathrm{x}$, beide vollständig mit Makrotrichien besetzt; M-Gabel kürzer als der M-Stiel; 
CuA-Stiel = 1,2 bis 1,3 x; Analader $\mathrm{A}_{1}$ nicht sichtbar und ohne Makrotrichien. Halteren kurz gestielt, mit gebräuntem Halterenkopf. Coxen und Femora gelb, Tibien und Tarsen angedunkelt; Vordertibienende mit großem Fleck aus palisadenartig angeordneten, hellen Borsten und mit bogenförmiger Berandung. Klauen ungezähnt. Abdomen: Tergite braun; 4. und 5. Tergit basal mit schmaler, gelblicher Aufhellung; Sternite gelblich-braun. Gonocoxite gelblich, ventral mit kurz und spärlich behaarten Innenseiten; Gonostyli braun, bauchig, apikal zugespitzt, in der Mitte der Innenseite mit einem dunklen Mitteldorn auf schmalem und relativ hohem Sockel; Stylusspitze mit kräftigem Zahn und 4 etwas kürzeren Dornen [2 Dorne über und 2 Dorne unter dem Zahn]; Genitalplatte membranös, fast so hoch wie breit und gerundet; Zähnchenfeld groß und rundlich, mit grob-einspitzigen Zähnchen. Aedeagus lang und dünn, mit trichterförmig breiter Basis. Größe: 2,0-2,6 mm

ㅇ. Siehe ENDERLEIN (1911): 134.

Bemerkungen: Die Typenserie von ENDERLEIN umfasst $22 \sigma^{\top} \sigma^{\star}$ und 1 , a a der uns $2 \sigma^{\top} \sigma^{\star}$ aus dem ZMHB vorlagen, die von ENDERLEIN handschriftlich als "Type ausgezeichnet waren. Amorim (1992) hat aus dem deutlich größeren Materialfundus im MZPW einen Lectotypus $\left(\sigma^{\star}\right)$ designiert, ohne dass er sich zuvor einen Gesamtüberblick über alle Syntypen verschafft hat. Aus seinem Katalog geht nicht hervor, wie viele Paralectotypen sich wirklich im MZPW befinden und ob das gesamte Typenmaterial - in Übereinstimmung mit dem Lectotypus - tatsächlich zu Pseudos. pygmaea (ENDERLEIN) gehört. Die Art ist durch den kräftig-kurzen Gonostylus mit basaler Ecke an der Stylusinnenseite, einen langen und nach innen-unten gerichteten Mitteldorn auf relativ hohem Sockel sowie die auffällige Körperfärbung charakterisiert.

\section{Pseudosciara (Pseudosciara) ribeiroi (LANE, 1955) restit.} (Fig. 30 a-b)

Locus typicus: Estado de Goiás, »Corumbá« [etikettiert als »Goiaz, Corumbá«; = Estado de Goiás, Corumbá de Goiás] (Brasilien).

Holotypus: ơ, Reg.-Nr. 7724, November 1945, leg. BARRETTO (MZSP).

Erhaltungszustand: Der Kopf mit den Fühlergeißeln, Thorax, Flügel, Coxen, Beine und Hypopygium sind gut erhalten (umpräpariert in Kanadabalsam).

Literatur: Trichosia ribeiroi LANE - LANE (1955): 255 und 256-257; Fig. 1. Trichomegalosphys ribeiroi (LANE) - Amorim (1992): 68 [nec Trichosia ribeiroi LAne als jüngeres Synonym zu Pseudos. melanocephala (FABRICIUs) - Mohrig (2003): 31-32; nec Pseudos. ribeiroi (Lane) sensu Mohrig - Mohrig \& Menzel (2009): 284, Fig. 16-25 und 289, Fig. 16-62; alle Fehlbestimmung, = bisher unbeschriebene Pseudosciara-Spezies].

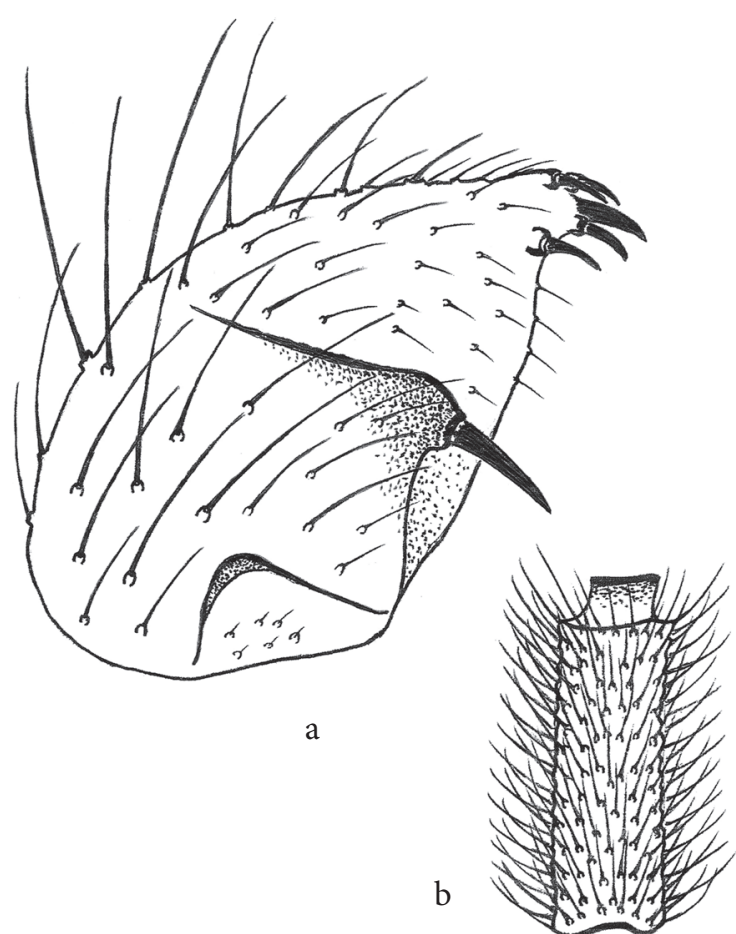

Fig. 30 a-b: Pseudosciara ribeiroi (LANE), Holotypus $\sigma^{*}$ : - a: Gonostylus ventral; - b: 4. Fühlergeißelglied.

Redeskription: $\sigma^{\top}$. Kopf: rundlich und dunkelbraun, mit etwas hellerem Gesicht. Augenbrücke 3-reihig. Scapus, Pedicellus und Fühlergeißel einfarbig dunkel; 4. Fühlergeißelglied 3,5 mal so lang wie breit; Geißelglieder grob, dicht, abstehend und dunkelbraun behaart; Basalteil mit sehr kurzen, feinen Sensillen und weißlich abgesetzten Insertionshöfen; Behaarung des Basalteils fast so lang wie die Gliedbreite; Halsteil kurz, scharf abgesetzt und deutlich zweifarbig; Palpen wahrscheinlich 3-gliedrig [Grundglieder deformiert; Palpenglieder 2 und 3 fehlend]; Palpengrundglied hochrückig und mit mehreren Borsten [Sensillenfeld nicht sichtbar]. Thorax: Mesonotum mit Ausnahme des Präscutums braun; Scutellum, Mediotergit, Metanotum und alle Sklerite der Thoraxseiten braun; Scutellum mit 4 stärkeren Randborsten; Postpronotum nackt. Flügel leicht bräunlich, die Spitzenhälfte der Flügelmembran bis zur Einmündung von $\mathrm{R}_{1}$ in die Costa mit Makrotrichien; $\mathrm{R}_{1}$ lang, $=0,8 \mathrm{R} ; \mathrm{C}=1 / 2 \mathrm{w}$; $\mathrm{y}=0,7 \mathrm{x}$, beide vollständig mit Makrotrichien besetzt; CuA-Stiel lang, = 1,3 x; hintere Flügeladern mit Makrotrichien [nur basales Drittel des CuA-Stiels unbeborstet]; Analader $\mathrm{A}_{1}$ mit einer Makrotrichienreihe. Halteren kurz gestielt, mit hellem Stiel und gebräuntem Halterenkopf. Coxen und Femora gelb, Tibien und Tarsen angedunkelt; Vordertibienende mit großem Fleck aus palisadenartig angeordneten, hellen Borsten und mit bogenförmiger Berandung. Klauen ungezähnt. Abdomen: braun, dunkel behaart. Hypopygium braun, ventrale Basis breit und etwas lobusartig vorgewölbt; Gonocoxite an der ventralen Innenseite nicht dicht, aber ziemlich lang behaart; Gonostyli kurz und kräftig; ventrale Innenseite der Gonostyli mit großem, daumenförmigem Fortsatz in der basalen Hälfte, der in einen kräftigen Dorn mündet; Stylus- 
spitze mit kurzem Zahn und 4 etwas kürzeren Dornen [2 Dorne über und 2 Dorne unter dem Zahn]; Genitalplatte breiter als hoch, membranös und etwas gebräunt; Genitalplatte apikal gerundet und in der oberen Hälfte mit großer, bogenförmiger Struktur; Zähnchenfeld breiter als hoch, mit groben und mehrspitzigen Zähnchen. Aedeagus mäßig lang und mit breiter, halbkreisförmiger Basis. Größe: 2,4 mm.

․ Unbekannt.

Bemerkungen: Die von LAne (1955) als Trichosia beschriebene Art wurde von AMORIM (1992) der Gattung Trichomegalosphys ENDERLEIN zugeordnet. Sie gehört wegen des langen CuA-Stiels, der Form und Bewehrung der Gonostyli sowie des charakteristischen Borstenflecks an den Vordertibien zur Gattung Pseudosciara Schiner. Sie ist nicht mit Pseudos. melanocephala (FABRICIUs) identisch, wie MoHrig (2003: 31) aufgrund des dichten Makrotrichienbesatzes auf der Flügelmembran angenommen hat [Fehlbestimmung; nec Pseudos. melanocephala »RüBSAAMEN «, recte (FABRICIUS)]. Die Detailzeichnungen bei MoHrIG (2003: Fig. 22 a-c) - die nach einem Exemplar aus Honduras angefertigt wurden - unterscheiden sich auch grundlegend von den Genital- und Flügelmerkmalen, die am Holotypus von T. ribeiroi LANE feststellbar sind. Das von Mohrig (2003) als "Pseudos. melanocephala (FABRICIUs)« vorgestellte und später in Mohrig \& Menzel (2009) als »Pseudos. ribeiroi (LANE) « bezeichnete ${ }^{\star}$ repräsentiert eine ganz andere Pseudosciara-Art, die neu für die Wissenschaft ist und an anderer Stelle beschrieben werden soll. Pseudos. ribeiroi (LANE) hat vor allem in der Spitzenhälfte der Flügelmembran Makrotrichien und ist in der basalen Flügelhälfte fast nackt. Außerdem zeichnet sich die Art durch lange, kräftige Fühlergeißelglieder und relativ kurze Gonostyli mit einem großen, daumenförmigen Basalfortsatz aus. Im Gegensatz dazu ist Pseudos. melanocephala (FABRICIUS) durch eine vollständig und dicht mit Makrotrichien besetzte Flügelmembran und durch ein gelbes Abdomen mit heller Behaarung charakterisiert. Zur Diskussion der Gattung Trichomegalosphys ENDERLEIN vergleiche auch mit den Bemerkungen bei Pseudosciara pubescens (Morgante).

\section{Pseudosciara (Pseudosciara) striata (RüBSAAMEN, 1894)}

Locus typicus: Oaxaca (Mexiko).

Holotypus: ㅇ, Mus.-Nr. 6201, ohne weitere Funddaten, leg. DEPPE (ZMHB).

Erhaltungszustand: Der Holotypus befindet sich in einem sehr schlechten Zustand. Beide Fühlergeißeln und ein Bein fehlen. Ein Flügel wurde abpräpariert [von diesem nur das Analfeld zerstört]. Das + war lange in Glyzerin eingebettet, was zur Aufquellung und Entfärbung führte. Gegenwärtig liegt das Exemplar in einer Luftblase mit angetrockneten Glyzerinresten. Dadurch sind bei dem zweiten Flügel nur noch die Vorderadern gut erhalten. Das Deckgläschen wurde mit Kanadabalsam umrandet.

Literatur: Sciara striata RÜBSAAMEN - RÜBSAAMEN (1894): 31 und 37-38; Taf. 2, Fig. 12; Taf. 3, Fig. 4. Sciara cf. striata RÜBSAAMEN - EDWARDS (1919): 144. Sciara striata RÜBSAAMEN - LENGERSDORF (1940): 247 [als Synonym zu Pseudos. hirtella Schiner]. Megalosphys striata (RübsaAmen) - Enderlein (1911): 135. Pseudosciara striata (RÜBSAAMEN) - AMORIM (1992): 65.

Redeskription: 우 Kopf: braun, einschließlich Mundpartie und Palpen. Augenbrücke 3 bis 4-reihig. Fühlergrundglieder braun; Fühlergeißelglieder fehlend. Palpen lang und 3-gliedrig; Grundglied groß und hochrückig, mit 10 bis 12 Borsten und mit großer, dunkler Sensillengrube; 2. und 3. Palpenglied schlank; 2. Glied 3/5 mal so lang wie das lange Endglied. Thorax: braun, [soweit erkennbar] mit einigen lateralen Aufhellungen; Katepisternit hoch-dreieckig und gebräunt, an der Spitze etwas aufgehellt; Mesonotum lateral und zentral relativ dicht, kurz und kräftig behaart, mit 9 grob-langen Borsten; Scutellum dicht beborstet, mit 4 starken Randborsten; Postpronotum nackt. Flügel groß und gebräunt, mit gut entwickeltem Analfeld; Flügelmembran ohne Makrotrichien; hintere Flügeladern vollständig und dicht mit Makrotrichien besetzt [nur CuA-Stiel unbeborstet]; M-Gabel lang und schmal, etwas kürzer als der M-Stiel; $\mathrm{R}_{1}$ sehr lang, = 1,1 $\mathrm{R}$ und gegenüber der M-Gabelbasis in c mündend; $y=0,9 \mathrm{x}$, beide mit Makrotrichien besetzt [y vollständig und beidseitig beborstet; $\mathrm{x}$ im basalen Drittel nackt und distal mit einseitig dorsalem Makrotrichienbesatz]; CuA-Stiel = 1,5 x, nur distal mit 5 Makrotrichien; C sehr kurz, $=2 / 5 \mathrm{w}$. Halteren kurz gestielt und gebräunt. Coxen und Beine lang und braun; Vordertibia mit einigen Dörnchen in der Grundbeborstung; Vordertibienende mit großem Fleck aus dicht und palisadenartig angeordneten Borsten; Borstenfleck etwa 1/2 mal so breit wie das Tibienende und mit scharfer, bogenförmiger Berandung; Tibienenden der $\mathrm{p}_{2}$ und $\mathrm{p}_{3}$ mit 2 gleichlangen Spornen, diese etwa doppelt so lang wie das Tibienende breit. Klauen ? ungezähnt. Abdomen: lang und gebräunt; Tergite und Sternite sehr dicht, kurz und fein behaart. Größe: 4,5 mm.

Bemerkungen: Die Zugehörigkeit zur Gattung Pseudosciara lässt sich anhand des langen CuA-Stiels, der beborsteten hinteren Flügeladern und des für Pseudosciara charakteristischen Borstenflecks an den Vordertibien sicher nachweisen. LENGERSDORF (1940) hat S. striata RüBSAAMEN zusammen mit Meg. luteicoxa Enderlein zu Pseudos. hirtella Schiner gestellt, was nicht korrekt ist, weil z. B. die Flügelmembran bei striata RÜBSAAMEN keinen dichten Makrotrichienbesatz zeigt. Eine Zuordnung zu einem schon beschriebenen Taxon oder eine Identifikation mit einem dazugehörigen $\sigma^{\star}$ wird aufgrund des schlechten Erhaltungszustandes nur 
schwer möglich sein. EDWARDs (1919) führt $2 \sigma^{\top} \sigma^{\top}$ und 3 우 aus Ecuador auf, die hierher gehören könnten.

\section{Pseudosciara (Pseudosciara) superba EDWARDS, 1934}

Locus typicus: »Mapiri, S. Carlos« [= Departamento La Paz, Cordillera Real, San Carlos südwestlich von Mapiri] (Bolivien).

Holotypus: ㅇ, $800 \mathrm{~m}$ ü. NN, 6.1.1903, leg. GarlepP (SMTD).

Erhaltungszustand: Beim Holotypus befinden sich die Kopfkapsel, der Thorax, 4 Beine und das Abdomen in sehr gutem Zustand. Die Fühlergeißelglieder und beide Hinterbeine fehlen. Ein Flügel ist fast vollständig erhalten [nur in der Mitte des Vorderrandes beschädigt]. Von dem anderen Flügel fehlt die vordere Flügelhälfte (umpräpariert in Kanadabalsam).

Literatur: Pseudosciara superba Edwards - Edwards (1934): 366-367; - LANE (1959b): 289; - AMORIM (1992): 65.

Redeskription: + . Kopf: rundlich und dunkelbraun, Gesicht und Palpen angedunkelt gelblich. Augenbrücke breit, 4 bis 5-reihig. Scapus und Pedicellus dunkelbraun [Fühlergeißelglieder im Präparat fehlend]; Palpen 3-gliedrig und dunkelbraun; Grundglied hochrückig verdickt, mit 10 Borsten sowie mit großem, scharf berandetem und etwas eingesenktem Sensillenfeld [dieses dicht mit kurzen, feinen Sensillen besetzt]; 2. Glied länglich-oval, und 3/4 mal so lang wie das schlanke Endglied. Thorax: Mesonotum vorn und lateral gelb-ockerfarben, zentral dunkel [ohne Trennung von Lateralflecken und Mittelstreif]; Scutellum, Mediotergit und Metanotum gelb; Scutellum dicht behaart und mit 4 stärkeren Randborsten; Pleuralsklerite einheitlich gelb-ockerfarben; Postpronotum nackt. Flügel groß, mit gut entwickeltem Analfeld und mit kräftig ausgebildeten Adern [nur $\mathrm{M}$-Stiel und $\mathrm{M}_{1}$ schwach sklerotisiert]; Flügelmembran ohne Makrotrichien, mit dunkelbraun ausgefärbtem Bereich zwischen der Costa und $\mathrm{R}_{1}$ sowie mit deutlich gebräunter Flügelspitze [Farbbinde von der $\mathrm{R}_{1}$-Einmündung über 2/3 der $\mathrm{M}$-Gabel bis zur $\mathrm{CuA}_{1}$-Einmündung reichend]; $R$ und $R_{1}$ sehr lang; $R_{1}=1,2 \mathrm{R}$ und weit hinter der M-Gabelbasis in c einmündend; $C$ sehr kurz, $=2 / 5 \mathrm{w}$; $\mathrm{y}$ sehr kurz und $\mathrm{x}$ sehr lang; $\mathrm{y}=2 / 5 \mathrm{x}$, beide vollständig mit beidseitigem Makrotrichienbesatz; CuA-Stiel sehr lang, [wegen der erheblichen Länge von $\mathrm{x}$ ] = 1,1 x; Analader $\mathrm{A}_{1}$ nicht sichtbar und ohne Makrotrichien; hintere Flügeladern vollständig mit Makrotrichien [einschließlich CuA- und M-Stiel]. Halteren kurz gestielt und dunkel. Coxen und Femora gelb-ockerfarben, Tarsen dunkler; Tibia der $\mathrm{p}_{3}$ ganz und Femur der $\mathrm{p}_{3}$ nach EDwards nur an der Basis dunkel $\left[\mathrm{p}_{3}\right.$ am Typexemplar fehlend]; Vordertibienende mit großem, dichtem und nur schwach bogig berandetem Borstenfleck [die endständigen, gebräunten Borsten sehr dicht in einer palisadenartigen
Reihe angeordnet; das Feld darüber unregelmäßig dicht beborstet]. Klauen ungezähnt. Abdomen: lang, grob, und dicht beborstet; Abdominalsegmente 1 bis 4 mit gelben, hell beborsteten Sterniten und mit braunen, dunkel beborsteten Tergiten [nach EDwARDs im Präparat nicht eindeutig zu erkennen]; Beborstung der anderen Abdonimalsegmente dunkelbraun; 5. Tergit dunkelbraun, 6. bis 8. Tergit bräunlich; Cerci lang-oval und gelbbraun, mit dichtem Miktrotrichienbesatz. Größe: 5,8 mm.

$\sigma^{\top}$. Unbekannt.

Bemerkungen: Die Art ist durch ihre außergewöhnliche Größe, das dunkle Mesonotum und die dazu im Kontrast stehende, gelbliche Färbung der Pleuralsklerite, der Coxen und Femora sowie der ersten 4 Abdominalsegmente auffallend gefärbt. In Verbindung mit der dunklen Flügelspitze, dem dunklen Flügelvorderrand und dem niedrigen $\mathrm{C}$ - $\mathrm{w}$-Index ist davon auszugehen, dass man das zurzeit noch unbekannte $\sigma^{\top}$ von Pseudos. superba EDWARDS sicher identifizieren kann.

\section{Pseudosciara (Pseudosciara) thoracica (LengersdoRf, 1930) \\ (Fig. 31; Tafel 2, Fig. H)}

Locus typicus: "State of S. Paulo, Cantareira« [= Estado de São Paulo, São Paulo, Cantareira] (Brasilien).

Neotypus: $0^{7}$, Reg.-Nr. 13.759, 8.8.1946, leg. BARRETTO (MZSP) [hier designiert]. In LANE (1959b: 298) wurde das Exemplar fälschlich als "Allotype" ausgewiesen [etikettiert als »Alotipo«].

Begründung: Der Holotypus [o] mit den Funddaten 16.6.1926, "Farm La Caja, $8 \mathrm{~km}$ westlich von S. José« [= Prov. Heredia, La Caja nordwestlich von San José] (Costa Rica) wurde bei einem Bombenangriff auf Hamburg mit Teilen der Sammlung des ZMUH im 2. Weltkrieg vernichtet (persönliche Mitteilung durch K. SснÜтte, ZMUH). АмоRIм (1992) gibt in seinem Katalog an, dass der Holotypus verloren gegangen ist. Auch in der Sammlung von Franz LENGERSDORF (ZFMK) befindet sich kein Exemplar mit dem Namen »Chaetomegalosphys thoracica«. Folglich sind die Exemplare aus der Kollektion LANE (MZSP) zurzeit die einzig verfügbaren Exemplare. Wegen der Ähnlichkeit zu anderen Pseudosciara-Arten ergab sich die Notwendigkeit, zur Stabilisierung des Namens für Pseudos. thoracica (LENGERSDORF) einen Neotypus festzulegen. Mit der Typenfestlegung werden auch die Untersuchungsergebnisse von EDWARDS (1934: 367) gestützt, der Chaetomegalosphys LENGERsDORF, 1930 [Typusart: Chaetomegalosphys thoracica Lengersdorf, 1930] als jüngeres Synonym zu Pseudosciara SCHINER, 1866 betrachtet. Bei der exemplarischen Auswahl wurden die Revisionsergebnisse von LANE (1959b) berücksichtigt, der das zu der Art gehörende $0^{\top}$ fand. Der Neotypus wurde in der Dipterensammlung des Museu de Zoologia da Universidade de São Paulo (MZSP) in São Paulo (Brasilien) deponiert. 


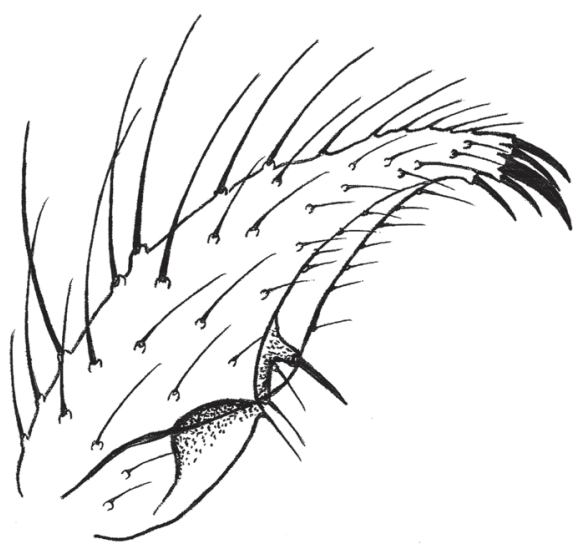

Fig. 31: Pseudosciara thoracica (LENGERSDorf), Neotypus o aus Brasilien (MZSP): Gonostylus ventral.

Erhaltungszustand: Bei dem untersuchten Neotypus [ $\overbrace{}^{\star}]$ sind beide Flügel und das Hypopygium in einem ausgezeichneten Zustand. Gut erhalten sind auch der Kopf, Thorax, Abdomen, 4 Beine [darunter beide Vorderbeine] sowie die basalen Glieder von beiden Fühlern [Scapus, Pedicellus, 1. und 2. Fühlergeißelglied] (umpräpariert in Kanadabalsam).

Literatur: Chaetomegalosphys thoracica LENGERSDORF LENGERSDORF (1930b): 123-124. Pseudosciara thoracica (LENGERSDORF) - LANE (1959b): 289 und 297-298; 293, Fig. 12; - АMORIM (1992): 65.

Redeskription: $\sigma^{*}$. Prefrons und Augenhinterrand gelblich, Ocellenregion dunkel. Augenbrücke 3-reihig. Fühlergrundglieder und 1. Fühlergeißelglied gelbbraun, 2. Glied dunkler; 2. Fühlergeißelglied 2,8 mal so lang wie breit [Geißelglieder ab dem 3. Glied fehlend]; Halsteil kurz und braun; Basalteil dicht, abstehend und dunkel behaart; Behaarung fast so lang wie die Gliedbreite. Palpen 3-gliedrig und gelblich; Grundglied hochrückig, mit kleiner Sensillengrube und 10 Borsten [davon eine Außenborste länger]; 2. Glied länglich-oval und 2/3 mal so lang wie das schlanke Endglied. Thorax: Mesonotum mit 2 kurzen dunklen Lateralflecken und sehr schmalem, wenig auffallendem Zentralstreif; alle anderen Sklerite des Thorax einschließlich Scutellum gelb; Scutellum dicht mit stärkeren Borsten besetzt, aber nur mit 2 kräftig-langen Randborsten; Postpronotum nackt. Flügel groß, mit gut entwickeltem Analfeld und hell [nur leicht gebräunt]; $\mathrm{R}_{1}$ lang, $=0,9 \mathrm{R}$, deutlich vor der $\mathrm{M}$-Gabelbasis in c mündend; $\mathrm{M}$-Stiel etwas länger als die schlanke M-Gabel; $\mathrm{y}=\mathrm{x}$, beide mit Makrotrichien; CuAStiel lang, $=1,2 \mathrm{x}$ und nur distal mit 4 Makrotrichien; $\mathrm{C}=2 / 3 \mathrm{w}$; Flügelmembran ohne Makrotrichien, alle hinteren Flügeladern mit Makrotrichienbesatz; Analader A nicht sichtbar und ohne Makrotrichien. Halteren mit gelbem Halterenstiel und dunklem Halterenkopf. Coxen und Beine gelb, Tarsen leicht angedunkelt; Vordertibienende mit großem Fleck aus palisadenartig angeordneten, hellen Borsten und mit bogenförmiger Berandung. Klauen ungezähnt. Abdomen: dunkelbraun, 1. Tergit gelb und 4. Tergit mit gelblicher Aufhellung; Sternite gelblich. Gonocoxite gelb; ventrale Innenseiten kurz behaart; Gonostyli dunkel, lang und schlank; Basalhälfte des Gonostylus wenig verbreitert und nur schwach eckig; nahe der Mitte der Innenseite mit einem dünnen, relativ kurzen Dorn [dieser auf einem kleinen und schmalen Sockel stehend]; Stylusspitze mit kräftigem Zahn und mit 4 etwas kürzeren Dornen [2 Dorne über und 2 Dorne unter dem Zahn]; Genitalplatte membranös und deutlich höher als breit, Genitalplattenseiten in der Mitte breit-höckerartig vorgewölbt, darüber bis zur gerundeten Spitze konisch verschmälert; obere Genitalplattenhälfte mit seitlichen Wülsten, die auch die Genitalplattenspitze umschließen und in eine membranöse Mittelstruktur münden [diese senkrecht nur bis zur Mitte der Genitalplatte reichend]; Zähnchenfeld groß und rundlich, mit groben und stumpf endenden Zähnchen. Aedeagus mäßig lang und sehr dünn. Größe: 3,1 mm.

†. Siehe LENGERSDORF (1930b): 123.

Bemerkungen: Die von Lengersdorf (1930b) beschriebene Körperfärbung des + stimmt mit der Färbung des untersuchten $\sigma^{\star}$ aus dem MZSP vollständig überein. Die Art ist durch den hellen Thorax, die schlanken Gonostyli und dem - im Vergleich zu ähnlichen PseudosciaraArten - kurzen und feinen Mitteldorn gut charakterisiert. Dieser Dorn steht etwas unterhalb der Gonostylusmitte. Außerdem besitzt der Neotypus nur 2 auffällig kräftige Randborsten auf dem Scutellum und eine sehr hohe Genitalplatte mit senkrecht stehender Mittelstruktur, die im Vergleich zu den anderen revidierten PseudosciaraSpezies eine ungewöhnliche Form hat.

\section{Subgenus Pseudosciarella subgen. nov.}

Typusart: Pseudosciara bifasciata EdwARds, 1934 Revista Entomologia, 4(3): 367-368 (hier festgelegt).

Diagnose: Das Subgenus Pseudosciarella zeichnet sich im Gegensatz zu Pseudosciara s. str. durch gerundete Gonostylusspitzen aus, die dicht mit kurzen, schlanken Dörnchen besetzt sind. Die länglich-schlanken Gonostyli mit den geschwärzten Spitzen ähneln den Gonostylusformen einiger Dolichosciara-Arten aus der Holarktis. Der für Pseudosciara s. str. typische Spitzenzahn fehlt und wird mit sekundärer Reduktion erklärt. Außerdem hat die Typusart ein unberandetes Sensillenfeld auf dem Palpengrundglied und auffallend lange Außenborsten auf dem 1. und 2. Palpenglied. Alle anderen Merkmale [einschließlich der lang gestielten $\mathrm{CuA}$, der ungezähnten Klauen und des palisadenartig angeordneten, bogenförmig berandeten Borstenfleckes an den Vordertibien] entsprechen der Gattungscharakteristik von Pseudosciara SCHINER.

Bemerkungen: In Anlehnung an Menzel \& Mohrig (2000: 72-80) sind die Reduktion des Spitzenzahns an der Gonostylusspitze und der Besitz von stark verlän- 
gerten Außenborsten auf dem 1. und 2. Palpenglied Apomorphien, mit denen das Subgenus Pseudosciarella begründet wird. Die hohe Anzahl von relativ schlanken Dornen, die die Gonostylusspitze weiträumig umschließen und auch zurückgesetzt auf der Außenseite inserieren, dürften aus einer ursprünglich dichten Spitzenbeborstung hervorgegangen sein [Transformationsstufe 1]. Es wird postuliert, dass sich daraus - bei gleichzeitiger Reduzierung der Dornenanzahl - die kräftigen Dorne mit höheren Sockeln bei Pseudosciara s. str. entwickelt haben [Transformationsstufe 2]. Gegenüber Pseudosciara s. str. sind das unberandete Sensillenfeld auf dem Palpengrundglied, der schlanke Gonostylus, die gerundete Gonostylusspitze und der fehlende lobusförmige Sockel in der Stylusmitte, auf dem sonst der basale Mitteldorn steht, plesiomorphe Merkmalszustände. Die zu Dolichosciara Tuomikoski gehörenden Arten unterscheiden sich von Pseudos. bifasciata EDWARDs vor allem durch den fehlenden ventralen Makrotrichienbesatz auf den Vorder- und Hinteradern [dort nur distale Bereiche von $\mathrm{R}_{5}$ beidseitig beborstet], den Besitz von mehreren schlank-hyalinen Dornen auf der Innenseite der Gonostyli, die pelzartig-dicht beborstete und unbedornte Gonostylusspitze sowie die viel kürzere Beborstung an den ventralen Innenseiten der Gonocoxite. Im Gegensatz zu den besprochenen Pseudosciara-Arten [incl. Pseudosciara s. str.] haben die Dolichosciara-Spezies ein pilzmückenähnlich hoch gewölbtes Mesonotum, mindestens 2 lange Borsten an der ventralen Spitze der Gonocoxite, einen dornartigeinreihigen Vordertibienfleck bei fehlender bogenför miger Berandung sowie kräftig gezähnte Klauen.

\section{Pseudosciara (Pseudosciarella) bifasciata EdwARDS, 1934 \\ (Fig. 32; Tafel 2, Fig. F)}

Locus typicus: Mamara [= Prov. Apurímac, Mamara östlich von Turpay] (Peru).

Holotypus: đ^, März 1911, leg. GARLEPP (SMTD).

Weiteres Material: $2 o^{\star} o^{\star} 1$, Sucumbíos, Sascha Lodge (Ecuador), 00,50 $0^{\circ} \mathrm{S} 76,5^{\circ} \mathrm{W}, 270 \mathrm{~m}$ ü. NN, 4.5.-14.5.1994 $\left[\begin{array}{ll}1 & \sigma^{\star}\end{array}\right]$ und 21.11.-1.12.1996 [ 1 o $^{\star} 1$ 우] ], leg. HibBs (PWMP); 1 주 2 우 우, Prov. Zamora-Chinchijpe, Rio Bombuscaro, $04,12^{\circ} \mathrm{S} 78,98^{\circ} \mathrm{W}$ (Ecuador), $1100 \mathrm{~m}$ ü. NN, Malaisefallenfang, 22.6.-4.7.1996, leg. Нiввs ( 1 क PWMP; $1 \sigma^{*}$ 1 i SDEI); $1 \sigma^{*}$, Prov. Ayacucho, oberhalb von Palco (Peru), 3240 m ü. NN, 10.4.1936, leg. GARLEPP (SMTD).

Erhaltungszustand: Der Holotypus ist in einem guten Zustand. Sehr gut erhalten sind das Hypopygium, das Abdomen, beide Flügel und 5 Beine. Die beiden Fühlergeißeln und ein Vorderbein fehlen. Die Kopfkapsel ist hinter den Ocellen und der Thorax im Bereich der Flügelbasis beschädigt (umpräpariert in Kanadabalsam).

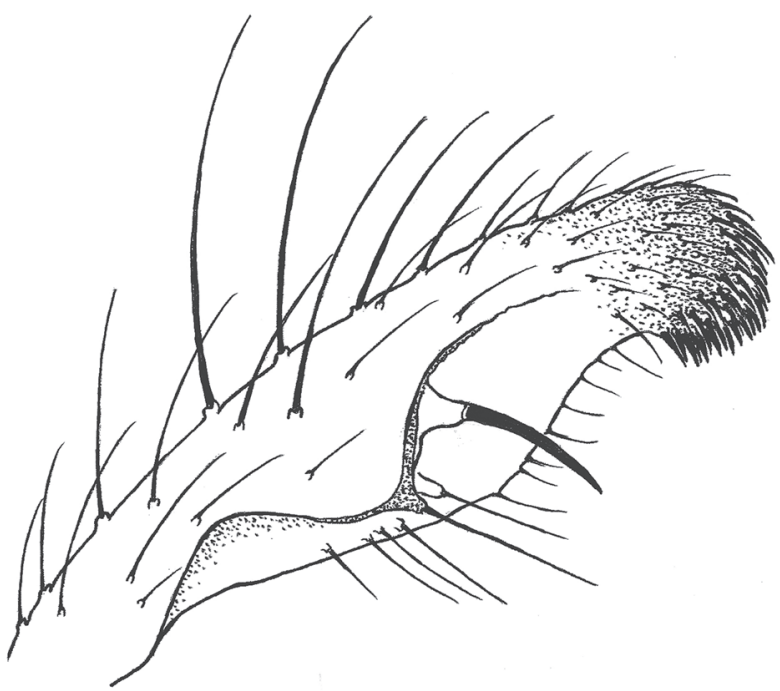

Fig. 32: Pseudosciara bifasciata Edwards, Holotypus $\sigma^{*}$ : Gonostylus ventral.

Literatur: Pseudosciara bifasciata EdWARds - EDWARds (1934): 367-368; - LENGERSDORF (1941): 205; - LANE (1959b): 288; - AMORIM (1992): 64.

Redeskription: ${ }^{\star}$. Kopf: Ocellenregion und Hinterkopf dunkel, Gesicht, Mundpartie und Palpen gelb. Augenbrücke 3 bis 4-reihig. Scapus und Pedicellus rötlich-gelb; Fühlergeißeln lang und schlank [ergänzt nach Exemplaren aus Ecuador]; 1. und 2. Geißelglied gelblich, alle anderen Geißelglieder dunkelbraun; 4. Fühlergeißelglied 3,9 bis 4,1 mal so lang wie breit; Basalteil dunkelbraun und rauh, mit extrem kurzen und sehr feinen Sensillen; Behaarung borstig, etwa so lang wie die Gliedbreite; Halsteil kurz, scharf abgesetzt und zweifarbig [apikal dunkelbraun beraucht]; Palpen 3-gliedrig, lang und hell; Grundglied kurz und hochrückig verdickt, mit 6 bis 7 Borsten und mit großem, unberandetem Sensillenfeld; Sensillen fein; 2. Palpenglied schlank, etwa $2 / 3$ mal so lang wie das lang-stabförmige Endglied; 1. und 2. Geißelglied mit je einer stark verlängerten Außenborste. Thorax: Mesonotum vorn und lateral gelb, zentral dunkel [ohne Trennung von Lateralflecken und Mittelstreif]; Scutellum und Mediotergit gelb, zentral angedunkelt; Scutellum mit 4 stärkeren Randborsten [davon 2 Borsten nur etwa $1 / 2$ mal so lang wie die anderen beiden]; Metanotum und Pleuralsklerite einheitlich gelb; Postpronotum nackt. Flügel mit zwei dunklen Bändern [eines im Spitzendrittel bis zur M-Gabel, das zweite in Höhe der Querader bis zum Flügelhinterrand]; $\mathrm{R}_{1}=2 / 3$ bis $3 / 4 \mathrm{R}$

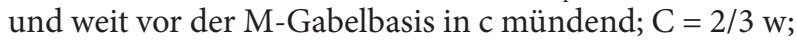
$y=3 / 5 x$, beide vollständig mit Makrotrichien; M-Gabel sehr schmal; Flügelmembran bis auf eine Makrotrichienreihe zwischen $R_{5}$ und $M_{1}$ nackt [diese beim Holotypus gut ausgeprägt, bei den $\sigma^{\star} \sigma^{\star}$ aber nicht immer vorhanden]; $R_{5}, M_{1}, M_{2}$, M-Stiel und y beidseitig mit Makrotrichien; $\mathrm{R}, \mathrm{R}_{1}$, $\mathrm{x}$ und CuA-Adern incl. CuA-Stiel meist mit einseitig dorsalem Makrochrichienbesatz [distal auch manchmal noch mit einigen ventralen Makrotri- 
chien]; CuA-Stiel = 1,2 bis 1,4 x; Analader $\mathrm{A}_{1}$ nicht sichtbar und ohne Makrotrichien. Halteren kurz gestielt und einfarbig hell. Coxen und Beine gelb, Tarsen dunkler; Vordertibienende mit großem Fleck aus palisadenartig angeordneten, hellen Borsten und mit bogenförmiger Berandung. Klauen ungezähnt. Abdomen: Behaarung grob, lang und dunkel; Abdominalsegmente 4 und 5 mit seitlichen Aufhellungen; Sternite gelblich. Hypopygium gelb; Gonocoxite ventral v-förmig ausgerandet; ventrale Innenseiten basal nackt, in der Mitte kurz und apikal länger und dichter behaart; Gonostyli schmal, etwa so lang wie die Gonocoxite, in der Mitte leicht bauchig und mit gebräunter Spitze; ventrale Innenseite des Gonostylus mit einem Mitteldorn auf schlankem Sockel; Spitze des Gonostylus gerundet, ohne Endzahn und dicht mit mehr als 20 schlanken und dunklen Dornen besetzt. Genitalplatte relativ klein, membranös und hoch gerundet; Zähnchenfeld groß und kreisförmig, mit grob-einspitzigen Zähnchen. Aedeagus mäßig lang und dünn. Größe: 2,9-3,1 mm

ㅇ. Fühlergeißeln kaum kürzer; Scapus und Pedicellus rötlich-gelb, 1. Geißelglied gelblich aufgehellt; 4. Fühlergeißelglied 4,1 mal so lang wie breit; Körperfärbung und dunkle Bänderung der Flügel wie beim o, nur die Abdominaltergite etwas dunkler; M-Gabel sehr schmal; die von EDWARDS erwähnte Makrotrichienreihe zwischen $\mathrm{R}_{5}$ und $\mathrm{M}_{1}$ bei den 우 우 deutlich ausgebildet; alle anderen Merkmale wie beim ${ }^{\star}$. Größe: 3,7 mm.

Bemerkungen: Die Art gehört aufgrund der gattungstypischen Flügeladerung [langer CuA-Stiel, beborstete hintere Flügeladern, Farbbinden auf der Flügelmembran], der dreigliedrig-langen Palpen mit reich beborstetem Grundglied, den ungezähnten Klauen sowie dem fast einreihigen Borstenfleck an den Vordertibien zweifellos zur Gattung Pseudosciara Schiner. Zum Grundmuster von Pseudosciara gehören auch die rauhen Fühlergeißelglieder mit zweifarbigen Halsteilen, die gelbliche Körperfärbung und die hoch gerundete, membranöse Genitalplatte.

\section{Sciara Meigen, 1803}

Typusart: Tipula thomae Linnaeus, 1767 - Syst. Nat. (Ed. 12), 1(2): 976 (mon.) [in Meigen (1803) als Hirtea thomae FABRICIUS; = Tipula hemerobioides SCOPOLI, 1763].

= Lycoria MeIgeN, 1800 - Nouv. Class.: 17.

Typusart: Tipula thomae Linnaeus, 1767 - Syst. Nat. (Ed. 12), 1(2): 976 [des. Coquillett (1910): 563] [= Tipula hemerobioides Scopoli, 1763]. Bei MeIGen (1800) wird unter Lycoria keine Art namentlich genannt [»6 espèces «]. Der Name Lycoria MeIgen wurde von der ICZN (1963) unterdrückt [Opinion 678. - Bull. zool. Nomencl., 20(5): 339-342].

= Molobrus LAtreille, 1805 - Hist. nat. Crust. Ins., 14: 288 .
Typusart: Tipula thomae LinnaEus, 1767 - Syst. Nat. (Ed. 12), 1(2): 976 (mon.) [als »tipule de Thomas«; = Tipula hemerobioides ScOpOLI, 1763].

= Nowickia KJEllander, 1943 - Opuscula Ent., 8(1-2): 54-55 [als Subgenus von Sciara Meigen, 1803] [praeocc.; nec Nowickia WachtL, 1894 - Diptera: Tachinidae].

Typusart: Sciara militaris NowICKI, 1868 - Verh. naturf. Ver. Brünn, 4 (1867): 4, 25, 51-52, 55-62; Tab. 1, Fig. 1-8 (orig. des.; mon.).

= Nowickiana KJELlander, 1943 - Kungl. Fysiol. Säll. Lund Förh., 13(11): 105 [nom. nov. pro Nowickia KJELLANDER, 1943].

= Semisciara KJellander, 1943 - Opuscula Ent., 8(1-2): 55-56.

Typusart: Semisciara agminis KJELlander, 1943 - Opuscula Ent., 8(1-2): 56-57, Fig. 10-17; 55, Fig. 1-3 und 6-9 (orig. des.; mon.) [= Sciara militaris NowıCKI, 1868].

Literatur: Lycoria MeIgen [ex parte] - Speiser (1909): 31; - ENDERLEIN (1911): 127 und 150; - LENGERSDORF (1940): 250; - LENGERSDORF (1944): 126. Sciara MEIGEN [mitunter ex parte] - MEIGEN (1803): 263; - RÜBSAAMEN (1894): 19 und 30; - Johannsen (1912): 113 und 117; - CURran (1930): 35; - Frey (1942): 14 und 28; - Shaw (1953): 29; - Curran (1965): 119; - Steffan (1966): 32 und 42; StefFAN (1981): 254; - AMORIM (1992): 67; - Evenhuis (1994): 173; - Poole (1996): 239; - ARnetT (2000): 856; - Menzel \& Mohrig (2000): 515 und 720; - VilkamaA (2000): 51; - Mohrig (2003): 3 und 65; - VilkamaA \& Hippa (2004): 4, 8 und 21; - Mohrig \& Menzel (2009): 281 und 292; - JAschHof (2011): 459; - Mohrig et al. (2013): 151 und 246; - SHIN et al. (2013): 835.

Bemerkungen: Alle neotropischen Spezies von Apelmocreagris ENDERLEIN sensu AMORIM (1992: 57) gehören nach unseren Revisionsergebnissen zur Gattung Sciara. Die ausführliche Gattungscharakteristik und einige phylogenetrische Aspekte zur Stellung von Sciara MEIGEN im System der Sciaridae wurden in Menzel \& Mohrig (2000: 217, 218) gegeben. Lycoria crinita LENGERSDORF, 1944 aus Mexiko wurde von Mohrig et al. (2013: 247) mit Sciara cingulata RüBSAAMEN, 1894 synonymisiert. Nachstehend werden die verbleibenden drei Arten aus Brasilien und Mexiko [Sciara blandula (LENGERSDORF, 1944) comb. nov., Sciara leucacrocera (ENDERLEIN, 1911) comb. nov. und Sciara penicillata (LENGERSDORF, 1944)] kurz abgehandelt.

\section{Sciara blandula (LENGERSDORF, 1944) comb. nov.}

Locus typicus: Finca Vergel (Mexiko).

Holotypus: ơ, Sam.-Nr. MF 4270, Lichtfang, 22.5.1935, leg. DAMPF (SDEI).

Erhaltungszustand: Der Holotypus wurde von LENGERSDORF in Kanadabalsam eingebettet. Er ist fast vollständig erhalten und befindet sich in einem guten Zustand. Nur 
einige Geißelglieder sind deformiert oder fehlen. Das männliche Genital wurde nicht separiert und liegt schräg im Präparat.

Literatur: Lycoria blandula LENGERSDORF - LENGERSDORF (1944): 129; 126, Fig. 7. Apelmocreagris blandula (LENGERSDORF) - AMORIM (1992): 57.

Bemerkungen: Mit 2,8 mm Körperlänge ist S. blandula (LENGERSDORF) eine relativ kleine Sciara-Art. Sie wurde von AMORIM (1992) ohne nähere Begründung in die Gattung Apelmocreagris ENDERLEIN, 1911 eingeordnet. Wegen der flaschenförmigen Halsteile der Fühlergeißelglieder, den Makrotrichien auf den hinteren Flügeladern, dem kurzen CuA-Stiel und dem großen, dicht beborsteten Vordertibienfleck gehört S. blandula zweifelsfrei zur Gattung Sciara MEIGEN. Sie ist unverkennbar charakterisiert durch einen dunkel beborsteten Lobus mit feinen Dornen an den abgeschrägten Innenseiten der Gonostyli. Ein Spitzenzahn fehlt. Nach Menzel \& Mohrig (2000: 519) gehört die Art zum Sciara helvolaTyp der S. hemerobioides-Gruppe.

\section{Sciara leucacrocera (ENDERLEIN, 1911) comb. nov.}

(Fig. 33 a-c)

Locus typicus: "Santa Catharina» [= Estado de Santa Catarina] (Brasilien).

Lectotypus: ${ }^{\star}$, Nr. 12/45, leg. LÜDERWALDT (MZPW) [des. АмоRim (1992): 57].

Paralectotypen: 3 ㅇ 우, gleicher Fundort (MZPW) [nicht untersucht!].

Erhaltungszustand: Der Lectotypus aus der Sammlung ENDERLEIN lag vor (umpräpariert in Kanadabalsam; 2 Präparate). Der Thorax ist im Bereich des Mesonotums deformiert. Am Kopf sind die beiden Palpen, die Fühlergrundglieder und die ersten 2 bzw. 5 Geißelglieder erhalten. Ein Flügel wurde separat eingebettet, der zweite Flügel ist an der Spitze zerstört. Von den 6 Beinen existieren noch 5 [darunter beide Vorderbeine]. Das Genital ist in einem guten Zustand. Nur der rechte Gonostylus ist stark deformiert.

Literatur: Apelmocreagris leucacrocera ENDERLEIN ENDERLEIN (1911): 148-149; - LENGERSDORF (1941): 204; - AMORIM (1992): 57.

Redeskription: ${ }^{*}$. Kopf: braun, einschließlich Palpen und Mundteile. Augenbrücke in der Mitte 3-reihig, seitlich 2-reihig; Fühler lang und dunkelbraun; Grundglieder dunkel; 4. Fühlergeißelglied 4,8 mal so lang wie breit, abstehend und so lang wie die Gliedbreite behaart; Halsteil kurz und flaschenförmig [deutlich breiter als hoch und vom Basalteil nicht scharf abgesetzt]; Palpen lang, 3-gliedrig, Grundglied ohne Sensillengrube, mit 7 bis 8 Borsten. Thorax: Mesonotum braun, zentral dunkler, kurz behaart; Scutellum mit mehreren Rand-

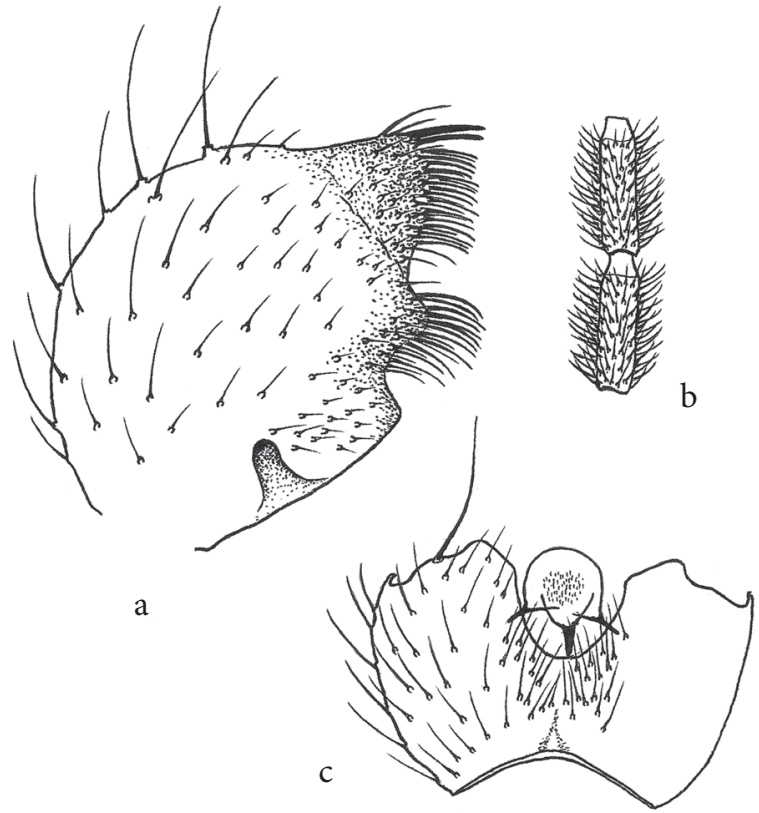

Fig. 33: Sciara leucacrocera (ENDERLein), Lectotypus $\sigma^{*}$ : - a: Gonostylus ventral; - b: 3. und 4. Fühlergeißelglied; - c: Gonocoxite mit Genitalplatte und Aedeagus ventral.

borsten; Pleuralsklerite einheitlich braun. Flügel bräunlich hell und relativ schmal; Analfeld gut entwickelt; Flügelmembran ohne Makrotrichien, am Vorderrand zwischen der Costa und $\mathrm{R}_{5}$ stärker gebräunt; $\mathrm{R}_{1}$ lang, = $1,2 \mathrm{R}, \mathrm{R}_{1}$ gegenüber der M-Gabelbasis in c einmündend, $\mathrm{C}=2 / 3 \mathrm{w} ; \mathrm{R}_{5}$ im distalen Drittel auch mit 3 bis 5 ventralen Makrotrichien; $\mathrm{y}=2,3 \mathrm{x}$, beide ohne Makrotrichien; $\mathrm{CuA}$-Stiel äußerst kurz und fast fehlend [erst kurz vor der Flügelbasis zusammenlaufend]; hintere Flügeladern mit einseitig dorsalem Makrotrichienbesatz [nur M-Gabel und Äste von $\mathrm{CuA}$ ]; M-Stiel sehr schwach ausgebildet, ohne Makrotrichien und etwas länger als die lange, weit geöffnete M-Gabel. Halteren kurz gestielt und dunkel. Coxen und Beine braun, wenig heller als der Thorax; Spitze der Vordertibien mit großem, dichtem und unberandetem Borstenfleck. Klauen ungezähnt. Abdomen: Tergite, Sternite und Hypopygium braun; Beborstung auf dem Abdomen lang; Hypopygium kräftig und kompakt; Gonocoxite kurz und breit, ventral mit sehr breit geschlossener Basis [dadurch ventraler Intercoxalspalt auffallend klein und Ränder der ventralen Innenseiten kurz]; ventrale Innenseiten der Gonocoxite spärlich und recht lang beborstet, am Rand zusätzlich kurz und fein behaart; Gonostyli groß und breit, fast so lang wie die Gonocoxite; Innenseite des Gonostylus in der Mitte mit einem Lobus und einem eckigen Vorsprung im basalen Drittel; an der Spitze mit 2 (? 3) schlanken Dornen, darunter bis zum Mittellobus mit vielen dornartigen Borsten; Lobus mit vergleichbaren Dornborsten besetzt; Basalecke nur spärlich und kurz behaart; Genitalplatte klein, sklerotisiert und gerundet; Zähnchenfeld klein und rundlich, mit grob-einspitzigen Zähnchen. Aedeagus sehr kurz, mit hoch-trichterförmiger Basis. Größe: 3,3 mm.

‥ Siehe ENDERLEIN (1911): 148. 
Bemerkungen: Die Art gehört aufgrund der flaschenhalsförmigen Fühlerhalsteile, des Makrotrichienbesatzes auf den hinteren Flügeladern, dem kurzen CuA-Stiel und dem großen, dicht beborsteten Vordertibienfleck zu Sciara Meigen. Sie ist durch die kurzen und breiten Gonocoxite, die rundlich-kompakten Gonostyli ohne Spitzenzahn, den großen apikalen und den kleineren mesialen Lobus [beide dicht und lang beborstet] sowie die 2 etwas längeren Dorne an der Spitze des apikalen Lobus gut charakterisiert.

\section{Sciara penicillata (LENGERSDORF, 1944)}

(als Lycoria: Arb. morph. taxon. Ent. Berl., 11(2-4):)

Locus typicus: Finca Vergel (Mexiko).

Lectotypus: $\sigma^{\star}$, Sam.-Nr. MF 4384, Lichtfang am Wasserfall, 1.6.1935, leg. DAmpF (SDEI) [des. Amorim (1992): 67].

Paralectotypen: $3 \sigma^{\star} o^{\star}$, gleiche Funddaten [im gleichen Präparat wie der Lectotypus] (SDEI).

Erhaltungszustand: Die vier Typexemplare mit einer Körperlänge von 2,7-3,2 mm sind in gutem Zustand und vollständig erhalten. LENGERSDORF hat alle $\sigma^{\star} \sigma^{\star}$ unter einem Deckglas in Kanadabalsam eingebettet. Bei allen $\sigma^{\star} \sigma^{\star}$ sind einige Fühlergeißelglieder deformiert. Der Lectotypus ist dasjenige Exemplar, bei dem das Genital am Besten in Ventralansicht untersucht werden kann.

Literatur: Lycoria penicillata LENGERSDORF - LENGERSDORF (1944): 126-127; Fig. 2. Sciara penicillata (LENGERSDORF) - AMORIM (1992): 67; - Mohrig (2003): 3; 4, Fig. 1 a-c; - Mohrig \& Menzel (2009): 288, Fig. 16.51.

Redeskription: $\sigma^{\star}$. Siehe Mohrig (2003): 3.

ㅇ. Unbekannt.

Bemerkungen: Bereits Mohrig (2003: 3) weist darauf hin, dass die Art zur S. hemerobioides-Gruppe gehört. Er meldet S. penicillata (Lengersdorf) auch aus Costa Rica.

\section{Verzeichnis der besprochenen Taxa und Übersicht zu den Korrekturen im System der Sciaridae}

Zur besseren Orientierung wurde hinter den jeweiligen Namen ein dreistelliger Buchstabencode beigefügt, der die zoogeographische Verbreitung und die Relevanz der nomenklatorischen Korrekturen für die genannten Regionen/Faunen angibt. Folgende Abkürzungen wurden dafür verwendet:

AET = Afrotropis; AUS = Australis; NEA = Nearktis; $\mathrm{NEO}=$ Neotropis $;$ ORI $=$ Orientalis PAL $=$ Paläarktis.

\footnotetext{
Apelmocreagris ENDERLEIN, 1911 - AET

thoracica (MACQUART, 1838) - AET

= bibionea (SPEISER, 1909) - AET

= bibionea var. miniaticeps ENDERLEIN, 1911 - AET

= ruficollis (WALKER, 1848) - AET
}

Cratyna WinneRTz, 1867 - AET / AUS / NEA / NEO / ORI / PAL

SG Cratyna WINNERTz, 1867 s. str. - AET / AUS / NEA / NEO / ORI / PAL

= Decembrina FREy, $1942-\mathrm{PAL}$

= Dendrosciara Frey, 1942 - NEO / PAL

= Plastosciara BERg, 1899 - AUS / NEA / NEO / ORI / PAL

= Pseudosciara Kieffer, 1898 [praeocc.] - PAL

= Pseudozygoneura STEFfaN, 1969 - AET / AUS / NEO / ORI

acuminata (Hippa, VilkamaA \& Heinakroon, 1998) comb. nov. - ORI

aimoresi (LANE, 1960) comb. nov. - NEO

aurora (HipPA, VilKAMAA \& HeINAKROON, 1998) comb. nov. - ORI

boracensis (LANE, 1960) comb. nov. - NEO

= barrettoi (LANE, 1960) syn. nov. - NEO

brevimera (Hippa, VilkamaA \& Heinakroon, 1998) comb. nov. - ORI

brevispina (Hippa, VilkamaA \& Heinakroon, 1998) comb. nov. - NEO

caraosi (LANE, 1960) comb. nov. - NEO

clavigera (Hippa, VilkamaA \& Heinakroon, 1998) comb. nov. - ORI

clavula (Hippa, VilKamaA \& Heinakroon, 1998) comb. nov. - NEO

clinostyla (Hippa, VilkamaA \& Heinakroon, 1998) comb. nov. - ORI

collina (Hippa, VilkamaA \& Heinakroon, 1998) comb. nov. - ORI

conica (Hippa, VilkamaA \& Heinakroon, 1998) comb. nov. - ORI

coniciformis (Hippa, Vilkamaa \& Heinakroon, 1998) comb. nov. - ORI

consilia (Hippa, VilkamaA \& Heinakroon, 1998) comb. nov. - ORI

constricta (Hippa, VilkamaA \& HeINAKroon, 1998) comb. nov. - ORI

coronicornis (Hippa, Vilkamaa \& Heinakroon, 1998) comb. nov. - ORI

crassichaeta (Hippa, VilkamaA \& Heinakroon, 1998) comb. nov. - ORI

crinita (Hippa, VilkamaA \& Heinakroon, 1998) comb. nov. - NEO

cucarisi (LANE, 1960) comb. nov. - NEO

= downsi (LANE, 1960) syn. nov. - NEO

dactylica (Hippa, VilkamaA \& Heinakroon, 1998) comb. nov. - ORI

delicia (Hippa, VilkamaA \& Heinakroon, 1998) comb. nov. - ORI

denticula (Hippa, VilkamaA \& Heinakroon, 1998) comb. nov. - ORI

epsilon (Hippa, VilkamaA \& Heinakroon, 1998) comb. nov. - ORI

excisa (Hippa, VilkamaA \& Heinakroon, 1998) comb. nov. - NEO 
expedita (Hippa, VilkamaA \& Heinakroon, 1998) comb. nov. - ORI

flagelloparva (Hippa, VilkamaA \& HeInAKRoon, 1998) comb. nov. - ORI

foveola (Hippa, VilkamaA \& Heinakroon, 1998) comb. nov. - ORI

ghanaensis (Hippa, VilkamaA \& Heinakroon, 1998) comb. nov. - AET

gigas (Hippa, VilkamaA \& Heinakroon, 1998) comb. nov. - ORI

index (Hippa, VilkamaA \& Heinakroon, 1998) comb. nov. - ORI

indotata (Hippa, VilkamaA \& Heinakroon, 1998) comb. nov. - AET

integra (HipPA, VilKAMAA \& HEINAKRoON, 1998) comb. nov. - NEO

intermedia (Hippa, Vilkamaa \& Heinakroon, 1998) comb. nov. - ORI

kirkspriggsi (Hippa, VilkamaA \& Heinakroon, 1998) comb. nov. - ORI

lagena (Hippa, VilkamaA \& Heinakroon, 1998) comb. nov. - ORI

latidactyla (Hippa, VilkamaA \& Heinakroon, 1998) comb. nov. - ORI

musicola (STEFFAN, 1969) - AUS

prominula (Hippa, VilkamaA \& Heinakroon, 1998) comb. nov. - ORI

protrusa (Hippa, VilkamaA \& HeInAKRoon, 1998) comb. nov. - AET

quadrifalx (Hippa, VilkamaA \& Heinakroon, 1998) comb. nov. - ORI

redunca (Hippa, VilkamaA \& HeINAKRoon, 1998) comb. nov. - ORI

sagitta (Hippa, VilkamaA \& Heinakroon, 1998) comb. nov. - ORI

senticosa (Hippa, VilkamaA \& Heinakroon, 1998) comb. nov. - AET

spicicauda (Hippa, VilkamaA \& Heinakroon, 1998) comb. nov. - ORI

torula (Hippa, VilKAMAA \& HEINAKROON, 1998) comb. nov. - AET

trichodactyla (Hippa, VilkamaA \& HeInakroon, 1998) comb. nov. - ORI

Euricrium ENDERLEIN, 1911 - AET / NEO / NEA = Mapiria EDWARds 1934 syn. nov. - NEA /NEO = Muhabbetiola KoçAK, 2009 syn. nov. - AET / NEO = Zygomma ENDERLEIN, 1911 syn. nov. [praeocc.] NEO

acutum (MOHRIG, 2003) comb. nov. - NEO

afrum LENGERSDORF, 1939 - AET

alboantennatum (LANE, 1946) comb. nov. - NEO

antennarium LENGERSDORF, 1926 - NEO

bolivianum (EDWARDs, 1934) comb. nov. - NEO

borgmeieri LENGERSDORF, 1926 - NEO

fasciatellum (ENDERLEIN, 1911) comb. nov. - NEO = maculipennis (LANE, 1946) [praeocc.] - NEO = stonei $($ LANE, 1947) $-\mathrm{NEO}$ freemani (LANE, 1955) comb. nov. - NEO glaberrimum (EDWARDS, 1934) comb. nov. - NEO modicum (MoHrig, 2003) comb. nov. - NEA / NEO myrmecophilum LENGERSDORF, 1925 - NEO pernitidum (EDWARDs, 1914) comb. nov. - AET ruebsaameni ENDERLEIN, 1911 - NEO

= fulgescens (ENDERLEIN, 1911) syn. nov. - NEO suspiciosum (MOHRIG, 2003) comb. nov. - NEO transversale EDWARDs, 1934 comb. nov. - NEO varians (LANE, 1955) comb. nov. - NEO

Metangela RÜBSAAMEN, 1894 - NEO

bicolorata (LENGERSDORF, 1930) comb. nov. - NEO calliptera RÜBSAAMEN, 1894 - NEO

fasciata LENGERSDORF, 1926 - NEO

ruebsaameni LANE, 1946 - NEO

spinata LANE, 1955 restit. - NEO

Pseudosciara SchIner, 1866 - NEA / NEO

SG Pseudosciara ScHINER, 1866 s. str. - NEA / NEO

= Chaetomegalosphys LENGERSDORF, 1930 - NEO

= Megalosphys ENDERLEIN, $1911-\mathrm{NEO}$

antunesi (LANE, 1946) comb. nov. - NEO

boracensis LANE, 1959 - NEO

cariba LANE, 1959 - NEO

coroicoensis EDWARDs, 1934 - NEA / NEO

delectata (WILlisTon, 1896) - NEA / NEO

forceps (PETtey, 1918) - NEA / NEO

= aitkeni LANE, 1959 syn. nov. - NEO

helleri MENZEL nom. nov. - NEO

$=$ debilis (Williston, 1896) [praeocc.] - NEO

hirtella SCHINER, 1866 - NEO

humeropicta (LENGERSDORF, 1931) - NEO

luteicoxa (ENDERLEIN, 1911) - NEO

melanocephala (FABRICIUS, 1805) - NEO

muricata (LENGERSDORF, 1926) - NEO

neotropica LANE, 1959 - NEO

pedunculata (ENDERLEIN, 1911) - NEO

pubescens (Morgante, 1969) comb. nov. - NEO

pygmaea (ENDERLEIN, 1911) - NEO

ribeiroi (LANE, 1955) restit. - NEO

striata (RÜBSAAMEN, 1894) - NEO

superba EDWARDS, 1934 - NEO

thoracica (LENGERSDORF, 1930) - NEO

willistoni MENZEL nom. nov. - NEO

= concinna (WILliston, 1896) [ praeocc.] $-\mathrm{NEO}$

SG Pseudosciarella Mohrig \& Menzel subgen. nov. NEO

bifasciata EDWARDs, 1934 - NEO

Sciara MEIGEN, 1803 - AET / AUS / NEA / NEO / ORI /

PAL

= Lycoria MEIGEN, $1800-$ AET / NEO / ORI / PAL

= Molobrus LATreILle, $1805-$ NEA / PAL

= Nowickia KJELlANDER, 1943 [praeocc.] - PAL

= Nowickiana KJELLANDER, 1943 - PAL

= Semisciara KJELLANDER, $1943-\mathrm{PAL}$

blandula (LENGERSDORF, 1944) comb. nov. - NEO 
cingulata RÜBSAAMEN, 1894 - NEA

= crinita $($ LENGERSDORF, 1944) - NEO

leucacrocera (ENDERLEIN, 1911) comb. nov. - NEO

penicillata (LENGERSDORF, 1944) - NEO

Trichomegalosphys ENDERLEIN, 1911 restit. - ORI laticornis (WALKER, 1857) comb. nov. - ORI

= funesta (ENDERLEIN, 1911) - ORI

= sulcata $($ VAN DER WULP, 1887) - ORI

\section{Danksagung}

Wir danken Dr. Mathias JaschHof (Greifswald), Dr. Pekka VilkamaA (Finnish Museum of Natural History, Helsinki) und Prof. Dr. Heıккi Hippa (Täby; früher: Naturhistoriska Riksmuseet Stockholm) für ihre Bemühungen, dass uns die LANE-Typen und andere relevante Materialien aus dem Museu de Zoologia da Universidade de São Paulo zur Untersuchung vorgelegt wurden. Zugleich sind wir den Kustodinnen und Kustoden folgender Museen zu Dank verpflichtet, die uns den Zugang zu diversen Typen ermöglichten oder uns jüngere Sciaridenaufsammlungen aus Mittelamerika zur Verfügung gestellt haben: Dr. BRIAN V. BROwN (Natural History Museum of Los Angeles County, Los Angeles); Sonia A. CASAri (Museu de Zoologia da Universidade de São Paulo); Dr. Ruth ContrerasLichtenberg und Peter Sehnal (Naturhistorisches Museum Wien); Uwe Kallweit (Museum für Tierkunde der Staatlichen Naturhistorischen Sammlungen Dresden); Dr. Elzbieta Kierych und Tomasz Huflejt (Polska Akademia Nauk, Muzeum i Instytut Zoologii, Warschau); Dr. JoAchim Ziegler (Leibniz-Institut für Evolutions- und Biodiversitätsforschung an der Humboldt-Universität zu Berlin, Museum für Naturkunde, Berlin); Dr. Karla Schneider (Zoologisches Institut der Martin-Luther-Universität Halle/Wittenberg, Halle an der Saale); Dr. Hans UlRICH (Grafschaft; früher: Zoologisches Forschungsinstitut und Museum Alexander Koenig Bonn); Nigel Wyatt (The Natural History Museum, London); Dr. James LiebHERR (Cornell University, Ithaca); Dr. DAvid Grimaldi (American Museum of Natural History, New York). Herrn KAI Schütтe (Zoologisches Institut und Zoologisches Museum der Universität Hamburg) verdanken wir weitreichende Auskünfte zum Schicksal der Hamburger Dipterensammlung und zum Verlust der dort einmal deponierten Sciaridentypen. Außerdem möchten wir unseren Kollegen KaI Heller (Quickborn) und ARne KöHLer (Senckenberg Deutsches Entomologisches Institut, Müncheberg) recht herzlich für ihre Unterstützung danken. Sie haben den Artikel mit ihren Diskussionsbeiträgen, Anregungen und Korrekturhinweisen wesentlich bereichert.

\section{Literatur}

Amabis, J. M. 1983: The polytene chromosomes of the salivary gland of Trichosia pubescens (Diptera: Sciaridae). - Revista Brasileira de Genética 6 (3): 415-424.

Amabis, J. M.; Reinach, F. C. \& Andrews, N. 1979: Spermatogenesis in Trichosia pubescens (Diptera: Sciaridae). - Journal of Cell Science 63: 199-213.

Amorim, D. S. 1992: A Catalogue of the family Sciaridae (Diptera) of the Americas South of the United States. - Revista Brasileira de Entomologia 36 (1): 55-77.

Amorim, D. S. \& Rindal, E. 2007: Phylogeny of the Mycetophiliformia, with proposal of the subfamilies Heterotrichinae, Ohakuneinae, and Chiletrichinae for the Rangomaramidae (Diptera, Bibionomorpha). - Zootaxa 1535: 1-92.

Andrioli, L. P.; Gorab, E. \& Amabis, J. M. 2008: The DNA puff $4 \mathrm{C}$ expresses a salivary secretion protein in Trichosia pubescens (Diptera; Sciaridae). - Archives of Insect Biochemistry and Physiology 67 (2): 76-86.

ArnetT, R. H. 2000: American insects. A Handbook of the insects of America North of Mexico. Second edition. xvii + 1003 S.; Boca Raton, London, New York \& Washington D. C.: CRC Press LLC.

Berg, C. 1899: Substitución de nombres genéricos. III. - Comunicaciones del Museo Nacional de Buenos Aires 1 (3): 77-80.

Büsen, W.; Amabis, J. M.; Leoncini, O; Stollar, B. D. \& LARA, F. J. S. 1982: Immunofluorescent characterization of DNA - RNA hybrids on polytene chromosomes of Trichosia pubescens (Diptera, Sciaridae). - Chromosoma 87: 247-262.

Curran, C. H. 1930: Report on the Diptera collected at the station for the study of insects, Harriman Interstate Park, N. Y. - Bulletin of the American Museum of Natural History 61: 21-115.

Curran, C. H. 1965: The families and genera of North American Diptera (Second Edition). 515 S.; Woodhaven: Henry Tripp.

EdwARds, F. W. 1914: Nematocera: Sciaridae, Mycetophilidae, Bibionidae, Simuliidae, Psychodidae et Culicidae. - Voyage de CH. Alluaud et R. Jeannel en Afrique Orientale (1911-1912). Résultats scientifiques. Insectes Diptères 2: 47-67.

Edwards, F. W. 1919: Diptères. Nématocères. S. 143-162. - In: Ministère de l'Instruction Publique (Hrsg.): Mission du service géographique de l'armée pour la mesure d'un arc de méridien équatorial en Amérique du Sud sous le contrôle scientifique de l'Académie des Sciences 1899-1906. Entomologie Botanique 10: 143-162.

EDwARDS, F. W. 1928: I. Diptera Nematocera from the Federated Malay States Museum. - Journal of the Federated Malay States Museums 14 (1): 1-139.

EDWARDS, F. W. 1931: Die Ausbeute der deutschen ChacoExpedition 1925/26. - Diptera: XXIII. Bibionidae and XXIV. Mycetophilidae. - Konowia 10 (1): 75-78. 
EDwARDs, F. W. 1934: New Neotropical Mycetophilidae (III) (Diptera). - Revista de Entomologia 4(3): 354-372.

Enderlein, G. 1911: Die phyletischen Beziehungen der Lycoriiden (Sciariden) zu den Fungivoriden (Mycetophiliden) und Itonididen (Cecidomyiiden) und ihre systematische Gliederung. - Archiv für Naturgeschichte 77 (1) Supplement 3: 116-201.

Esteban, M. R.; Campos, M. C. C.; Perondini, A. L. \& GodAY, C. 1997: Role of microtubules and microtubule organizing centers on meiotic chromosome elimination in Sciara ocellaris. - Journal of Cell Science 110 (6): 721-730.

Evenhuis, N. L. 1994: Catalogue of the fossil flies of the world (Insecta: Diptera): 600 S.; Leiden: Backhuys Publishers.

FABRICIUS, J. C. 1805: Systema antliatorum secundum ordines, genera, species adiectis synonymis locis, observationibus, descriptionibus: xiv +372 S. + 30 S. Appendix; Brunsvigae [Braunschweig]: Carolus Reichhard.

Freeman, P. 1951: Diptera of Patagonia and South Chile based mainly on material in the British Museum (Natural History). Part III - Mycetophilidae. 138 S.; London: British Museum (Natural History), B. Quaritch Ldt. \& H. M. Stationery Office.

FreY, R. 1942: Entwurf einer neuen Klassifikation der Mückenfamilie Sciaridae (Lycoriidae). - Notulae Entomologicae 22: 5-44.

Fuge, H. 1994: Unorthodox male meiosis in Trichosia pubescens (Sciaridae). Chromosome elimination involves polar organelle degeneration and monocentric spindles in first and second division. - Journal of Cell Science 107 (1): 299-312.

Fuge, H. 1997: Nonrandom chromosome segregation in male meiosis of a sciarid fly: Elimination of paternal chromosomes in first division is mediated by non-kinetochore microtubules. - Cell Motility and the Cytoskeleton 36 (1): 84-94.

Fuge, H. 1999: Monastral bipolar spindles in meiosis II of male Trichosia pubescens (Sciaridae): Early stages of spindle formation and chromosome orientation. Cell Motility and the Cytoskeleton 44 (3): 190-201.

Goday, C. \& Esteban, M. R. 2001: Chromosome elimination in sciarid flies. - BioEssays $23(3)$ : 242-250.

GonçAlves, P. A. S. 2006: Moscas-da-cebola (Diptera), Delia platura (Meigen) (Anthomyiidae); Pseudosciara pedunculata (ENDERleIN) (Sciaridae). - S. 174-181. - In: Wordell Filho, J. A.; Rowe, E.; Gonçalves, P. A. S.; Debarba, J. F.; Boff, P. \& Thomazelli, L. F. (Hrsg.): Manejo fitossanitário na cultura da cebola. 226 S.; Florianópolis: Epagri.

Hippa, H.; Menzel, F. \& Jaschhof, M. 1997: The status and phylogeny of Moehnia Pritchard, 1960 (Diptera: Sciaridae). - Beiträge zur Entomologie 47 (1): 153-161.
Hippa, H.; VilkamaA, P. \& Heinakroon, A. 1998: The genus Pseudozygoneura Steffan (Diptera, Sciaridae). - Acta Zoologica Fennica 210: 1-86.

ICZN [= International Commission on Zoological Nomenclature] (1999): International Code of Zoological Nomenclature. Fourth Edition, adopted by the International Union of Biological Sciences. xxix + 306 S.; London: International Trust for Zoological Nomenclature.

IKZN [= Internationale Kommission für Zoologische Nomenklatur] (2000): Internationale Regeln für die Zoologische Nomenklatur. Vierte Auflage. Angenommen von International Union of Biological Sciences. Offizieller deutscher Text. - Abhandlungen des Naturwissenschaftlichen Vereins in Hamburg (Neue Folge) 34: 232 S.; Keltern-Weiler: Goecke \& Evers.

Jaschnof, M. 2011: Phylogeny and classification of the Sciaroidea (Diptera: Bibionomorpha): Where do we stand after AMORIM \& Rindal (2007)? - Beiträge zur Entomologie 61 (2): 455-463.

JAschно,, M. \& Mohrig, W. 2005: A remarkable new genus Manzumbadoa gen. n. from Costa Rica (Diptera: Sciaridae). - Beiträge zur Entomologie 55 (2): 305-312.

Johannsen, O. A. 1912: The fungus gnats of North America, Part IV. - Bulletin of the Maine Agricultural Experimental Station 200: 57-146.

KIEFFER, J. J. 1898: Description d'un nouveau genre et d'une nouvelle espèce de Sciaride [Dipt.]. - Bulletin de la Société Entomologique de France 1898 (9): 194-196.

KJellander, E. 1943a: Einige Beobachtungen über den Heerwurm in Schweden mit Beschreibung der ihn bildenden Mücke Semisciara agminis n. gen. n. sp. Opuscula Entomologica 8 (1-2): 44-58.

KJellander, E. 1943b: Einige Versuche mit Heerwürmern in Schweden nebst Beschreibung der Larve von Semisciara agminis KJELlander. - Kungliga Fysiografiska Sällskapets i Lund Förhandlingar 13 (11): 105-123.

KoçAK, A. Ö. \& Kemal, M. 2009: Two replacement names in the family Sciaridae (Diptera). - Miscellaneous Papers 147-148: 6-7.

Laicine, E. M.; Alves, M. A. R.; De Almeida, J. C.; Rizzo, E.; Albernaz, W. C. \& Sauaia, H. 1984: Development of DNA puffs and patterns of polypeptide synthesis in the salivary glands of Bradysia hygida. - Chromosoma 89: 280-284.

LANE, J. 1946: New Brazilian Mycetophilidae (Diptera, Nematocera). - Revista de Entomologia 17 (3): 339-360.

LANE, J. 1947: Espécies Brasileiras de Stilobezzia (Dipt. Ceratopogonidae) e Zygoneura stonei nov. nom. (Dipt. Mycetophilidae). - Revista de Entomologia 18 (1-2): 197-214.

LANE, J. 1955: Novos Sciarinae do Brasil (Diptera, Nematocera, Mycetophilidae (Fungivoridae)). Arquivos do Museu Nacional 42 (1): 255-260. 
Lane, J. 1959a: On Neotropical Neosciara (Diptera, Sciaridae). - Studia Entomologica 2 (1-4): 69-104.

LANE, J. 1959b: On Neotropical "Pseudosciara" (Diptera, Sciaridae). - Revista Brasileira de Biologia $19(3)$ : 287-298.

Lane, J. 1960: New Neotropical Plastosciara (Diptera, Sciaridae). - Revista Brasileira de Entomologia 9: 119-126.

LARA, F. J. S. 1987: Gene amplification in Rhynchosciara (1955-1987). - Memorias do Instituto Oswaldo Cruz 82 (Supplement 3): 125-138.

Latreille, P. A. 1805: Histoire naturelle, genérale et particulière, des Crustacés et des Insectes 14: 432 S.; Paris: F. Dufart.

LENGERSDORF, F. 1925: Über die Gattung Euricrium End. (Dipt. Lestr.). - Wiener Entomologische Zeitung 42 (4-10): 92-94.

Lengersdorf, F. 1926: Neue Sciariden- (Lycoriiden-) Arten aus Südamerika. (Dipt.). - Deutsche Entomologische Zeitschrift 1926: 164-168.

Lengersdorf, F. 1930a: Die Ausbeute der deutschen Chaco-Expedition 1925/26. Diptera. XVII. Lycoriidae (Sciaridae). - Konowia 9 (1): 55-59.

Lengersdorf, F. 1930b: Neue Sciara (Lycoria)-Arten des Zoologischen Museums in Hamburg aus Borneo und Kostarika. - Zoologischer Anzeiger 92 (5-6): 123-130.

Lengersdorf, F. 1931: Neue Sciara- (Lycoria) Arten aus der Sammlung des Zoologischen Instituts der Universität Halle. - Zoologischer Anzeiger 96 (9-10): 251-255.

Lengersdorf, F. 1940: Beitrag zur Kenntnis der Lycoriiden (Sciariden) in Mexiko. (Diptera). Arbeiten über morphologische und taxonomische Entomologie aus Berlin-Dahlem 7 (3): 245-251.

LeNGersdorf, F. 1941: Lycoriidae (Dipt.). - Beiträge zur Fauna Perus 1: 201-206.

LENGERSDORF, F. 1942: Revision der südamerikanischen Lycoriiden aus der Sammlung des Naturkundemuseums Stettin. - Decheniana. Verhandlungen des Naturhistorischen Vereins der Rheinlande und Westfalens (Festschrift) 101 (A-B): 98-99.

LENGERSDORF, F. 1944: Beitrag zur Kenntnis der Lycoriiden (Sciariden) in Mexiko. (Diptera: Lycoriidae). 2. Teil. - Arbeiten über morphologische und taxonomische Entomologie aus Berlin-Dahlem 11 (2-4): 123-130.

Madalena, C. R. G.; Amabis, J. M.; Stocker, A. J. \& GorAB, E. 2007: The localization of ribosomal DNA in Sciaridae (Diptera: Nematocera) reassessed. Chromosome Research 15 (4): 409-416.

Madalena, C. R. G.; Andrioli, L. P. M. \& Gorab, E. 2008: Ribosomal RNA gene insertions in the R2 site of Rhynchosciara (Diptera: Sciaridae). - Chromosome Research 16 (8): 1233-1241.
Meigen, J. W. 1800: Nouvelle classification des mouches à deux ailes, (Diptera L.), d'après un plan tout nouveau: 40 S.; Paris: J. J. Fuchs.

Meigen, J. W. 1803: Versuch einer neuen GattungsEintheilung [sic!] der europäischen zweiflügligen Insekten. - Magazin für Insektenkunde 2: 259-281; Braunschweig: Karl Reichard.

Malavasi, A; Da Cunha, A. B.; Morgante, J. S. \& MARQUES, J. 1976: Relationships between the gregarine Schneideria schneiderae and its host Trichosia pubescens (Diptera, Sciaridae). - Journal of Invertebrate Pathology 28 (3): 363-371.

Menzel, F. (in Vorbereitung): Die Trauermücken (Diptera, Sciaridae) der Erde - The Black Fungus Gnats (Diptera, Sciaridae) of the world. 485 S. [Weltkatalog unveröffentlicht].

Menzel, F. \& Mohrig, W. 1998: Beiträge zur Taxonomie und Faunistik der paläarktischen Trauermücken (Diptera, Sciaridae). Teil VI - Neue Ergebnisse aus Typenuntersuchungen und die daraus resultierenden taxonomisch-nomenklatorischen Konsequenzen. Studia dipterologica 5 (2): 351-378

Menzel, F. \& Mohrig, W. 2000: Revision der paläarktischen Trauermücken (Diptera: Sciaridae). - Studia dipterologica Supplement 6 (1999): 761 S.; Halle an der Saale: Ampyx-Verlag.

Mohrig, W. 1999: Die Trauermücken (Diptera: Sciaridae) von Papua-Neuguinea. Teil I - Gattungen Sciara, Schwenckfeldina, Aerumnosa gen. nov., Cratyna, Phytosciara und Chaetosciara. - Studia dipterologica 6 (1): 153-203.

Mohrig, W. 2003: Black fungus gnats of Central America. Part I. (Diptera, Sciaridae). - Beiträge zur Entomologie 53 (1): 1-69.

Mohrig, W.; Heller, K.; Hippa, H.; VilkamaA, P. \& Menzel, F. 2013: Revision of Black Fungus Gnats (Diptera: Sciaridae) of North America. - Studia dipterologica 19 (1-2) (2012): 141-286.

Mohrig, W. \& JaschHoF, M. 1999: Sciarid flies (Diptera, Sciaridae) of New Zealand. - Studia dipterologica Suppl. 7: 101 S.; Halle an der Saale: Ampyx-Verlag.

Mohrig, W. \& Menzel, F. 2009: 16. Sciaridae (Black Fungus Gnats). - S. 279-292. - In: Brown, B. V.; Borkent, A.; Cumming, J. M.; Wood, D. M.; WoodLEy, N. E. \& Zumbado, M. A. (Hrsg.): Manual of Central American Diptera 1: xi + 714 S.; Ottawa: NRC Research Press.

Mohrig, W. \& Röschmann, F. 2005: Sciarid flies from Dominican Amber (Diptera, Sciaridae). - Beiträge zur Entomologie 55 (2): 319-361.

Mohrig, W.; Röschmann, F. \& Rulik, B. 2004: The fauna of sciarid flies from the Dominican Republic (Diptera, Sciaridae). - Beiträge zur Entomologie 54 (2): 267-331.

Morgante, J. S. 1969: Three new species of Brazilian Sciaridae (Diptera, Nematocera). - Revista Brasileira de Biologia 29 (4): 571-576. 
Penalva, L. O. F.; Yokosawa, J.; Stocker, A. J.; Soares, M. A. M.; Graessmann, M.; Orlando, T. C.; Winter, C. E.; Botella, L. M.; Graessmann, A. \& LARA, F. J. S. 1997: Molecular characterization of the C-3 DNA puff gene of Rhynchosciara americana. Gene 193 (2): 163-172.

Pettey, F. W. 1918: A revision of the genus Sciara of the family Mycetophilidae (Diptera). - Annals of the Entomological Society of America 11 (4): 319-343.

Poole, R. W. 1996: Diptera. - S. 15-604. - In: Poole, R. W. \& Gentili, P. (Hrsg.): Nomina Insecta Nearctica. A Check List of the Insects of North America 3: 1143 S.; Rockville: Entomological Information Services.

RApP, W. F. 1946: Two new Nemocera Diptera (Sciaridae and Cecidomyidae) [sic !]. - Transactions of the American Entomological Society 71: 125-128.

RÜBSAAMEN, E. H. 1894: Die aussereuropäischen Trauermücken des Königlichen Museums für Naturkunde zu Berlin. - Berliner Entomologische Zeitschrift 39 (1): 17-42.

SChineR, J. R. 1866: Bericht über die von der Weltumseglungsreise der k. Fregatte Novara mitgebrachten Dipteren. - Verhandlungen der kaiserlich-königlichen zoologisch-botanischen Gesellschaft in Wien 16: 927-934

Schulz, U. 2002: Forschung in Regenwäldern als Selbstzweck? Methoden und Erfahrungen bei der Untersuchung der Vogel- und Insektenfauna eines mittelamerikanischen Bergregenwaldes und die Instrumentalisierung der Ergebnisse für verschiedene Schutzkonzeptionen. - S.7-23 und 63-65. - In: Phyllodrom e.V. (Hrsg.): Tagungsbericht 3. Interdisziplinäre Fachtagung zur RegenwaldThematik, Leipzig, 19.-20. Oktober 2002. - Phyllodrom-Journal. Abhandlungen und Berichte aus der Regenwaldforschung 2: 1-70.

Schulz, U. \& Menzel, F. 2000: Dominante Arthropodentaxa und Sciaridae in Nebelwäldern Guatemalas: Ein Inventarvergleich von hängenden Böden und Waldböden. - Mitteilungen der Deutschen Gesellschaft für allgemeine und angewandte Entomologie 12 (1-6): 197-202.

Serna, E.; Gorab, E.; Ruiz, M. F.; Goday, C.; EirínLópez, J. M. \& SÁnchez, L. 2004: The Gene Sex-lethal of the Sciaridae family (Order Diptera, Suborder Nematocera) and its phylogeny in Dipteran insects. Genetics 168 (2): 907-921.

Schmitz, H. 1915: Over Zygomma Enderlein en Zygoneura MeIgen. - Entomologische Berichten 4 (82): 157-159.

SHAW, F. R. 1953: A review of some of the more important contributions to our knowledge of the systematic relationships of the Sciaridae (Diptera). - Proceedings of the Hawaiian Entomological Society 15 (1): 25-32.

SHAw, F. R. \& SHAW, M. M. 1951: Relations of Certain Genera of Fungus Gnats of the Family Mycetophilidae. - Smithsonian Miscellaneous Collections 117 (3): 1-23.
Shin, S.; Jung, S.; Menzel, F.; Heller, K.; Lee, H. \& LEE, S. 2013: Molecular phylogeny of black fungus gnats (Diptera: Sciaroidea: Sciaridae) and the evolution of larval habitats. - Molecular Phylogenetics and Evolution 66 (3): 833-846 + 13 S. Appendix.

Siviero, F; Rezende-Teixeira, P.; Andrade, A.; Machado-Santelli, G. M. \& Santelli, R. V. 2006: Analysis of expressed sequence tags from Rhynchosciara americana salivary glands. - Insect Molecular Biology 15 (2): 109-118.

SPEISER, P. 1909: [Abteilung] 10 Diptera. 4 Orthorhapha [sic!]. Orthorhapha [sic!] Nematocera. Wissenschaftliche Ergebnisse der schwedischen zoologischen Expedition nach dem Kilimandjaro, dem Meru und den umgebenden Massaisteppen Deutsch-Ostafrikas 1905-1906 unter der Leitung von Prof. Dr. Yngve SJöstedT. S. 31-65; Stockholm: P. Palmquists Aktiebolag [Separatabdruck im Oktober 1909].

Speiser, P. 1910: [Abteilung] 10 Diptera. 4 Orthorhapha [sic!]. Orthorhapha [sic!] Nematocera. - S. 31-65. In: Y. SJöstedT (Hrsg.): Wissenschaftliche Ergebnisse der schwedischen zoologischen Expedition nach dem Kilimandjaro, dem Meru und den umgebenden Massaisteppen Deutsch-Ostafrikas 1905-1906 unter der Leitung von Prof. Dr. Yngve Sjöstedt, Band 2: 844 S. + 19 Tafeln; Stockholm: P. Palmquists Aktiebolag.

Steffan, W. A. 1966: A generic revision of the family Sciaridae (Diptera) of America North of Mexico. University of California Publications in Entomology 44: 1-77.

Steffan, W. A. 1969: Insects of Micronesia. Diptera: Sciaridae. - Insects of Micronesia 12 (7): 669-732.

Steffan, W. A. 1980: 16. Family Sciaridae. - S. 231-234. - In: Crosskey, R. W.; Cogan, B. H.; Freeman, P.; Pont, A. C.; Smith, K. G. V. \& Oldroyd, H. (Hrsg.): Catalogue of the Diptera of the Afrotropical Region. Publication of the British Museum (Natural History) 821: 1437 S.; London: British Museum (Natural History).

Steffan, W. A. 1981: 15. Sciaridae. - S. 247-255. - In: McAlpine, J. F; Peterson, B. V.; Shewell, G. E.; Teskey, H. J.; Vockeroth, J. R. \& Wood, D. M. (Hrsg.): Manual of Nearctic Diptera, Volume 1. Monograph 27: vi + 674 S.; Ottawa: Research Branch Agriculture Canada.

Stocker, A. J.; Madalena, C. R. G. \& Gorab, E. 2006: The effects of temperature shock on transcription and replication in Rhynchosciara americana (Diptera: Sciaridae). - Genetica 126 (3): 277-290.

Stone, A. \& Laffoon, J. L. 1965: Family Sciaridae (Lycoriidae). - S. 229-236. - In: STONE, A.; SABrosky, C. W.; Wirth, W. W.; Foote, R. H. \& Coulson, J. R. (Hrsg.): A catalog of the Diptera of America north of Mexico. - Agriculture Handbook 276: iv + 1696 S.; Washington D. C.: United States Department of Agriculture. 
VilkamaA, P. 2000: Phylogeny of Prosciara Frey and related genera (Diptera: Sciaridae). - Systematic Entomology 25 (1): 47-72.

VilkamaA, P. \& Hippa, H. 2004: The genus Xenosciara gen. n. and the phylogeny of the Sciaridae (Diptera). - Zootaxa 699: 1-24.

Wiedemann, C. R. W. 1821: Diptera exotica. Pars I. Tabulis aeneis duabus. xix +244 S.; Kiliae [Kiel]: C. R. G. Wiedemann [Selbstverlag].

Wiedemann, C. R. W. 1828: Außereuropäische zweiflügelige Insekten 1: $608 \mathrm{~S}$; Hamm: Schulzische Buchhandlung.

Williston, S. W. 1896: XI. On the Diptera of St. Vincent (West Indies). - The Transactions of the Entomological Society of London 1896 (3): 253-446.

WinnertZ, J. 1867: Beitrag zu einer Monographie der Sciarinen: 187 S.; Wien: W. Braumüller. 